\title{
ॠUSGS
}

science for a changing world

\section{Fort Collins Science Center- Science Accomplishments for Fiscal Years 2012 and 2013}

Compiled by Juliette T. Wilson and David B. Hamilton
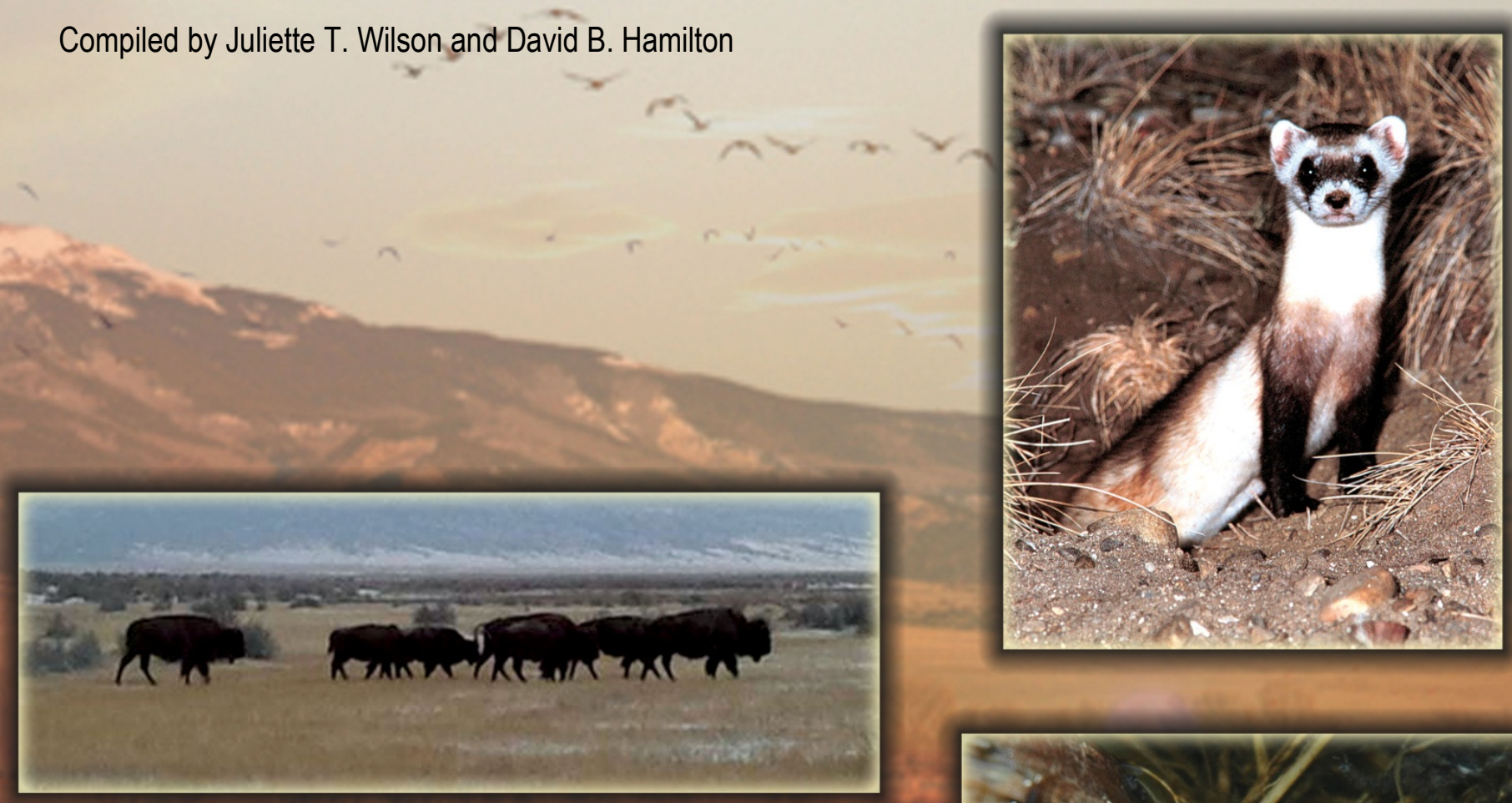

Open-File Report 2014-1143

U.S. Department of the Interior

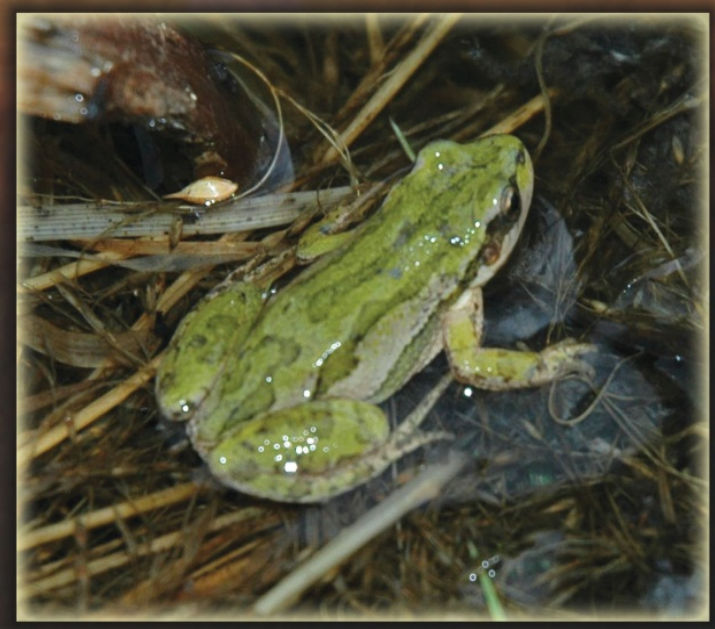

U.S. Geological Survey 


\title{
U.S. Department of the Interior \\ SALLY JEWELL, Secretary
}

\section{U.S. Geological Survey}

Suzette Kimball, Acting Director

\author{
U.S. Geological Survey, Reston, Virginia: 2014
}

For more information on the USGS-the Federal source for science about the Earth, its natural and living resources, natural hazards, and the environment-visit

http://www.usgs.gov or call 1-888-ASK-USGS

For an overview of USGS information products, including maps, imagery, and publications, visit $h$ ttp://www.usgs.gov/pubprod

To order this and other USGS information products, visit http://store.usgs.gov

Suggested citation:

Wilson, J.T., and Hamilton, D.B., comps., 2014, Fort Collins Science Center-Science accomplishments for fiscal years 2012 and 2013: U.S. Geological Survey Open-File Report 2014-1143, 113 p., http://dx.doi.org/10.3133/ofr20141143.

Any use of trade, product, or firm names is for descriptive purposes only and does not imply endorsement by the U.S. Government.

Although this information product, for the most part, is in the public domain, it also may contain copyrighted materials as noted in the text. Permission to reproduce copyrighted items must be secured from the copyright owner.

ISSN 2331-1258 (online) 


\section{Table of Contents}

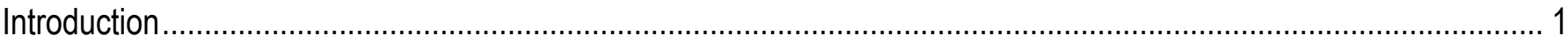

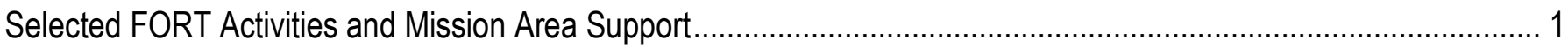

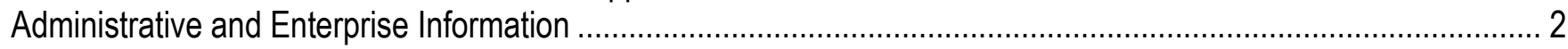

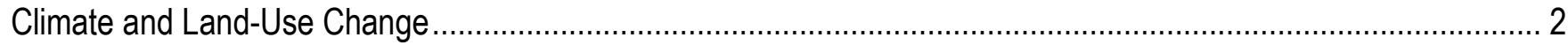

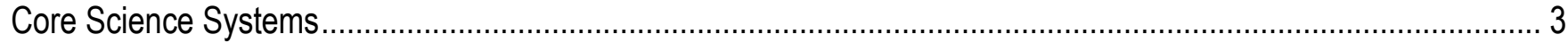

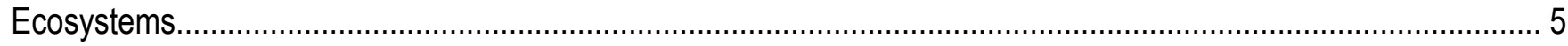

Ecosystems_Fisheries: Aquatic and Endangered Resources............................................................... 5

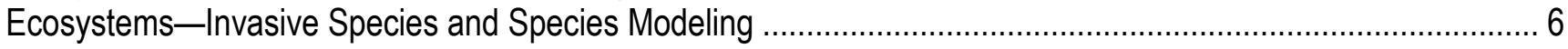

Ecosystems_Status and Trends of Biological Resources ....................................................................... 7

Ecosystems-Terrestrial, Freshwater, and Marine Environments ............................................................... 8

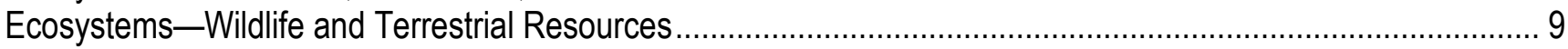

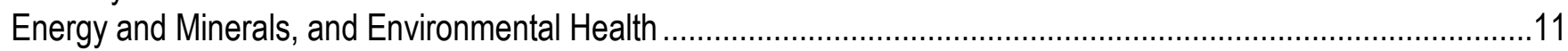

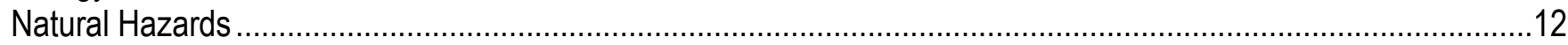

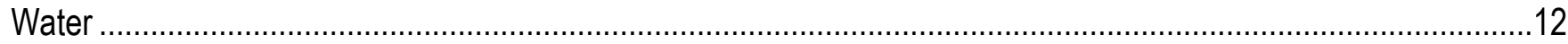

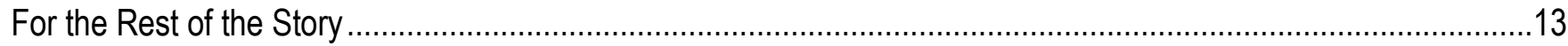

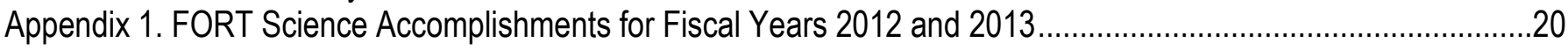

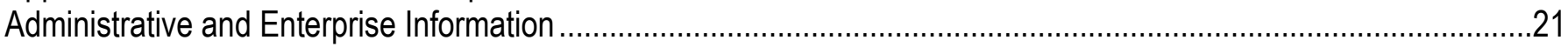

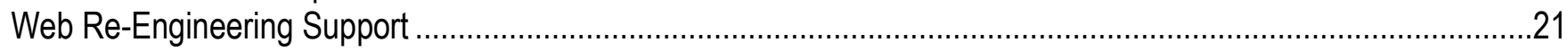

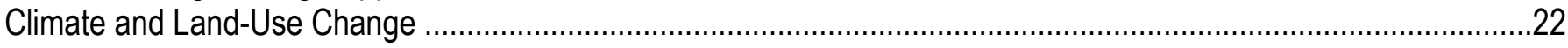

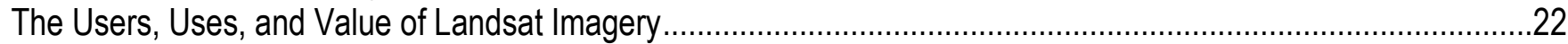

National Climate Change and Wildlife Science Center Data Management and Project Support............................23

The Western Mountain Initiative: Forest Ecosystem Responses to Climate Drivers in the

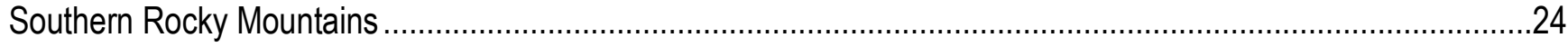

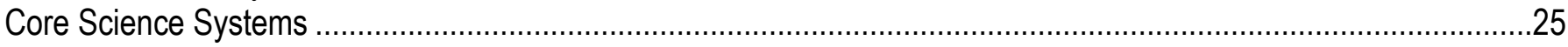

Scientific Breakthroughs: The John Wesley Powell Center for Analysis and Synthesis.......................................25

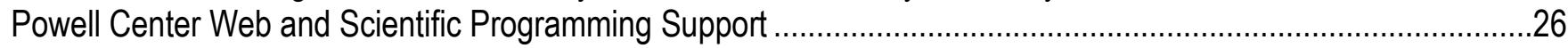

The Use of High Throughput Computing for USGS Core Sciences Research ................................................27

Integrating High Performance Computing with Geospatial Applications: Expanding Upon a Suite of USGS

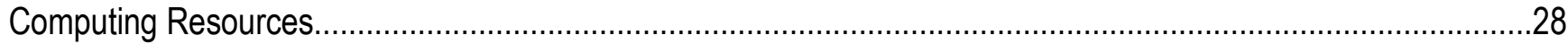

The Development and Application of Derived Bioclimatic Variables from Climate Normals and Time-Series Data..29

Great Northern Landscape Conservation Cooperative Spatial Toolkit and Phenology Server...............................30

Landscape Conservation Cooperative Data Management Support ..................................................................31

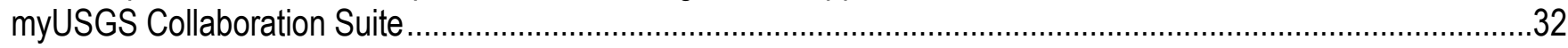

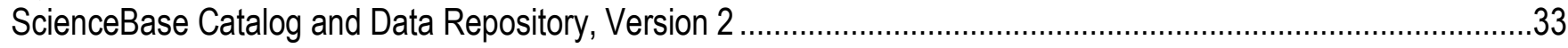

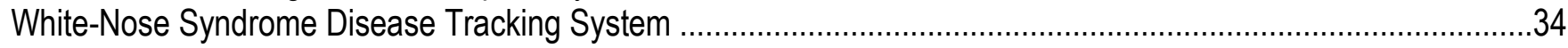

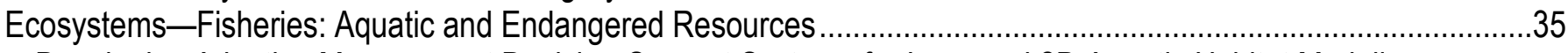

Developing Adaptive Management Decision-Support Systems for Improved 2D Aquatic Habitat Modeling

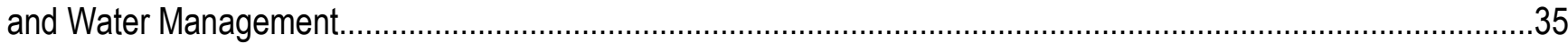

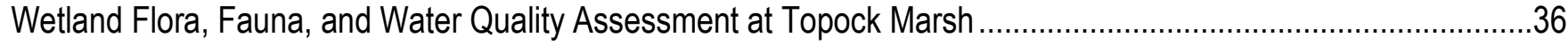

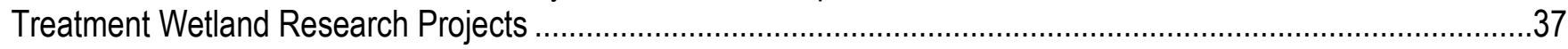

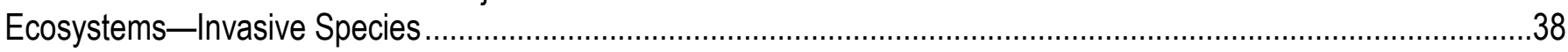

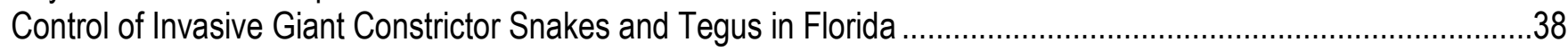

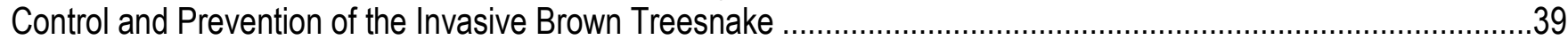

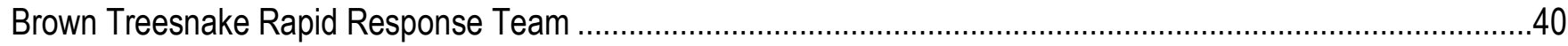

Biology, Impacts, and Control of Invasive Boa Constrictors in Puerto Rico .......................................................41

Forecasting Africanized Honey Bee Spread in the United States .............................................................42 
Modeling Invasive Weeds in Coastal Alaska

Developing a Decision-Support Model for Buffelgrass Management in Southern Arizona.......................................44

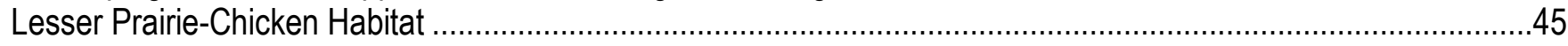

Resource for Advanced Modeling and Software for Assisted Habitat Modeling .................................................46

Using Environmental DNA in Water Samples to Track Invasive Pythons in Florida.............................................47

Potential Effects of Climate Change on Invasive and Native Riparian Plants in the U.S. West .............................48

Ecosystems -Status and Trends of Biological Resources ..............................................................................49

2012 Science Workshop: Delivering USGS Science to Wyoming Landscape Conservation Initiative Partners........49

Assessment and Monitoring of Semi-Arid Woodlands in the Little Mountain Ecosystem ........................................50

Mapping Rural Residential Growth and Energy Development in Sublette County, Wyoming ..................................51

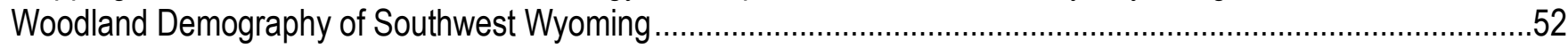

Assessing Socioeconomic Planning Needs (ASPN) ……........................................................................5

Assessing Visitor Experiences on National Wildlife Refuges .........................................................................54

Assessment of Ecosystem Service Values for the Central Everglades Planning Project.........................................55

Assessment of Native Pollinators in Eastern Colorado Conservation Reserve Program Fields ...............................56

The Benefit Transfer and Visitor-Use Estimating Models Toolkit .....................................................................57

BLM Social Science Concepts and Methods Training Module .......................................................................58

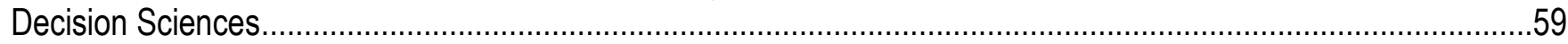

Dynamics of Land-Use Change and Conservation in the Prairie Pothole Region of the United States:

Environmental and Economic Implications with Linkages to Rural Community Well-Being ...................................60

Economic Contribution of Federal Investments in Restoration of Degraded, Damaged, or

Destroyed Ecosystems

Evaluation of Native and Non-Native Vegetation Response to Exceptional Drought and Grazing

in Southern Plains Conservation Reserve Program Field ...........................................................................62

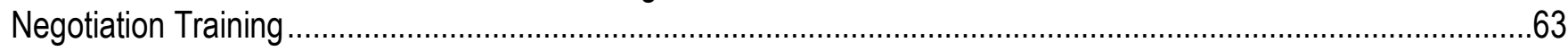

Science in Support of Policy: The Interactive Effects of Climate Change and Reactive Nitrogen on U.S.

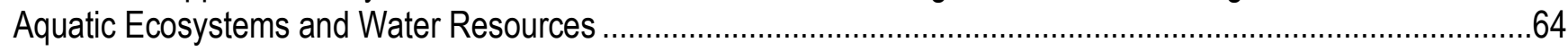

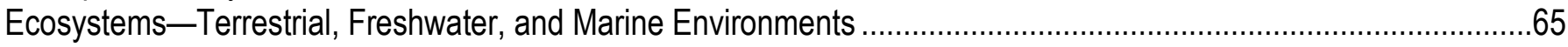

Bison, Elk, and Vegetation Ecology in the Great Sand Dunes Ecosystem....................................................65

Developing a More Accurate Aerial Population Survey Technique for Elk in Rocky Mountain National Park,

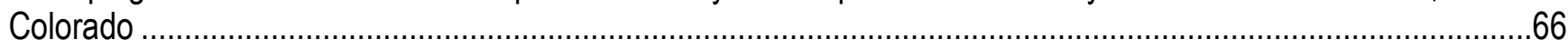

Sandhill Cranes in Colorado's San Luis Valley: Exploring New Technology for Improved

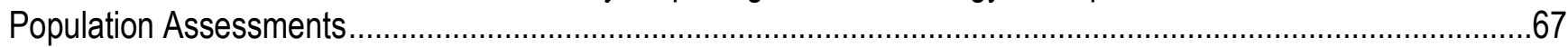

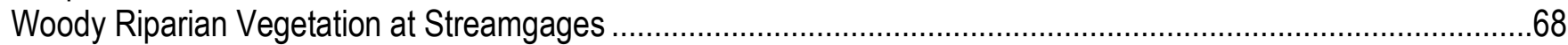

Microbial-Driven Nitrogen Cycling in Aquatic Alpine Ecosystems .................................................................69

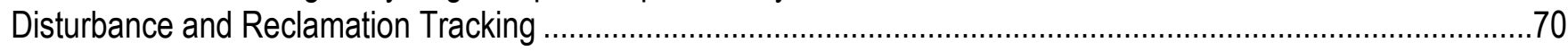

Integrated Assessment for the Wyoming Landscape Conservation Initiative........................................................

Assessing Effects of Energy Development in Colorado and New Mexico ............................................................72

Wyoming Basin Rapid Ecoregional Assessment for the Bureau of Land Management .........................................73

Pygmy Rabbits and Gas Field Development in Wyoming ..........................................................................

Golden Eagle Population Dynamics across the West …………...................................................................

Raptors and Wind Development: Developing Science-based Conservation Tools ................................................76

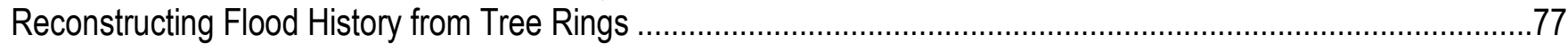

Gunnison Sage-Grouse Habitat Use and Movement: The Crawford Population..................................................78

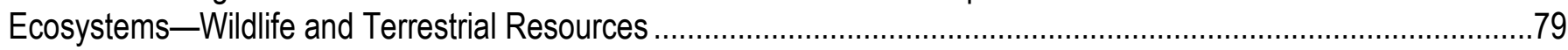

Field Testing an Oral Plague Vaccine for Prairie Dogs ...............................................................................

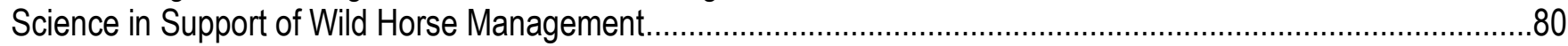

Assessing Habitat Use and Seasonal Distributions of Tree-Roosting Bats at Risk from Industrial

Wind Energy Development 


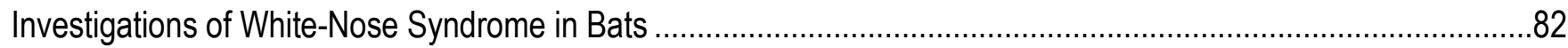

Investigating Causes and Consequences of Bat Fatalities at Wind Turbines ....................................................83

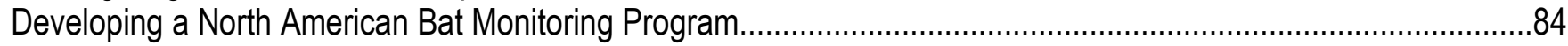

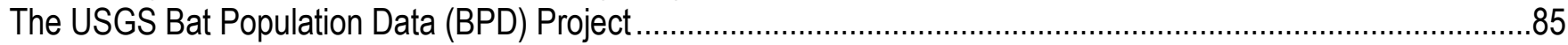

Greater Sage-Grouse or Not? Using Genomic Methods to Resolve Taxonomic Uncertainty ..................................86

Weather Radar Identifies Bird Migration Stopover Habitat in the Arid Southwest ................................................87

Implications of Climate Change for Avian Conservation in Great Plains Landscapes...........................................88

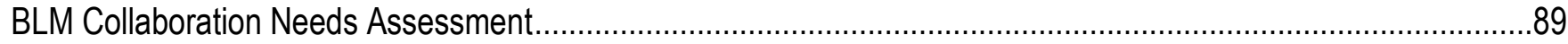

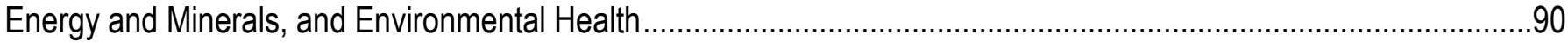

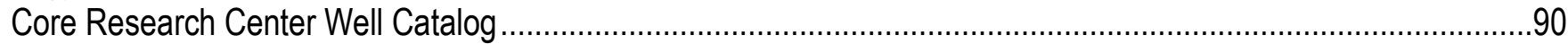

Aquatic Experimental Laboratory Capabilities Developed at FORT .................................................................91

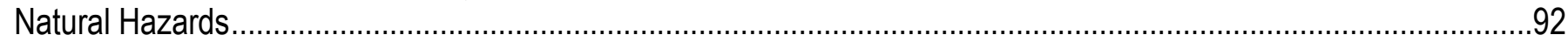

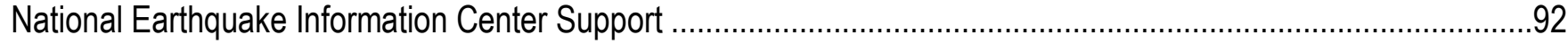

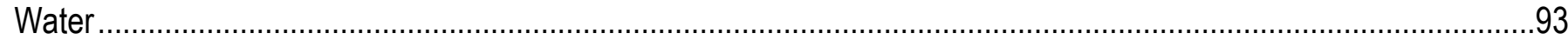

Assessing Potential Effects of Hydraulic Fracturing for Energy Development on Water Resources .........................93

\section{Tables}

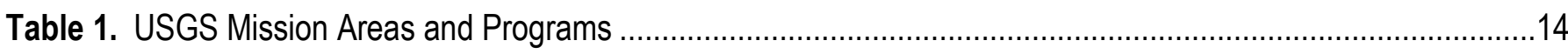

Table 2. FORT Publications and Other Information Products Released in FY2012 and 2013 ..................................94 


\section{Fort Collins Science Center-Science Accomplishments for Fiscal Years 2012 and 2013}

\section{Executive Summary}

\section{Introduction}

The Fort Collins Science Center (FORT) is a multi-disciplinary research and development center of the U.S. Geological Survey (USGS) located in Fort Collins, Colorado. Organizationally, FORT is within the USGS Southwest Region, although our work extends across the Nation and into several other countries. FORT research focuses on needs of the land- and water-management bureaus within the U.S. Department of the Interior (DOI), other Federal agencies, and those of State and non-government organizations. As a Science Center, we emphasize a multi-disciplinary science approach to provide information for resource-management decisionmaking. FORT's vision is to maintain and continuously improve the integrated, collaborative, world-class research needed to inform effective, science-based land and resource management.

Our science and technological development activities and unique capabilities support all USGS scientific Mission Areas and contribute to successful, collaborative science efforts across the USGS and DOI. We organized our report into an Executive Summary, a cross-reference table, and an appendix. The executive summary provides brief highlights of some key FORT accomplishments for each Mission Area. The table cross-references all major FY2012 and FY2013 science accomplishments with the various Mission Areas that each supports. The one-page accomplishment descriptions in the appendix are organized by USGS Mission Area and describe the many and diverse ways in which our science is applied to resource issues. As in prior years, lists of all FY2012 and FY2013 publications and other product types also are appended.

\section{Selected FORT Activities and Mission Area Support}

Below are examples of science accomplishments over the past two years that illustrate support to USGS Mission Areas. Within the Ecosystems Mission Area, which funds the majority of our work at FORT, we list accomplishments by program. Each subheading is linked to the section of appendix 1 containing summaries for all associated FY2012 and FY2013 accomplishments for that Mission Area or program. 


\section{HOW TO NAVIGATE THIS REPORT}

- To "jump to" the section of appendix 1 containing science accomplishment summaries for a particular Mission Area or program, simply click on the heading in the Table of Contents or in the Executive Summary.

- To jump to an individual accomplishment summary, click on its Table of Contents heading or table 1 accomplishment title.

- Important! To return to the place of any originating link you just used, hold down the ALT key and click the left arrow key [ALT $\leftarrow$ ].

\section{Administrative and Enterprise Information}

The USGS Office of Administration and Enterprise Information (AEI) provides bureau-level policy, program development and direction related to the business administration; information technology infrastructure; and enterprise IT processes and systems.

- Web Re-Engineering Support. In FY2012 and FY2013, the FORT Web Applications Team worked with AEI staff to implement several new technologies designed to provide additional IT governance, provide new tools to USGS content specialists and applications developers, and save the agency money. These technologies included the Web Hosting and Application Registry (WHAR), the Information Backbone Concept (IBC), the content management and system optimization, and a mobile framework.

\section{Climate and Land-Use Change}

A changing climate will, among other things, modify habitats being preserved for protected species and possibly increase the land area at risk for invasive species. Regional- and taxa-specific research needed to connect climate drivers with species habitat must have practical applications for resource managers' top-priority conservation issues and must support the work of the DOI Climate Science Centers. Many FORT activities in FY2012 and FY2013 addressed aspects of climate change (see table 1, especially the accomplishments listed under Ecosystems - Terrestrial, Freshwater, and Marine Environments). Three activities focusing on climate-change needs, as well as the Landsat Mission component, are:

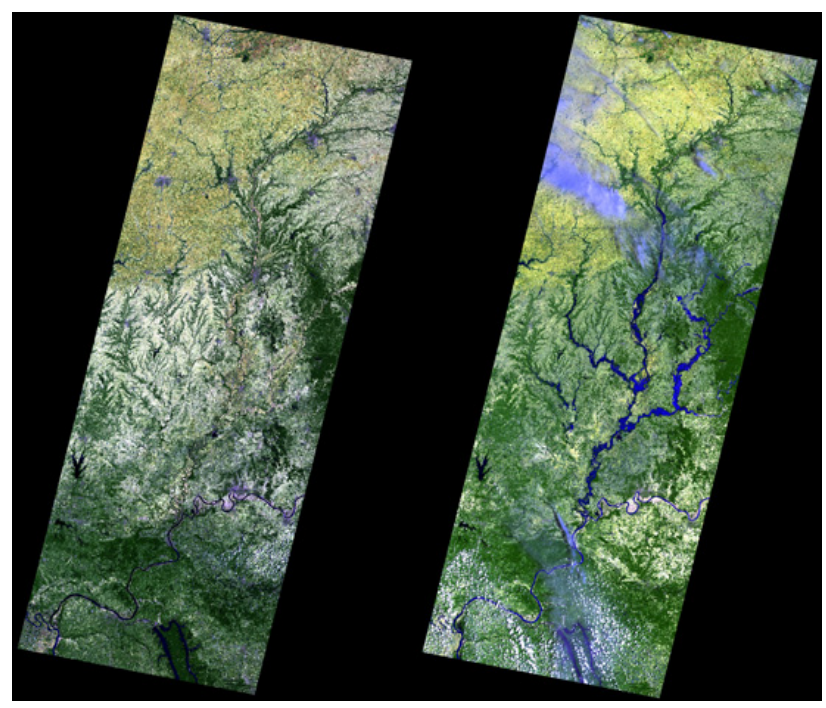

Landsat images before (2007) and during (2008) flooding along the Wabash River along the Indiana-Illinois (USA) border.

\section{- The Users, Uses, and Value of Landsat}

Imagery. In FY2012 and FY2013, FORT social scientists administered and analyzed data from a survey conducted for the USGS Land Remote Sensing Program on the users, uses, and value of Landsat imagery. This was the second survey conducted for this study, following one in 2009. We also conducted a case study of the value of Landsat imagery in forestry applications, which included interviews with Federal government employees and other State and private users. 
- National Climate Change and Wildlife Science Center Data Management and Project Support. The National Climate Change and Wildlife Science Center (NCCWSC) manages a number of projects across the U.S., generating a substantial amount of data and products. The challenge facing the NCCWSC in FY2012 and FY2013 included designing new ways to organize and deliver coherent information on these many projects, as well as managing the many terabytes of data held in multiple repositories around the nation. To help achieve this goal, the FORT Web Applications Team provided data management, data search, geoprocessing, project tracking, and web portal development support for the NCCWSC.

- The Western Mountain Initiative Responses to Climate Drivers in the Southern Rocky Mountains. The USGS, including FORT, the Western Ecological Research Center, and the Northern Rocky Mountain Science Center, continues to collaborate in the Western Mountain Initiative with the U.S. Department of Agriculture Forest Service, National Park Service, Los Alamos National Laboratory, and university scientists from across the West and around the world associated with long-term, global change research. In FY2012 and FY2013, research continued on drought-caused tree mortality, fire history, and fire effects, with new findings on the role of temperature as a potent driver of forest drought stress. FORT continued to provide extensive support to interagency land managers responding to the high-severity Las Conchas Fire (New Mexico) of 2011.

\section{Core Science Systems}

Assembling data and presenting it in meaningful ways becomes increasingly important as natural resource issues span larger geographic, political, organizational, and scientific boundaries. In FY2012 and FY2013, FORT's cadre of more than 40 information technologists helped tackle a number of priority science and information issues by developing processes and products that have saved considerable time and money. These technologies have provided access to and easy use of enormous aggregations of data that were once computationally intractable using local resources. Examples include:

- The Development and Application of Derived Bioclimatic Variables from Climate Normals and TimeSeries Data. Species are affected by both climatic and non-climatic factors, and climate change can affect species distributions over time. To address historical and

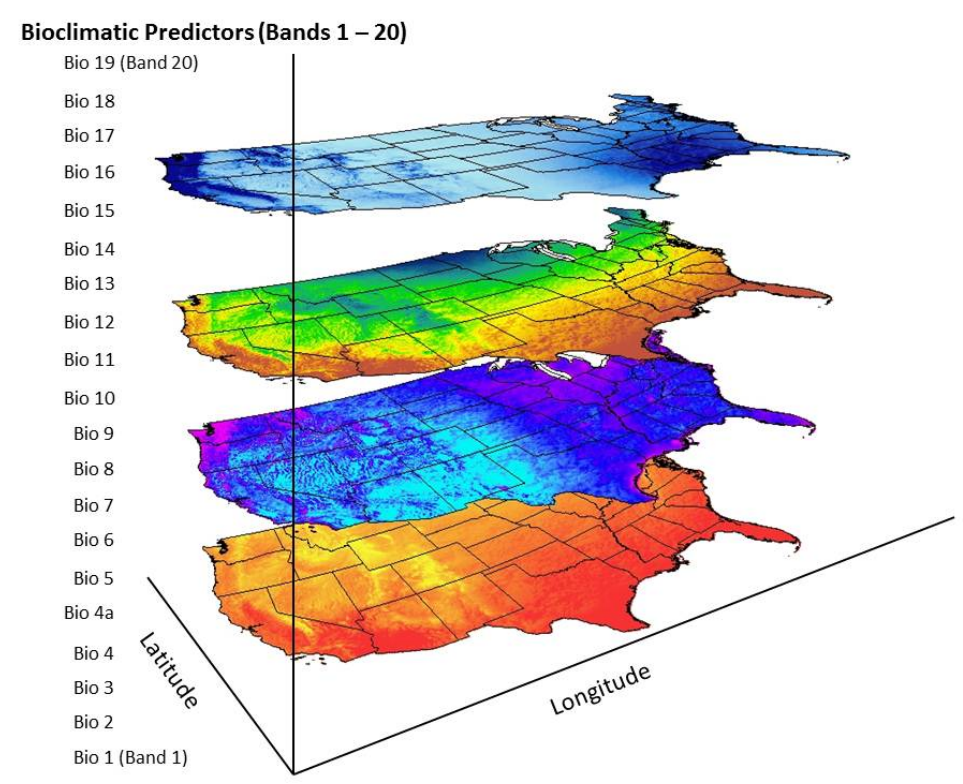
current scenarios, FORT scientists derived bioclimatic predictors from geographic information system

Graphic representation of 20 bioclimatic predictors.

(GIS) data for the conterminous U.S. that researchers and land managers can use to inform habitat management decisions in the present while still considering future climate changes. In FY2012 and FY2013, FORT published a report describing the methods and publicly available data for download from USGS ScienceBase. 
- Use of High Throughput and High Performance Computing. To address complex ecological questions across time and space often requires extremely large spatial datasets, multiple datasets, and a large number of computations, or a combination of these components. FORT has implemented two technologies to provide the expanded computing resources needed to address such questions: high throughput computing (HTC) and high performance computing (HPC). In FY2012 and FY2013, FORT integrated two commonly used software applications (ESRI ArcGIS and ERDAS) into an HTC system so that scientists can now take advantage of distributed computing without requiring HTC knowledge. Three new spatial analyses presented an opportunity to explore the use of HPC when they did not fit into a distributed (HTC) computing framework.

- Support to Landscape Conservation Cooperatives (LCCs) using the USGS ScienceBase Catalog project. The FORT Web Applications Team worked with multiple LCCs to develop LCMAP, an application that allows LCC partners, regardless of their agency affiliation, to securely share, access, and analyze common datasets and information. LC-MAP is currently being used by 9 LCCs. The Web Applications Team and the GIS and Remote Sensing Team developed an integrated set of geospatial services and an ArcMap toolbox for the Great Northern LCC that provides users with convenient remote access, visualization, and landscape analysis of MODIS vegetation phenology data extracted from satellite imagery.

- White-Nose Syndrome (WNS) Disease Tracking System. Because white-nose syndrome, a devastating disease of hibernating bats in North America, is spreading rapidly, field surveillance data, diagnostic field samples, and other critical information must be communicated quickly to State and Federal land managers. Working with the U.S. Fish and Wildlife Service (FWS), the FORT Web Applications team developed a system that provides customizable disease tracking maps and data exports for all U.S. States and counties, tissue sample database management, reporting contacts for all U.S. States and Federal resource management agencies, and a directory of laboratories involved in white-nose syndrome diagnostic analyses.

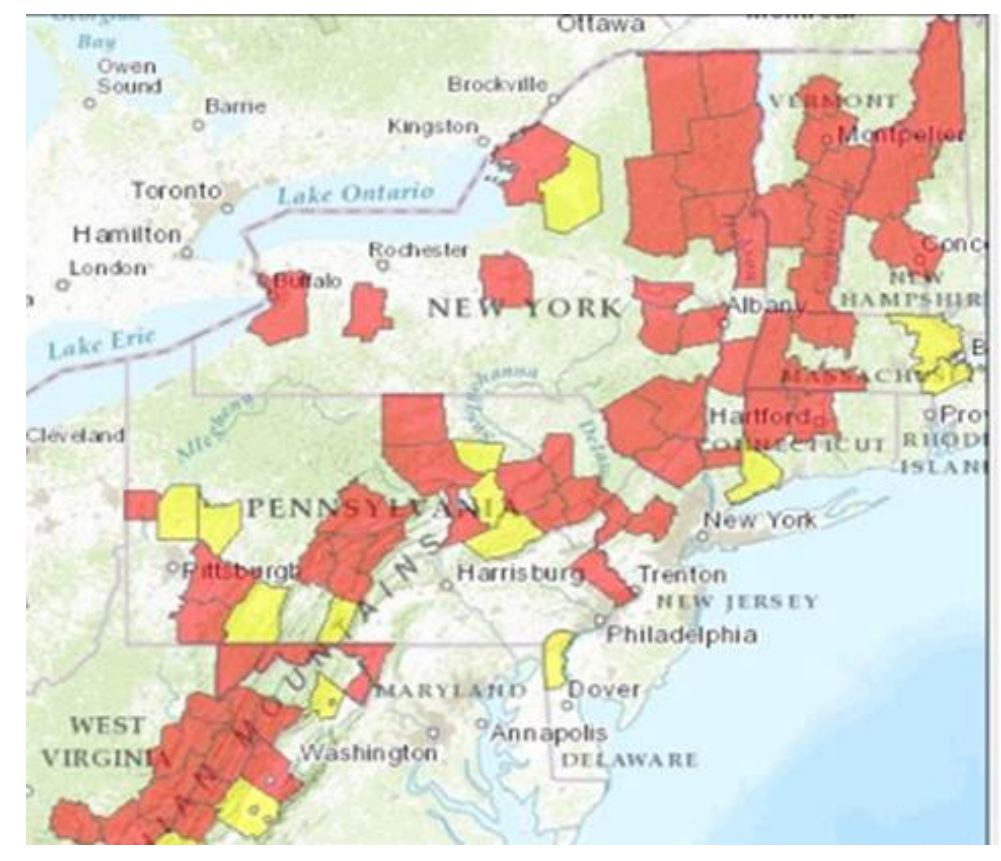

White-nose syndrome occurrences. USGS image.

- USGS ScienceBase Catalog and Data Repository (Version 2). ScienceBase is a data cataloging and collaborative data management platform that provides rapid data discovery options to all users, as well as data sharing, management, and publication support to the USGS and partner research projects. The FORT Web Applications team worked with staff from Core Science Analytics and Synthesis (CSAS) to design, develop, and release Version 2 of ScienceBase. Key aspects addressed in FY2012 and FY2013 included ways to quickly ingest datasets with millions of records, optimize searching for millions of metadata records, and automatically provide multiple ways to find and use every entered or referenced dataset. 


\section{Ecosystems}

Knowledge of ecological systems and their responses to natural and human stressors is a continuing key science need. It is a serious challenge to integrate multiple science disciplines to conceptualize and plan the interdisciplinary research needed to produce this knowledge from the beginning. FORT scientists led many interdisciplinary research projects in FY2012 and FY2013 that connected (1) human impacts, decision processes, and economic analysis; and (2) data integration, analyses, and access, with complex ecological studies championed by the USGS. Examples follow, organized by program focus.

\section{Ecosystems—Fisheries: Aquatic and Endangered Resources}

- Developing Adaptive Management Decision-Support Systems for Improved 2D Aquatic Habitat Modeling. Instream flows is a long-standing research theme for FORT scientists, but recent work has moved beyond general support for the Instream Flow Incremental Methodology (IFIM) framework and its components, such as the Physical Habitat Simulation (PHABSIM) software. Topics now include (1) formal consideration of how different hydraulic models and data densities affect estimates of potential habitat to address the question of how much study effort is enough, (2) use of landscape ecology concepts in habitat analysis supported by two-dimensional (2D) hydraulic models, (3) development of streamflow response and valuation models for riparian vegetation, and (4) development of decision-support-system and GIS (geographic information system)-derived spatial visualization tools to make the multivariate output from multiple flow alternatives more accessible to water managers and interested parties.

- Wetland Flora, Fauna, and Water Quality Assessments at Topock Marsh. FORT scientists worked on a FWS Quick Response Request to determine how the biotic and abiotic elements of the marsh responded to unusually low flow conditions and compared the newly collected data with historical data collected by U.S. Department of the Interior Bureau of Reclamation's (Reclamation) Lower Colorado Region and Arizona's Game and Fish Department. This rapid on-site assessment proved to be valuable in documenting how specific conductivity, total dissolved solids, and turbidity concentrated within the marsh as well as showing how quickly the higher

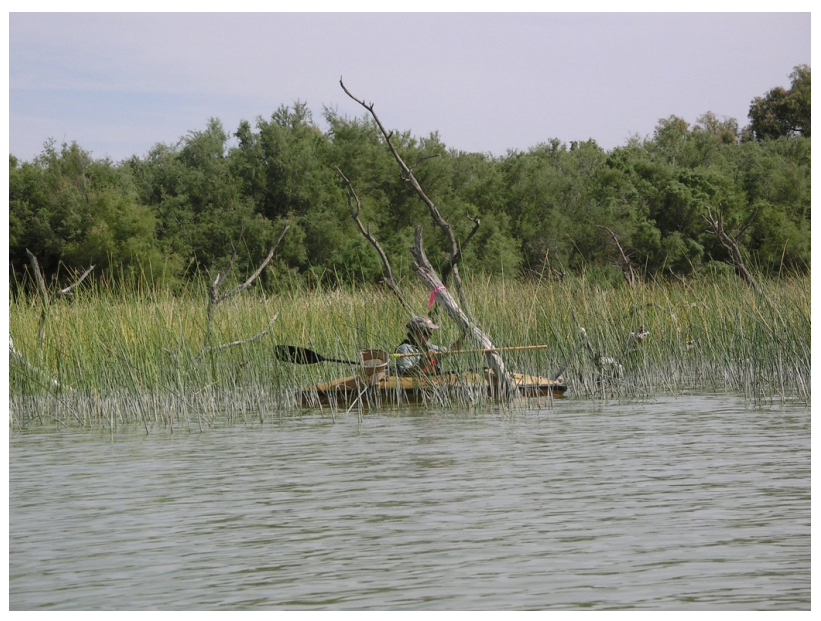

Topock Marsh concentrations of materials could be reduced with more typical flows. Armed with this information, FWS will be able to plan, design, and implement more effective water management strategies necessary to maintain quality wetland habitat in this desert environment.

- Treatment Wetland Research Projects. FORT scientists are collaborating with the USGS National Research Program, the Bureau of Reclamation Technical Service Center, and several university and municipal partners to better understand and design treatment wetlands. Current research projects address the potential of treatment wetlands to break down or attenuate endocrine-disrupting compounds, better managing the waste concentrates from water purification processes, monitoring and evaluating a newly built saline constructed treatment wetland, and demonstrating innovative constructed wetland designs for improving reclaimed water quality at Bureau of Reclamation facilities. 
Ecosystems-Invasive Species and Species Modeling

- Biology and Control of Invasive Constrictor Snakes and Tegus in Florida, Brown

Treesnakes on Guam, and Boa Constrictors in Puerto Rico. In FY2012 and FY2013, FORT scientists continued development of capture tools for Burmese pythons and initiated radiotelemetry and trapping studies of Argentine tegus, large invasive lizards that are rapidly expanding their range in extreme southern Florida. On Guam, FORT scientists concluded a monumental project to assess population status of

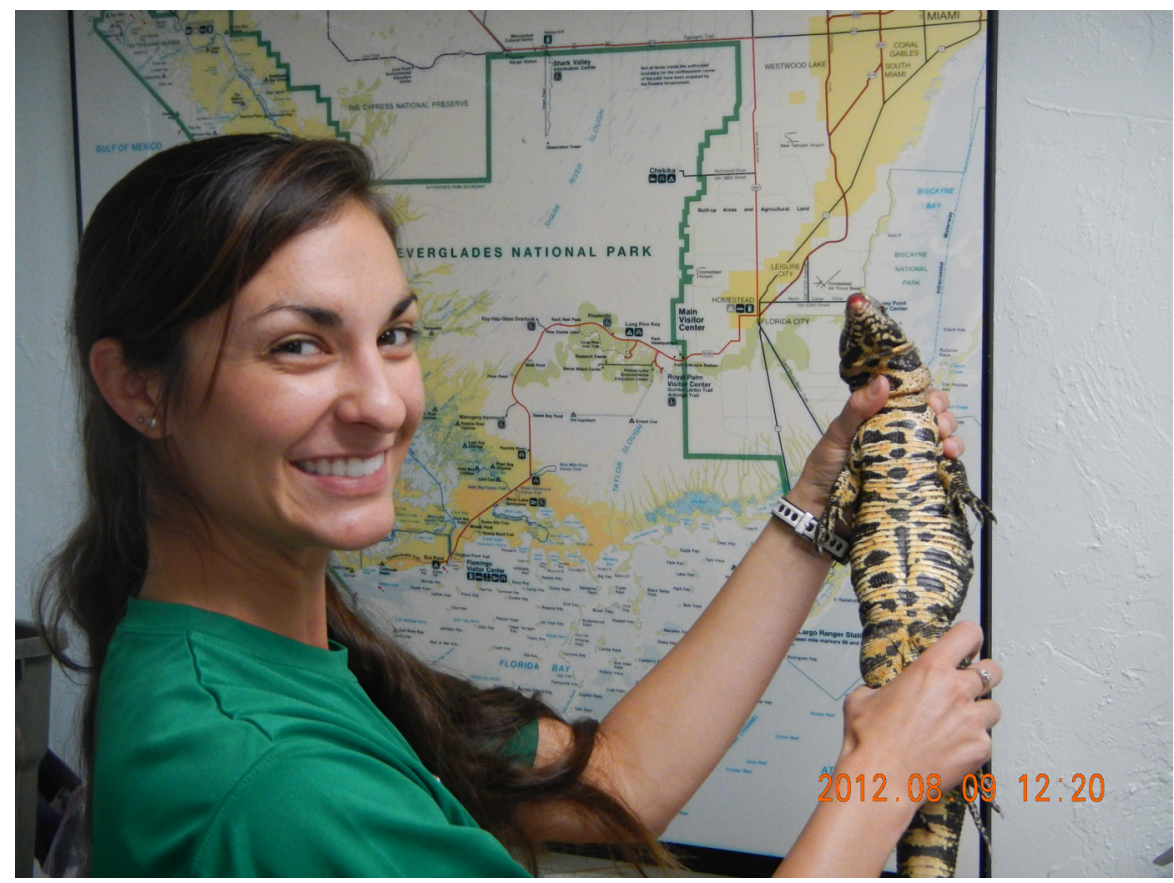

Argentine tegu brown treesnakes across the entire island, conducted a pilot project to assess whether roads can be used as management boundaries for landscape-level control, conducted radiotelemetry studies of juvenile snakes to examine reasons for their low capture rate in traps, continued to assist the FWS and the U.S. Department of Defense (DOD) with snake barrier construction, and continued support for the brown treesnake rapid response team. In Puerto Rico, FORT scientists are working with Federal agencies and the local university to collect snakes and conduct necropsies to better understand their diets, reproduction, and body size variation and to conduct a genetic study to determine the origin and genetic diversity of the population.

- Developing a Decision-Support Model for Buffelgrass Management in Southern Arizona. Buffelgrass (Pennisetum ciliare) poses a problem in the deserts of the United States by growing in dense stands and introducing a wildfire risk in an ecosystem not adapted to fire. Given the urgency of the buffelgrass invasion and the limited resources available, the USGS worked in cooperation with various partners and the Southern Arizona Buffelgrass Coordination Center to develop a spatially explicit decision-support system to evaluate potential strategies, using buffelgrass infestations on the south slope of the Santa Catalina Mountains as a test case.

- Lesser Prairie-Chicken Habitat Model. The lesser prairie-chicken is considered an umbrella species of mixed- and short-grass prairie but has suffered habitat and population decreases. FORT researchers worked with the Kansas Department of Wildlife and Parks to develop habitat suitability models for lesser prairie-chickens across the state and were then invited to participate in the Western Governors' Association Lesser Prairie-Chicken Technical Team to lead creation of similar models for both nesting and mating (lek) habitat across the lesser prairie-chicken's entire range including parts of Colorado, Kansas, New Mexico, Oklahoma, and Texas. This effort was the first time all of the states shared their location data together and involved partnerships with each state's fish and wildlife agencies and the Playa Lakes Joint Venture. 
- Using Environmental DNA in Water Samples to Track Invasive Pythons in Florida. Currently, nighttime road surveys and confirmed sightings are the only methods used to document python distribution in Everglades National Park and other areas in southern Florida, but low detection probabilities mean that these methods miss most individuals. FORT researchers are working with the USGS Southeast Ecological Science Center to use a relatively new method to test for python DNA in water samples (from feces, urine, skin cells, sloughed skin) to determine where these invasive snakes occur. Results will help refine understanding of the current distribution of these damaging invaders and provide an important earlywarning tool for land managers attempting to determine if pythons are present on their lands.

\section{Ecosystems-Status and Trends of Biological Resources}

- 2012 Science Workshop: Delivering USGS Science to Wyoming Landscape Conservation Initiative Partners. The Wyoming Landscape Conservation Initiative (WLCI), implemented in 2007, is a long-term, science-based effort to conserve and enhance aquatic and terrestrial habitats while facilitating responsible development through local collaboration and partnerships. The USGS has the lead role for developing and distributing scientific information to the WLCI community. During 2012, FORT scientists planned and hosted the WLCI Science Workshop attended by more than 200 people from industry, Federal and State land management agencies, grazing associations, non-government organizations (NGOs), academia, and the public. The workshop included 85 oral and poster presentations. During the workshop and tours, partner discussions focused on how to use scientific information more fully in management and how to tailor future science activities for improving on-the-ground utility and application.

- Socioeconomics Planning Tools. In FY2012 and FY2013, improvements were made to two socioeconomic planning tools. Assessing Socioeconomic Planning Needs (ASPN) is a web-based tool used by resource planners and field staff to identify and prioritize the social and economic issues they may need to address and to determine the proper social and economic methods to use to analyze impacts of management actions. The Benefit Transfer and Visitor-Use Estimating Models Toolkit helps natural resource planners and managers determine how the public uses and values recreational opportunities and ecosystem services provided by their resource management area and evaluate economic tradeoffs between alternative ways of managing resource use on those public lands. 
- Assessing Visitor Experiences on National Wildlife Refuges. The 2012 National Wildlife Refuge Visitor Survey, commissioned by the FWS, was conducted on 25 refuges across the country, with two separate sampling periods selected for each participating refuge in an effort to capture the specific visitation patterns of those refuges. In addition, two USGS data series were published in FY2012 and FY2013 as part of the 2010-2011 survey: Data Series 643, which disseminated 53 individual station-specific reports, and Data Series 685 , which addressed aggregatelevel data representing the combined results for stations having a minimum of 25,000 visitors annually.

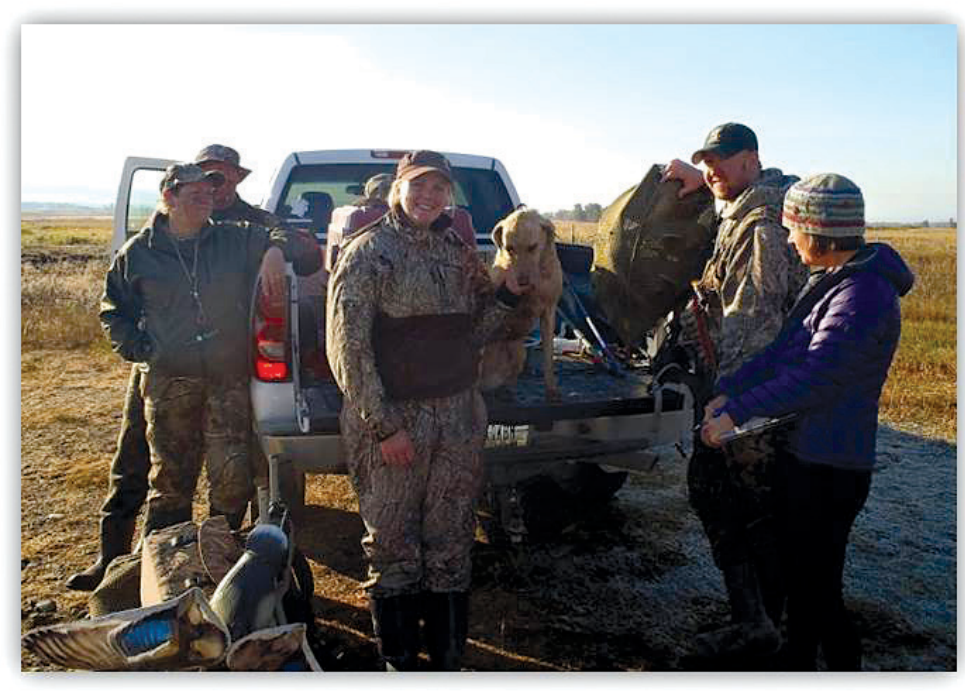

Contacting visitors at Lee Metcalf National Wildlife Refuge, Mont. Photo courtesy of Ron Osborn, USGS retired.

- Assessment of Ecosystem Service Values for the Central Everglades Planning Project. Restoration activities that will take place in Florida's central Everglades under the Central Everglades Planning Project's (CEPP) Tentatively Selected Plan (TSP) could impact a range of ecosystem services that benefit both local communities and society as a whole. In FY2012 and FY2013, FORT economists, in collaboration with the University of Florida, U.S. Army Corps of Engineers (USACE), and other CEPP team members, began conducting an assessment of the value of ecosystem services that will be affected by these restoration activities.

\section{Ecosystems-Terrestrial, Freshwater, and Marine Environments}

- Bison, Elk, and Vegetation Ecology in the Great Sand Dunes Ecosystem. With the Northern Rocky Mountain Science Center, the FORT is initiating a public-private partnership with three Federal agencies, an NGO, and a private rancher to investigate expanding the existing bison population (and ultimately establishing a contiguous bison herd) in Colorado's San Luis Valley. This work supports DOI's recently initiated Bison Conservation Initiative.

- Raptors and Wind Development: Developing Science-Based Conservation Tools. Working with State, Federal, and non-governmental entities, FORT investigators have collected extensive records of raptor nest locations across Wyoming. We extracted

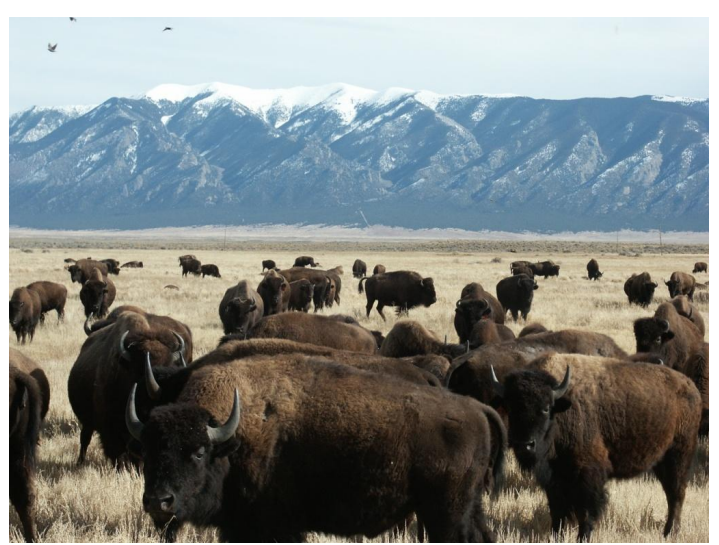

Bison grazing against a backdrop of the Sangre de Cristo Mountains. and created spatial data layers representing features that raptors key in on when choosing nest sites, combined the spatial data with statistical models to predict relative habitat quality, and overlaid spatial data layers representing wind-energy potential to provide agencies with the most rigorous planning tool available to date. Partners, including the U.S. Fish and Wildlife Service, can use the models to guide energy-development companies with project-siting decisions. 
- Assessing Effects of Energy Development for the Wyoming Landscape Conservation Initiative, Colorado, and New Mexico. FORT scientists are helping develop a multi-resource Integrated Assessment (IA) for the Wyoming Landscape Conservation Initiative (WLCI) area to inform planning and decisionmaking in southwestern Wyoming. The IA evaluates the natural, economic, and social context for energy development and other land uses, with a focus on informing conservation actions and decisions. The IA identifies areas with high potential for conservation, restoration, and (or) development for both the current landscape and future landscapes.

- Wyoming Basin Rapid Ecoregional Assessment for the Bureau of Land Management. The overall goal of the Bureau of Land Management's (BLM) Rapid Ecoregional Assessments (REA) is to provide information that facilitates development of ecoregionbased land-management strategies on public lands and to facilitate planning and analysis for the management of ecological resources. The REA provides an assessment of ecological conditions and can be used to identify priority areas for conservation or restoration of native plant and animal communities as well as

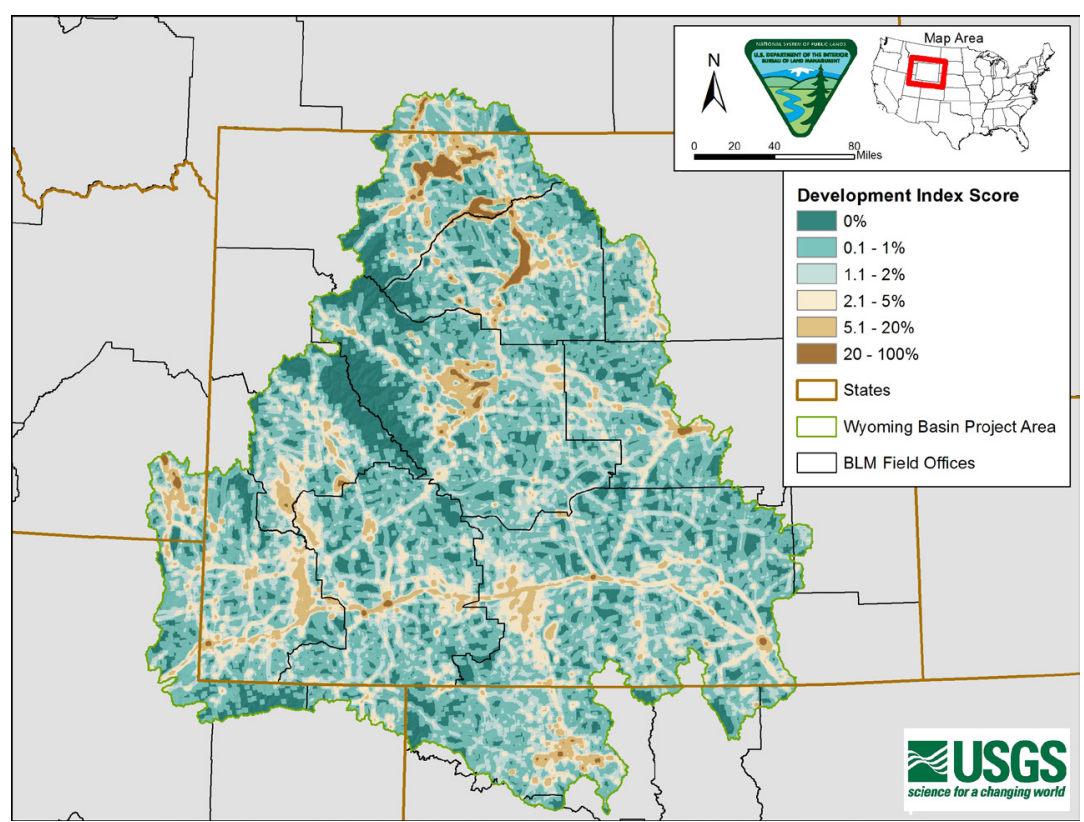

Cumulative effects of surface disturbance resulting from energy extraction, transportation, agriculture, and other forms of development. areas for development. FORT scientists are leading the Wyoming Basin Ecoregion REA for the BLM. The work plan for addressing the priority management questions and evaluating the status of Conservation Elements has been developed and approved, and the associated analyses began in FY2013.

- Reconstructing Flood History from Tree Rings. FORT scientists are using tree rings of plains cottonwood to relate tree growth and establishment to flow and climate along the Little Missouri River in Theodore Roosevelt National Park, North Dakota. In FY2012 and FY2013, they developed a chronology based on cores collected from 339 cottonwood trees at the North Unit of the park, and related cottonwood growth to climate and flow. Over the next two years, they will use the tree-ring record to reconstruct a 267-year record of past climate and flow and to assess the potential effects of future climate change on cottonwood growth and establishment.

\section{Ecosystems-Wildlife and Terrestrial Resources}

- Investigations of White-Nose Syndrome in Bats. White-nose syndrome (WNS) is an emerging disease of hibernating bats that is causing unprecedented population declines in multiple species in North America and has now spread to 19 states and 4 Canadian provinces. During FY2012 and FY2013, FORT scientists continued participating in efforts to coordinate the national response to this wildlife emergency, provided support to disease researchers at the USGS National Wildlife 
Health Center (NWHC), and expanded a video-monitoring field study with the National Park Service (NPS) to identify causes and consequences of the disease. Also in FY2012 and FY2013, FORT scientists took the lead for Data and Technical Transformation Management, an element identified in A National Plan for Assisting States, Federal Agencies, and Tribes in Managing White-Nose Syndrome in Bats, and used habitat-association modeling to predict the potential spread of WNS (with Colorado State University, Fort Collins, Colo.).

- Bats and Wind Turbines. Wind energy is one of the fastest-growing industries in the world and represents an important step toward reducing dependence on nonrenewable sources of power. However, turbines are causing unprecedented mortality of migratory treeroosting bats. Causes of bat collisions with turbines remain unknown. In FY2012 and FY2013, USGS scientists (FORT, Pacific Islands Research Science Center) in collaboration with University of Colorado, initiated a new project to determine how landscape features (for example, mountains or forests) and environmental conditions (for example, temperature and humidity) influence the migration and seasonal distribution patterns of tree bats to help assess the risk posed by turbines. In another study, scientists from

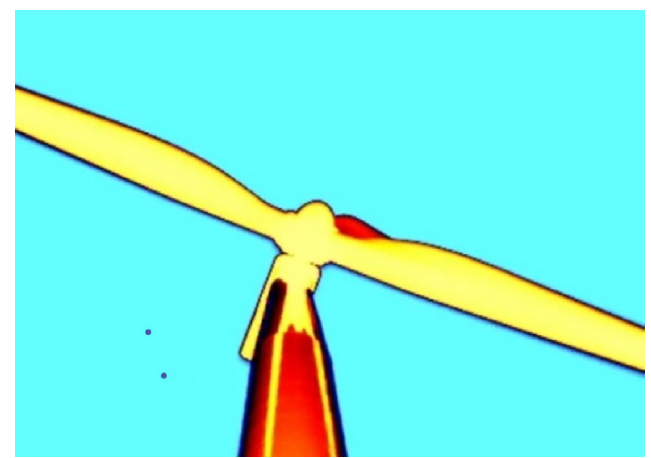

Snapshot from thermal video of two bats (blue dots in lower left quadrant) interacting during the middle of the night near the tower of an industrial wind turbine. Image by Paul Cryan, USGS.

FORT and four other USGS science centers (Forest and Rangeland Ecosystem Science Center, Northern Rocky Mountain Science Center, Northern Prairie Wildlife Research Center, and Pacific Island Ecosystems Research Center) partnered with industry and a conservation organization to conduct a video monitoring experiment examining the hypothesis that bats are attracted to wind turbines, particularly during low-wind conditions. These new video observations revealed that bats consistently approach wind turbines in predictable ways. These observations are helping find new ways of monitoring and possibly mitigating bat activity and fatalities at wind turbines.

- Implications of Climate Change for Avian Conservation in Great Plains Landscapes. The vulnerability of wetland-dependent avian species in the face of impending climate and land-use change is of major concern to land managers within the U.S. Department of the Interior, the Plains and Prairie Pothole Landscape Conservation Cooperative, and the FWS Prairie Pothole Joint Venture. In FY2012 and FY2013, in cooperation with the USGS South Dakota Water Science Center, the National Center for Atmospheric Research, and the University Corporation for Atmospheric Research, FORT scientists provided down-scaled climate models for use in determining where to best apply conservation actions; summarized projected climate for the Prairie Pothole region of North Dakota, South Dakota, Minnesota, and Iowa; and modeled the probability of occurrence of breeding wetland-dependent birds during contemporary (1981-2000) and future (2040-2049) time periods.

- Weather Radar Identifies Bird Migration Stopover Habitat in the Arid Southwest. Twice a year, millions of North American landbirds migrate thousands of miles between their breeding and wintering grounds. Research shows that this is arguably the most hazardous period of a migratory bird's annual life cycle. The United States-Mexico borderlands region typifies the potentially inhospitable arid and mountainous landscapes that western birds traverse during migration; the great majority of western migratory species funnel through this region. Recognizing the need for research at broader spatial scales than could be conducted using traditional field methodologies, FORT collaborated with the U.S. Fish and Wildlife Service and University of Southern Mississippi to use weather surveillance radar and satellite-based land use 
and land-cover data to study bird stopover habitat associations at broad spatial and temporal scales. A paper describing their findings was published in 2012.

- Field Testing an Oral Plague Vaccine for Prairie Dogs. Wildlife diseases continue to be a particularly critical issue to species recovery and maintenance. In addition to the direct effects of wildlife diseases on populations of at-risk species, indirect effects of wildlife lost to disease include loss of ecosystem services that benefit human health and economies, as well as increased risk of disease transmission at the human-wildlife interface. In FY2012 and FY2013, FORT scientists participated with USGS National Wildlife Health Center scientists and biologists from other State and Federal agencies to form a "science advisory team" to help plan and oversee the required safety and efficacy field trials of an oral plague vaccine on prairie dogs. Plague is well known for its capability to cause large-scale epidemics in humans and similarly large-scale epizootics in rodents, and the disease is a limiting factor in the successful reintroduction of the endangered black-footed ferret.

\section{Energy and Minerals, and Environmental Health}

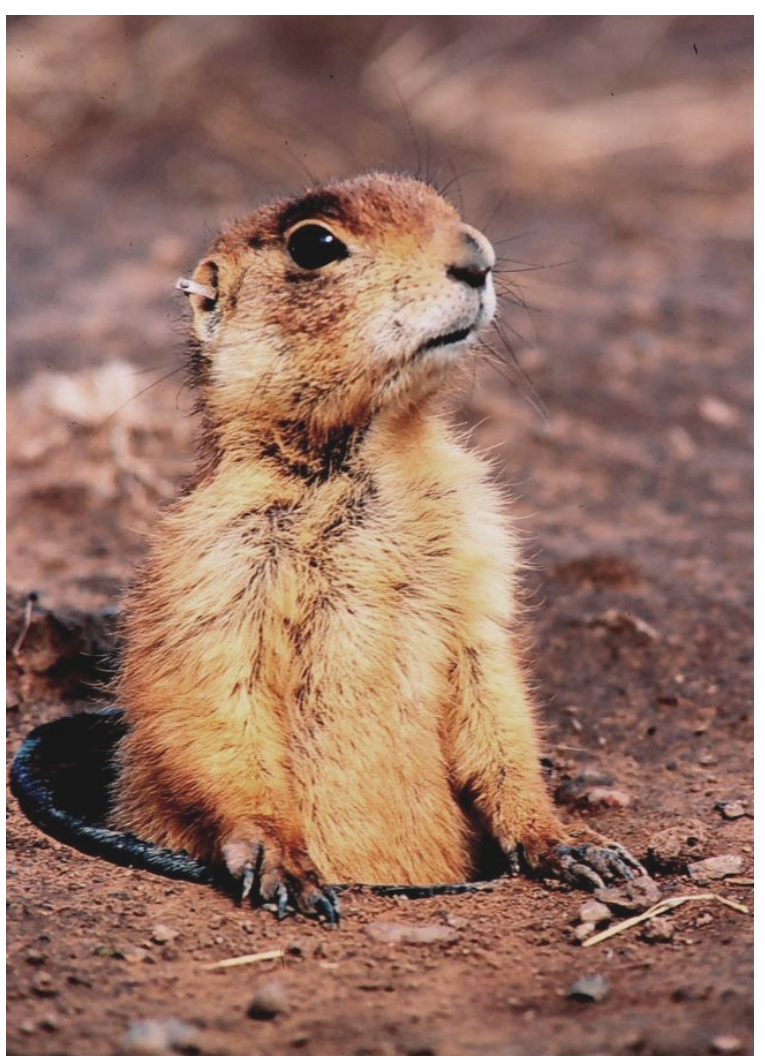

Utah prairie dog. USGS photo by Dean Biggins.

Integrated assessment of energy and mineral resources is an explicit goal in the USGS Science Strategy and is required for understanding the full costs and benefits of developing different energy and mineral resources. Although energy development is important for the economic growth and security of the Nation, it is likely to have unintended impacts on environmental health. The Energy and Minerals, and Environmental Health Mission Area provides oversight for USGS energy and minerals resource programs, the USGS Science and Decisions Center, toxics hydrology, and contaminants biology programs.

- Measuring Contaminant Exposure in Riparian Food Webs of the Lower Manistique River and Harbor in Michigan Using Sentinel Species to Support Remediation and Restoration by the U.S. Environmental Protection Agency (EPA). The Manistique River and Harbor are one of the Great Lakes Areas of Concern (AOC). These AOCs are heavily contaminated sites around the Great Lakes that are prioritized for remediation and restoration by the U.S. Environmental Protection Agency (EPA). Study results will be used to evaluate the relationship between sediment contamination and biological exposures. More importantly, these data will establish baseline conditions to assess future remedial actions at the site. Currently, a multi-agency task force (EPA,

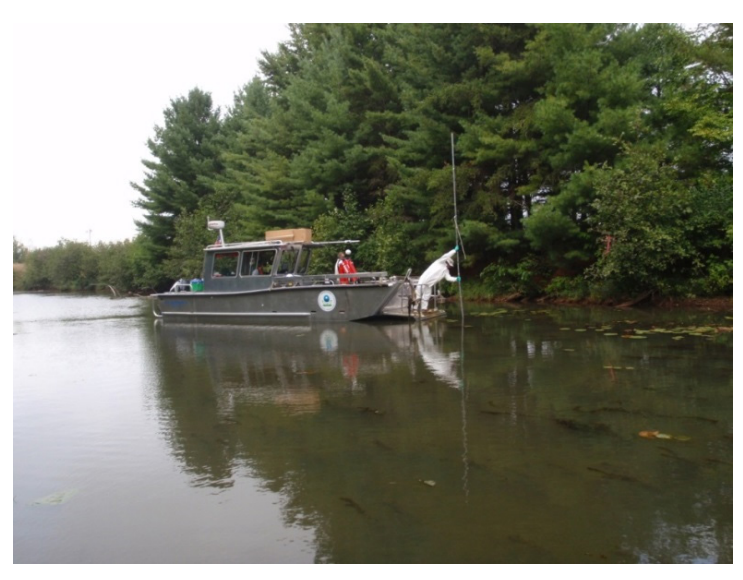

Sampling contaminated sediments in a backwater of the Manistique River in Michigan. Photo: David Walters, USGS. 
National Oceanic and Atmospheric Administration (NOAA), FWS, USGS, and various State agencies) is planning a $\$ 30$ million remediation of the site. Data collected by FORT are already informing this massive restoration effort. This project is part of the USGS Great Lakes Restoration Initiative (GLRI).

- Core Research Center Well Catalog. The Core Research Center (CRC) was established in 1974 by the USGS to preserve valuable borehole rock cores and cuttings for use by scientists and educators from government, industry, and academia. In FY2012 and FY2013, the Fort Collins Science Center Web Applications Team worked with CRC staff to implement a geospatial webenabled Well Catalog Cores Database and Cuttings Database (http://my.usgs.gov/crcwc). This effort allows scientists outside USGS to locate cores and cuttings available for study.

\section{Natural Hazards}

Every year in the United States, natural hazard events threaten lives and livelihoods, resulting in deaths and billions of dollars in damage. One role of the six science programs in the Natural Hazards Mission Area is to provide alerts and warnings of various hazards. Increasingly, web and mobile applications are being used to gather information and provide those alerts.

- National Earthquake Information Center Support. The National Earthquake Information Center (NEIC) compiles and maintains an extensive, global seismic database on earthquake parameters and their effects. These data serve as a solid foundation for basic and applied earth science research, and NEIC looks to develop ways to quickly disseminate this information to concerned national and international agencies, scientists, and the general public. In FY2012 and FY2013 the Fort Collins Science Center Web Applications Team supported a number of projects including (1) the Tweet Earthquake

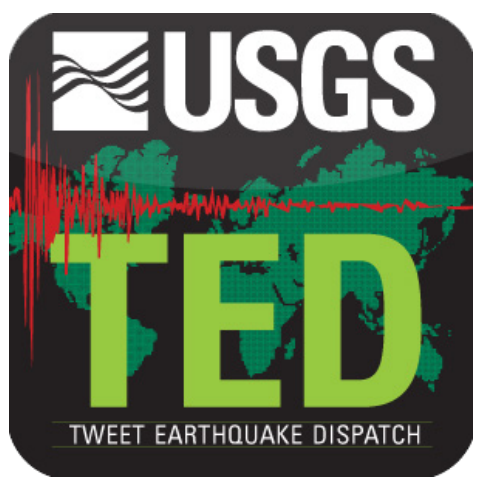
Dispatcher (@USGSted) that distributes alerts for earthquakes worldwide with magnitudes of 5.5 and above, (2) the NEIC Executive Summary Tool that pulls earthquake event parametrics from NEIC systems and builds customized reports within one hour of the event for distribution to a limited, high-level USGS audience, (3) new versions of ShakeCast that notify institutions of shaking levels at user-selected facilities, and (4) the Geomagnetism Reporting Tool that provides real-time scalable charting of the Earth's magnetic field.

\section{Water}

Historically, "instream flows" have focused on annual minimum flows, but the pattern of flows both within and across years is extremely important in determining instream habitat quality for a variety of native fish, mussels, and invertebrates, as well as for invasive species. The pattern is also very important from the standpoints of geomorphology, bed movement, establishment of riparian vegetation, and water quality. In addition, predicting future flows and water quality due to energy development, climate change, changing agricultural practices, and increased domestic demand will be important. FORT has a 35-year history addressing these important issues. Although supported by funding from other mission areas, a number of FY2012 and FY2013 accomplishments address key aspects of the Water science strategy as can be seen in the Water cross-reference column of table 1. Two examples include:

\section{- Assessing Potential Effects of Hydraulic Fracturing for Energy Development on Water}

Resources. Production of oil and gas from "unconventional" plays (low-permeability reservoirs of shale gas, shale oil, and tight-sands gas) is increasing in the United States. Extracting hydrocarbons from a low-permeability formation requires increasing its permeability by hydraulic 
fracturing; however, little scientific information is available on potential impacts. To help fill this data gap, USGS scientists from the FORT and other centers received FY2011 funding from the USGS John Wesley Powell Center for Analysis and Synthesis to lead the first broad-scale, databased assessment of hydraulic fracturing's potential effects on water resources in the United States. In FY2012 and FY2013, the team completed the process of acquiring and assembling national water-quality datasets for both surface water and groundwater and identified the parameters in the databases that might be suitable for assessing effects of hydraulic fracturing on water resources. The team then developed statistical approaches to analyze the data, conducted initial analyses, and developed several information products.

- Establishing a "Living Stream" Laboratory at FORT for Conducting Experiments on Lake, Stream, and Riparian Ecosystems. Capabilities and planned work include investigating (1) the effects of climate change on stream chemistry and chemical exposure, (2) pathways of organism and contaminant movement between aquatic and riparian ecosystems, and (3) effects of contaminants (such as ash and fire retardants following forest fires) on stream communities.

\section{For the Rest of the Story}

The science accomplishments highlighted

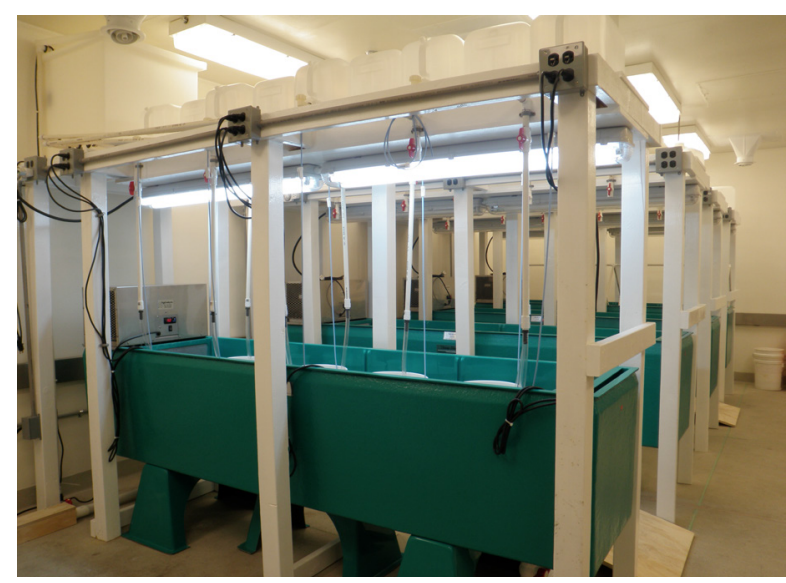

Living stream units. above represent just some of the FORT activities associated with or supportive of each USGS Mission Area. As table 1 and this summary show, results from the studies supported by one Mission Area often have implications across other Mission Areas as well. For summaries of each of the FY2012 and FY2013 accomplishments selected for reporting this year, please refer to Appendix 1. FORT Science Accomplishments.

\section{David B. Hamilton}

Director, Fort Collins Science Center

January 2014 
Table 1. USGS Mission Areas and Programs supported by FY2012 and FY2013 Fort Collins Science Center (FORT) scientific and technical accomplishments, as reported in this document. Task accomplishments are listed by their primary USGS Mission Area (and under the Ecosystems Mission Area, which supports the bulk of our research, also by Program). Click the accomplishment title to jump to its summary.

\section{To return to the table, hold down the Alt button and click the left arrow key: $\langle A L T \leftrightarrow$.}

\begin{tabular}{|c|c|c|c|c|c|c|}
\hline \multirow{2}{*}{$\begin{array}{l}\text { Accomplishment Title by USGS } \\
\text { Mission Area or Ecosystems Mission } \\
\text { Area Program }\end{array}$} & \multicolumn{6}{|c|}{ Mission Areas Addressed } \\
\hline & $\begin{array}{l}\text { Eco- } \\
\text { systems }\end{array}$ & $\begin{array}{l}\text { Climate and } \\
\text { Land-Use } \\
\text { Change }\end{array}$ & $\begin{array}{l}\text { Energy and } \\
\text { Minerals, and } \\
\text { Env. Health }\end{array}$ & $\begin{array}{l}\text { Natural } \\
\text { Hazards }\end{array}$ & Water & $\begin{array}{l}\text { Core } \\
\text { Science } \\
\text { Systems }\end{array}$ \\
\hline \multicolumn{7}{|c|}{ Administrative and Enterprise Information } \\
\hline Web Re-Engineering Support & & & & & & $\checkmark$ \\
\hline \multicolumn{7}{|c|}{ Climate and Land-Use Change } \\
\hline $\begin{array}{l}\text { The Users, Uses, and Value of } \\
\text { Landsat Imagery }\end{array}$ & $\checkmark$ & & & & & \\
\hline $\begin{array}{l}\text { National Climate Change and } \\
\text { Wildlife Science Center Data } \\
\text { Management and Project Support }\end{array}$ & & $\checkmark$ & & & & \\
\hline $\begin{array}{l}\text { The Western Mountain Initiative: } \\
\text { Forest Ecosystem Responses to } \\
\text { Climate Drivers in the Southern } \\
\text { Rocky Mountains }\end{array}$ & $\checkmark$ & $\checkmark$ & & & & \\
\hline \multicolumn{7}{|c|}{ Core Science Systems } \\
\hline $\begin{array}{l}\text { Scientific Breakthroughs: The John } \\
\text { Wesley Powell Center for Analysis } \\
\text { and Synthesis }\end{array}$ & $\checkmark$ & $\checkmark$ & $\checkmark$ & $\checkmark$ & $\checkmark$ & $\checkmark$ \\
\hline $\begin{array}{l}\text { Powell Center Web and Scientific } \\
\text { Programming Support }\end{array}$ & $\checkmark$ & $\checkmark$ & $\checkmark$ & $\checkmark$ & $\checkmark$ & $\checkmark$ \\
\hline $\begin{array}{l}\text { The Use of High Throughput } \\
\text { Computing for USGS Core Sciences } \\
\text { Research }\end{array}$ & $\checkmark$ & $\checkmark$ & & & $\checkmark$ & $\checkmark$ \\
\hline $\begin{array}{l}\text { Integrating High Performance } \\
\text { Computing with Geospatial } \\
\text { Applications: Expanding Upon a } \\
\text { Suite of USGS Computing }\end{array}$ & $\checkmark$ & & & & & $\checkmark$ \\
\hline $\begin{array}{l}\text { The Development and Application of } \\
\text { Derived Bioclimatic Variables from } \\
\text { Climate Normals and Time-Series } \\
\text { Data }\end{array}$ & $\checkmark$ & $\checkmark$ & & & & $\checkmark$ \\
\hline $\begin{array}{l}\text { Great Northern Landscape } \\
\text { Conservation Cooperative Spatial } \\
\text { Toolkit and Phenology Server }\end{array}$ & $\checkmark$ & $\checkmark$ & & & & $\checkmark$ \\
\hline $\begin{array}{l}\text { Landscape Conservation Cooperative } \\
\text { Data Management Support }\end{array}$ & $\checkmark$ & $\checkmark$ & $\checkmark$ & & $\checkmark$ & $\checkmark$ \\
\hline myUSGS Collaboration Suite & $\checkmark$ & $\checkmark$ & $\checkmark$ & $\checkmark$ & $\checkmark$ & $\checkmark$ \\
\hline
\end{tabular}


Table 1. USGS Mission Areas and Programs supported by FY2012 and FY2013 Fort Collins Science Center (FORT) scientific and technical accomplishments, as reported in this document. Task accomplishments are listed by their primary USGS Mission Area (and under the Ecosystems Mission Area, which supports the bulk of our research, also by Program). Click the accomplishment title to jump to its summary.-Continued

\section{To return to the table, hold down the Alt button and click the left arrow key: $\langle A L T \leftrightarrow$.}

\begin{tabular}{|l|c|c|c|c|c|c|}
\hline $\begin{array}{l}\text { Accomplishment Title by USGS } \\
\text { Mission Area or Ecosystems Mission } \\
\text { Area Program }\end{array}$ & $\begin{array}{c}\text { Mission Areas Addressed } \\
\text { Eco- } \\
\text { systems }\end{array}$ & $\begin{array}{c}\text { Climate and } \\
\text { Land-Use } \\
\text { Change }\end{array}$ & $\begin{array}{c}\text { Energy and } \\
\text { Minerals, and } \\
\text { Env. Health }\end{array}$ & $\begin{array}{c}\text { Natural } \\
\text { Hazards }\end{array}$ & Water & $\begin{array}{c}\text { Core } \\
\text { Science } \\
\text { Systems }\end{array}$ \\
\hline $\begin{array}{l}\text { ScienceBase Catalog and Data } \\
\text { Repository, Version 2 }\end{array}$ & $\checkmark$ & $\checkmark$ & $\checkmark$ & $\checkmark$ & $\checkmark$ & $\checkmark$ \\
\hline $\begin{array}{l}\text { White-Nose Syndrome Disease } \\
\text { Tracking System }\end{array}$ & $\checkmark$ & $\checkmark$ & $\checkmark$ & & & $\checkmark$ \\
\hline
\end{tabular}

Ecosystems-Fisheries: Aquatic and Endangered Resources (FAER)

\begin{tabular}{|l|c|l|l|l|l|l|}
\hline $\begin{array}{l}\text { Developing Adaptive Management } \\
\text { Decision-Support Systems for } \\
\text { Improved 2D Aquatic Habitat } \\
\text { Modeling }\end{array}$ & $\checkmark$ & & & & & \\
\hline $\begin{array}{l}\text { Wetland Flora, Fauna, and Water } \\
\text { Quality Assessment at Topock Marsh }\end{array}$ & $\checkmark$ & & & & $\checkmark$ & $\checkmark$ \\
\hline $\begin{array}{l}\text { Treatment Wetland Research } \\
\text { Projects }\end{array}$ & $\checkmark$ & & & & $\checkmark$ & \\
\hline
\end{tabular}

Ecosystems-Invasive Species

\begin{tabular}{|l|c|l|l|l|l|}
\hline $\begin{array}{l}\text { Control of Invasive Giant Constrictor } \\
\text { Snakes and Tegus in Florida }\end{array}$ & $\checkmark$ & & & & \\
\hline $\begin{array}{l}\text { Control and Prevention of the } \\
\text { Invasive Brown Treesnake }\end{array}$ & $\checkmark$ & & & & \\
\hline $\begin{array}{l}\text { Brown Treesnake Rapid Response } \\
\text { Team }\end{array}$ & $\checkmark$ & & & & \\
\hline $\begin{array}{l}\text { Biology, Impacts, and Control of } \\
\text { Invasive Boa Constrictors in Puerto } \\
\text { Rico }\end{array}$ & $\checkmark$ & & & & \\
\hline $\begin{array}{l}\text { Forecasting Africanized Honey Bee } \\
\text { Spread in the United States }\end{array}$ & $\checkmark$ & & & & \\
\hline $\begin{array}{l}\text { Modeling Invasive Weeds in Coastal } \\
\text { Alaska }\end{array}$ & $\checkmark$ & & & & \\
\hline $\begin{array}{l}\text { Developing a Decision-Support } \\
\text { Model for Buffelgrass Management } \\
\text { in Southern Arizona }\end{array}$ & $\checkmark$ & & & & \\
\hline Lesser Prairie-Chicken Habitat & $\checkmark$ & & & & \\
\hline $\begin{array}{l}\text { Resource for Advanced Modeling } \\
\text { and Software for Assisted Habitat } \\
\text { Modeling }\end{array}$ & $\checkmark$ & $\checkmark$ & & & \\
\hline $\begin{array}{l}\text { Using Environmental DNA in Water } \\
\text { Samples to Track Invasive Pythons } \\
\text { in Florida }\end{array}$ & $\checkmark$ & & & & \\
\hline $\begin{array}{l}\text { Potential Effects of Climate Change } \\
\text { on Invasive and Native Riparian } \\
\text { Plants in the U.S. West }\end{array}$ & $\checkmark$ & $\checkmark$ & & & \\
\hline
\end{tabular}


Table 1. USGS Mission Areas and Programs supported by FY2012 and FY2013 Fort Collins Science Center (FORT) scientific and technical accomplishments, as reported in this document. Task accomplishments are listed by their primary USGS Mission Area (and under the Ecosystems Mission Area, which supports the bulk of our research, also by Program). Click the accomplishment title to jump to its summary.-Continued

\section{To return to the table, hold down the Alt button and click the left arrow key: $\langle A L T \leftrightarrow$.}

\begin{tabular}{|c|c|c|c|c|c|c|}
\hline \multirow{2}{*}{$\begin{array}{l}\text { Accomplishment Title by USGS } \\
\text { Mission Area or Ecosystems Mission } \\
\text { Area Program }\end{array}$} & \multicolumn{6}{|c|}{ Mission Areas Addressed } \\
\hline & $\begin{array}{l}\text { Eco- } \\
\text { systems }\end{array}$ & $\begin{array}{l}\text { Climate and } \\
\text { Land-Use } \\
\text { Change }\end{array}$ & $\begin{array}{l}\text { Energy and } \\
\text { Minerals, and } \\
\text { Env. Health }\end{array}$ & $\begin{array}{l}\text { Natural } \\
\text { Hazards }\end{array}$ & Water & $\begin{array}{l}\text { Core } \\
\text { Science } \\
\text { Systems }\end{array}$ \\
\hline \multicolumn{7}{|c|}{ Ecosystems-Status and Trends of Biological Resources } \\
\hline $\begin{array}{l}2012 \text { Science Workshop: Delivering } \\
\text { USGS Science to Wyoming } \\
\text { Landscape Conservation Initiative } \\
\text { Partners }\end{array}$ & $\checkmark$ & $\checkmark$ & $\checkmark$ & & $\checkmark$ & \\
\hline $\begin{array}{l}\text { Assessment and Monitoring of Semi- } \\
\text { Arid Woodlands in the Little } \\
\text { Mountain Ecosystem }\end{array}$ & $\checkmark$ & $\checkmark$ & $\checkmark$ & & & \\
\hline $\begin{array}{l}\text { Mapping Rural Residential Growth } \\
\text { and Energy Development in Sublette } \\
\text { County, Wyoming }\end{array}$ & $\checkmark$ & $\checkmark$ & $\checkmark$ & & & \\
\hline $\begin{array}{l}\text { Woodland Demography of } \\
\text { Southwest Wyoming }\end{array}$ & $\checkmark$ & $\checkmark$ & & & & \\
\hline $\begin{array}{l}\text { Assessing Socioeconomic Planning } \\
\text { Needs (ASPN) }\end{array}$ & $\checkmark$ & & & & & $\checkmark$ \\
\hline $\begin{array}{l}\text { Assessing Visitor Experiences on } \\
\text { National Wildlife Refuges }\end{array}$ & $\checkmark$ & & & & & $\checkmark$ \\
\hline $\begin{array}{l}\text { Assessment of Ecosystem Service } \\
\text { Values for the Central Everglades } \\
\text { Planning Project }\end{array}$ & $\checkmark$ & & & & & \\
\hline $\begin{array}{l}\text { The Benefit Transfer and Visitor-Use } \\
\text { Estimating Models Toolkit }\end{array}$ & $\checkmark$ & & & & & \\
\hline $\begin{array}{l}\text { BLM Social Science Concepts and } \\
\text { Methods Training Module }\end{array}$ & $\checkmark$ & & & & & \\
\hline Decision Sciences & $\checkmark$ & $\checkmark$ & & & & \\
\hline $\begin{array}{l}\text { Economic Contribution of Federal } \\
\text { Investments in Restoration of } \\
\text { Degraded, Damaged, or Destroyed } \\
\text { Ecosystems }\end{array}$ & $\checkmark$ & & $\checkmark$ & & & \\
\hline $\begin{array}{l}\text { Evaluation of Native and Non-Native } \\
\text { Vegetation Response to Exceptional } \\
\text { Drought and Grazing in Southern } \\
\text { Plains Conservation Reserve } \\
\text { Program Field }\end{array}$ & $\checkmark$ & & & & & \\
\hline Negotiation Training & $\checkmark$ & & & & & \\
\hline $\begin{array}{l}\text { Science in Support of Policy: The } \\
\text { Interactive Effects of Climate } \\
\text { Change and Reactive Nitrogen on } \\
\text { U.S }\end{array}$ & $\checkmark$ & $\checkmark$ & & & & \\
\hline
\end{tabular}


Table 1. USGS Mission Areas and Programs supported by FY2012 and FY2013 Fort Collins Science Center (FORT) scientific and technical accomplishments, as reported in this document. Task accomplishments are listed by their primary USGS Mission Area (and under the Ecosystems Mission Area, which supports the bulk of our research, also by Program). Click the accomplishment title to jump to its summary.-Continued

\section{To return to the table, hold down the Alt button and click the left arrow key: $\langle A L T \leftrightarrow$.}

\begin{tabular}{|l|c|c|c|c|c|c|}
\hline \multirow{2}{*}{$\begin{array}{l}\text { Accomplishment Title by USGS } \\
\text { Mission Area or Ecosystems Mission } \\
\text { Area Program }\end{array}$} & \multicolumn{5}{|c|}{ Mission Areas Addressed } \\
\cline { 2 - 7 } & $\begin{array}{c}\text { Eco- } \\
\text { systems }\end{array}$ & $\begin{array}{c}\text { Climate and } \\
\text { Land-Use } \\
\text { Change }\end{array}$ & $\begin{array}{c}\text { Energy and } \\
\text { Minerals, and } \\
\text { Env. Health }\end{array}$ & $\begin{array}{c}\text { Natural } \\
\text { Hazards }\end{array}$ & Water & $\begin{array}{c}\text { Core } \\
\text { Science } \\
\text { Systems }\end{array}$ \\
\hline
\end{tabular}

Ecosystems-Terrestrial, Freshwater, and Marine Environments

\begin{tabular}{|c|c|c|c|c|c|c|}
\hline $\begin{array}{l}\text { Bison, Elk, and Vegetation Ecology } \\
\text { in the Great Sand Dunes Ecosystem }\end{array}$ & $\checkmark$ & & & & & \\
\hline $\begin{array}{l}\text { Developing a More Accurate Aerial } \\
\text { Population Survey Technique for Elk } \\
\text { in Rocky Mountain National Park, } \\
\text { Colorado }\end{array}$ & $\checkmark$ & & & & & \\
\hline $\begin{array}{l}\text { Sandhill Cranes in Colorado's San } \\
\text { Luis Valley: Exploring New } \\
\text { Technology for Improved Population } \\
\text { Assessments }\end{array}$ & $\checkmark$ & $\checkmark$ & & & & \\
\hline $\begin{array}{l}\text { Golden Eagle Population Dynamics } \\
\text { across the West }\end{array}$ & $\checkmark$ & & $\checkmark$ & & & \\
\hline $\begin{array}{l}\text { Raptors and Wind Development: } \\
\text { Developing Science-based } \\
\text { Conservation Tools }\end{array}$ & $\checkmark$ & & $\checkmark$ & & & \\
\hline \begin{tabular}{|l|} 
Disturbance and Reclamation \\
Tracking
\end{tabular} & $\checkmark$ & & $\checkmark$ & & & \\
\hline $\begin{array}{l}\text { Integrated Assessment for the } \\
\text { Wyoming Landscape Conservation } \\
\text { Initiative }\end{array}$ & $\checkmark$ & $\checkmark$ & $\checkmark$ & $\checkmark$ & $\checkmark$ & $\checkmark$ \\
\hline $\begin{array}{l}\text { Assessing Effects of Energy } \\
\text { Development in Colorado and New } \\
\text { Mexico }\end{array}$ & $\checkmark$ & $\checkmark$ & $\checkmark$ & & $\checkmark$ & $\checkmark$ \\
\hline $\begin{array}{l}\text { Pygmy Rabbits and Gas Field } \\
\text { Development in Wyoming }\end{array}$ & $\checkmark$ & $\checkmark$ & $\checkmark$ & & & \\
\hline $\begin{array}{l}\text { Wyoming Basin Rapid Ecoregional } \\
\text { Assessment for the Bureau of Land } \\
\text { Management }\end{array}$ & $\checkmark$ & & & & & \\
\hline $\begin{array}{l}\text { Gunnison Sage-Grouse Habitat Use } \\
\text { and Movement: The Crawford } \\
\text { Population }\end{array}$ & $\checkmark$ & $\checkmark$ & $\checkmark$ & & & $\checkmark$ \\
\hline \begin{tabular}{|l|} 
Microbial-Driven Nitrogen Cycling \\
in Aquatic Alpine Ecosystems
\end{tabular} & $\checkmark$ & $\checkmark$ & & & $\checkmark$ & \\
\hline $\begin{array}{l}\text { Reconstructing Flood History from } \\
\text { Tree Rings }\end{array}$ & $\checkmark$ & $\checkmark$ & & & $\checkmark$ & \\
\hline $\begin{array}{l}\text { Woody Riparian Vegetation at } \\
\text { Streamgages }\end{array}$ & $\checkmark$ & & & & $\checkmark$ & \\
\hline
\end{tabular}


Table 1. USGS Mission Areas and Programs supported by FY2012 and FY2013 Fort Collins Science Center (FORT) scientific and technical accomplishments, as reported in this document. Task accomplishments are listed by their primary USGS Mission Area (and under the Ecosystems Mission Area, which supports the bulk of our research, also by Program). Click the accomplishment title to jump to its summary.-Continued

\section{To return to the table, hold down the Alt button and click the left arrow key: $\langle A L T \leftrightarrow$.}

\begin{tabular}{|l|c|c|c|c|c|c|}
\hline \multirow{2}{*}{$\begin{array}{l}\text { Accomplishment Title by USGS } \\
\text { Mission Area or Ecosystems Mission } \\
\text { Area Program }\end{array}$} & \multicolumn{5}{|c|}{ Mission Areas Addressed } \\
\cline { 2 - 7 } & $\begin{array}{c}\text { Eco- } \\
\text { systems }\end{array}$ & $\begin{array}{c}\text { Climate and } \\
\text { Land-Use } \\
\text { Change }\end{array}$ & $\begin{array}{c}\text { Energy and } \\
\text { Minerals, and } \\
\text { Env. Health }\end{array}$ & $\begin{array}{c}\text { Natural } \\
\text { Hazards }\end{array}$ & Water & $\begin{array}{c}\text { Core } \\
\text { Science } \\
\text { Systems }\end{array}$ \\
\hline
\end{tabular}

Ecosystems-Wildlife and Terrestrial Resources

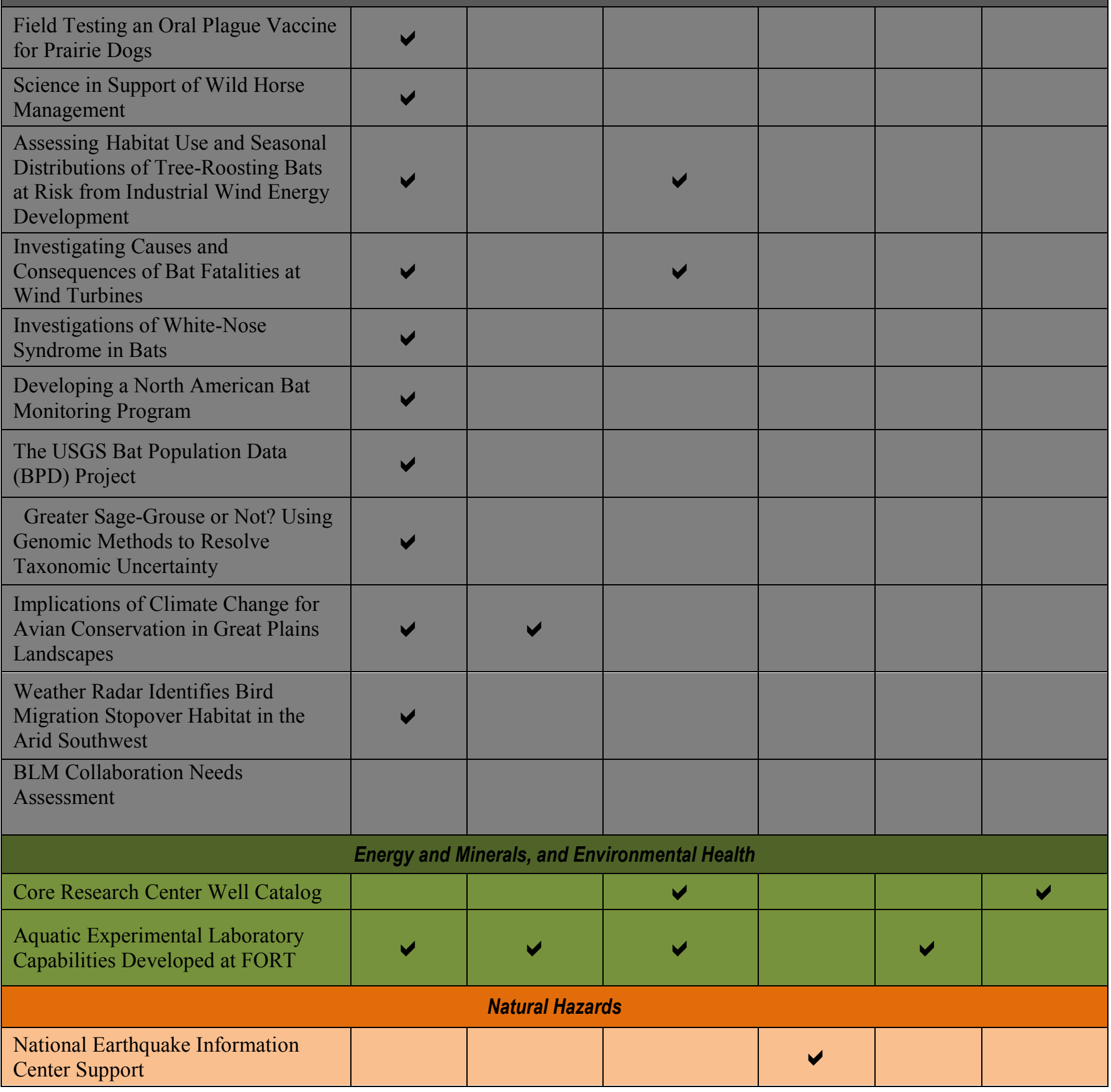




\section{Appendix 1. FORT Science Accomplishments for Fiscal Years 2012 and 2013}

Highlights of FORT project accomplishments in FY2012 and FY2013 are described below, grouped under the specific USGS Mission Area (and within Ecosystems, the science program) with which each task is most closely associated, although there is considerable overlap. The work of FORT's six branches (Aquatic Systems, Ecosystem Dynamics, Information Science, Invasive Species Science, Policy Analysis and Science Assistance, and Trust Species and Habitats) often involves major partnerships with other agencies and cooperation throughout the USGS across its Mission Areas, geographic regions, and science centers. These are noted using the following symbols:

= major collaborative venture

integrated science projects across USGS Mission Areas

$\mathrm{N}_{\mathrm{E} J \mathrm{~W}}=$ new science direction 


\section{Administrative and Enterprise Information}

\section{Web Re-Engineering Support}

In these times of reduced resources, the U.S. Department of the Interior is undertaking a major Information Technology restructuring operation (DOI IT Transformation) designed to save hundreds of millions of dollars over the next 10 years. To support this effort, USGS Enterprise Information worked with FORT to implement several new technologies designed to provide additional IT governance, to provide new tools to USGS content specialists and applications developers, and to save the agency money. The FORT Web Applications Team, as a part of this Web Re-engineering effort, worked with Enterprise Information staff to provide the applications and other forms of IT support described below.

- Web Hosting and Application Registry (WHAR) - This application provides a way for users to easily register their web site and application, as well as discover whether domain names, technologies, and hosting solutions are available for their project. The application also provides reports on the various hosting solutions and technologies that are used by registered sites and applications, and it provides reports on the current state of any registered site or application.

- Information Backbone Concept (IBC)-As the current number of USGS-generated web pages surpasses the 10 million mark, content management and information reuse has become a management challenge. The Web Applications Team developed an application that builds off a set of open-source projects to search and index content from these millions of pages. The technology, built from the concepts developed in the ScienceBase project, allows content managers to find and reuse information found in other pages and provides a way for USGS librarians to tag and organize information found on these pages in a catalog. The application also provides tools to let USGS and project management determine if any pages are missing critical snippets of information, if any pages are using code conventions that violate USGS policy, and if the state of site and page metadata is acceptable.

- Content Management System Optimization-More and more science center web portals are moving to dynamic content models. To support this effort, the Web Applications Team developed a reference content management solution that has been used by several sites, collaborated with the NatWeb team to design a robust database replication strategy consistent with content management systems use, and worked with Enterprise Information staff to construct a set of content management development best practices.

- Mobile Framework -Working with Enterprise Information staff and Community for Data Integration (CDI) partners, the Web Applications Team helped design a draft framework for mobile application development consistent with the U.S. Department of the Interior and USGS policy constraints. The team then applied the draft framework to some ongoing projects to test implementation. This work resulted in the first USGS mobile-ready web site (USGS Frequently Asked Questions at http://www.usgs.gov/faq/), a mobileready USGS visual identity draft standard, implementation of several hybrid mobile applications, multiple presentations to CDI general meetings and working groups, and a presentation to the Enterprise Leadership Team on USGS mobile activities.

Contact: Gail Montgomery

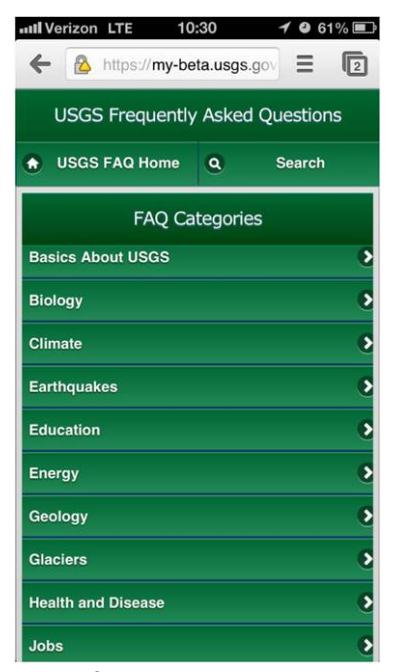

Example of mobile-ready web design and data service use. USGS image. 


\section{Climate and Land-Use Change}

\section{The Users, Uses, and Value of Landsat Imagery}

The currently operating Landsat satellites provide high-quality, multi-spectral, moderateresolution imagery of urban, rural, and remote lands for all areas of the world. Since 2007, FORT social scientists have been conducting a survey to investigate how users actually use and value the availability of federally sponsored, moderate-resolution land imaging.

In FY2012 and FY2013, FORT social scientists administered and analyzed data from a survey conducted for the USGS Land Remote Sensing Program on the users, uses, and value of Landsat imagery. The survey was the second conducted for this study, following an earlier survey in 2009. In June 2012, a presentation on the valuation results from the 2009 survey of Landsat imagery users was given at the Global Earth Observation System of Systems (GEOSS) Workshop on Defining, Measuring, and Communicating the Socioeconomic Benefits of Geospatial Information. We also conducted a case study of the value of Landsat imagery in forestry applications, which included interviews with Federal government employees and other users. The USGS Land Remote Sensing Program is using the study results to inform delivery of the products and services related to Landsat imagery and to understand how and why the imagery is important to users in decisionmaking.

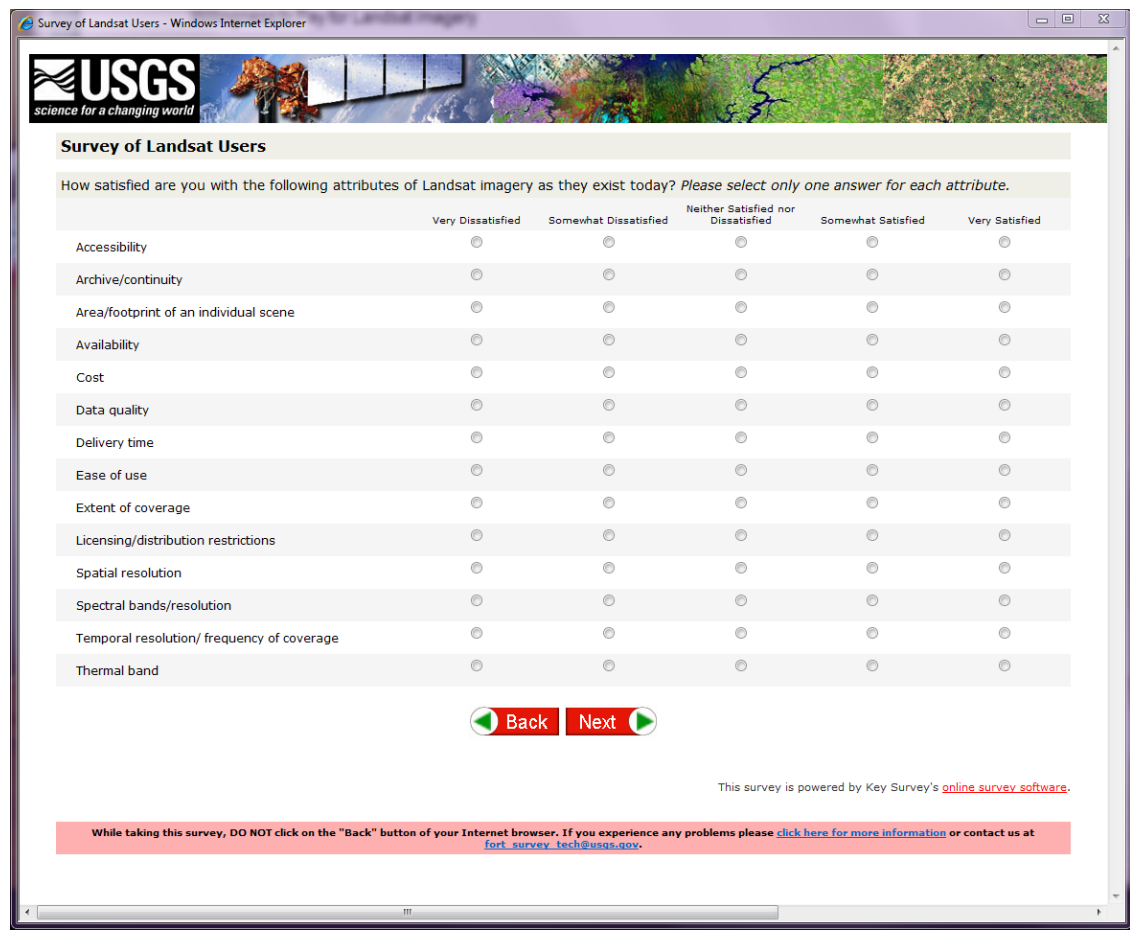

Screenshot of a page in the FORT Landsat User Survey. This page asks respondents to indicate their level of satisfaction with the Landsat imagery attributes as they exist today. USGS image.

\section{Products:}

Miller, H.M., Richardson, L.A., Koontz, L., Loomis, J., and Koontz, S.R., 2013, The users, uses, and value of Landsat satellite imagery-Results from the 2012 survey of users: U.S. Geological Survey Open-File Report 2013-1269, 51 p., http://dx.doi.org/10.3133/ofr20131269.

\section{Contact: Holly Miller}




\section{National Climate Change and Wildlife Science Center Data Management and Project Support}

The National Climate Change and Wildlife Science Center (NCCWSC) manages a number of projects across the U.S., generating a substantial amount of data and products. The Fort Collins Science Center Web Application Team has worked with the NCCWSC staff since FY2011 to help them keep track of their many funded projects, including the products and publications that stem from these projects. The challenge facing the NCCWSC in FY2012 and FY2013 included designing new ways to organize and deliver coherent information on these many projects, as well as the storage of many terabytes of data held in multiple repositories around the Nation.

To help achieve this goal, the Web Applications Team provided data management, data search, geoprocessing, project tracking, and web portal development support for the NCCWSC. The different facets were integrated into the following data publication workflow:

- Team software developers and project managers worked within the USGS ScienceBase application to build project tracking with data and metadata capture, review, and distribution tools focused on Climate Science Center projects. ScienceBase allows principal investigators (PIs) to control access to datasets while in the review stage.

- Team data stewards worked with PIs to document and track all project products, as well as complete product and project metadata, define discovery terms, and develop options for dataset visualization. These data stewards ensure that datasets are ready for publication.

- Team staff worked with the Center for Integrated Data Analytics (CIDA) and the Northwest Knowledge Network (NKN) to design and implement ways to discover, access, process, subset, and summarize large datasets held in remote repositories (federated search and multi-node geoprocessing services).

- Team web site developers worked with NCCWSC staff to design displays of project metadata, product lists, and published datasets stored in ScienceBase.

The integrated nature of the work allows a seamless display of the products on the NCCWSC's web portal. The multiple components are invisible to the user. As far as the user is concerned, the NCCWSC web site contains all relevant project information and related data.

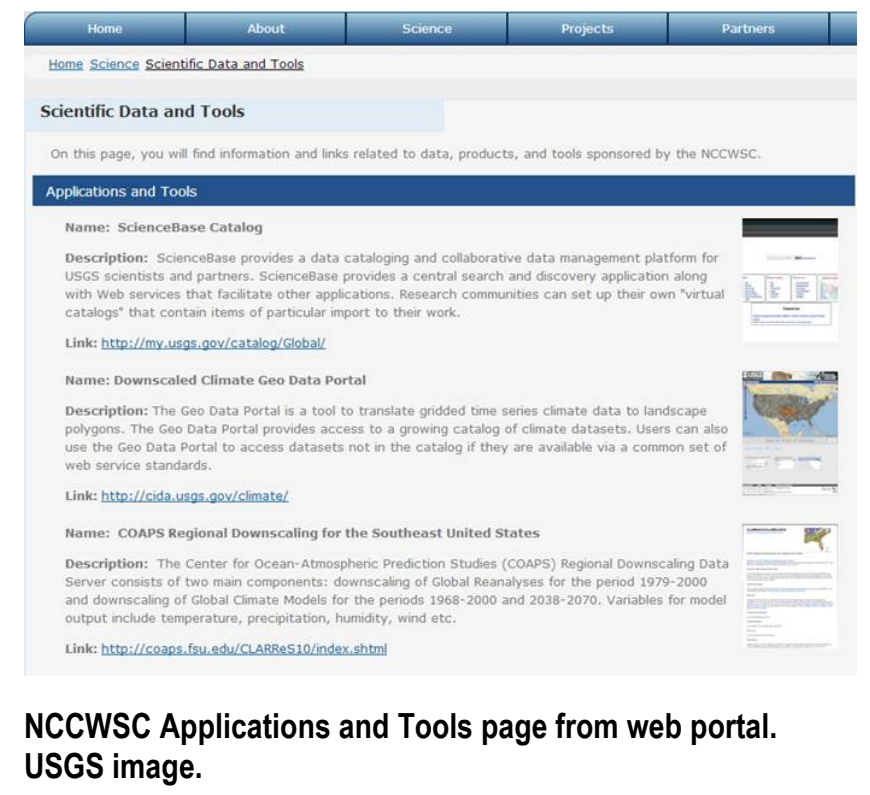

Contact: Tim Kern 


\section{The Western Mountain Initiative: Forest Ecosystem Responses to Climate Drivers in the Southern Rocky Mountains}

Climate-induced changes in water dynamics are beginning to affect mountain ecosystem processes in the western United States as pervasive warming drives increased drought stress. Cascading effects on forest ecosystems include increasing vegetation mortality, die-off of entire forest stands, longer and more intense fire seasons, and susceptibility to insect outbreaks. Over the past decade, these trends have been particularly evident in montane forests of the southwestern United States, where warm droughts are resulting in widespread tree mortality. Climate projections suggest that these phenomena will become more pronounced in the Southwest. Improved understanding of how mountain ecosystems respond to climate change is essential for successful natural resource management and taking climate effects into consideration during management planning and implementation will reduce surprises and damage to natural resources.

The USGS, including FORT, the Western Ecological Research Center, and the Northern Rocky Mountain Science Center, has been collaborating with the Forest Service, National Park Service, Los Alamos National Laboratory, and university scientists from across the West and around the world associated with long-term, global change research. Together, they are addressing these and related issues through an integrated project, "The Western Mountain Initiative (WMI): Vulnerability and Adaptation to Climate Change in Western Mountain Ecosystems." Initiated in 2003, the WMI conducts long-term studies centered on national parks and forests in the Sierra Nevada, Cascade Range, and Rocky Mountains. The objective of the project is to synthesize and integrate data and other information to provide perspectives on how climate variability and change are affecting disturbance regimes, vegetation dynamics, and hydrologic processes across the West. FORT scientists based at the Jemez Mountains Field Station, located at Bandelier National Monument in New Mexico, have been focusing on the southern Rocky Mountains. Specifically, we are studying recent changes in long-term patterns of disturbance processes; forest growth; dynamics of change in vegetation cover; interactions among broad-scale forest die-off, fire, and insect outbreaks; and the variability of these disturbances across time, space, and land use.

In FY2012 and FY2013, we continued our research on drought-caused tree mortality, fire history, and fire effects, with new findings on the role of temperature as a potent driver of forest drought stress. We continued to provide extensive support to interagency land managers responding to the high-severity Las Conchas Fire of 2011, which burned 156,000 acres in the Jemez Mountains, including 60 percent of Bandelier National Monument. Overall, our work is advancing the scientific community's understanding of how global climate change is affecting forests and the disturbance processes that drive these ecosystems. The products and results of our work are being used by agencies and organizations throughout the world to inform policy and management.

\section{Products:}

National Public Radio, 2013, Dr. Craig Allen featured in a National Public Radio 4-part special science report with photos and audio slideshow on web site, August 2012: National Public Radio. [Available at $h t t p: / / w w w . n p r . o r g / s e r i e s / 158936457 / m e g a f i r e s-t h e-n e w-n o r m a l-i n-t h e-s o u t h w e s t$.

U.S. Senate Committee on Energy and Natural Resources, 2012, Testimony by Dr. Craig Allen before the U.S. Senate Committee on Energy and Natural Resources: Santa Fe, N. Mex., U.S. Senate Committee on Energy and Natural Resources, August 17, 2012, at http://www.energy.senate.gov/public/index.cfm/2012/8/full-committee-field-hearingclimate-change-and-intermountain-west.

Australian Broadcasting Corporation, 2012, Dr. Craig Allen featured in "Tree Death," a Catalyst science documentary: Australia Broadcasting Corporation public television, April 26, 2012, at http://www.abc.net.au/catalyst/stories/ 3488105.htm.

Williams, A.P., Allen, C.D., Macalady, A.K., Griffin, D., Woodhouse, C.A., Meko, D.M., Swetnam, T.W., Rauscher, S.A., Seager, R., Grissino-Mayer, H.D., Dean, J.S., Cook, E.R., Gangodagamage, C., Cai, M., and McDowell, N.G, 2012, Temperature as a potent driver of regional forest-drought stress and tree mortality: Nature Climate Change, v. 2, online at http://www.nature.com/nclimate/journal/vaop/ncurrent/full/nclimate1693.html.

Hicke, J.A., Allen, C.D., Desai, A.R., Dietze, M.C., Hall, R.J., Hogg, E.T., Kashian, D.M., Moore, D., Raffa, K., Sturrock, R., and Vogelmann, J., 2012, Effects of biotic disturbances on forest carbon cycling in the United States and Canada: Global Change Biology, v. 18, p. 7-34.

Margolis, E.Q., Swetnam, T.W., and Allen, C.D., 2011, Historical stand-replacing fire in upper montane forests of the Madrean Sky Islands and Mogollon Plateau, southwestern USA: Fire Ecology, v. 7, p. 88-107.

\section{Contact: Craig Allen}




\section{Core Science Systems}

\section{Scientific Breakthroughs: The John Wesley Powell Center for Analysis and Synthesis}

Housed at the USGS Fort Collins Science Center, the John Wesley Powell Center for Analysis and Synthesis (http://powellcenter.usgs.gov) facilitates the synthesis of interdisciplinary information to address complex environmental and societal problems. The Center encourages the use of USGS databases to create new knowledge and tools, offers the opportunity to focus on complex earth system and natural resource questions, and supports scientist-initiated interdisciplinary activities. Powell Center topics cover all aspects of USGS science. Recent examples include Global Croplands and Their Water Use for Food Security in the $21^{\text {st }}$ Century; The Distribution of Fibrous Erionite in the US: Implications for Human Health; Defining which Microbial Processes Matter most to Ecosystem Function and How to Measure Them; and Global Probabilistic Modeling of Earthquake Recurrence Rates and Maximum Magnitudes.

In FY2012 and 2013, the Powell Center hosted 405 participants in eight new Working Groups and five ongoing Working Groups from previous years. The FY2012 and 2013 participants came from all continents except Antarctica. New publications, funded proposals, and web site products can be found at https://powellcenter.usgs.gov/products/all (two are listed below). High performance computing capabilities for the Powell Center are now in place, and the White House and former USGS Director McNutt used the Powell Center as an example of how the Federal government is addressing big data issues. The Powell Center bicycle fleet provides Working Group members with muscle-powered, carbon emission-free transportation.

We are well on our way to major synthesis products. I told you before I'm a believer and I'll tell anyone who asks - very good things happen when you are given the chance to bring the right people together in the right setting. Fort Collins is that setting.

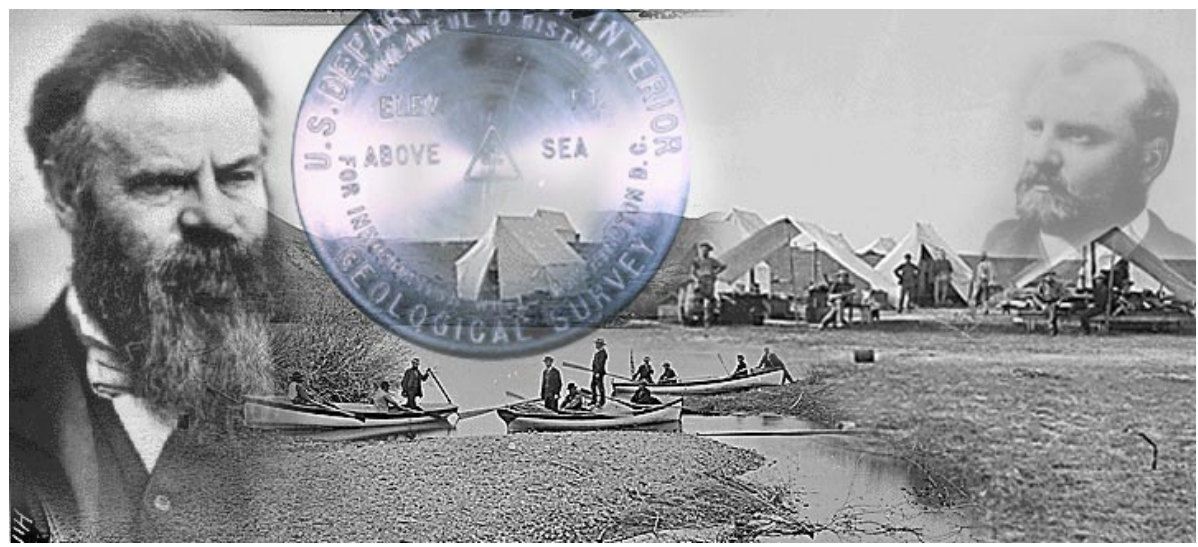

John Wesley Powell historic photo composite. Carol Quesenberry, USGS.

\section{Products:}

Dowsett, H.J., Robinson, M.M., Haywood, A.M., Hill, D.J., Dolan, A.M., Stoll, D.K., Chan, W-L., AbeOuchi, A., Chandler, M.A., Rosenbloom, N.A., Otto-Bliesner, B., Bragg, F.J., Lunt, D.J., Foley, K.M., and Riesselman, C.R., 2012, Assessing confidence in Pliocene sea surface temperatures to evaluate predictive models: Nature Climate Change, v. 2, p. 365-371.

Ruger N., and Condit, R., 2012, Testing metabolic theory with models of tree growth that include light competition: Functional Ecology, v. 26, p. 759-765. 
As part of Powell Center Informatics Support, the Fort Collins Science Center Web Applications Team worked with multiple working groups to develop data collection, management, access, and publication processes:

- Mercury cycling, bioaccumulation, and risk across western North America: A landscape scale synthesis linking long-term dataset-The Web Applications Team developed a data collection and access web application for the working group. Cooperators can upload mercury-specific datasets and enter critical metadata on that dataset; then the Working Group can use this dataset in their synthesis work. Published datasets can then be distributed beyond the working group through ScienceBase.

- The distribution of fibrous erionite in the United States and implications for human health-The working group consists of a combination of health professionals and earth scientists; health professionals contributed incidences of mesothelioma around the world, and the earth scientists generated spatial data on erionite deposits. The Web Applications Team collaborated with Working Group geospatial analysts to develop map-based visualizations of these data to help the working group see associations and assess areas where more data may be needed.

- Hydraulic fracturing and water resources: An assessment of the potential effects of shale gas development on water resources in the United States - The Web Applications Team developed a web-based hydraulic fracturing citation database as a companion product to the working group's publication.

- Global croplands and their water use for food security in the 21st century-To prepare for the data publication process, the Working Group compiled multiple model outputs and geospatial datasets. The Web Applications Team worked with the group to establish a ScienceBase area for these many datasets, supplied data steward support to the group, built a web application that uses the data and content in ScienceBase to deliver reports and results to the public, and adapted ScienceBase to accommodate the unique needs of the Working Group.

- System analysis of land use and climate effects on ecosystem services affecting $C$ and $N$ exchanges with the atmosphere and water cycles - A critical part of this working group effort was to adapt an existing model (Century) to a new version of Daymet climate data. This adaptation had to consider both the revised format of the Daymet data and the architecture available to run the model. The Web Applications Team developed a number of programs in various software frameworks to prepare the data for model runs, thread the model to run on multiple nodes of a cluster, and recombine node-based model outputs into an integrated result set.

Contact: Tim Kern

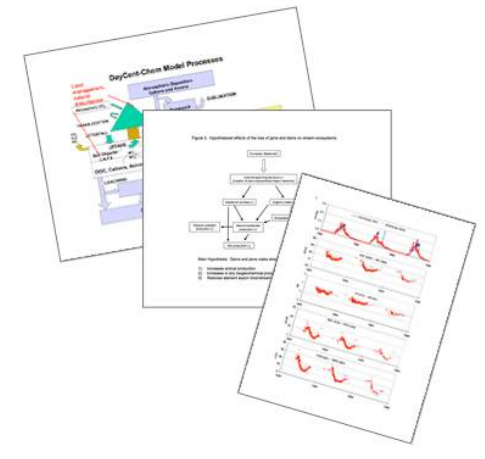

Example products from working group collaborations. USGS image. 


\section{The Use of High Throughput Computing for USGS Core Sciences Research}

In order to help managers in DOI agencies and other Federal, State, and private entities, researchers have found that the science needed to address their complex ecological questions across time and space produces substantial amounts of data that require greatly expanded computing resources to analyze. To meet this need for greater computational capacity, FORT implemented a high throughput computing (HTC) system in 2011 called HTCondor ${ }^{\mathrm{TM}}$ (http://research.cs.wisc.edu/htcondor/). We evaluated the system for selected case studies: (1) species-distribution models using maximum entropy, (2) 2D/3D hydrodynamic numerical modeling, (3) species trend analysis and the effects of the surrounding environment, (4) development of bioclimatic variables, (5) landscape-scale ecological modeling, and (6) geostatistical simulations and statistical analysis. Consequently, we were able to demonstrate the efficacy of HTC for a diverse and realistic set of projects, its effectiveness in substantially reducing overall computing time, and its ability to harness existing computer resources.

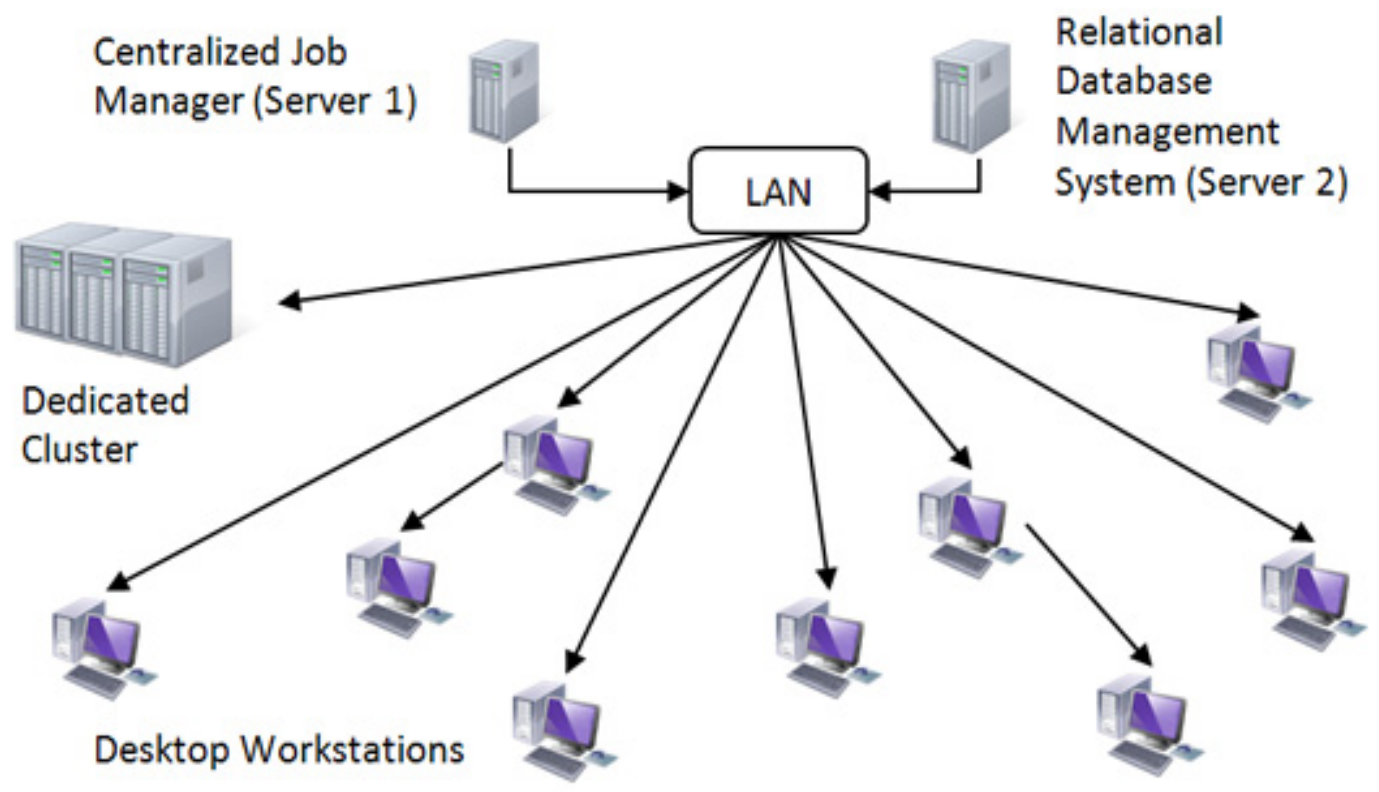

Schematic illustrating how a centrally managed system of desktop workstations and servers can distribute and manage processes throughout a Local Area Network (LAN). Graphic created by Michael O'Donnell, USGS.

In FY2012 and 2013, FORT integrated the use of HTC with two commercialized software products (ESRI ArcGIS ${ }^{\circledR}$ Desktop and ERDAS Imagine ${ }^{\circledR}$ ) for geographic information systems and remote sensing applications. We developed an ESRI ArcToolbox that allows users to submit geoprocessing (GP) tasks to the HTC system. With this functionality, one can incorporate data dependencies, monitor job progress, and distribute any of ESRI's GP tasks to computers across the local area network (LAN). We also integrated the use of ERDAS remote sensing processing with HTCondor. Integrating two commonly used software applications into an HTC system expands FORT's capabilities of distributed computing for spatial applications and allows scientists to take advantage of distributed computing without requiring HTC knowledge. With these new capabilities, USGS can decrease processing times and turnarounds of delivering scientific results that rely on spatial analysis without purchasing new hardware.

Contact: Michael O’Donnell 


\section{NEWy Integrating High Performance Computing with Geospatial Applications: Expanding Upon a Suite of USGS Computing Resources}

With increasing demands for analyzing large spatial datasets, multiple datasets, and datasets requiring a large number of computations, or a combination of these components, FORT integrated the use of moderate high performance computing (HPC) workstations (e.g., 24 CPU nodes and 24 GB memory) and spatial analyses to increase scientific data processing capabilities and efficiencies. In FY2012 and 2013, three new spatial analyses presented an opportunity to explore the use of HPC when they did not fit a distributed computing framework (high throughput computing).

The first case study involves thresholding of habitat suitability models. We developed spatially explicit greater sage-grouse models using telemetry data, available locations, and logistic regression to represent habitat on a continuous scale of relative probability. We then developed software that compared the proportion of locations occurring within the predicted habitat for a given threshold with the proportion of locations occurring within the predicted habitat by chance. Using these results, we could establish thresholds for binning (grouping) the data into relative habitat importance. This thresholding approach is a repeatable and statistically definitive protocol for binning habitat probabilities into presence, absence, and lower/upper confidence categories. For each potential threshold (a ranked value of resource-selection function assigned to each use location), the software creates a binary (presence/absence) spatial dataset. Consequently, as many as 1,000 large datasets (3-4 GB each) are processed for each habitat model. With the use of symmetric parallel processing (SMP), we reduced the computer processing time from 7 days (CPU-serial) to 3 hours (SMP) for the most data-intensive model. The 36 models needed to evaluate using this thresholding approach required approximately 70 days using CPU-serial (single machine) computing, but instead the analyses were completed in approximately 2 to 3 days using SMP (single HPC machine) computing.

A unique question arose while FORT researchers were ascertaining what influences the emergence of zoonotic viruses (viruses that are transferable between species such as a mosquito and a human). Scientists were interested in investigating whether a spatial component could provide information explaining the occurrence of some zoonotic viruses. The spatial analyses used for investigating this question required approximately 40,000 different combinations of queries. Because the amount of data was small but the number of computations extremely large, we wrote a software application that used SMP and a high performance workstation. For two different sets of analyses, we used 43 hours of CPU time to produce results that researchers then processed in statistical software without SMP. Accomplishing these tasks with CPU-serial computing would have been cost prohibitive, if not impossible.

Lastly, because of increasing demands for knowing the availability of data produced and maintained at FORT, we developed a semi-automated means of creating project-level metadata. To better document the data stored and collected at FORT, we developed several tools that glean spatial/aspatial information from past and ongoing endeavors, which we then populate in an enterprise relational database. The analyses required querying information commonly stored in both GIS and non-GIS data. Spatial coordinates, map projections, feature types, feature counts, and other information were gleaned from all data for a project; a user then manually adds descriptions to data, categorizes the data into themes, and assigns metadata compliance via a web browser. The web browser provides access to updating the database components and allows users to search for all data. Because of the amount of information queried and then populated into a database, we used SMP to reduce computing times. The ability to document data and have information on past and current projects is extremely useful for locating data, as well as using past projects as foundations for developing new proposals. The use of SMP and the tools described here increases the availability of information, reduces time for inventorying data, and improves USGS efficiency.

In summary, FORT is using HPC for numerous spatial analyses with both open-source and commercialized software when HTC is not appropriate. HTC and HPC are expanding FORT's capabilities for analyzing data, decreasing the time required to run analyses, and addressing questions that could not easily be answered in the past, while accomplishing project objectives with nearly the same resources. Computing resources such as these are essential for achieving the goals of the USGS Science Strategy.

Contact: Michael O’Donnell 


\title{
The Development and Application of Derived Bioclimatic Variables from Climate Normals and Time- Series Data
}

All species are affected by both climatic and non-climatic factors. Climate change can impose physiological constraints on species and therefore can affect species distributions to varying degrees. The relationship between climate and most species varies due to local adaptation and other factors limiting distribution, such as dispersion constraints related to habitat availability. Additionally, examining climate over time is useful when quantifying the effects of climate change on species distributions for past, current, and forecasted climate scenarios.

To address historical and current scenarios, in FY2011 FORT derived bioclimatic predictors (as defined by Nix, 1986) from GIS data for the conterminous United States. We used two climate data sources, one from Oregon State University (www.prism.oregonstate.edu/) and the other from Climate Source (www.climatesource.com/) to better represent the types of seasonal trends pertinent to the physiological constraints of different species. Due to the volume, spatial extent, and spatial and temporal resolution of the data, FORT used high throughput computing (HTC) to manage the data processing via the HTCondor software (http://research.cs.wisc.edu/condor/). Each set of 20 bioclimatic predictors (20 products are derived for each calendar year) required the development of approximately 200 interim datasets for a total of 576,000 datasets to obtain the final derived products. Further, all datasets required conversion to GIS data formats, conversion of units for precipitation and temperature using relevant scale factors, a defined map projection, and the importation and editing of metadata.

The bioclimatic variables derived from this process are an important source of biologically relevant climate data for ecologists. Researchers and land managers can use these data to inform habitat management decisions in the present based on species relationships with climate and available habitat, while still considering future climate changes. In FY2012, FORT published these products (O'Donnell and Ignizio, 2012), which include a report describing the methods (http://pubs.usgs.gov/ds/691/; data download linked here) and publicly available data for download from the USGS ScienceBase Catalog (http://www.ScienceBase.gov).

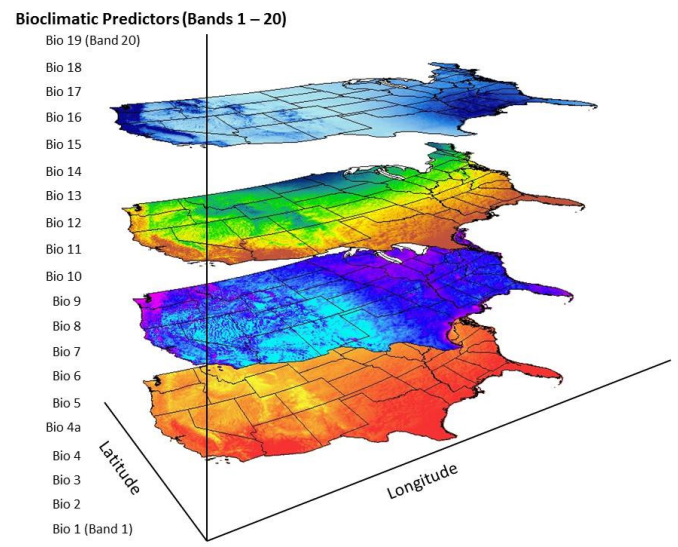

\author{
Graphic representation of 20 bioclimatic predictors \\ within a raster data set. Graphic created by Michael \\ O'Donnell, USGS, and Drew Ignizio, Cherokee \\ Services Group, contracted to the USGS.
}

\section{Reference:}

Nix, H.A., 1986, A biogeographic analysis of Australian elapid snakes, in Longmore, R., ed., Atlas of elapid snakes of Australia-Australian flora and Fauna Series 7: Canberra, Australia, Australian Government Publishing Service, p. 4-15.

\section{Product:}

O’Donnell, M.S., and Ignizio, D.A., 2012, Bioclimatic predictors for supporting ecological applications in the conterminous United States: U.S. Geological Survey Data Series 691, 10 p.

\section{Contact: Michael O’Donnell}




\section{Great Northern Landscape Conservation Cooperative Spatial Toolkit and Phenology Server}

In FY2012 and FY2013, the FORT GIS and Remote Sensing Team, working with the FORT Web Applications Team, developed and delivered an integrated set of geospatial services and an ArcMap toolbox (https://www.sciencebase.gov/catalog/folder/5061be4fe4b0ce47085a8d08). This provides users with convenient remote access, visualization, and analysis to over 500GB of MODIS (Moderate Resolution Imaging Spectroradiometer) vegetation phenology data extracted from satellite imagery.

Phenology refers to recurring plant and animal life cycle stages, such as leafing and flowering, maturation of agricultural plants, emergence of insects, and migration of birds. Many of these events are both sensitive to climatic variation and important to land-management actions. Landscape phenology from satellite data provide consistent, wall-to-wall coverage of plant seasonality and can be used to evaluate the vegetation on preserved areas in the context of surrounding lands. It also provides information on both intra- and inter-annual variability.

The project, initially developed for the Great Northern Landscape Conservation Cooperative and the National Park Service, provides a way for a user group to stage these large imagery datasets in the USGS ScienceBase application and then access these data from an ArcGIS toolbox. The ScienceBase space also can be used to stage model components, scripts, workflow tracking tools, and metadata, in addition to the datasets.

The ScienceBase phenology image service serves the more than 40 phenology layers for each year since 2001. These datasets originally come from individual, high-dynamic-range files generated by NASA. The individual files were merged to create wall-to-wall coverage of the continental United States. After the images were loaded into the ScienceBase ArcGIS Image Server implementation, customized tools necessary to intelligently serve these data were constructed by the GIS and Remote Sensing Team. The FORT Invasive Species Science Branch consulted with the GIS and Remote Sensing Team on the best ways to present and use these data for analysis, and the GIS and Remote Sensing Team implemented this information as an ArcGIS toolkit.

The ArcGIS toolkit provides a simple way for ArcMap users to access these components and run landscape models on any area covered by the imagery. The tool, a set of Python scripts working on a statistical model in the R statistical software package, generates graphical scenarios based on the variable chosen. The tool is written to allow different users to plug in different algorithms and models, and connect to different ScienceBase spaces. This project lets modelers and analysts collaborate on model workflows, upload model outputs, then repeat and evaluate runs, all from their desktop ArcGIS systems. By using ScienceBase as the collection point for the project components, the users are assured of data and code persistence and security.

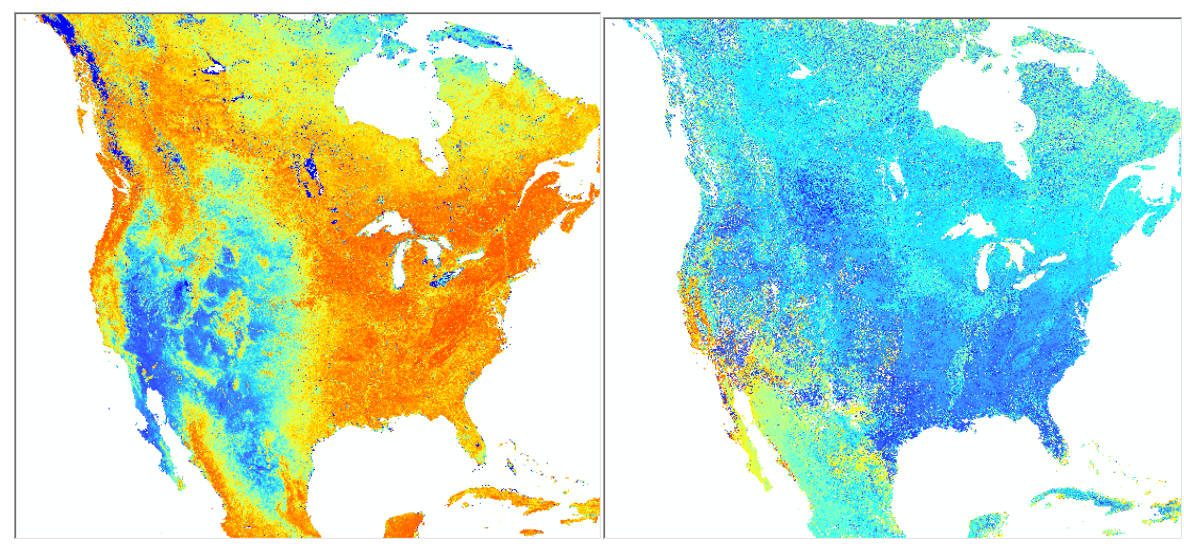

FORT developed an application that provides ArcGIS users with a suite of easily accessible vegetation phenology data (Moderate Resolution Imaging Spectroradiometer, or MODIS) extracted from satellite imagery. The maps above are examples of data that users may access and display with the application. Specifically, the maps show minimum (mid-winter, on the left) and maximum (mid-summer, on the right) greenness of vegetation across North America. Cooler colors (blues and greens) indicate less greenness, and warmer colors (oranges and yellows) show more greenness. USGS image.

Contacts: Colin Talbert, Tim Kern 
The Landscape Conservation Cooperative (LCC) system consists of 22 individual partnerships, each tasked with providing a forum for States, Tribes, Federal agencies, non-governmental organizations, universities and other groups to work together on conservation topics. Each LCC faces a daunting challenge, providing scientific and technical expertise on conservation planning at a landscape level and, at the same time, promoting collaboration among members in defining conservation goals. To help the LCC network achieve these goals, the FORT Web Applications Team worked with multiple LCCs to allow LCC partners, regardless of their agency affiliation, to securely share, access, and analyze common datasets and information. Providing means to coordinate research management and resource conservation allows these individual LCCs to meet the data management and integration goals outlined above. Working with a common framework with the individual LCCs also allows the national program to coordinate activities among LCCs.

The Web Applications Team has provided support for data sharing and management efforts to the Great Northern LCC (GNLCC) since FY10, defining and developing the Landscape Conservation Management and Analysis Portal (LC MAP) in FY2011. To serve the broader LCC network, the Web Applications Team added extensive data management capabilities through the USGS ScienceBase project, the backbone behind LC MAP. ScienceBase is an open-source, scientific-data management and integration system that employs Web-service communications to display and transfer data in a variety of formats. Version 2 of Science Base was released in FY2012 AND FY2013, greatly expanding the data access and management tools available to users.

These features allow analysts in different locations to securely collaborate on provisional datasets, find work products that could help their efforts, track different versions of their products, and control access to their work efforts. Other additions included new ways to find data across multiple repositories, allowing full read and write access to data held in ScienceBase from LCC-specific portals and partner desktop systems, and full audit logging of every transaction against an LCC-managed item. Each LCC can take advantage of each new feature and capability added to ScienceBase from within their own LCCspecific workflow.

The Web Applications Team also worked with staff from multiple LCCs to support LC MAP users with unique data management issues that ranged from very large dataset handling to cross-agency data publication workflows. A significant amount of time was spent developing data stewardship best practices, conducting training sessions with large groups of users on these practices, and designing ways to capture new and derived spatial layers and metadata with an eye to dataset publication. The Team also worked with the LCC National Office to help define an Integrated Data Management Network, a project that started in FY2013.

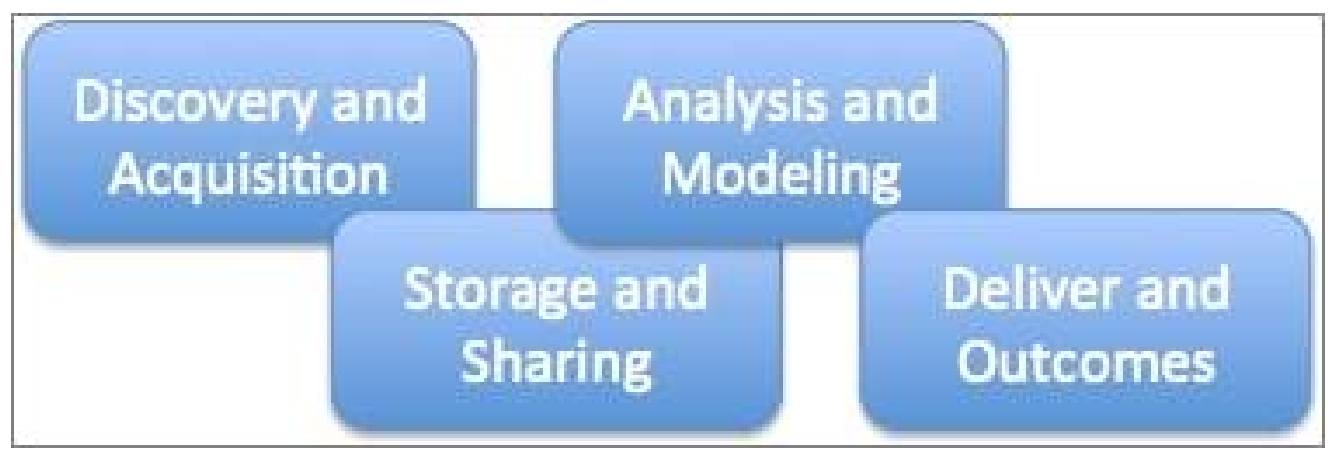

Data management support workflow. USGS image.

Contact: Tim Kern 


\section{myUSGS Collaboration Suite}

The myUSGS suite of online tools has provided scientific collaboration capabilities for the USGS and science partner projects since 2007. The application manages over 400,000 documents and is open to all USGS staff and project partners. Almost half of the 10,000 users are from partner agencies and organizations. FORT's Web Applications Team has provided design and software development support for the myUSGS project since version 1. The challenge facing the project is one that plagues all software products - how to maintain existing capability to users dependent on the system while migrating to more modern software protocols.

To address this challenge, the Web Team worked with staff from Core Science Analytics and Synthesis (CSAS) to implement version 4 of the project. myUSGS version 4 consists of five core capabilities:

- Enterprise Wiki and Document Management - Confluence provides community wiki and document management capabilities. The community can select (1) from a set of site designs, (2) from a number of custom features (plugins) to include in pages, and (3) which users can access any part of the community wiki.

- Issue and Task Tracking - Designed for software and applications development projects, the JIRA issue tracking system allows these projects to customize the data collected on a community-bycommunity basis. Agile projects can develop sprint plans and project backlogs, and communities can design custom workflows for issue resolution.

- Virtual Directory Services - myUSGS supports users within the U.S. Department of the Interior, staff from other agencies, and users from partner organizations. The Virtual Directory Service design supports any number of credential stores, allowing different groups to authenticate against different directory services. Also, non-myUSGS applications can use this service to authenticate users. Over 80 web and GIS-based applications use the myUSGS authentication services.

- Event Management-EventManager is a flexible online web application used to set up, manage, or register for a USGS-sponsored conference or workshop. EventManager provides users with a way to customize an event registration: defining allowed submission, creating custom forms, sending and managing email confirmations, and determining who can manage, view, or register for an event. The application provides registration via a friendly custom URL, lets any USGS staff member start an event, and provides event coordinators a number of flexible reporting options.

- Java-based Web Application Hosting - myUSGS provides high-end web application hosting services. The technology stack includes clustered instances of Apache Tomcat, Apache HTTPD, PostgreSQL, PostGIS, MySQL, MongoDB, ElasticSearch, ArcGIS, GeoServer, GeoPortal, and a variety of open-source projects implemented to support over 50 mission-critical applications.

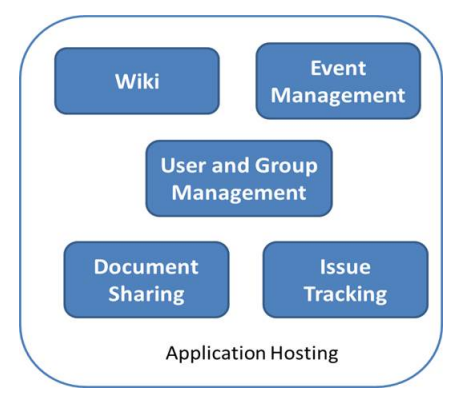

Services provided by myUSGS. USGS image.

\section{Contact: Tim Kern}




\section{ScienceBase Catalog and Data Repository, Version 2}

ScienceBase is a data cataloging and collaborative data management platform for USGS scientists and partners that provides rapid data discovery options to all users and data sharing, management, and publication support to USGS and partner research projects. The project's FY2012 and FY2013 challenges included ways to quickly import millions of records and datasets, optimize searching for millions of metadata records, and automatically provide multiple ways to find and use every entered or referenced dataset.

To accomplish this, the FORT Web Applications Team worked with staff from Core Science Analytics and Synthesis (CSAS) to design, develop, and release Version 2 of ScienceBase (https://www.sciencebase.gov/catalog/). Following the guidelines described by the President's Digital Government Strategy, ScienceBase moves data and metadata in and out of the system via web services. The approach requires users to change their expectation of a "data repository," with the system focusing on storage, search, and delivery instead of project-specific user interfaces. Instead of trying to be a onestop shop for data, the ScienceBase methodology allows projects to build independent, mission-specific visualization and analysis applications that can use any combination of the 3 million items maintained by the application.

Using the tools provided by ScienceBase, projects can find, submit, access, and distribute data and metadata any number of ways, from within their local ArcGIS to project web portals to mobile devices to ScienceBase's own search and discovery tools. ScienceBase is also home to several enterprise collections and provides a workflow for data life cycle management (from the research phase to engineering testing to operational release).

The Web Applications Team researched architectural options, designed a software approach to accommodate millions of items, provided Agile project management and software development support to implement the design, and constructed a hosting infrastructure compatible with cloud deployment of the project. The software development team built ScienceBase around a set of open-source projects and ensured that the application met all Federal and U.S. Department of the Interior security requirements. Working with CSAS product owners, the Web Applications Team refined data organization and access features to meet the needs of a number of critical USGS enterprise collections, including the National Geospatial Program and the National Geological and Geophysical Data Preservation Program.

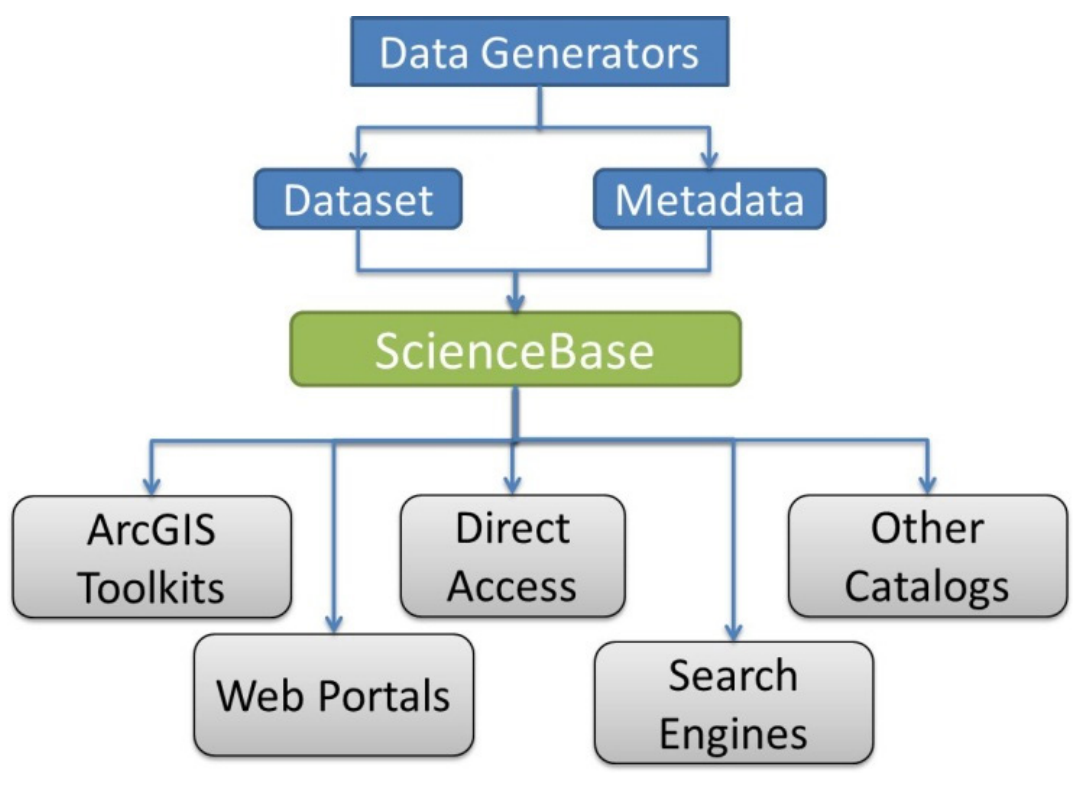

ScienceBase workflow. USGS image.

Contact: Tim Kern 


\section{White-Nose Syndrome Disease Tracking System}

White-nose syndrome is a devastating wildlife disease caused by the cold-growing fungus

Pseudogymnoascus destructans that infects the skin of hibernating bats and causes life-threatening alterations in their physiology and behavior. White-nose syndrome has spread rapidly across the eastern United States and Canada since it was first documented in New York in the winter of 2006. This new disease is causing mass mortality and detrimentally affects most of the six species of bats that hibernate in the northeastern United States. Particularly hard-hit are the little brown bat (Myotis lucifugus), northern long-eared bat (Myotis septentrionalis), eastern small-footed bat (Myotis leibii), and federally endangered Indiana bat (Myotis sodalis). Several more species are also now known to be exposed to the fungus in the Midwest and Southeast. The sudden and widespread mortality associated with white-nose syndrome is unprecedented in any of the world's bats and is a cause for international concern as the fungus and the disease spread farther north, south, and west. Loss of these long-lived insect-eating bats could have substantial adverse effects on agriculture and forestry through loss of natural pest-control services.

The White-Nose Syndrome Disease Tracking System (WNS v.1) was designed to create a national database of state-level field and laboratory data and to improve communication of current disease status on a regional and national scale. WNS v.1 does this by providing State and Federal research partners with authenticated, web-based data entry and reporting tools to assist them with securely managing their data throughout its life cycle. This includes the ability to control/restrict public access to their data, a critical requirement for WNS v.1 research partners.

In addition, WNS v.1 provides customizable search options (state, county, species, date) for identifying specific sets of white-nose syndrome data and exporting those results to a PDF or CSV file. Also included in customized search results and reports are interactive disease-tracking maps that illustrate the current known disease status at user-defined geographic scales. The search and reporting features are available to public users, as well as authenticated WNS v.1 research partners. However, public users are limited to searching and reporting only on records marked as "non-confidential" by a research partner. Confidential data access is limited to the owner, the WNS v.1 research partner who created the records.

WNS v. 1 is a co-funded collaboration between the U.S. Fish and Wildlife Service Region 5 and the USGS Fort Collins Science Center. Since its release in November, 2011, the National White-Nose Syndrome Working Group has conducted a usability test and provided a review of current public white-nose syndrome disease data, validating the current WNS v.1 data management tools and reporting features as well as verifying that the disease maps and data are current.

\section{Product:}

Everette, A.L., P.M. Cryan, and K. Peterson, 2012, White-nose syndrome disease tracking system (v.1): USGS Fort Collins Science Center, https://www.fort.usgs.gov/publication/23402.

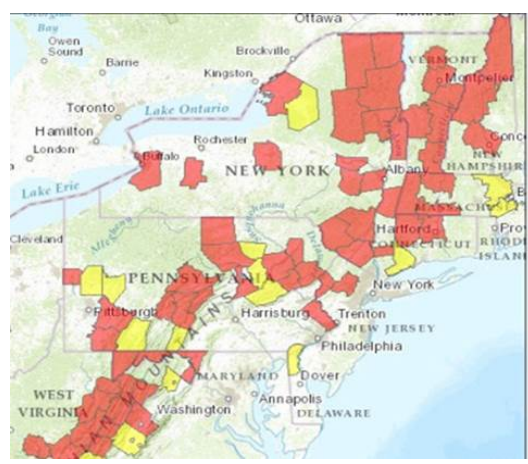

WNS occurrences. USGS image.

\section{Contact: Lance Everette}




\section{Ecosystems-Fisheries: Aquatic and Endangered Resources}

\section{Developing Adaptive Management Decision-Support Systems for Improved 2D Aquatic Habitat Modeling and Water Management}

Developing tools and approaches for quantifying effects of flow alteration to inform water management is a long-standing research theme for FORT scientists. Recent work has moved beyond general support for the Instream Flow Incremental Methodology (IFIM) framework and its components, such as the Physical Habitat Simulation (PHABSIM) software. Topics now include (1) formal consideration of how different hydraulic models and data densities affect estimates of weighted, usable area to address the question of how much study effort is enough, (2) use of landscape ecology concepts in habitat analysis supported by 2D hydraulic models, (3) development of streamflow response and valuation models for riparian vegetation, and (4) development of decision-support-system and GIS-derived spatial visualization tools to make the multivariate output from multiple flow alternatives more accessible to water managers and interested parties.

Aquatic 2D habitat modeling is a complex process requiring numerous scientific inputs and outputs. Separate input and output data are needed for each flow, habitat variable, species, and life-stage combination requiring hundreds of inputs that must be classified, recombined, and processed to produce hundreds of output files. Current GIS processing and viewing software is capable of handling the data and processing needs. FORT has developed a desktop application to allow decisionmakers and scientists to easily view and change the inputs and parameters used in aquatic 2D habitat modeling. This application has built-in GIS functionality for viewing inputs and visually inspecting how changes to instream flow and modeling parameters will affect model output. The user can dynamically change all modeling equations and parameters, then re-run the required geoprocessing. Habitat outputs can be viewed side by side and queried to investigate how individual parameters affect modeling results.

Building on previous work in the South Platte, Toulome, Trinity, and Yakima River systems, the updated adaptive management application will be released for the Upper Delaware River in December 2012. Upgrades include the ability to explore all existing hydrographs for the system, zoom into an area to view expected available habitat for multiple life stages and (or) multiple species simultaneously, and explore the effects of modifying habitat equations including the ability to add, change, or remove variables. These upgrades are programmed to allow the framework to be quickly and easily applied to a new river system, where data inputs are available. Through our continued research efforts and new developments in instream flow science to quantify flow effects on aquatic and riparian ecosystems, we are able to focus on providing unbiased, sound scientific results to resource managers and thereby improving decisionmaking. Our current research and associated projects promote an understanding of the relationships among aquatic species and habitats, which in turn helps to conserve and (or) restore community structure and function-especially for at-risk species.

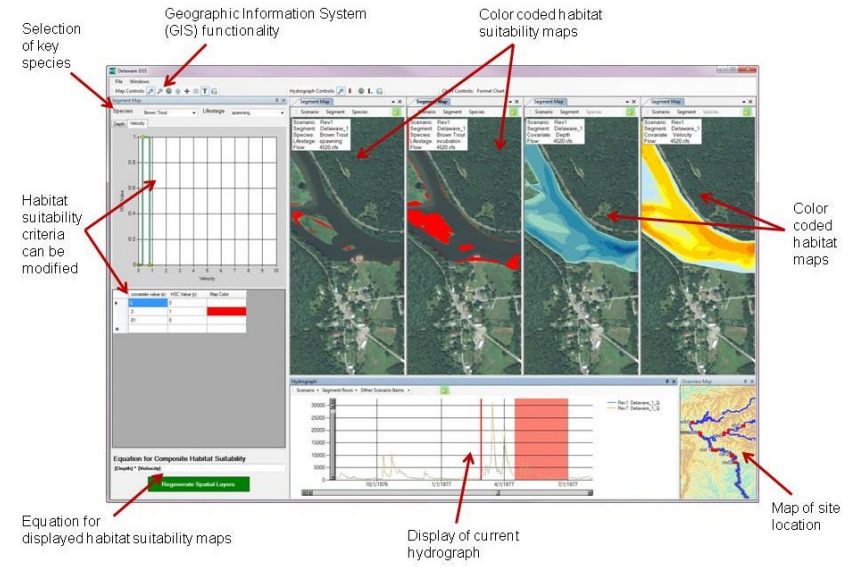

Contact: Chris Holmquist-Johnson
Example screenshot of the Delaware River Decision Support System, comparing habitat suitability maps for spawning and incubation for brown trout as well as a spatial representation of depth and velocity distribution within a specified study. USGS image. 
During the summer of 2011, Topock Marsh, under the management of the Havasu National Wildlife Refuge (NWR) near Needles, Calif., was experiencing unusually low water levels. In order to assess how the local aquatic flora and fauna were dealing with the harsh conditions, Region 2 of the U.S. Fish and Wildlife Service (FWS) initiated a Quick Response Request to obtain assistance from USGS biologists in determining the current status of Topock Marsh. To fulfill the U.S. Fish \& Wildlife Services' request, FORT biologists made five trips to Arizona in July, September, and October 2011, and in January-February and March 2012 to collect flora, fauna, soil, and water samples within the marsh. After analyzing the samples and collating the data, USGS prepared a report for the refuge to describe how the biotic and abiotic elements of the marsh responded to the unusually low flow conditions and compared the newly collected data with historical data collected by Bureau of Reclamation's Lower Colorado Region and Arizona's Game and Fish Department. This rapid on-site assessment proved to be valuable in documenting how specific conductivity, total dissolved solids, and turbidity concentrated within the marsh, as well as showing how quickly the higher concentrated water could be flushed out with more typical flows. Opening up the new Firebreak Canal on the west side enabled the resumption of more normal conditions faster than by using only the original inlets. Surprisingly, no discernible, critically negative impacts that could be attributed to the effects of low water levels during this time period were revealed, at least in the short term.

Armed with this information, FWS will be able to plan, design, and implement more effective water-management strategies necessary to maintain quality wetland habitat in this desert environment. As new infrastructure is completed and becomes part of the normal operations at Topock Marsh, more control of the water flow will be available for long-range management.

All sampling efforts were heavily coordinated among the USGS, Havasu NWR, Arizona Fish and Wildlife Conservation Office in Parker, Ariz., and Bureau of Reclamation Technical Service Center based in Denver, Colo.

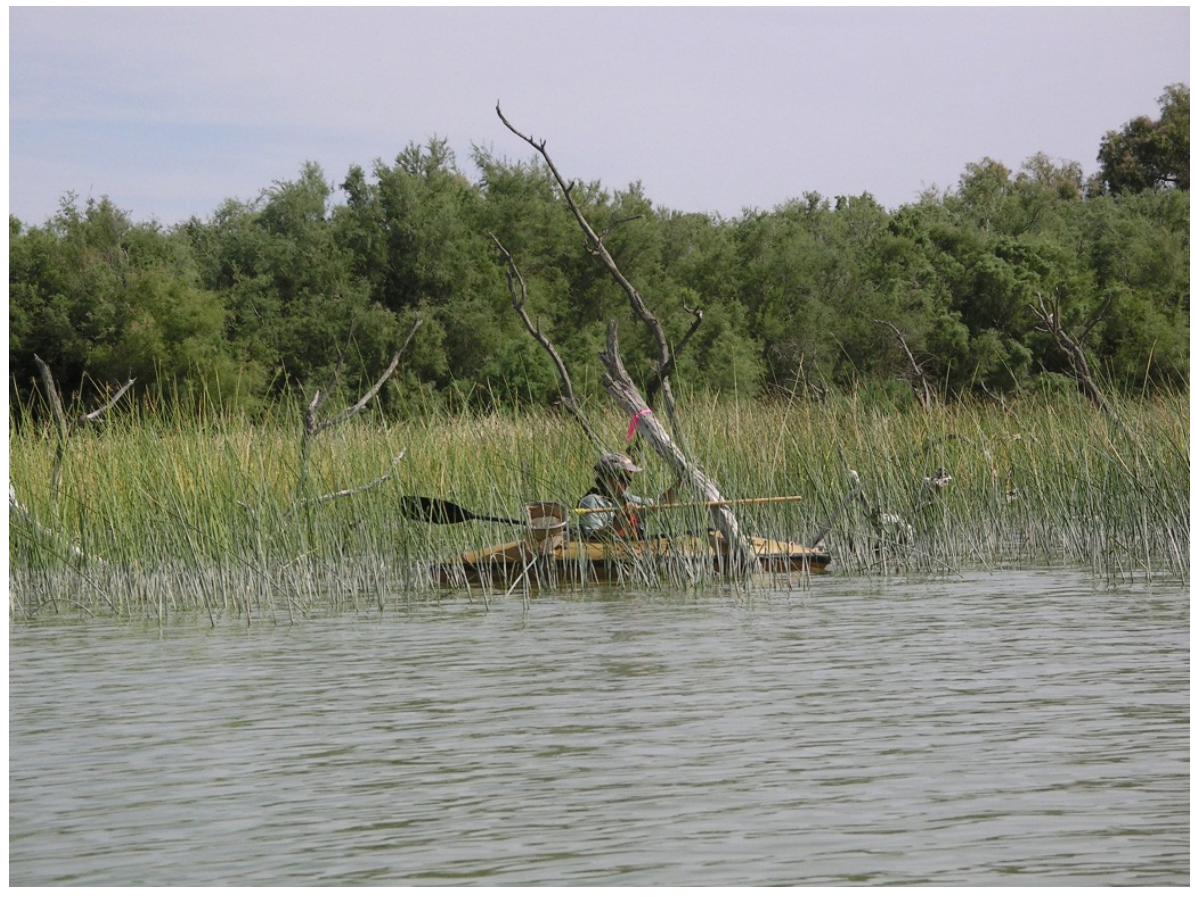

USGS scientist sampling in Topock Marsh in Arizona. USGS photo by J.S. Daniels.

Contacts: Joan Daniels and Jeanette Haegele 
Recently, there has been worldwide concern over the fate of waterborne consumer product chemicals such as pharmaceuticals, hormones, and other endocrine-disrupting compounds (EDCs) and their potential effects on aquatic ecosystems and human health. These compounds are ubiquitous in wastewater treatment plant effluents, and at combined concentrations, they have the potential to impact the reproductive health of fish and interfere with ecosystem function. While wetlands perform many of the processes known to break down or attenuate EDCs, effective removal has not been verified or optimized at the demonstration scale. USGS scientists therefore have initiated research to determine whether their innovative constructed wetland design can attenuate these emerging contaminants to ensure public health and safety and maintain healthy ecosystems downstream.

Likewise, better strategies are needed for managing the waste concentrates derived from water purification processes using membrane technologies. The FORT wetland scientist has been requested to help in overseeing the management, monitoring, and evaluation of a newly built saline constructed treatment wetland for removing contaminants from waste concentrate and creating or restoring brackish or salt marsh coastal wetlands downstream.

The Bureau of Reclamation's (Reclamation) Science and Technology Program is the primary Research and Development arm of Reclamation and is focused on innovative solutions for water and facility managers and western water stakeholders. USGS scientists began working under this project with Reclamation's Oklahoma-Texas Area Office (O-TAO) and Southern California Area Office (SCAO) to identify local interested municipal water districts to partner with to demonstrate innovative constructed wetland designs for improving reclaimed water quality. Once local partnerships were created within both areas, USGS scientists and their collaborators selected the site; developed conceptual design plans and a detailed monitoring plan for the EDC research wetland in Waco, Texas; and developed a detailed monitoring plan, performed baseline sampling, and suggested additional research topics for the previously built saline wetlands in Oxnard, Calif.

Under the support of the USGS Status and Trends Program for both projects, FORT is collaborating extensively with scientists from USGS-National Research Program, the ReclamationTechnical Service Center, and Baylor University. Additional partners include Reclamation's O-TAO and SCAO; the City of Waco, Texas; the Texas Water Quality Development Board; the City of Oxnard, Calif.; and CH2M Hill.
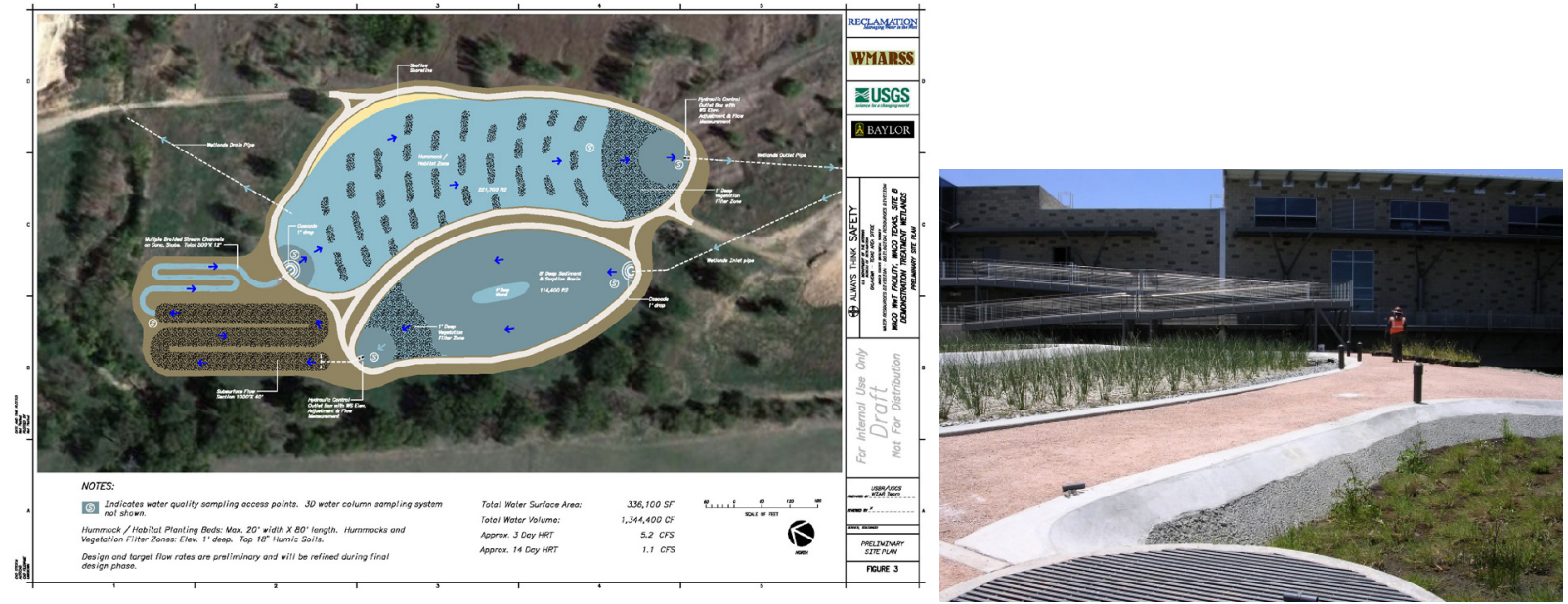

Constructed wetland site plan, at 30 percent completion (left). Oxnard saline treatment wetland (right). USGS photos.

\section{Contact: Joan Daniels}




\section{Ecosystems-Invasive Species}

\section{Control of Invasive Giant Constrictor Snakes and Tegus in Florida}

Invasive Burmese pythons (Python molurus) are established in the greater Everglades ecosystem and are expanding their range in southern Florida. These giant snakes (up to 20 feet and 200 pounds) are efficient predators of warm-blooded species ranging from wrens to deer and represent a novel threat to which native species are poorly adapted. Since 2006, FORT scientists with expertise in control of invasive reptiles have worked with cooperating agencies to develop techniques to detect, capture, and control populations of giant constrictor snakes in Florida and elsewhere.

In FY2012 and FY2013, FORT continued development of capture tools for Burmese pythons in areas with high python densities outside of Everglades National Park. To support conservation efforts for federally endangered mammals, the results of our work will be applied to detecting and capturing pythons as they invade Key Largo. FORT scientists have examined new ways of assessing risks associated with invasive reptiles, finding that expert assessments of ecological characteristics can better identify those species that are likely to have major negative impacts on the ecosystem (Reed and others, 2012). In addition, the FORT has initiated radiotelemetry and trapping studies of Argentine tegus, large invasive lizards that are rapidly expanding their range in extreme southern Florida. FORT scientists Robert Reed, Edward Metzger, and Jim Duquesnel were named as co-recipients of a "Partners in Conservation" award from the multi-agency Everglades Cooperative Invasive Species Management Area in recognition of their technical assistance to cooperators. Robert Reed continues to be regularly invited to speak about giant constrictor snakes to a variety of audiences, including the USGS Public Lecture Series, the National Wildlife Refuge System invasive species coordinators, and the interagency Brown Treesnake Technical Working Group.

Working with FORT and the USGS Southeast Ecological Science Center in Davie, Florida, cooperating agencies include the Endangered Species and National Wildlife Refuges branches of the U.S. Fish and Wildlife Service, National Park Service, South Florida Water Management District, Florida Department of Environmental Protection, University of Florida, Florida Wildlife Commission, and others.

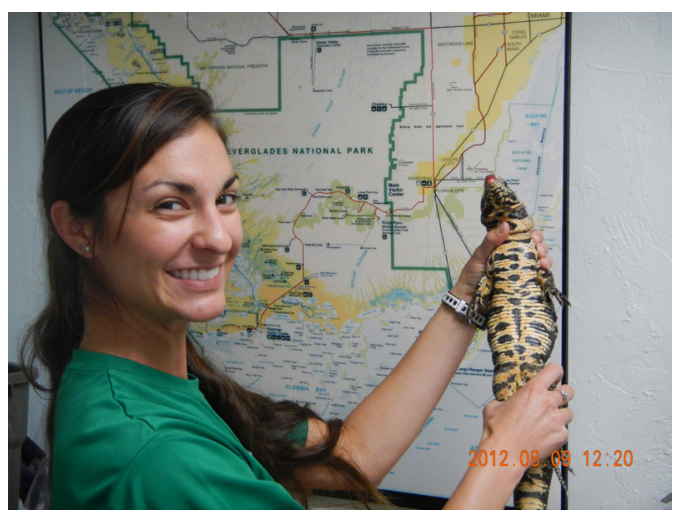

USGS biologist Michelle McEachern with an invasive Argentine tegu trapped along a canal in extreme southern Florida. USGS photo.

\section{Products:}

Reed, R.N., Willson, J.D., Rodda, G.H., and Dorcas, M.E., 2012, Ecological correlates of invasion impact for Burmese pythons in Florida: Integrative Zoology, v. 7, p. 254-270.

Reed, R.N., and Tucker, A.D., 2012, Determining age, sex, and reproductive condition, in McDiarmid,

R.W., and others (eds.), Reptile biodiversity-Standard methods for inventory and monitoring:

University of California Press, Berkeley, Calif., p. 151-163.

\section{Contact: Bob Reed}




\section{Control and Prevention of the Invasive Brown Treesnake}

The brown treesnake (BTS) is a highly destructive, invasive reptile that has extirpated many native bird species bats and lizards on the island of Guam. Visual searching is one technique currently used to detect and control BTS, especially incipient populations. The cost of an eradication program depends upon the least-capturable individual. Heterogeneity (analysis of capture variability) in visualdetection probabilities sets the cost for control efforts, particularly control programs directed at eradicating an incipient or nearly extirpated population. Visual searches and trapping efforts of BTS on Guam continue to provide data for many related projects.

In FY2012 and FY2013, FORT scientists concluded a monumental project to assess population status of BTS across the entire island of Guam. Field crews collected 100 snakes from each of 18 field sites that represented six different major habitat types, and collected information on body size, sex, diet, reproductive condition, and other measures. Results of this two-year study will be used to refine predictions of the potential efficacy of snake control at a landscape scale as the tools to conduct such control become available. We conducted a pilot study in 2012 to assess whether roads can be used as management boundaries for landscape-level control. The results suggest that snakes cross roads at a much lower rate than predicted if they were moving randomly, and this pilot study was greatly expanded in FY2013. We conducted

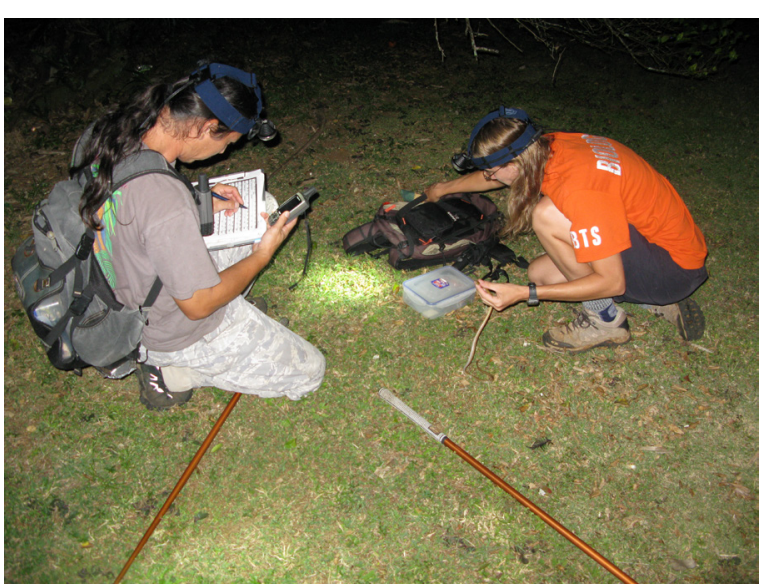

Biologists Tom Hinkle and Rebecca Lechalk process a juvenile Brown Treesnake captured during a nighttime visual survey. Photo by L.R. Bonewell, USGS. radiotelemetry studies of juvenile snakes to examine proximate reasons for their low capture rates in snake traps and found that our inability to predictably capture juveniles is not a function of low movement rates. In FY2011, we removed all of the adult BTSs from our 5-ha snake enclosure on Guam to simulate a toxicant application, and in FY2012 and FY2013, we have continued to monitor recovery of the population since that time. In the ensuing year, we have seen rodent populations increase dramatically as a result of snake suppression, suggesting that snake populations will also recover quickly after toxicant application as a result of this prey bonanza, unless rodents are controlled simultaneously.

We continue to assist the U.S. Fish and Wildlife Service (FWS) and the Department of Defense in snake barrier construction and maintenance plans related to the Habitat Management Unit, a 66-ha area on Guam, and a larger barrier on the Guam National Wildlife Refuge. Cooperators include the U.S. Department of the Interior Office of Insular Affairs, FWS, U.S. Navy, U.S. Air Force, Guam Division of Aquatic and Wildlife Resources, USDA Wildlife Services, Hawaii Department of Agriculture, Hawaii Department of Forestry and Wildlife, and Commonwealth of the Northern Mariana Islands Department of Fish and Wildlife.

\section{Products:}

Campbell, E.W., Yackel Adams, A.A., Converse, S.J., Fritts, T.H., and Rodda, G.H., 2012, Do predators control prey species abundance? An experimental test with brown treesnakes on Guam: Ecology, v. 93, p. 1194-1203.

Rodda, G.H., 2012, Population size and demographics, in McDiarmid, R.W., and others (eds.), Reptile biodiversity — standard methods for inventory and monitoring: University of California Press, Berkeley, Calif., p. 283-322.

\section{Contact: Bob Reed}




\section{Brown Treesnake Rapid Response Team}

Brown treesnakes (BTS) continue to cause major problems for the ecology, economy, and quality of life on the island of Guam. In 2002, a multi-agency Rapid Response Team (RRT), led by the USGS, was established to assist in detection and capture of these snakes on recipient islands if a snake was accidentally transported from Guam. The RRT has incorporated research results from USGS, such as means to improve snake detectability at low densities, effectiveness of control tools in rodent-rich environments, and predicting movements of snakes translocated accidentally. Since its creation, the RRT has conducted 1-5 training courses annually and performed over 20 field operations.

During FY2012 and FY2013, there were no full responses by the RRT to a BTS sighting on any Pacific island other than Guam. This is encouraging, as it suggests that interdiction activities on Guam are effective in removing the great majority of snakes from transportation pathways. However, the threat of accidental BTS transportation to other islands remains high, and the RRT includes more than 75 trained responders on islands across the Pacific, ready to conduct visual searching, trapping, and other activities if a snake sighting is reported.

One refresher training course was held on Guam in FY2012 and FY2013 for team members from three cooperating agencies in Hawaii. The trainees quickly regained their proficiency in visual searches, finding an average of four snakes each during the course. Trainees also received refresher training in trapping snakes and interview techniques for use

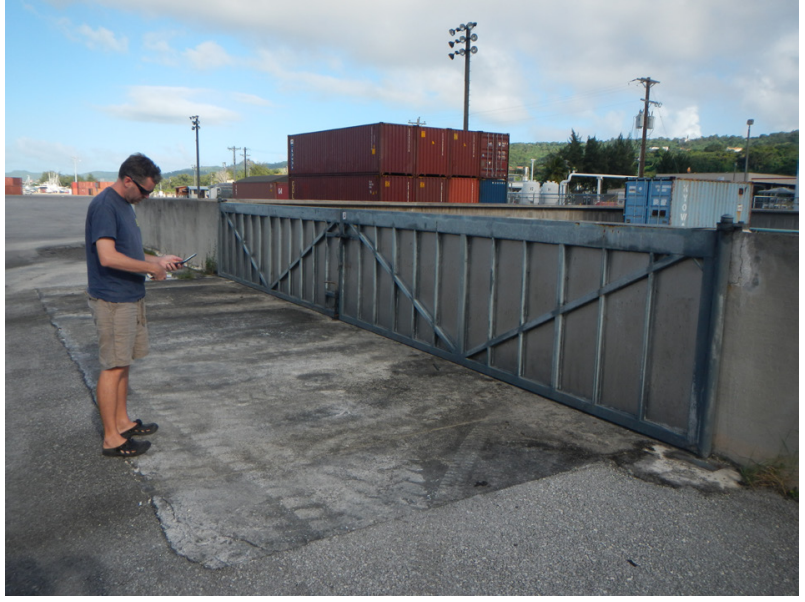

Rapid Response Team coordinator James Stanford of FORT examining a barrier at the port on Saipan, Northern Mariana Islands. High-risk cargo from Guam is placed in this barrier prior to inspection for brown treesnakes. Photo by Robert Reed, USGS. with the public. The RRT coordinator made visits to the islands of Chuuk, Majuro, Kosrae, and Pohnpei for brown treesnake outreach and education purposes, meeting with RRT members, agency cooperators, and the U.S. Ambassador to the Marshall Islands.

Numerous outreach and speaking engagements were conducted on Guam, including visits to the USGS research lab by school groups, presentations at University of Guam venues, and booth displays of invasive/native species with the Guam Department of Agriculture at the local Earth Day celebration. Assistance was supplied to the National Invasive Species Council on the development of the Micronesia Biosecurity Plan (MBP), including MBP biological team support throughout the region.

Support to the U.S. Fish and Wildlife Service continued in the Commonwealth of the Northern Mariana Islands (CNMI), including assistance in the development of a quarantine barrier for the Island of Rota.

Cooperators include the DOI Office of Insular Affairs, FWS, U.S. Department of Defense, USDA Wildlife Services and APHIS, Guam Division of Aquatic and Wildlife Resources, Hawaii's Coordinating Group on Alien Pest Species and Invasive Species Committees, Hawaii Department of Agriculture, and Hawaii Department of Forestry and Wildlife. Additional quarantine, agriculture, and natural resources cooperators include officials from the Federated States of Micronesia, the Commonwealth of the Northern Mariana Islands CNMI, the Republic of the Marshall Islands, and the Republic of Palau. Assistance was provided to the USGS Western Ecological Research Center's San Diego Field Station in California.

\section{Contact: Bob Reed}


FORT scientists in the Invasive Species Branch have extensive experience with invasive snakes but have previously focused on brown treesnakes on Guam and Burmese pythons in Florida. In FY2012 and FY2013, we expanded our efforts to include invasive boa constrictors in Puerto Rico. A population of these snakes has been identified in the far western part of the island near the city of Mayagüez, representing the first established population of a non-native constrictor snake in the United States and its territories outside of Florida. Initial site visits by FORT scientists led them to conclude that the population was more widespread than previously thought, and there appears to be no barriers to the expansion of boa constrictors across the entire island. This snake may prey on native species, including species of conservation concern such as the Puerto Rican parrot, and it may compete with or spread pathogens to the endangered native Puerto Rican boas.

In FY2012 and FY2013, USGS supported efforts by agency personnel in Puerto Rico to collect information and specimens, including buying freezers in which wildlife rangers can store specimens and supplying field datasheets and

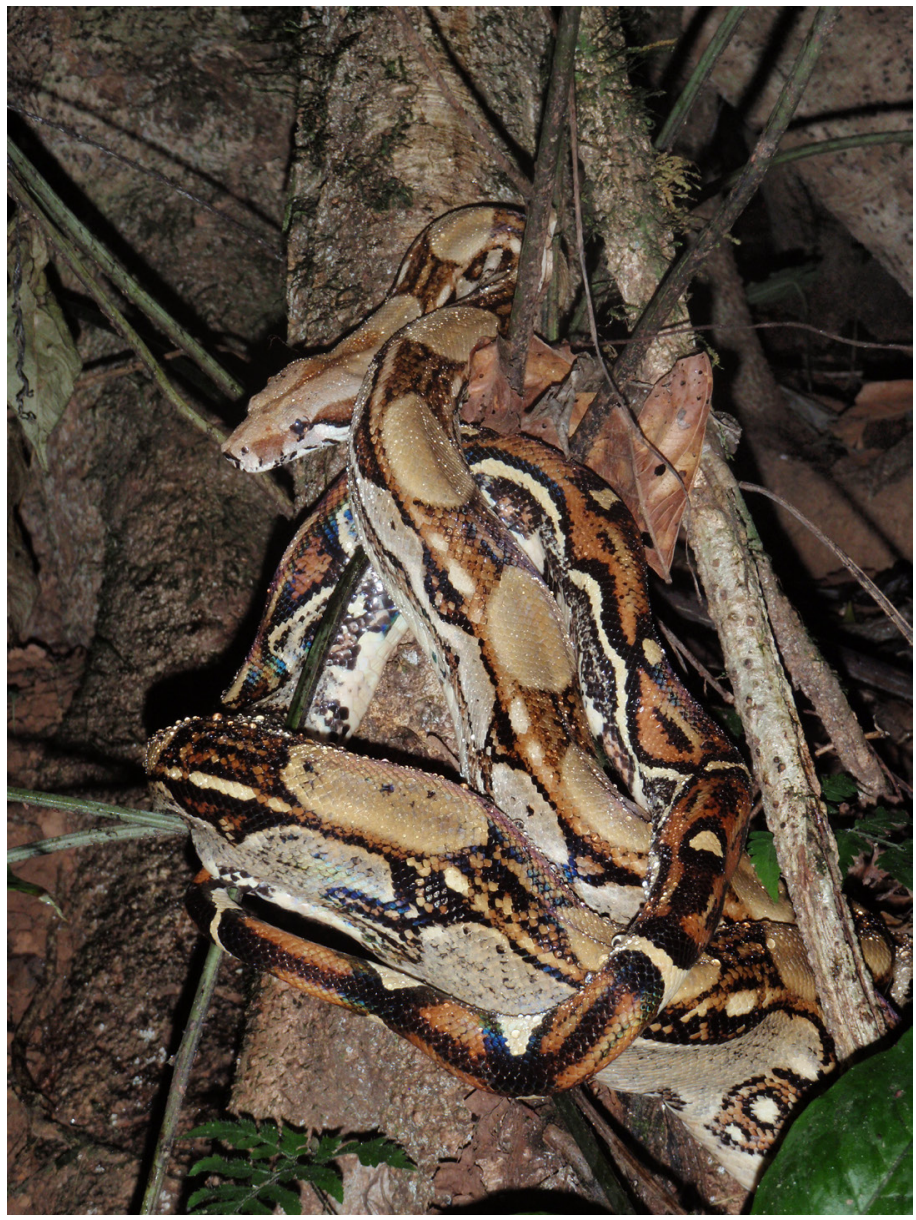

An invasive boa constrictor on a tree buttress in a forest in Puerto Rico. Photo by Robert Reed, USGS. protocols. USGS is funding an expert on Puerto Rican snakes to collect snakes and conduct necropsies, allowing a better understanding of dietary habits, reproductive characters, and body size variation. We are also cooperating with university colleagues on a genetic study to determine the origin and genetic diversity of this population.

Our work on boa constrictors in Puerto Rico is highly collaborative in nature, and cooperators include representatives of U.S. Fish and Wildlife Service, National Invasive Species Council, Puerto Rico Department of Natural Resources Conservation, University of Massachusetts, Universidad Interamericana de Puerto Rico, and others.

\section{Product:}

Reynolds, R.G., Puente-Rolon, A.R., Reed, R.N., and Revell, L.J., 2013, Genetic analysis of a novel invasion of Puerto Rico by an exotic constricting snake: Biological Invasions, v. 15, no. 5, 953-959.

\section{Contact: Bob Reed}


Africanized honey bees (AHB; a hybrid of African (Apis mellifera scutellata) and a variety of European honey bee species) have been spreading north in the Americas since their introduction to Brazil in 1957, reaching the United States in 1990. The Africanized honey bee (AHB) can have significant effects on existing pollinator populations, agricultural production, and human health. Previous maps of the northern extent of the AHB are relatively coarse and show inconsistencies with the current extent of their spread.

A partnership between NASA and USGS researchers created new maps through the USGS Resource for Advanced Modeling (http://www.fort.usgs.gov/ram), using habitat suitability modeling approaches and GIS data that included phenology information (e.g., timing of vegetation green-up and brown-down). We created models for the entire United States, the U.S. Southwest, and the U.S. Southeast to examine differences between different parts of the country. With these methods, we produced new maps highlighting suitable habitat for AHB in the United States.

The results were incorporated into a web site developed at Colorado State University (http://www.ahb.colostate.edu) that can be used by State apiarists and other managers dealing with AHB. The results were presented to the Apiary Inspectors of America and were turned into a publication currently in review. These model results can be used by the apiarists to guide sampling efforts to detect the spread of these bees. The models also can suggest where to focus public education efforts on the potential health threat posed by the bees.

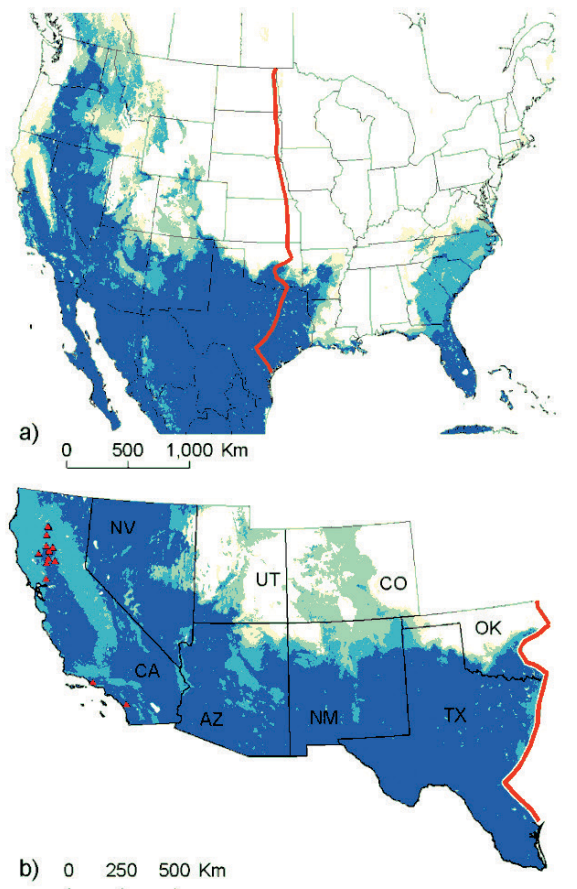

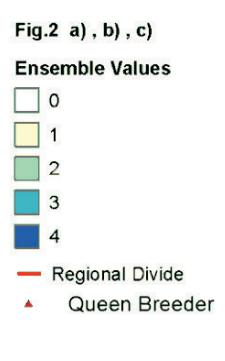

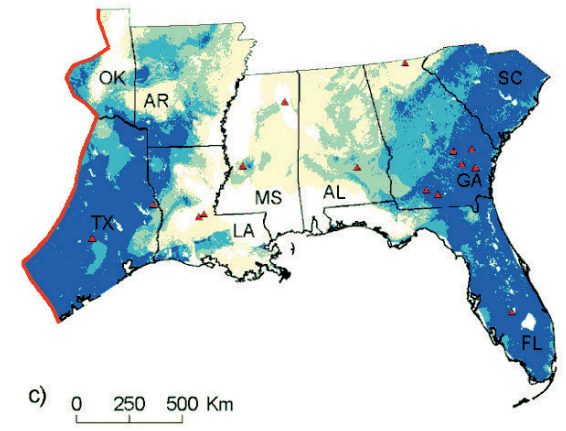

\begin{abstract}
Habitat suitability models for Africanized honey bees in (a) the United States, (b) the southwestern United States, and (c) the southeastern United States, with values ranging between 0 (low predicted suitability) to 4 (high predicted suitability).
\end{abstract}

\section{Product:}

Stohlgren, T.J., Jarnevich, C.S., Esaias, W., and Morisette, J.T., 2011, Bounding species distribution models: Current Zoology, v. 57, no. 5, p. 642-647.

\section{Contact: Catherine Jarnevich}




\section{Modeling Invasive Weeds in Coastal Alaska}

Global climate models predict that climate warming effects will be greatest in northern high latitudes like the Arctic. A relatively short growing season, highly variable climate, and lower biological diversity contribute to Arctic region vulnerability. Significant annual and seasonal mean temperature increases have been recorded for Alaska in the past fifty years, with the largest increases occurring in the winter in interior Alaska. FORT scientists are assessing the ability to create accurate predictive models for high-risk invasive plant species using climatic, environmental, and anthropogenic variables at multiple scales in a region of rapidly changing climate.

FORT staff uses species distribution models to answer the following questions:

- Can we identify specific areas on which to focus intense invasive-species control efforts (e.g., bottlenecks, passes) based on predictive modeling outcomes at the local scale?

- Can regional, local, and combined predictive outcomes be effectively applied to management strategies?

- Are predictions improved with including both climatic and anthropogenic variables?

FORT scientists collaborated with researchers and land managers from the Alaska Natural Heritage Program, USDA Agricultural Research Service, Alaska Department of Natural Resources, and Forest Service to begin to answer these questions in an attempt to help land managers in the largely pristine areas of Alaska reduce the likelihood of non-native plant invasions.

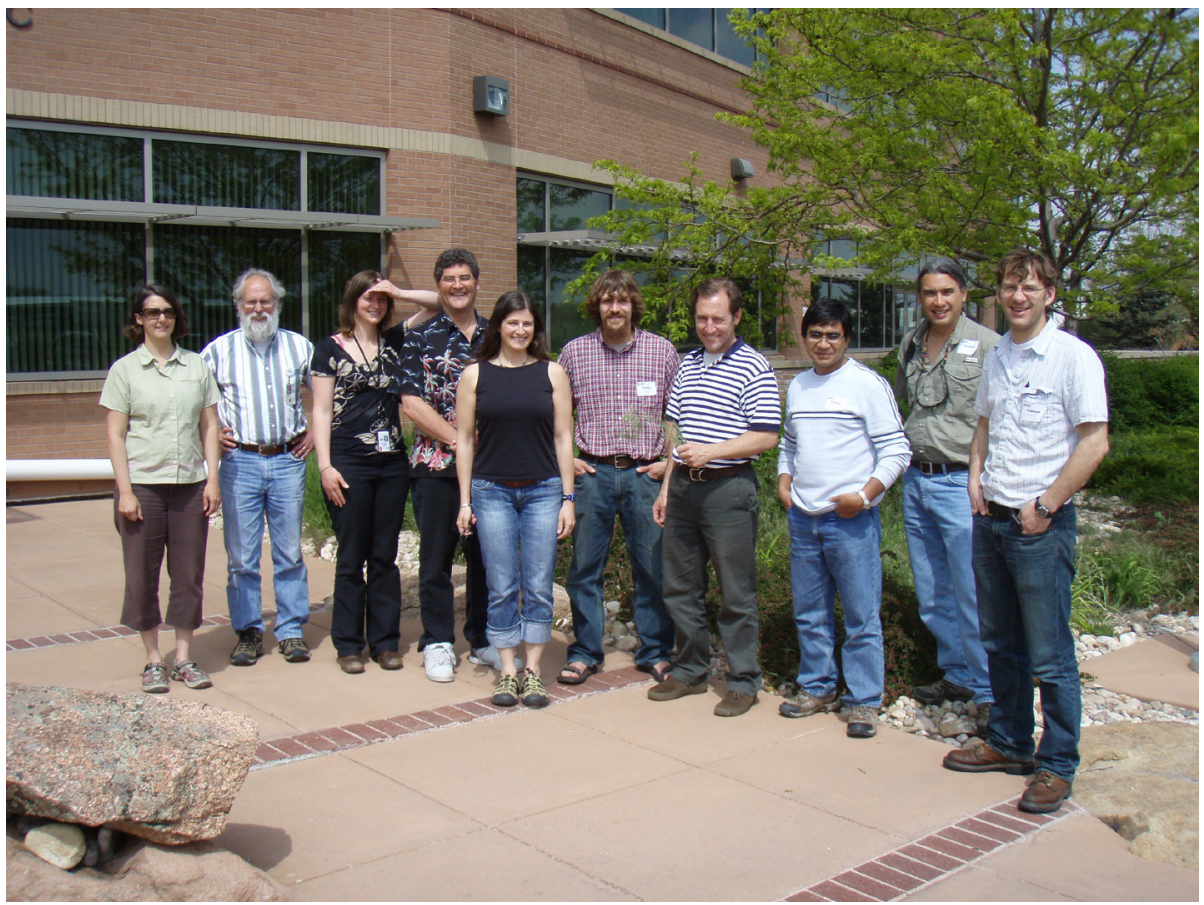

The Alaska modeling team. FORT scientists include Catherine Jarnevich, far left; Tom Stohlgren, fourth from left; and Jeff Morisette, fourth from right. Photo by Laurie Hughes, USGS.

\section{Contact: Catherine Jarnevich}



Arizona

Buffelgrass (Pennisetum ciliare) poses a problem in the deserts of the United States by growing in dense stands and introducing a wildfire risk in an ecosystem not adapted to fire. Given the urgency of the buffelgrass invasion and the limited resources available, land managers need tools to evaluate the potential efficacy of alternative mitigation strategies. The USGS FORT staff worked in cooperation with ESSA Technologies (http://www.essa.com/) and the Southern Arizona Buffelgrass Coordination Center to focus on the development of a spatially explicit model as a decision-support system to evaluate potential control strategies using buffelgrass infestations on the south slope of the Santa Catalina Mountains as a test case. questions:

We ran a formal decision-support/adaptive management simulation model to ask the following

- What level of resources is required to prevent buffelgrass spread?

- How should these resources be allocated among inventory, treatment, and maintenance?

Continuing with buffelgrass and decision-support efforts, we have extended our efforts near Tucson, Ariz., from the southern slopes of the Santa Catalina Mountains to a second location, the Ironwood Forest National Monument, advancing our knowledge of invasion ecology of buffelgrass and of the modeling techniques used. We presented preliminary scenario results at a workshop in Tucson in February 2012, giving land managers a view of buffelgrass infestation levels under different management scenarios and gleaning more information from them to help refine the model.

The decision-support model for the wildland-urban interface of the Santa Catalina Mountains demonstrates the potential of undetected invasions by identifying potentially suitable habitat and calibrating spread rates while also looking at allocation of resources among inventory, treatment and maintenance (Frid and others, 2013). Our model shows untreated buffelgrass patches could spread from as little as 80 hectares (ha) to more than 6,000 ha by 2060. A targeted up-front investment in inventory and treatment could reduce overall management costs.

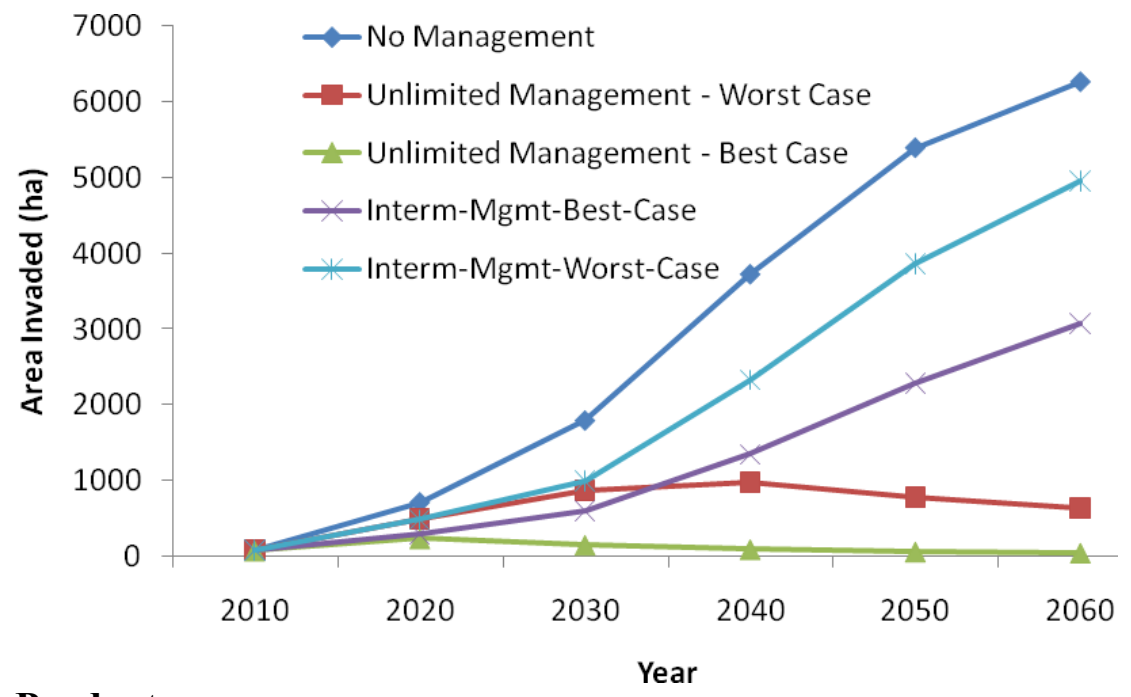

Graph illustrating the area predicted by to become invaded by buffelgrass (in hectares) by the year 2060 under different management scenarios with two different management effectiveness rates. Graphic created by Tracy Holcombe, USGS.

\section{Product:}

Frid, L., Holcombe, T., Morisette, J., Olsson, A., Brigham, L., Bean, T., Betancourt, J., and Bryan, K., 2013, Using state and transition modeling to account for imperfect knowledge in invasive species management: Invasive Plant Science and Management, v. 6, p. 36-47.

\section{Contact: Tracy Holcombe}


The lesser prairie-chicken (Tympanuchus pallidicinctus) was once found across a five-state area in the southern Great Plains but has suffered habitat and population decreases. This species is also considered a representative species of mixed- and short-grass prairie. Given the recent increase in energy development across the lesser prairie-chicken range, agencies are working with energy development companies to minimize the potential impacts to this bird.

USGS researchers from the FORT worked with the Kansas Department of Wildlife and Parks to develop habitat suitability models for lesser prairie-chickens across the state. The researchers were then invited to participate in the Western Governors' Association Lesser Prairie-Chicken Technical Team to lead the creation of similar models for both nesting and mating (lek) habitat across the lesser prairiechickens' entire range, including parts of Colorado, Kansas, New Mexico, Oklahoma, and Texas. This effort was the first time all of these states shared their location data and involved partnerships with each State's fish and wildlife agencies and the Playa Lakes Joint Venture. Models for the two different life stages — nesting and mating — could provide a regional estimate of the habitat available to support this species.

Model results are being used by the state agencies to guide future sampling efforts to locate leks. They are also being used to make management decisions, with the habitat suitability models being one of the pieces used to classify the landscape into critical habitat categories. The designation under these categories then aids in decisions on siting energy development. The research team is working on a publication of these results.

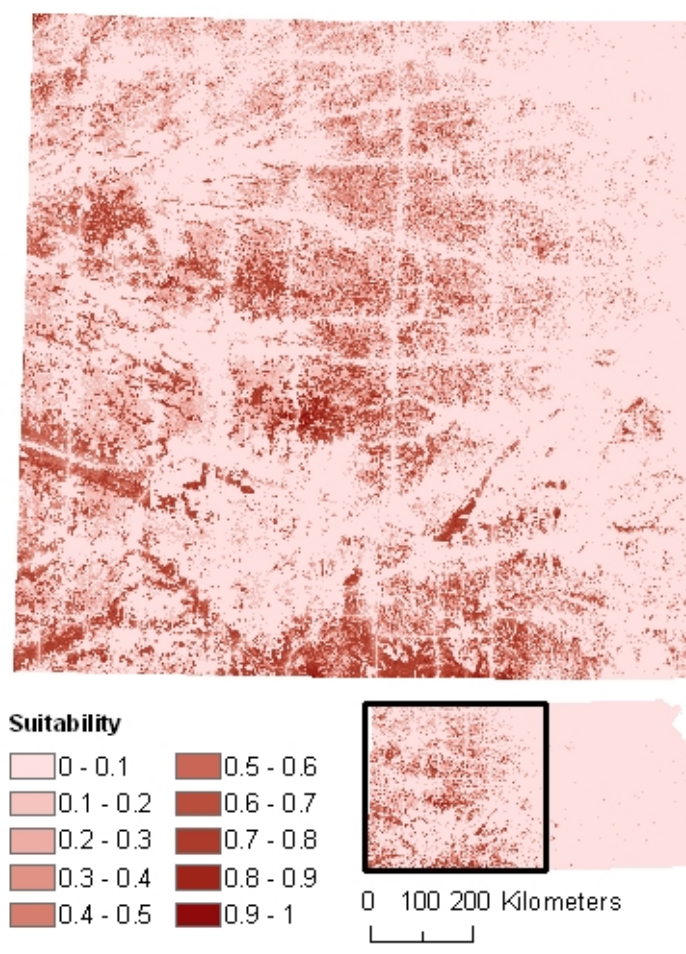

Lesser prairie chicken habitat suitability in Kansas, with 0 being unsuitable and 1 being perfectly suitable. Adapted from Jarnevich and Laubhan (2011).

\section{Reference:}

Jarnevich, C.S. and Laubhan, M.K., 2011, Balancing energy development and conservation-A method utilizing species distribution models: Environmental Management, no. 47, v. 5, p. 926-936.

\section{Contact: Catherine Jarnevich}




\section{Resource for Advanced Modeling and Software for Assisted Habitat Modeling}

In 2012, FORT continued to maintain and invest in its Resource for Advanced Modeling (RAM). Established in 2009, this facility was recognized that year with a U.S. Department of the Interior (DOI) Partners in Conservation Award. The RAM continues to provide a collaborative working environment for scientists and land managers from universities, non-profits, USDA, and DOI to work together on modeling activities and ecological studies. These sessions included a variety of landscape ecology, species distribution modeling, and data synthesis studies across a wide range of taxa and spatial domains. The large number of users and broad array of studies highlights the high demand and utility of this facility. A RAM publication (Jarnevich and others, 2010) was awarded outstanding paper of the year in 2012 by the Weed Science Society of America.

As reported in 2011, USGS researchers have continued to work with researchers at National Aeronautic and Space Agency's (NASA) Ames Research Center (ARC) in California; Colorado State University (CSU); and New York University Polytechnic School of Engineering (NYU Poly) to extend RAM capabilities. During 2012, the group launched version 1.0 of the Software for Assisted Habitat Modeling package for VisTrails (SAHM: VisTrails). This package has been created to both expedite habitat modeling and help maintain a record of the various input data, pre- and post- processing steps, and modeling options incorporated in the construction of a species distribution model. In 2012, the FORT officially implemented a powerful new capability within its Resource for Advanced Modeling: a bank of 24 wall-mounted, 27-inch monitors, arrayed 6 across and 4 high, that can be used for displaying large or numerous GIS datasets, photos, or other data products. This visualization wall, or "VisWall" for short, was built to support interactive exploration of model input and model output. The $6 \times 4$ Vis Wall monitor array can be configured to show a single map spread across all 24 monitors, 24 individual monitor outputs, or a combination of intermediate-sized outputs, such as six $2 \times 2$ - or three 4x2- monitor maps. Current SAHM modules were launched during 2012, including Version 1.0, a user guide and tutorial, and related peer-review publications.

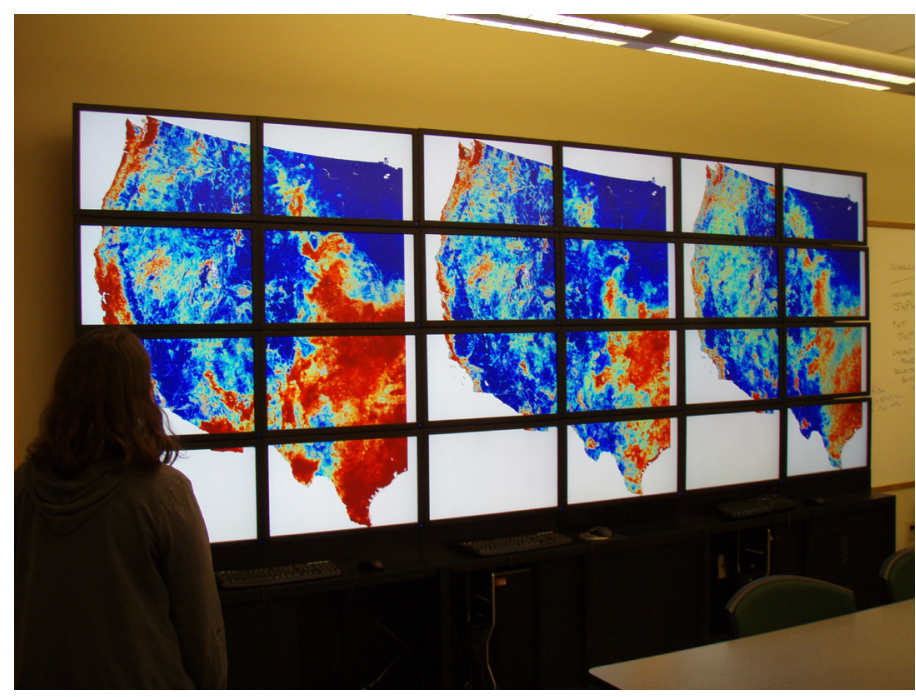

VisWall display using a $4 \times 2$ array to compare 3 related maps. Photo by Tracy Holcombe, USGS.

\section{Product:}

Morisette, J.T., Jarnevich, C.S., Holcombe, T.R., Talbert, C., Talbert, M., Ignizio, D. Silva, C., Koop, D., Swanson, A., and Young, N., 2013, VisTrails SAHM: Visualization and workflow management for species habitat modelling: Ecography, v. 36, p. 129-135.

\section{Award:}

Award of excellence for outstanding paper of the year from Weed Science Society of America for: Jarnevich, C.S., Holcombe, T.R., Barnett, D.T., Stohlgren, T.J., and Kartesz, J., 2010, Forecasting weed distributions using climate data-A GIS early warning tool: Invasive Plant Science and Management, v. 3, no. 4, p. 365-375.

\section{Contact: Catherine Jarnevich}



Florida

Several species of non-native giant constrictor snakes have become established in southern Florida. The Burmese python (Python molurus bivittatus) and the northern African python (Python sebae), in particular, pose significant threats to the native animal communities. These giant snakes (up to 20 feet long and 200 pounds in weight) are efficient predators of warm-blooded species ranging from wrens to deer, are highly adaptable to a variety of habitats, and represent a novel threat to which native species are poorly adapted. Previous USGS studies have found that precipitous declines in formerly common mammals in Everglades National Park have been linked to the presence of Burmese pythons. Information on the distribution of these two pythons (and where they are not) is needed to help manage and control these invasive species. Currently, nighttime road surveys and confirmed sightings are the only method used to document python distribution, but low detection probabilities mean that these methods miss most individuals.

Luckily, pythons spend a significant amount of time in waterways in Florida and leave behind clues that they have been there (feces, urine, skin cells, and sloughed skin). DNA can be extracted from these leftover biological samples. FORT scientists, in collaboration with scientists at the USGS Southeast Ecological Science Center, will be utilizing a relatively new method of non-invasive genetics to determine where invasive snakes occur, simply by collecting water samples and then extracting DNA from that sample. By knowing the individual DNA markers for a species, scientists can probe all the DNA and cell contents collected from the water to determine if a species was present. FORT scientists are developing python-specific genetic markers that will allow them to determine whether either species of python have been in the water that was collected. Blind testing of water samples with varying amounts of DNA known from captive animals will be used to assess the species-specificity and sensitivity of the technique, after which samples will be tested from multiple water bodies in southern Florida. Results will help refine understanding of the current distribution of these damaging invaders and provide an important earlywarning tool for land managers attempting to determine if pythons are present on their lands.

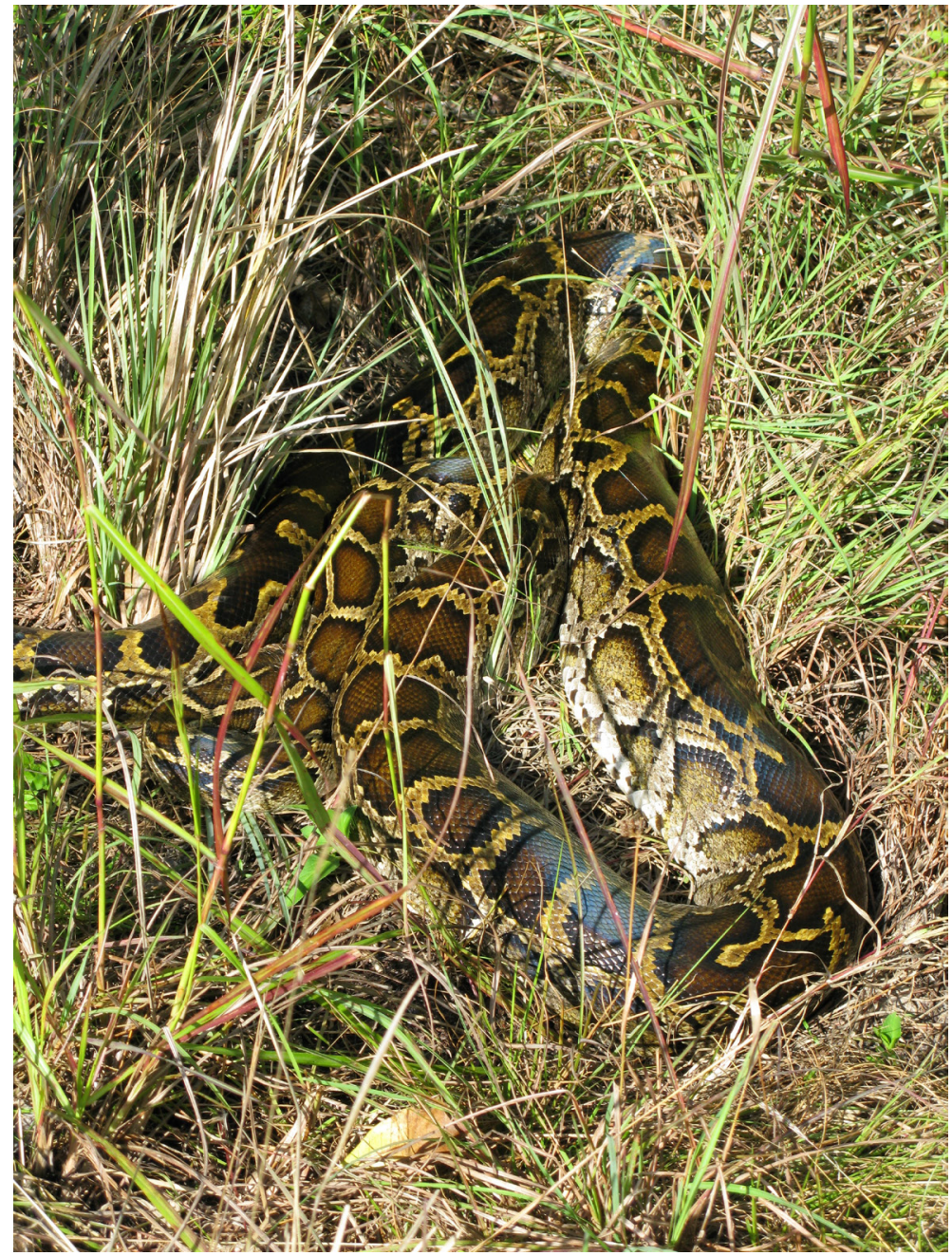

A Burmese python basking on a canal bank in the Everglades. Photo by Robert Reed, USGS.

Contacts: Sara Oyler-McCance, Robert Reed 


\section{Potential Effects of Climate Change on Invasive and Native Riparian Plants in the U.S. West}

Riparian forests contribute substantially to regional biodiversity, and they provide essential ecosystem functions and wildlife habitat in arid and semi-arid regions. Climate change is likely to alter riparian plant community structure and dynamics, by way of direct effects on plants and indirect effects via streamflow, biotic interactions, and human activities. Of particular interest to land and water managers is whether or not the distribution and abundance of invasive species are likely to increase. Research by FORT scientists addresses several knowledge gaps with respect to climate-change effects on riparian vegetation. It includes the following projects and accomplishments in FY2012 and FY2013:

- We completed a manuscript (Guilbault and others, 2012) describing results of a greenhouse experiment that examined effects of different cold temperature regimes on seed and bud dormancy in Russian olive, with implications for possible effects of warmer temperatures on the southern distribution limit of Russian olive. This work was completed in collaboration with Colorado State University.

- We completed a manuscript (Perry and others, 2013) describing a greenhouse experiment designed to help us evaluate the potential for elevated $\mathrm{CO}_{2}$ to offset negative effects of lower summer streamflows on recruitment of western woody riparian species. We examined differential responses of five common woody riparian plant species (two native, three exotic). This project was completed in collaboration with scientists from the USDA, Agricultural Research Service.

- We began work on a project funded by the North Central Climate Science Center, entitled, "Projecting climate change effects on cottonwood and willow seed dispersal phenology, flood timing, and seedling recruitment in western riparian forests." We are linking hydrologic models with seed-release phenology models to predict potential changes in seedling recruitment under a range of future climate scenarios in the South Platte River Basin. Hydrologic modeling is being done collaboratively with scientists from the USGS National Research Program.

- We are analyzing potential for stream hydrology to shift from perennial to non-perennial flow and associated changes to riparian vegetation in the Upper Colorado River Basin (UCRB) under climate change. In FY2012 and FY2013, we completed streamgage analyses, initiated Random Forest modeling, and conducted field sampling at more than 60 sites in the UCRB. This work was initially supported by the USGS Climate Effects Network and is now fully funded through a grant from the Southern Rockies LCC awarded to collaborators at Colorado State University.

- The final version of Perry and others (2012), reported in FY2011 and published in FY2012.

\section{Products:}

Guilbault, K.R., Brown, C.S., Friedman, J.M., and Shafroth, P.B., 2012, The influence of chilling requirement on the southern distribution limit of exotic Russian Olive (Elaeagnus angustifolia) in western North America: Biological Invasions, v. 14, p. 1711-1724.

Perry, L.G., Andersen, D.C., Reynolds, L.V., Nelson, S.M., and Shafroth, P.B., 2012, Vulnerability of riparian ecosystems to elevated $\mathrm{CO}_{2}$ and climate change in arid and semiarid western North America: Global Change Biology, v. 18, p. 821-842.

Perry, L.G., Shafroth, P.B., Blumenthal, D.M., Morgan, J.A., and LeCain, D.R., 2013, Elevated $\mathrm{CO}_{2}$ increases seedling growth but not drought tolerance in native and exotic woody riparian species: New Phytologist, v. 197, p. 532-543.

\section{Contact: Pat Shafroth}




\section{Ecosystems-Status and Trends of Biological Resources}

\section{Science Workshop: Delivering USGS Science to Wyoming Landscape Conservation Initiative Partners}

Over the past decade, large-scale oil and gas development has accelerated in Southwest Wyoming. In response, land management agencies, local governments, land owners, and the public identified a clear need to understand the implications of development on the area's natural resources. The Wyoming Landscape Conservation Initiative (WLCI), implemented in 2007, addresses this need through long-term, science-based efforts to conserve and enhance aquatic and terrestrial habitats while facilitating responsible development through local collaboration and partnerships. Initiative partners include agencies and organizations from the local, state, and national levels. The USGS has the lead role for developing and distributing scientific information to the WLCI community. One of the approaches used by USGS and other WLCI partners for communicating their current WLCI activities, scientific findings, and future WLCI activities is to convene periodic workshop-style meetings, during which participants may provide oral and poster presentations. These workshops are designed to foster collaboration among governmental and non-governmental organizations (NGOs), academia, and the public, and to help bridge the communication gap between scientists and land management planners and decisionmakers.

During 2012, two FORT scientists, including the USGS-WLCI Coordinator and the WLCI Science Lead, and the USGS Regional Science Coordinator led the planning effort for and hosted the 2012 WLCI Science Workshop, which took place on May 14-17 in Rock Springs, Wyoming. The workshop comprised four themes relevant to WLCI science and management activities: (1) changing landscapes, with an emphasis on the development and influence of energy and mineral resources, (2) tools and approaches for assessing and monitoring landscape change, (3) understanding the status and trends of important habitats, and (4) addressing change through management and conservation actions. More than 200 people from industry, Federal and State land management agencies, grazing associations, NGOs, academia, and the public participated in the workshop, which included 85 oral and poster presentations. The workshop also provided two evening socials and four tours, including site visits to better understand (1) how industry is implementing best management practices at current and future oil and gas fields, and (2) science needs related to restoration practices. During the workshop and tours, partner discussions focused on how to use scientific information more fully in management, and how to tailor future science activities for improving on-the-ground utility and application.
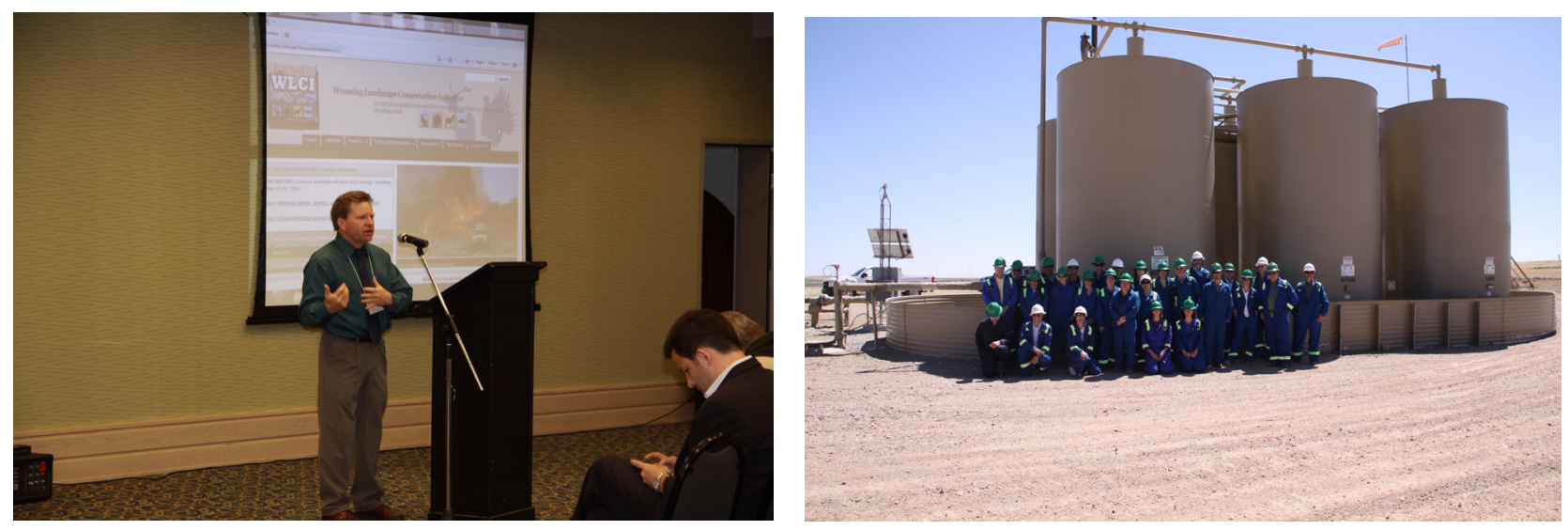

FORT's USGS-WLCI Coordinator, Pat Anderson, presenting information during the 2012 WLCI Science Workshop (left) and workshop participants during a tour of an oil and gas field (right). Photo by Genevieve Skora, FWS.

Contact: Pat Anderson 
The Little Mountain Ecosystem (LME) in southwestern Wyoming has been identified as a priority area for conservation by the Bureau of Land Management (BLM) and the Wyoming Game and Fish Department (WGFD). Several wooded, lower-elevation ridges form a transition zone between arid basins and mountainous areas. In these areas, mixed woodlands dominated by aspen and several coniferous species occur as relatively small patches on moist sites in a context of sagebrush steppe. The woodlandsteppe matrix provides important habitat for many wildlife species, including big game, migratory and resident birds, and Colorado River Cutthroat Trout, as well as important grazing lands for domestic livestock. Furthermore, these habitats are located within the boundaries of the Wyoming Landscape Conservation Initiative (WLCI), a long-term science based effort to assess and enhance aquatic and terrestrial habitats at a landscape scale in southwest Wyoming.

The LME woodlands have been affected by multiple disturbance types within the last 20 years. Active management of the woodlands, through prescribed fire and mechanical thinning, has been conducted to rejuvenate decadent aspen stands and reduce conifer encroachment in successional aspen stands. The area also experienced wildfires and a multi-year drought in the early 2000s, which may have stressed the trees and led to mortality in portions of the woodlands. Managers with the BLM Rock Springs Field Office have asked FORT scientists to develop research that establishes baseline information about the LME woodlands.

FORT scientists are working with the BLM and WGFD to conduct research that entails mapping the extent of deciduous and coniferous woodlands in the LME (specifically on Little Mountain), assessing the extent and timing of disturbance, and estimating drought impact on canopy of the woodlands. A longterm objective of this research is to determine the feasibility of developing a method for monitoring both abrupt and gradual forest and woodland changes by using the archives of satellite imagery for large areas of southwestern Wyoming. In FY2012 and FY2013, the mapping objective of the project was completed and data products were distributed to USGS partners. A fine-scale map of woodland distribution in the LME is critical to the WLCI Effectiveness Monitoring project, which, in turn, will help guide future landmanagement efforts to maximize habitat goals. Furthermore, this project provided an opportunity to develop methods for mapping a WLCI focal ecosystem type (aspen) at the landscape scale. The results include information on the amount and distribution of woodland patch type, which can be used to prioritize management efforts and aid subsequent USGS science activity in the area.

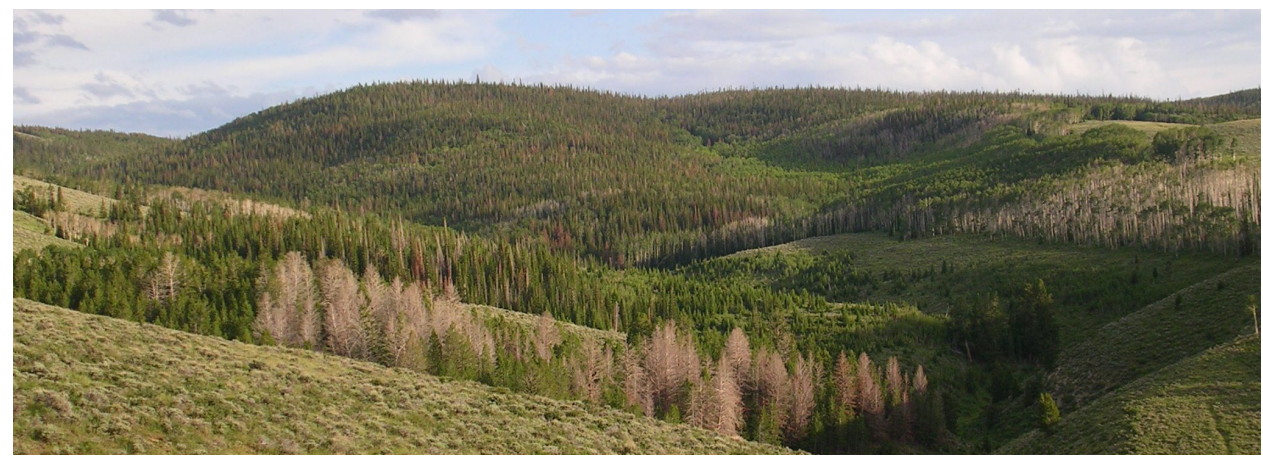

Mixed woodlands of the Little Mountain Ecosystem. Photo by Tim Assal, USGS.

\section{Product:}

Assal, T.J., Anderson, P.J., and Urza, A.K., 2012, Assessment and monitoring of semi-arid woodlands in the Little Mountain Ecosystem: Presented at the 2012 WLCI Science Meeting, May 14-17, 2012, Rock Springs, Wyo.

Contact: Tim Assal 


\section{Mapping Rural Residential Growth and Energy Development in Sublette County, Wyoming}

Land-use and land-cover change creates a broad range of impacts on ecosystems from global to local scales. Two drivers of land-use change in southwestern Wyoming are energy development and, to a lesser degree, rural residential growth. In Sublette County, Wyo., energy development increased by nearly six times between 1980 and 2010, and the county's population, which more than doubled during that time period, is expected to grow more than 70 percent by 2030 . The population growth is due, in part, to an increased energy workforce and a surge in rural second homes.

Sublette County is one of five counties included in the Wyoming Landscape Conservation Initiative (WLCI) geographic area. The WLCI is a long-term, multi-agency, science-based effort to assess and preserve wildlife habitats while fostering responsible energy development in southwestern Wyoming. One objective of the WLCI is to evaluate the natural, economic, and social context for energy development and other land uses. Sublette County encompasses critical habitat for many Wyoming's Species of Greatest Conservation Need, but land-use change may be resulting in direct loss and increased fragmentation of wildlife habitat. To assess the effects of land-use change on wildlife, land managers need a method for monitoring landscape-scale changes in land cover over time. One means of measuring land-use change would be to map socio-economic data, but such data are available only at the county level. Furthermore, data regarding rural housing development are seldom provided at a scale finer than that of a census block, and only on a decadal time scale.

To help address this important protocol and data gap, in FY2012 and FY2013, FORT scientists used Sublette County as the basis for developing a method for mapping change in land cover over time. This entailed integrating energy production data, population census data, ownership parcel data, and a series of satellite images. The resulting map illustrates changes in land cover/land use at five-year intervals (1984-2009) in an area of substantial energy and rural residential development. While we do not attempt to quantify the effect of land-use change on wildlife species, we believe our results provide important baseline information that the Bureau of Land Management, Wyoming Game and Fish Department, and other agencies can incorporate into land-use planning and wildlife ecology research at the landscape scale.

"I've been involved with doing or teaching GIS and remote sensing since 1983. Best paper using remote sensing data to correlate landscape change with population growth that I've read to date! Congratulations on your very fine work."

- Anonymous reviewer for product publication in Journal of Maps

\section{Product:}

Assal, T.J., and Montag, J.M., 2012, A tale of two land uses in the American West: Rural residential growth and energy development: Journal of Maps, v. 8, no. 4, p 327-333.

Rural residential development in Sublette County, Wyoming, from 2001 (left) to 2009 (right). Imagery Source: National Agriculture Imagery Program. Map by Tim Assal, USGS.

Contact: Tim Assal

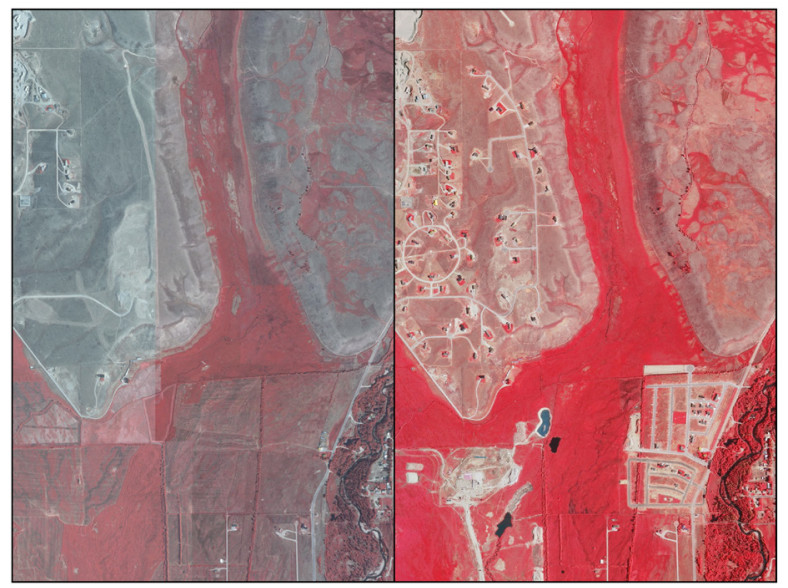


Aspen is a clonal organism that primarily reproduces vegetatively via root suckering. Rapid reproduction is often triggered by a disturbance that allows aspen to dominate woodland cover for some time after the event. Aspen stands in the western U.S. commonly co-occur with several conifer species. In some areas, slow-growing conifers begin to dominate over aspen after long periods since the last disturbance. The Little Mountain Ecosystem (LME) in southwestern Wyoming has been identified as a priority area for conservation by the Bureau of Land Management (BLM) and the Wyoming Game and Fish Department (WGFD). In addition, the LME is located within the boundary of the Wyoming Landscape Conservation Initiative (WLCI), a long-term, science based effort to assess and enhance aquatic and terrestrial habitats at a landscape scale in southwestern Wyoming. Aspen woodlands within the LME provide important habitat for many wildlife species, including big game, migratory and resident birds, and Colorado River Cutthroat Trout, as well as important grazing lands for domestic livestock. Since 1990, more than $\$ 2$ million has been spent on habitat restoration and enhancement projects in the LME. Many of these efforts have focused on restoring aspen communities to maintain or improve water quality and to enhance ungulate habitat.

As part of the WLCI Effectiveness Monitoring project, the USGS has been collaborating with the BLM to address questions pertaining to land-management and habitat-restoration actions. Overall, the Effectiveness Monitoring studies are designed to evaluate the effectiveness of management actions, and to develop ecological baseline data crucial for the success of WLCI efforts. Managers with the BLM Rock Springs Field Office, which encompasses the LME, specifically asked FORT scientists to conduct research that provides baseline information on the demography of LME woodlands. In FY2011, FORT scientists initiated a demographic study that entails estimating stand-establishment dates in aspen and conifer communities of the LME. Since disturbances typically drive the establishment of new aspen stands, establishment dates of aspen clones can indicate when the most recent disturbance occurred (likely fire), and establishment dates of conifers will provide insights about changes in species composition of the woodlands. More than 900 trees were sampled, including core or cross-section samples and diameter measurements, in 60 study plots. In FY2012 and FY2013, we analyzed the data and developed a chronology of the study area. The completed analysis will be published in a final report. The results of this work will provide WLCI partners, including the BLM, WGFD, and others, with insights as to the effectiveness of their land-management action, and will be used to inform future management actions.
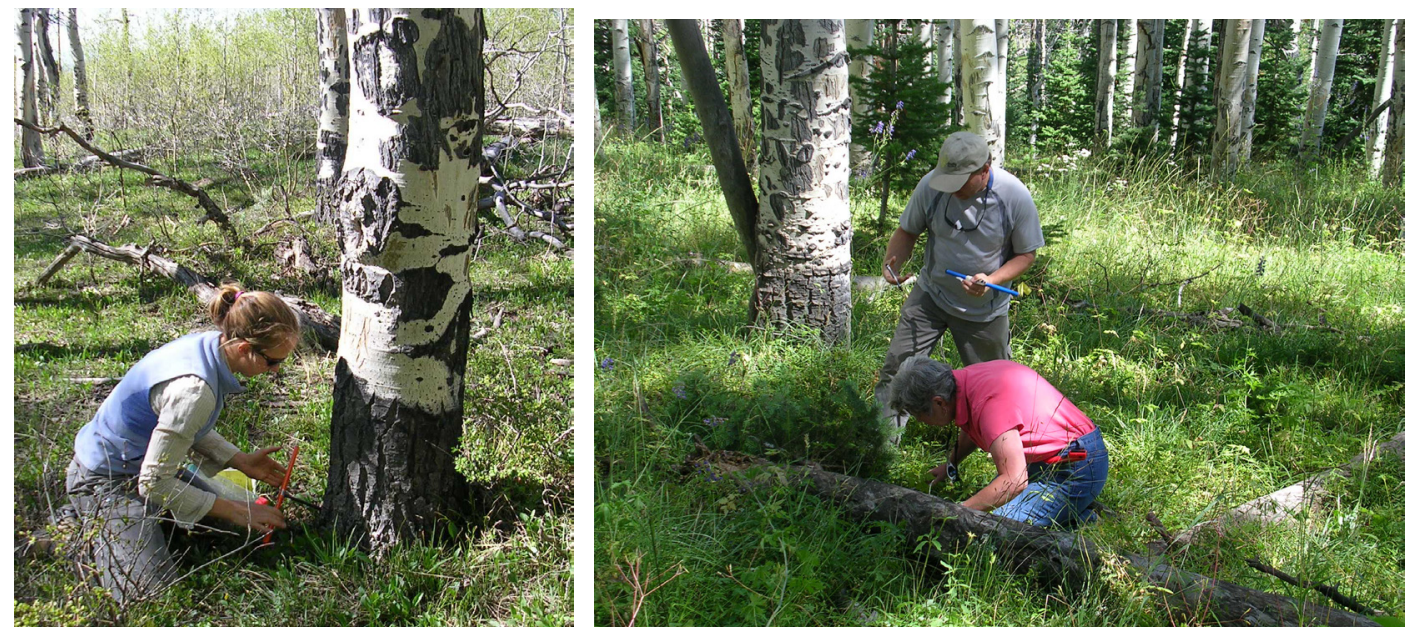

(Left) Alexandra Urza extracts a core from an aspen tree. (Right) Pat Anderson gets field assistance from Bonnie Cannon, Congressional District Representative, while conducting an outreach meeting on Little Mountain. Photos by Tim Assal, USGS.

Contact: Tim Assal 


\section{Assessing Socioeconomic Planning Needs (ASPN)}

Land-management actions often have significant social and economic impacts. Over the years, there has been an increased need to address and analyze these impacts, given laws such as the National Environmental Policy Act and increased litigation and appeals on land-management decisions. However, there is a lack of a consistent framework within each agency and across agencies regarding how to objectively and comprehensively identify the social and economic impacts of their management actions. In addition, resource planners and field staff may not be aware of the variety of social and economic methods that can be used to analyze these impacts. Further, agencies often have limited planning budgets and timeframes to conduct such analyses, requiring a prioritization of the most pressing issues.

As reported in FY2011, FORT economists and social scientists and FORT's Web Applications Team collaborated with the Bureau of Land Management, the National Park Service, the Forest Service, and the U.S. Fish and Wildlife Service to develop a web-based tool to support this analysis need. The resulting tool, Assessing Socioeconomic Planning Needs (ASPN), is designed to:

- provide demographic and economic data for the counties and states within an agency's specified planning area;

- help decisionmakers identify and prioritize the social and economic issues that may need to be addressed given a specific land-management action;

- highlight the range of applicable social and economic methods and analyses that are available to address these issues; and

- guide project management of social and economic analyses.

ASPN provides a consistent framework to ensure that best science practices are used in the social and economic analysis components of land-management planning. In FY2012 and FY2013, pilot testing of the tool took place with each agency, and the program content was reviewed. We anticipate that ASPN will be available for agency use in the spring of 2013. It is expected that a broad range of users, including decisionmakers, on-the-ground managers, and regional planners, will find ASPN to be a helpful tool in their land-management planning efforts.

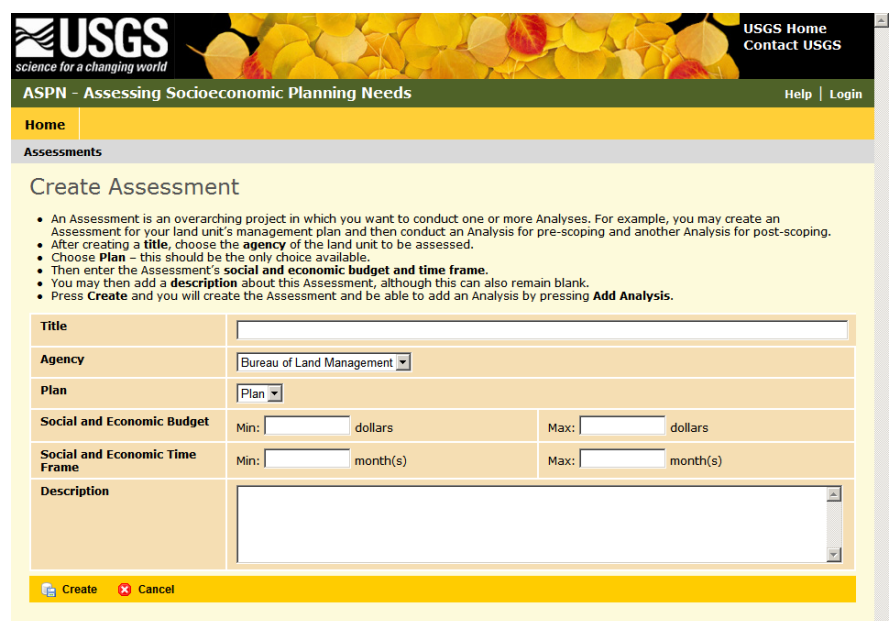

ASPN “Create Assessment” page. USGS image.

Contact: Leslie Richardson 


\section{Assessing Visitor Experiences on National Wildlife Refuges}

In what activities are visitors participating when they visit National Wildlife Refuges? How satisfied are visitors with their refuge experiences? How much are visitors spending in the local community as part of their visits? For the past year, researchers from the Policy Analysis Science Assistance Branch have been exploring these and other questions as part of an ongoing survey of visitors to National Wildlife Refuges. The 2012 National Wildlife Refuge Visitor Survey was conducted on 25 refuges across the country, with two separate sampling periods selected for each participating refuge in an effort to capture the specific visitation patterns of those refuges.

The survey, commissioned by the U.S. Fish and Wildlife Service (FWS) Division of Visitor Services and Communications and the U.S. Department of Transportation Federal Lands Highways Program, provides refuge managers, planners, and visitor services specialists with a better understanding of:

- visitors' trip characteristics, such as where visitors are from, the distance they travelled, who they came with, and the time they spent on refuges;

- visitors' opinions about the refuge they visited, including the recreational opportunities they experienced and the services provided by staff and volunteers;

- visitors' associated spending in the local communities near the refuges; and

- visitors' opinions about larger issues facing the Refuge System, including provision of alternative transportation and communication on the topic of climate change.

Over 7,000 visitors agreed to participate in the 2012 national survey effort. The response rate is 70 percent, an achievement that can be attributed to the hard work of the refuge staff, volunteers, and FORT personnel who actively recruited visitors onsite. In addition to the sampling at refuges as part of the 2012 survey, two USGS data series were published in FY2012 as part of the 2010-2011 survey: Data Series 643, which disseminated 53 individual station-specific reports, and Data Series 685, which addressed aggregatelevel data representing the combined results for stations having a minimum of 25,000 visitors annually. These reports and associated results are important for tracking status and trends of visitors and their experiences over time and will further help the Refuge System address many of the unprecedented challenges outlined in the FWS “Conserving the Future: Wildlife Refuges \& the Next Generation” strategic vision.

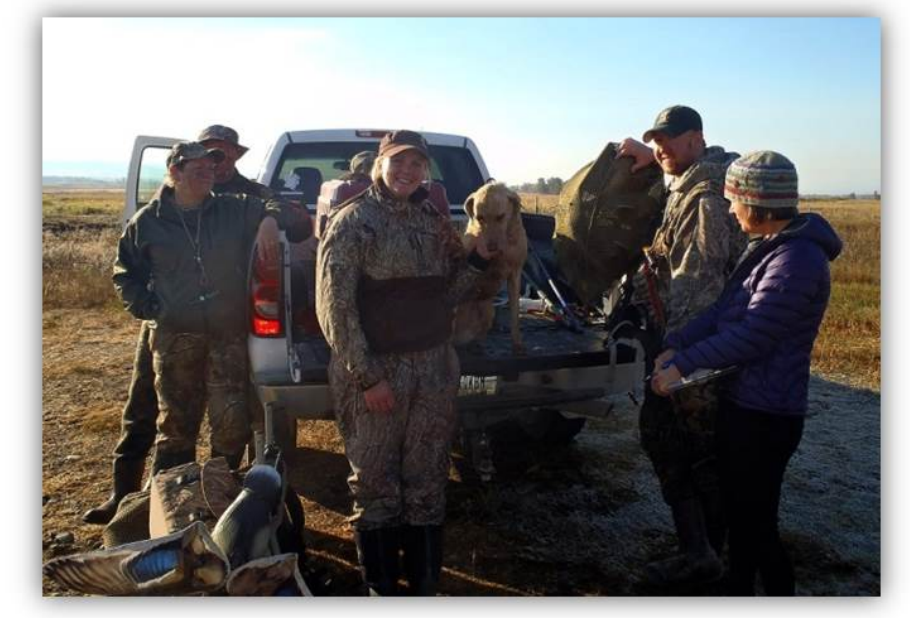

USGS staff member Earlene Swann (far right) contacting visitors at Lee Metcalf National Wildlife Refuge, Mont. Photo courtesy of Ron Osborn, USGS.

\section{Products:}

Sexton, N.R., Dietsch, A.M., Don Carlos, A.W., Koontz, L., Solomon, A., and Miller, H., 2012, National Wildlife Refuge visitor survey 2010/2011-Individual refuge results: U.S. Geological Survey Data Series 643.

Sexton, N.R., Dietsch, A.M., Don Carlos, A.W., Miller, H.M., Koontz, L.M., and Solomon, A.N., 2012, National Wildlife Refuge visitor survey results_2010/2011: U.S. Geological Survey Data Series 685.

Contact: Rudy Schuster 
Calculating the monetary value of "ecosystem services" is a means of expressing the value of a natural or restored ecosystem. Ecosystem services are defined as the beneficial services from ecosystems that are integral to human well-being, such as recreation, carbon sequestration, or protection of water quality. Humans, in turn, affect the quantity and quality of ecosystem services through our behavior and decisionmaking. However, ecosystem services and natural capital have not historically been explicitly accounted for in economic decisionmaking and have therefore frequently been subjected to exploitation and degradation. To ensure continued provision of the ecosystem services upon which we rely for our well-being and to prevent their further degradation, it is important to improve understanding of ecosystem service monetary values, which can then play a role in decisionmaking processes that affect ecosystem service quality and quantity. Currently several stakeholders and agencies in Florida, as well as U.S. Army Corps of Engineers (USACE) leadership, have asked for such an assessment of Everglades restoration.

Restoration activities that will take place in Florida's central Everglades under the Central Everglades Planning Project's (CEPP) Tentatively Selected Plan (TSP) could impact a range of ecosystem services that benefit both local communities and society as a whole. In FY2012, FORT economists, in collaboration with the University of Florida, U.S. Army Corps of Engineers, and other CEPP team members, began conducting an assessment of the value of ecosystem services affected by these restoration activities.

The team will assess the difference in available ecosystem services between CEPP TSP implementation and not-that is, a comparison of the future with the project to the future without the project. The team will monetize the value of select ecosystem services using existing data and benefit transfer methods and provide a qualitative description and non-monetary quantification of services that will not be significantly impacted by restoration activities or cannot be valued monetarily due to a lack of existing data. This effort will highlight gaps in the existing literature to efficiently guide future ecosystem service valuation research in the central Everglades and will have significance for the Comprehensive Everglades Restoration Plan and its stakeholders, the general public, USACE Jacksonville District, and USACE nationally.

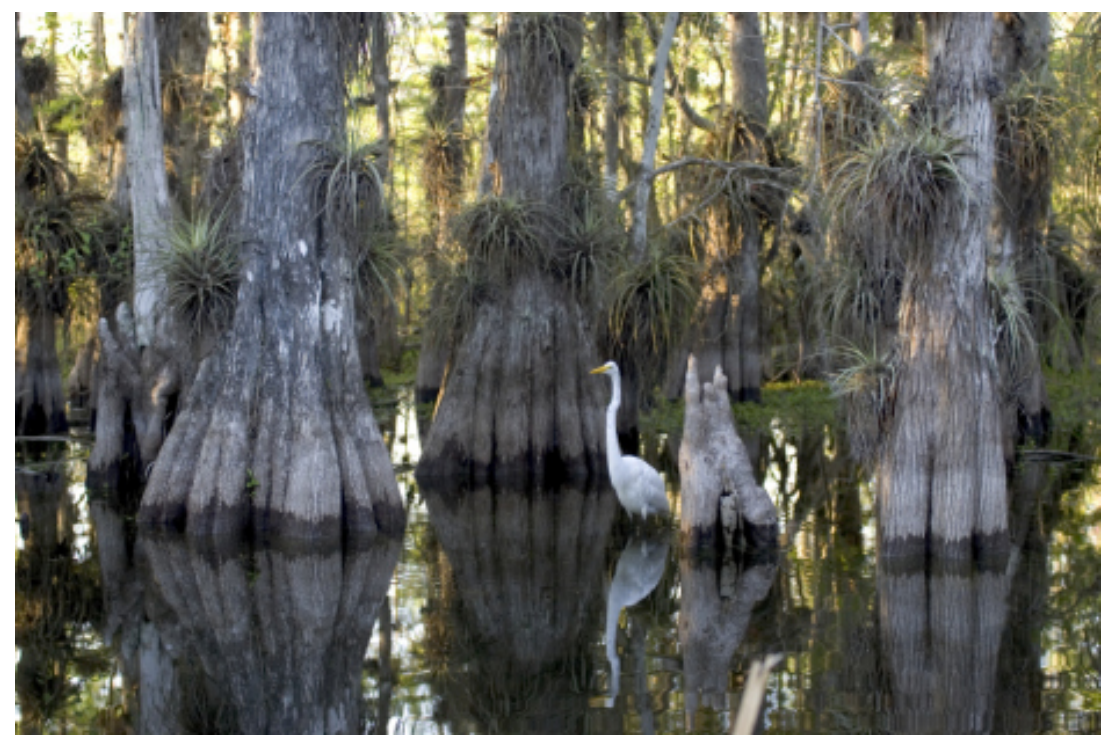

An American egret roams a cypress grove in Everglades National Park. Photo courtesy of the National Park Service.

Contact: Leslie Richardson 
The 2008 Farm Bill authorized the Secretary of Agriculture to prioritize the protection of pollinators and their habitats. The importance of pollinators is reflected by the estimated $\$ 20$ billion annual value that pollinators contribute to crop production, and evidence suggests a relationship between agriculture and the reduced distribution and population of pollinators. The conservation of pollinator habitat was a priority among USDA conservation programs of the 2008 Farm Bill. In FY2012, a cooperative study between the Farm Service Agency (FSA) and the FORT was initiated to evaluate the effectiveness of the USDA's pollinator habitat initiative on Conservation Reserve Program (CRP) grasslands in eastern Colorado. FORT is examining how increasing alteration of natural landscapes by agriculture affects habitat loss and degradation for pollinators and contributes to their population declines and will examine the potential role of CRP in providing pollinator habitat.

In FY2012 and FY2013 FORT collected more than 5,500 pollinators from eight CRP fields while developing a pollinator monitoring protocol to evaluate the extent to which the CRP pollinator habitat initiative encourages native pollinators in both agricultural and rangeland landscapes. This research will be continued and expanded to investigate the extent to which pollinator habitat provides additional benefits, such as wildlife habitat.

This study will evaluate CRP pollinator habitat plantings and help develop measures of conservation effectiveness in providing pollination services. The results will help the USDA learn how effective the pollinator habitat initiative is at attracting native pollinators. They also will help the USDA identify how best to broaden the goals of its conservation programs and the specific goals of the CRP.

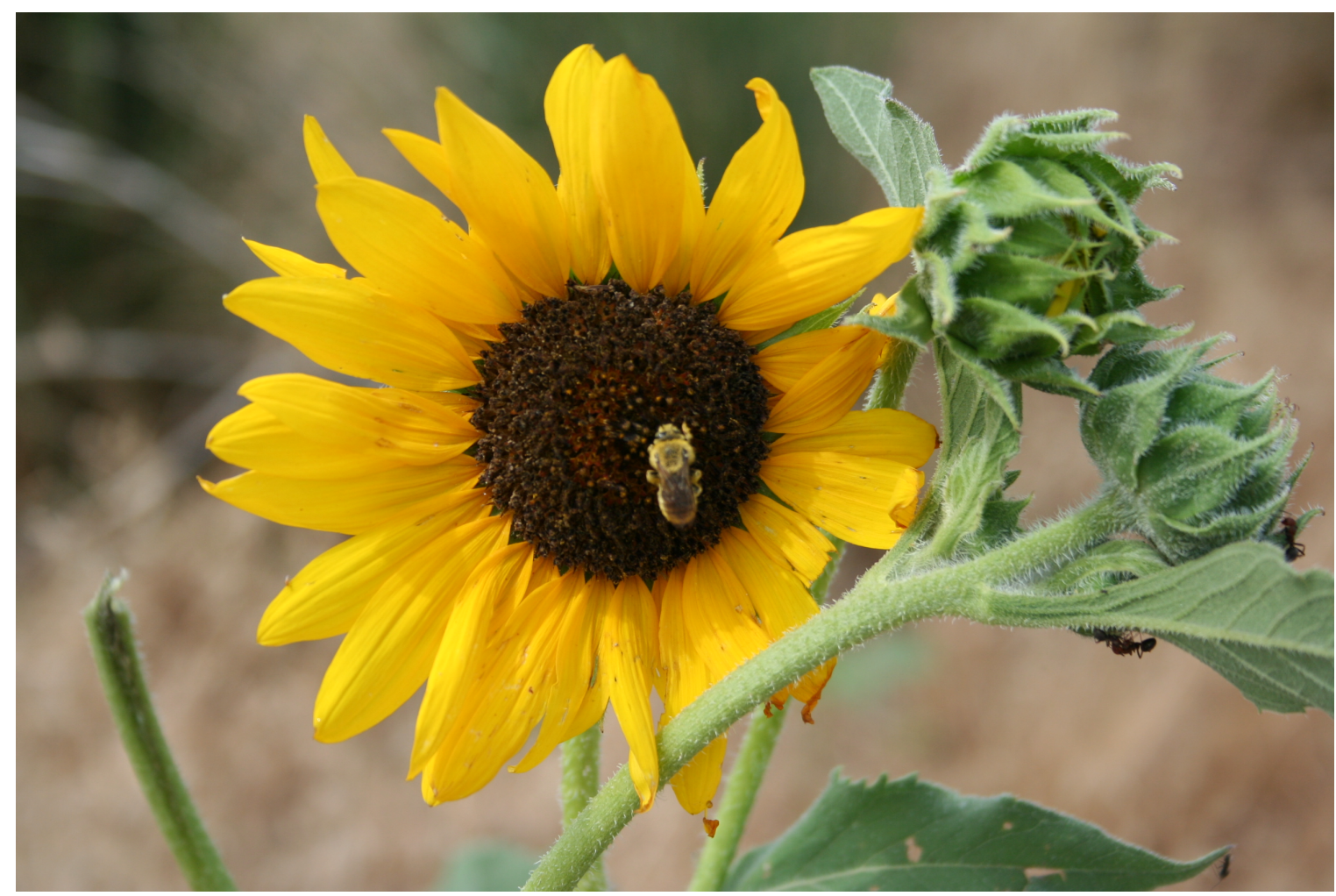

Native bee on a sunflower in Logan County, Colo. Photo by Mark Vandever, USGS.

Contact: Mark Vandever 


\section{The Benefit Transfer and Visitor-Use Estimating Models Toolkit}

Our Nation's public and private lands provide a variety of recreational opportunities and other ecosystem goods and services that offer considerable value to local communities, visitors, and society as a whole. Determining how the public uses and values these opportunities and services is of increasing importance. Natural resource planners and managers often wish to evaluate economic tradeoffs between alternative ways of managing natural resource use on public lands. To achieve these goals, two pieces of information often needed are:

1. estimates of the economic value held by the public for various recreational opportunities and other ecosystem services, and

2. estimates of current visitor use or changes in visitor use associated with a management action.

Conducting original studies and collecting primary data to obtain this information is not always feasible given time or budget constraints and may not be justified if resource impacts are expected to be low. Given the abundance of non-market valuation studies quantifying the economic value that the public places on various public goods and services, an alternative is to apply this existing data to unstudied policy sites, a practice referred to as "benefit transfer." In 2007, researchers at Colorado State University and Defenders of Wildlife created a simple, Web-based toolkit to help apply improvements in benefit transfer methods by public agencies and consultants. This toolkit allows users to apply the benefit transfer method to estimate the economic value to the public of wildlife-based recreation activities, wildlife habitats, wildlife species, and open space.

In FY2012, FORT economists began working with the Bureau of Land Management (BLM) to update the toolkit with additional recreational opportunities and ecosystem services specific to BLM lands. Once the toolkit is updated, FORT economists, with the assistance of Colorado State University economists and BLM socioeconomic staff, will work with approximately four BLM field offices to demonstrate and work through the process of using the toolkit to incorporate non-market values in planning and project assessments. This exercise will highlight both the successes and difficulties that arise in framing this economic information for decisionmaking. The results of this exercise will be documented in a guidebook for BLM resource planners and field staff. The updated toolkit will be available online, with FORT supporting and maintaining it. The current toolkit is available at http://dare.agsci.colostate.edu/outreach/tools/.

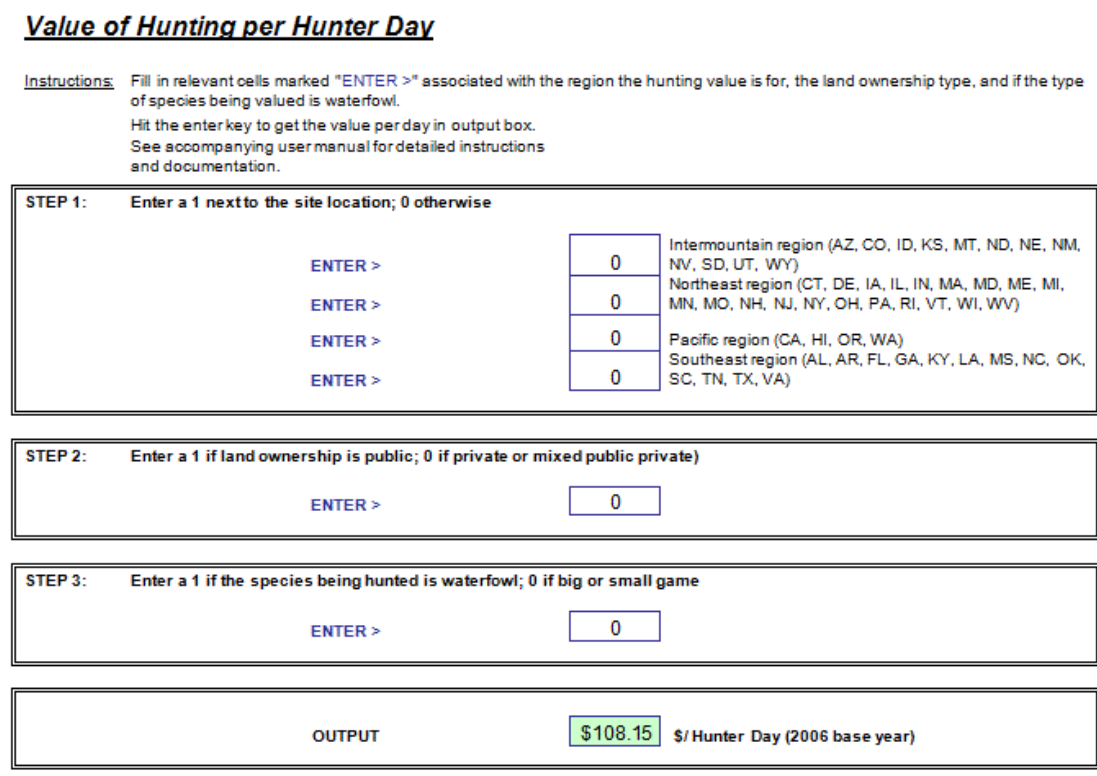

Value estimator model output for hunting. USGS image.

Contact: Leslie Richardson 


\section{BLM Social Science Concepts and Methods Training Module}

Management decisions and plans regarding public lands generally involve the integrated use of biological, sociological, and economic information. Combining this information provides a more comprehensive basis for developing, implementing, and monitoring the outcomes of a management plan or decision. This project aims to provide Bureau of Land Management (BLM) managers, planners, and resource specialists with a better understanding of social science through the creation of a web-based social science training module.

The module will strengthen the ability of BLM staff - most of whom have educational backgrounds in wildlife, biology, fisheries, or recreation - to address the social aspects of planning and decisionmaking, such as assessing public attitudes, knowledge, and values concerning future management scenarios and their implementation. The objectives for the training module are to enable BLM staff to be better able to

- identify social interests to be considered in plans, projects, and programs;

- identify the appropriate social study area;

- identify relevant social research/investigative tools and methods for application to various resource management activities; and

- consider social effects of management actions in BLM decisions.

In FY2012 and FY2013, FORT social scientists completed the majority of the course content in collaboration with BLM staff. The final product of this effort will be served through DOI Learn, enabling BLM staff from across the county to partake in the training without the need for travel-thereby eliminating financial constraints to participation while also reducing environment impacts.

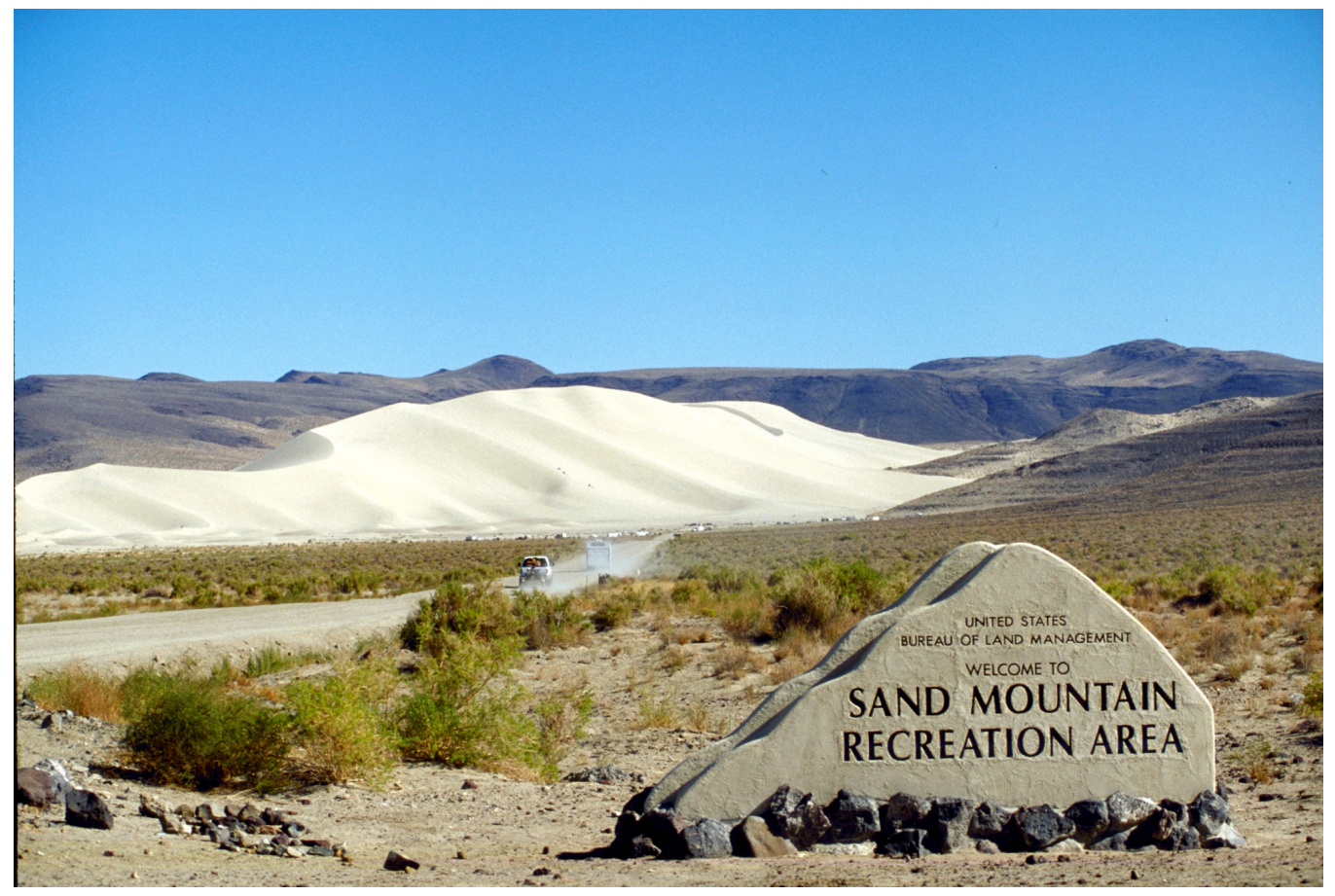

Sand Mountain Recreation Area. Photo courtesy of Bureau of Land Management, Nevada State Office.

Contact: Rudy Schuster 


\section{Decision Sciences}

In FY2012 and FY2013, FORT researchers participated in and facilitated several Decision Analysis (DA) and Structured Decision Making (SDM) trainings and workshops. DA and SDM are a set of tools and processes designed to help decision makers make better decisions, and have become an important tool in complex natural resource management decisions. SDM is a transparent process that starts by explicitly identifying the underlying values and objectives of all stakeholders involved in a problem. The process also deals explicitly with uncertainty. By analyzing each component of a problem (management objectives, decision options, and predictions of decision outcomes), the SDM process increases understanding of the underlying values of stakeholders as well as potential alternatives and tradeoffs, and ultimately improves the quality of decisionmaking. SDM workshops and trainings are offered through the National Conservation Training Center and also through individual contracts.

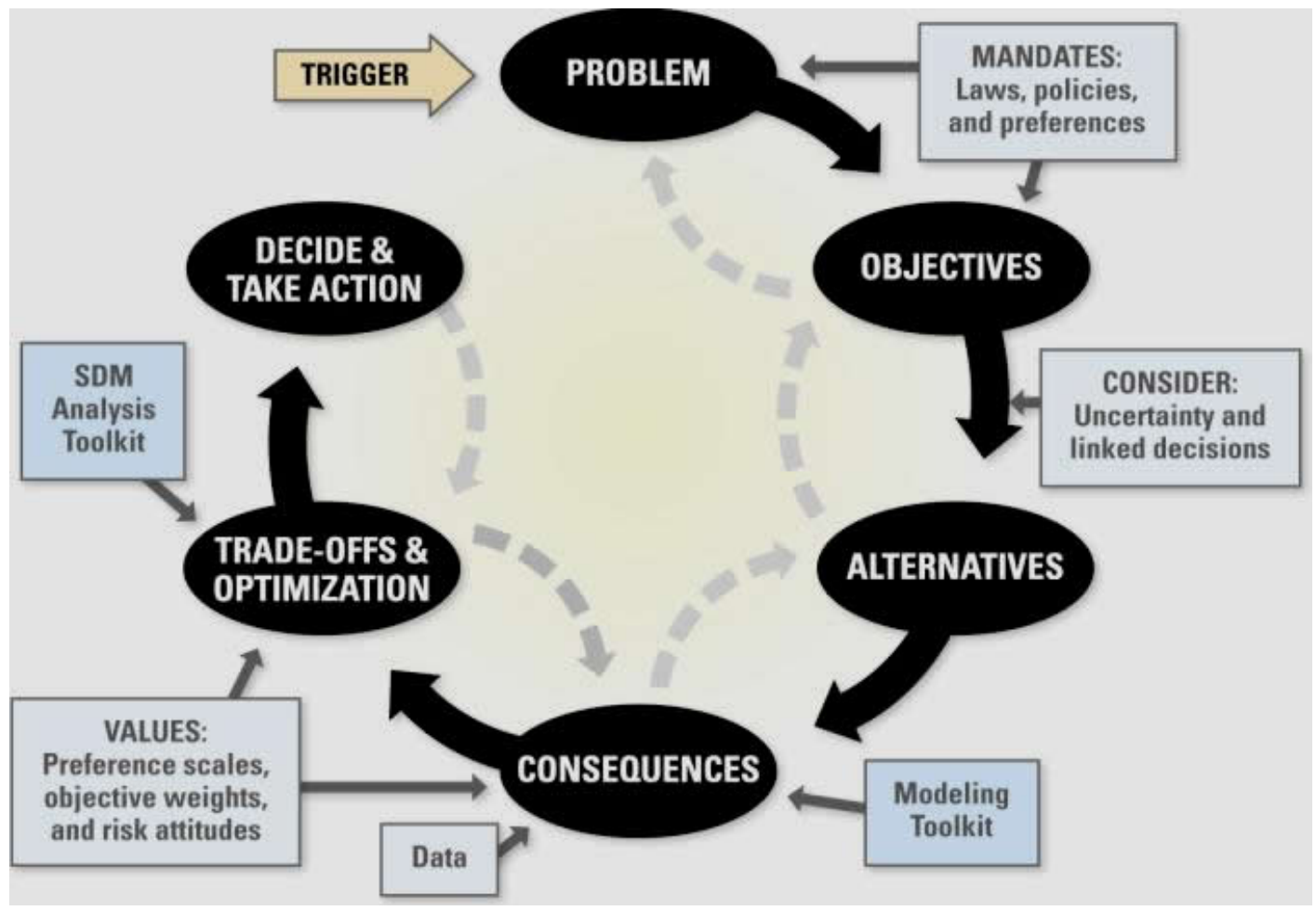

The Structured Decision Making (SDM) process involves breaking a problem into its essential components, which include (1) clearly articulating the problem, (2) identifying the fundamental objectives and desired outcomes, (3) identifying a broad range of alternative solutions to the problem, (4) building simple or complex models to estimate the consequences of each alternative on the fundamental objectives, (5) conducting a tradeoff analysis by weighing each fundamental objective, and (6) making an informed decision based on the outcome of the analysis. The SDM process is iterative and non-prescriptive. By breaking a problem into these components, decision makers are able to identify where the impediments to a decision are and focus their efforts on the right piece. The SDM analysis and modeling toolkits provide a wide array of modeling and analytical tools for dealing with each unique decision problem. Image created by Jean Cochrane.

\section{Contact: Cathy Cullinane Thomas}




\section{Dynamics of Land-Use Change and Conservation in the Prairie Pothole Region of the United States: Environmental and Economic Implications with Linkages to Rural Community Well-Being}

Rural communities in much of the United States continue to witness declines in economic indicators that are vital to sustainable community health. Decreases in the available workforce, increases in farm consolidation, higher median age, and deteriorating infrastructure are observable trends. The Prairie Pothole Region (PPR) of the United States - incorporating portions of Montana, North Dakota, South Dakota, Minnesota, and Iowa-is home to many rural communities experiencing such conditions. The region is largely dependent on the agricultural sector, yet is also known for its ecological value to migratory waterfowl and other wildlife species. Given record-high commodity prices, renewable fuels initiatives, oil and gas development, and potential legislative changes to conservation programs in the Farm Bill, land-use change in the region is imminent. Thus, it is important to understand the economic impacts that various land uses have on rural communities.

In FY2012 and FY2013, FORT economists continued to investigate these economic linkages for the Plains and Prairie Pothole Landscape Conservation Cooperative. The research over the past year included the following components:

1. A comprehensive review of land-use in the PPR, both past and present. The review addresses changes in farming, the expansion of oil and gas development, and the current distribution of perennial habitat acres in the region.

2. A description of the PPR economy and identifiable linkages to the landscape. This component includes statistics and figures outlining the role of the farm economy and the economic contribution of perennial habitat lands to the region's economy.

3. A synthesis of quantitative and qualitative findings regarding variables of rural community well-being in relation to land-use patterns. This includes income and employment effects, population and migration patterns, and levels of sustainability and resiliency.

4. A summary of lessons learned and a discussion into the future of conservation in the PPR.

The results have been compiled into a USGS Professional Paper with accompanying fact sheet. When complete, the findings of this study will help inform policymakers who are concerned with the impacts of land-use change in their local areas. The study will also qualitatively outline the economic impacts of habitat conservation in the PPR and its ties to rural community health.

\section{Products:}

Gascoigne, W.R., Hoag, D., Johnson, R., Koontz, L.M., 2013, Dynamics of landuse change and conservation in the Prairie Pothole Region of the United StatesEnvironmental and economic implications with linkages to rural community well-being: USGS Professional Paper, 1800.

Gascoigne, W.R., Hoag, D., Johnson, R.R., Koontz, L.M., Thomas, C.C., 2013, Landuse change, economics, and rural wellbeing in the Prairie Pothole Region of the United States: USGS Fact Sheet, 2013-3046.

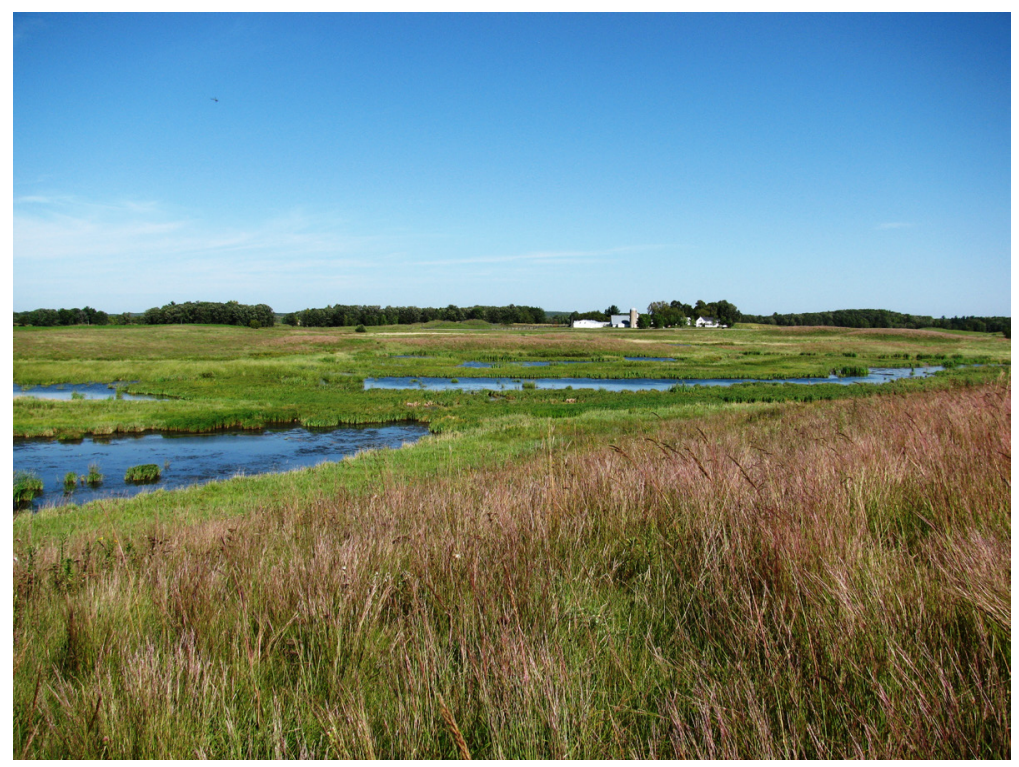

Minnesota farmland enrolled in the Wetland Reserve Program to restore grassland and wetlands. Photo courtesy of Minnesota Waterfowl Association. 
Restoration projects are underway nationwide to mitigate environmental damages and improve the health and resilience of terrestrial, freshwater, and marine ecosystems via the American Recovery and Reinvestment Act of 2009 and land-management agencies within the U.S. Department of the Interior (DOI) and U.S. Department of Agriculture (USDA). Federal investments in ecosystem restoration and monitoring protect Federal trust species, ensure public health and safety, and preserve and enhance essential ecosystem services. Furthermore, these investments provide jobs. In a climate of tightening budgets with a strong focus on job creation, there is a need to better understand the connection between restoring the health and productivity of ecosystems and the resulting economic benefits to local communities.

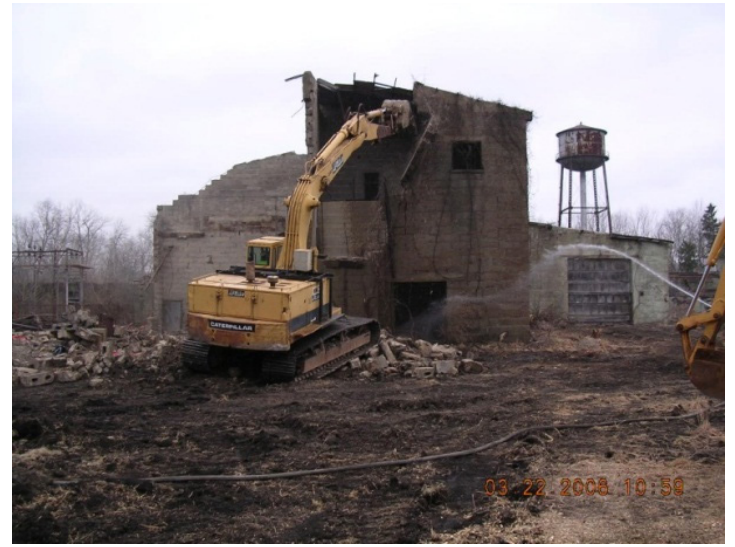

The historic Jaite Paper Mill, part of the Cuyahoga Valley National Park, was severely damaged during a fire in 1992. The National Park Service demolished the building to eliminate a human health and safety hazard, while preserving historical features for park interpretation. NPS photo.

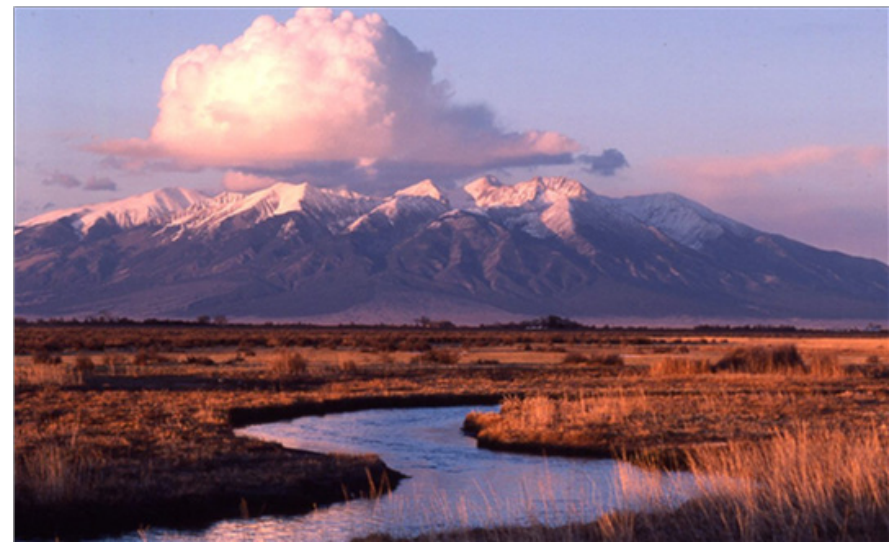

The historic Jaite Paper Mill, part of the Cuyahoga Valley National Park, was severely damaged during a fire in 1992. The National Park Service demolished the building to eliminate a human health and safety hazard, while preserving historical features for park interpretation. NPS photo.

This project is an ongoing collaborative effort that aims to increase the available information on the costs and required inputs for ecosystem restoration and the resultant economic benefits of these investments to local economies. Project collaborators include the USGS, the DOI Office of Policy Analysis, the DOI Restoration Program, and the Bureau of Land Management. The project comprises a series of case studies that quantify the economic impacts of restoration projects.

As of 2012, nine case studies of a wide range of restoration projects have been completed and published in The DOI's Economic Contributions, FY 2011 report. Over 20 additional case studies were completed in 2013 and will be incorporated into a database of impact estimates. The case studies include examples of collaboratively funded and managed projects to restore a wide range of degraded, damaged, or destroyed ecosystems. In addition to providing improved information on the economic impacts of restoration, these case studies highlight DOI restoration efforts and tell personalized stories about each project and the communities that are positively affected by restoration activities. Project methods include the collection of primary expenditure data and economic input-output modeling.

Contact: Cathy Cullinane Thomas 


\section{Evaluation of Native and Non-Native Vegetation Response to Exceptional Drought and Grazing in Southern Plains Conservation Reserve Program Field}

A cooperative study between the Farm Service Agency (FSA) and FORT was initiated to evaluate the effectiveness of USDA's requirement to seed native grasses into established, non-native Old World Bluestem Conservation Reserve Programs (CRP) fields. Successful establishment of native grasses in established Old World bluestem (Bothriochloa sp.) fields requires elimination of living and residual vegetation. Multiple years of exceptional drought in the southern plains have allowed a majority of CRP fields to be grazed under emergency conditions.

The FORT has identified multiple fields across eight southern plains counties where Old World bluestem has been the dominant cover for more than 10 years. Old World bluestem is an aggressive species that tends to become dominant in grasslands where it has been introduced. Data from an earlier study showed that CRP fields planted to bluestem and lesser amounts of native grasses in the early years of the program had become almost totally dominated by Old World bluestem by the time the fields were 10 years old. FORT will revisit and sample some of these same fields to (1) assess the cumulative effects of extreme drought and grazing on the vegetation community and structure, (2) determine whether those effects are homogeneous, and (3) assess whether these fields continue to provide valuable cover for wildlife and prevent erosion.

FORT will conduct a systematic analysis of differences in the performance of native and introduced CRP plantings under drought conditions to provide information that will help the Farm Service Agency (FSA) refine CRP implementation in a region susceptible to drought. The results will help USDA better understand how to (1) employ grazing as a management tool to refine long-term management of CRP grasslands, and (2) meet high-plains steppe ecological conditions and structural vegetative needs for wildlife species adapted to the shortgrass ecosystem. A summary of the 2012-2013 data will be provided to FSA.

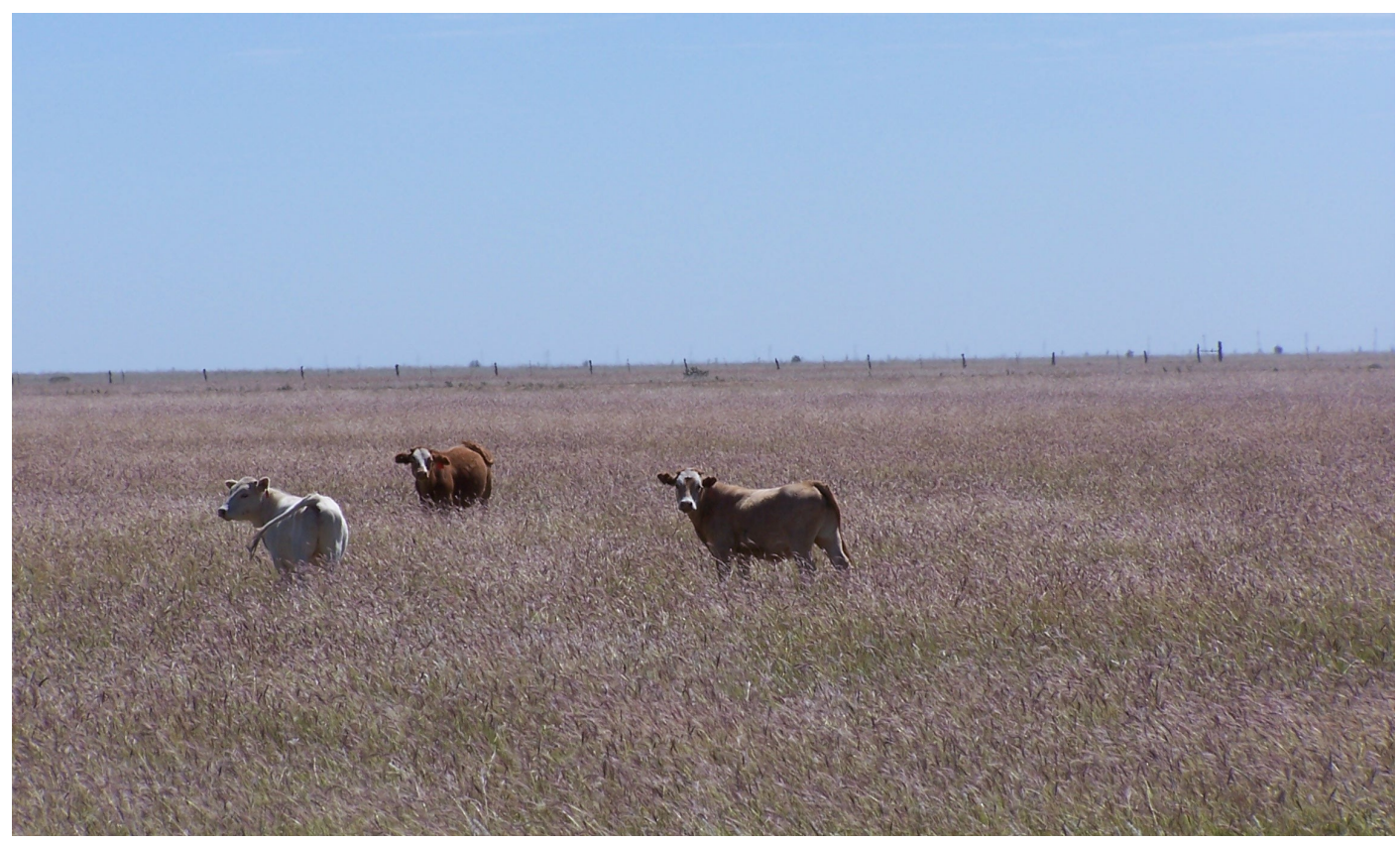

Cows grazing an Old-World bluestem CRP field in the Texas Panhandle. Photo by Mark Vandever, USGS. 


\section{Negotiation Training}

Negotiation is a part of everyday professional life for many employees of Federal and State natural resource management or science agencies. Many Federal statutes require agencies to engage with a variety of stakeholders, including other agencies, as management plans or regulations are developed. Scientists negotiate with their counterparts about what studies to conduct and how to interpret the data. Supervisors and those they oversee negotiate about performance plans and other matters. Public employees are required to achieve "good outcomes"- those that maximize service to the public, are efficient, and uphold agency missions. Developing negotiation skills is one way to increase the likelihood of successful outcomes.

FORT scientists have been conducting research on multi-party natural resource negotiation since the 1980s and using the findings from this research to develop negotiation classes that are targeted to meet the needs of Federal and State natural resource personnel. Currently, two classes are taught annually at FORT: (1) Negotiation Skills for Natural Resource Professionals-Building a Foundation, and (2) Strategies and Tactics for the Experienced Natural Resource Negotiator. Additionally, the FORT staffer leading this project also is an instructor for the "Negotiation and Conflict Resolution" segment of the USGS Leadership 101 class, taught twice per year at the National Conservation Training Center in West Virginia. She also assists in teaching negotiation classes sponsored by the Ruckelshaus Institute at the University of Wyoming.

The classes taught at FORT include participants from a wide variety of agencies and locations. In 2012 and 2013, our enrollees included representatives from the Arizona Game and Fish Department, Bureau of Reclamation, City of Boulder: Parks and Recreation, Colorado Department of Parks and Wildlife, Colorado Department of Transportation, Colorado Geological Survey, Minnesota Department of Natural Resources, Missouri Department of Conservation, National Oceanic and Atmospheric Administration/National Marine Fisheries Service, National Park Service, Oregon Department of Fish \& Wildlife, State of Colorado: Department of Natural Resources, USDA Animal and Plant Health Inspection Service (APHIS) and USDA Forest Service, U.S. Fish and Wildlife Service, USGS, and Wyoming Department of Environmental Quality. The Leadership 101 classes include participants from all USGS Mission Areas and regions. One thing that we are often told by students is that it is highly beneficial for them to interact with those from other agencies and locations in a learning (as opposed to a decisionmaking) environment. Students consistently give a high rating to the negotiations classes.

"Greatly appreciate the resources and the expertise! Thank you-I have a great foundation to build on as I grow in my negotiation interactions."

-2012 Building a Foundation participant

\section{Contact: Nina Burkardt}




\section{Science in Support of Policy: The Interactive Effects of Climate Change and Reactive Nitrogen on U.S. Aquatic Ecosystems and Water Resources}

Water resources in the United States are at risk from multiple stressors. Two important stressors that occur simultaneously and are interactive include climate change and excess reactive nitrogen (Nr). Two new publications show that effects of climate change on U.S. water resources are already evident, caused by altered precipitation patterns, intensity, and type; occurrence of drought; increased evaporation; warming temperatures; changes in soil moisture and runoff; and changes in ocean circulation. At the same time, the Nation's waters are biologically and chemically responsive to the influx of reactive nitrogen that now pervades most freshwater and coastal ecosystems.

As part of a National Science Foundation Research Coordination Network (RCN) on Reactive Nitrogen in the Environment, FORT scientists led a comprehensive synthesis in FY2012 of what is known about how climate change will interact with already extensive nitrogen pollution in the Nation's freshwaters and estuaries. The products were a major contribution to the U.S. National Climate Assessment and a special issue of Biogeochemistry. Some major adverse effects of $\mathrm{Nr}$ include harmful algal blooms, hypoxia of fresh and coastal waters, ocean acidification, long-term harm to human health, and increased emissions of greenhouse gases. Denitrification and sedimentation of organic nitrogen $(\mathrm{N})$ to sediments are important processes that divert $\mathrm{N}$ from downstream transport and reduce the pollution impact. In doing so, however, they may increase emissions of greenhouse gases. Aquatic ecosystems are particularly important denitrification hotspots. Carbon storage in sediments is enhanced by $\mathrm{Nr}$, but whether carbon is permanently buried is unknown. The effect of climate change on $\mathrm{N}$ transport and processing in fresh and coastal waters will be felt most strongly through changes to the hydrologic cycle; $\mathrm{N}$ loading is mostly climate independent.

Both infrastructure and climate change alter the landscape connectivity and hydrologic residence time that are essential to denitrification. While $\mathrm{Nr}$ inputs to and removal rates from aquatic systems are influenced by climate and management, reduction of $\mathrm{N}$ inputs from their source will be the most effective means to prevent or minimize environmental and economic impacts of excess $\mathrm{Nr}$ to the nation's water resources.

\section{$\mathrm{N}_{2} \mathrm{O}$ Production in Freshwaters}

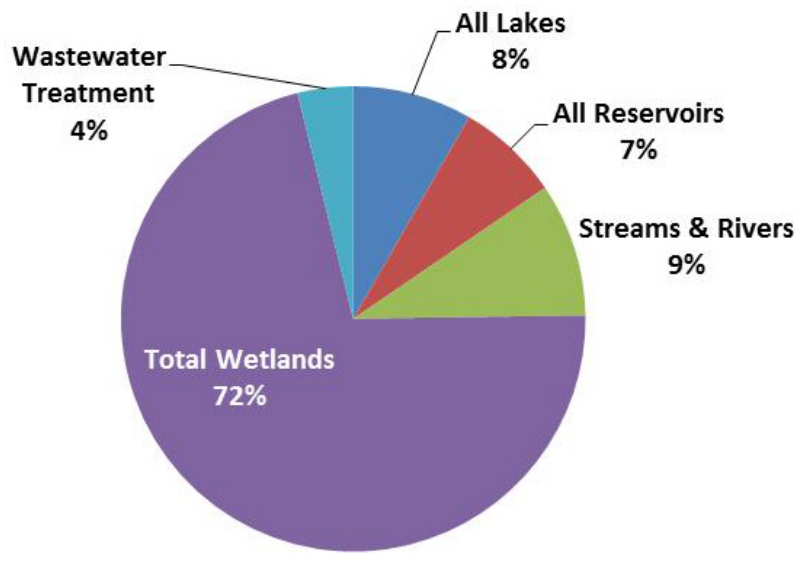

\begin{tabular}{|l|c|}
\hline \multicolumn{1}{|c|}{ System } & \multicolumn{1}{|c|}{$\begin{array}{c}\text { Percent of } \\
\text { Total } \\
\text { Denitrification }\end{array}$} \\
\hline Continental Shelf & 44 \\
\hline Terrestrial Soils & 22 \\
\hline $\begin{array}{l}\text { Freshwaters (GW, } \\
\text { lakes, rivers) }\end{array}$ & 20 \\
\hline $\begin{array}{l}\text { Ocean Oxygen } \\
\text { Minimum Zone }\end{array}$ & 14 \\
\hline Estuaries & 1 \\
\hline
\end{tabular}

\section{Products:}

Baron, J.S., Hall, E.K., Nolan, B.T., Finlay, J.C., Bernhardt, E.S., Harrison, J.A., Chan, F., and Boyer, E.W., 2012, The interactive effects of excess reactive nitrogen and climate change on aquatic ecosystems and water resources of the United States: Biogeochemistry, v. 114, nos. 1-3, p. 71-92.

Suddick, E., and Davidson, E.J., eds., 2012, The role of nitrogen in climate change and the impacts of nitrogen-climate interactions on terrestrial and aquatic ecosystems, agriculture and human health. A technical report submitted to the US National Climate Assessment: Falmouth Mass., North American Nitrogen Center of the International Nitrogen Initiative. Woods Hole Research Center, online at http://nitrogennorthamerica.org/pdf/NxCC_NCA_report_2012.pdf.

Contact: Jill Baron 


\section{Ecosystems-Terrestrial, Freshwater, and Marine Environments}

\section{Bison, Elk, and Vegetation Ecology in the Great Sand Dunes Ecosystem}

The acquisition and establishment of Great Sand Dunes National Park and Preserve and the new Baca National Wildlife Refuge in the San Luis Valley of Colorado was one of the most significant land conservation actions in the U.S. West in recent years. These actions were the result of cooperation between the National Park Service (NPS), U.S. Fish and Wildlife Service (FWS), Bureau of Land Management (BLM), Forest Service (FS), and The Nature Conservancy. The area encompassed by the park and refuge protects a number of natural wonders and features, including a unique ecosystem of natural sand dunes, the surface and ground waters that are necessary to preserve the dunes and recharge adjacent wetlands, a unique stunted forest, and other valuable riparian vegetation communities that support a host of associated wildlife and bird species. Until our project began, however, there had been no formal research on the ecology, forage relations, population dynamics, or habitat relations of elk and bison in the Great Sand Dunes-Sangre de Cristo-Baca area. The primary purpose of this project was to provide science-based information needed by Federal land managers to help them understand how elk and bison herbivory affect vegetation in the Great Sand Dunes ecosystem, and provide a science foundation for the development of their ungulate management plan.

To that end, FORT ungulate ecologists conducted a 5-year field study in the Great Sand Dunes ecosystem of the arid San Luis Valley to ascertain plant responses to herbivory and identify potential constraints on plant compensation. More specifically, the study entailed comparing plant responses in grazed and ungrazed areas used by elk and bison with grazed and ungrazed areas used only by elk. Fenced exclosures were established to serve as the ungrazed treatments, and to test theory on grazing optimization and plant compensation. Arid systems pose challenges to grazing theory because it is assumed that external factors, such as moisture, have more dominant roles than internal interactions, such as herbivory.

In FY2012 and FY2013, the data analyses were completed and Kate Schoenecker's associated Ph.D. dissertation was published. Additionally, the project report to the NPS was completed. Results of this work indicated that grazing effects varied between woody and herbaceous species. Responses of herbaceous vegetation to grazing indicated that there is overcompensation for tissue losses, and responses of woody vegetation indicated that water and climate may influence these plants more strongly than herbivory, particularly as it relates to recruitment and density. In fact, the measurements of cottonwood stand age structure indicated that recruitment has been lacking for some time. The NPS and FWS are already using this crucial information for guiding their landmanagement efforts in the Great Sand Dunes ecosystem, and as the foundation for the park's Ungulate Management Plan. In addition, it is providing the needed science information to managers making decisions about potentially restoring bison to the San Luis Valley ecosystem.

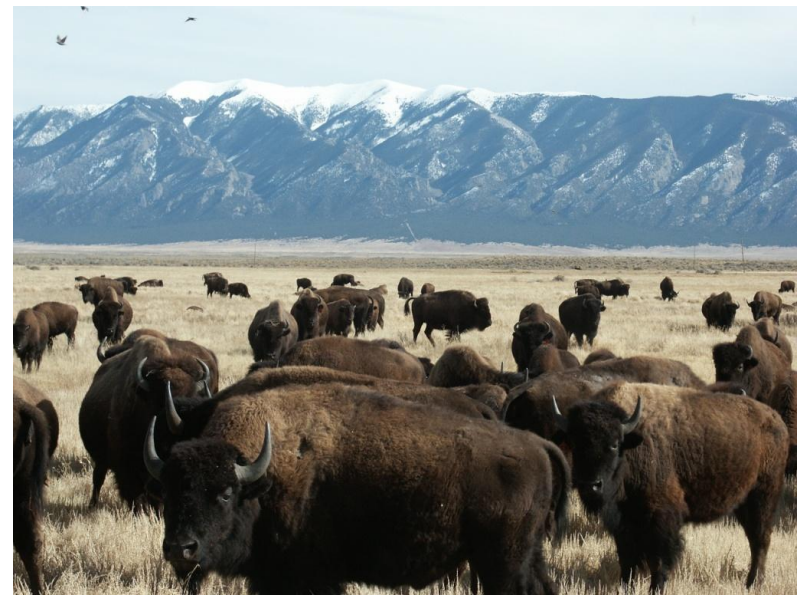

Bison grazing against a backdrop of the Sangre de Cristo Mountains. Photo by Kate Schoenecker, USGS.

\section{Product:}

Schoenecker, K.A., 2012, Bison, elk and vegetation ecology in an arid ecosystem: Fort Collins, Colo., Colorado State University, Ph.D. Dissertation.

Contact: Kate Schoenecker 


\section{Developing a More Accurate Aerial Population Survey Technique for Elk in Rocky Mountain National Park, Colorado}

Over the past decade, a large amount of effort and funding was expended to conduct research and develop the 20-year Elk and Vegetation Management Plan for Rocky Mountain National Park (RMNP). A number of management activities have been implemented to address different aspects of the Management Plan. The elk population size has been reduced with guided culling, aversion techniques have been used to redistribute elk and reduce habituation, and temporary fences were built to protect aspen and willow. The goal of the plan is to have a target population size that falls within the natural range of variation, with lower elk densities and up to 860 acres of aspen and willow protected from herbivory until full restoration is achieved. An education program was established to inform stakeholders of the need for management action and ongoing results.

To implement the management actions called for in the plan, accurate and reliable population estimates were needed to guide elk reductions over the course of the plan. Inaccurate population estimates or incomplete understanding of the spatial-temporal distribution patterns could result in substantially missing the target population levels, with potentially long-term effects on herds or ecosystems.

The core of this project was the development of an exact set of procedures most appropriate for the elk population and survey conditions in RMNP. We began by evaluating and selecting revised aerial survey procedures appropriate for the difficult, high altitude terrain in RMNP. We developed these procedures based on published and other well-established and tested techniques in a collaborative effort between statistical, field, and management specialists to ensure that the Plan met theoretical assumptions for statistical validity and practical requirements for application in the field, as well as complying with all park management needs and safety requirements. Past survey data from this population and the expertise of the same personnel who have conducted and analyzed previous surveys were used as the basis for developing the initial survey plan. Our survey design evolved over the course of the study based on information gained from telemetry data as it became available and through feedback from the aerial observers as they tested the survey design with each flight. After each survey, the data were analyzed and the plans and procedures for the next survey were adjusted as necessary based on the information gained. Thus, the overall procedure was an adaptive, iterative approach of survey design and planning followed by execution, testing, analysis, and refinement of the plans and procedures.

In FY2012, we conducted the data analyses for this project, and the final report was completed in FY2013.
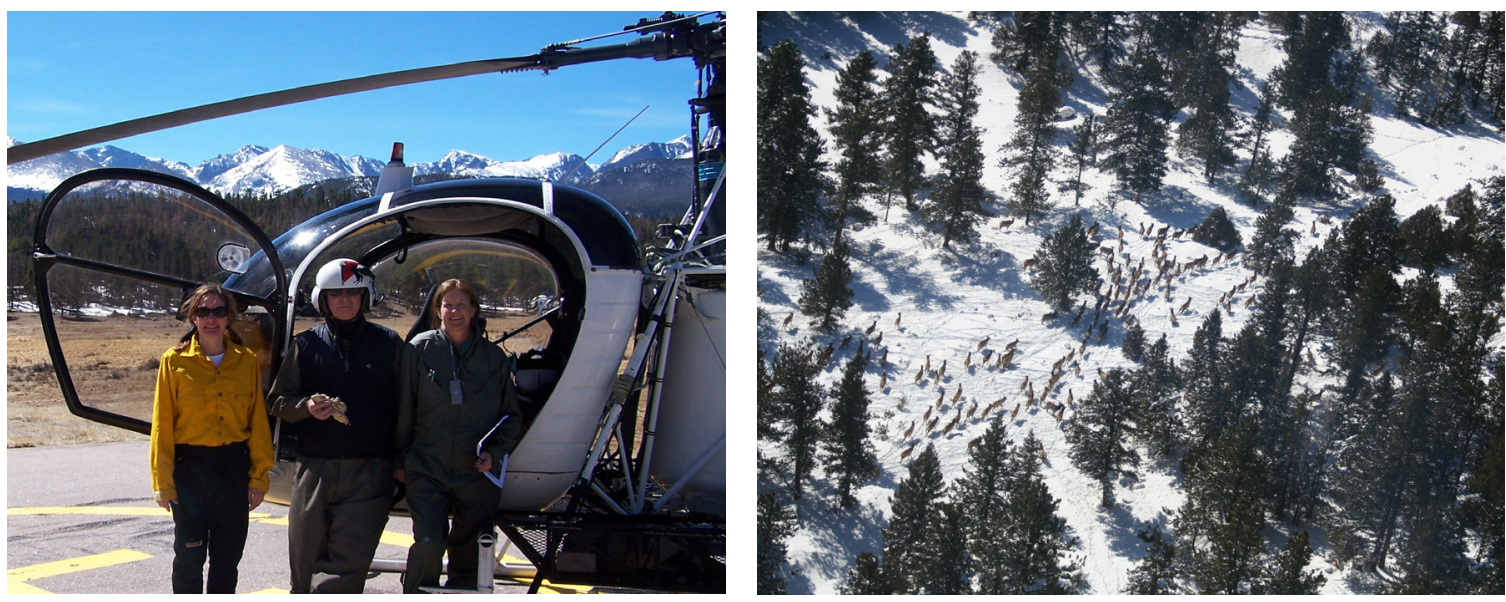

Principal investigator, Kate Schoenecker (left), pilot, and Resource Manager Johnson of RMNP completing an aerial helicopter survey (left). Elk running through tree cover during an aerial survey (right). Photo credits: USGS (left), Kate Schoenecker (right).

Contact: Kate Schoenecker 


\section{Sandhill Cranes in Colorado's San Luis Valley: Exploring New Technology for Improved Population Assessments}

The U.S. Fish and Wildlife Service (FWS), Division of Migratory Bird Management, seeks alternatives to manned, fixed-wing aerial surveys for some of their wildlife monitoring to reduce (1) costs, (2) the number of manned flights by having an alternative method for new survey efforts in the future, and (3) the amount of fuel needed to conduct surveys to lessen their carbon footprint. The FWS selected the sandhill crane (Grus canadensis) project to explore new ways of assessing the bird's abundance on the Monte Vista National Wildlife Refuge (NWR) in Colorado. Building on the success of the 2011 flights - which proved the Raven-A small Unmanned Aerial System (sUAS) to be a nonintrusive, safe, and accurate way to estimate sandhill crane populations — nighttime flights over five roosts at Monte Vista NWR were conducted in March 2012. These flights were the first FAA-approved sUAS night flights in the United States. Nighttime flights over sandhill cranes at Monte Vista NWR resulted in several immediate benefits, including minimizing the potential for mid-air conflicts between cranes and the aircraft, minimizing double-counting of cranes, and minimizing impacts to refuge visitors.

Additionally, in 2012, crane feathers were collected for DNA and stable isotope analysis. The goal of this analysis is to identify the proportion of the migrating crane population at Monte Vista NWR as either the greater (G. c. tabida) or lesser (G. c. canadensis) sandhill crane subspecies. By identifying the proportion of these subspecies in the migrating population, managers will better understand differences in ecological and resource use between the crane subspecies. This improved understanding will lead to better overall population management relating to the availability of habitat and food resources on critical crane breeding, migrating, and wintering areas.

The results of these studies will affect future wildlife-abundance projects. This research combines emerging remote-sensing and laboratory technologies that will result in improved and safer wildlifepopulation survey techniques, as well as new ways to analyze crane feathers for subspecies identification. Collaborators and cooperators include the USGS Unmanned Aircraft Systems (UAS) Project Office, FWS Region 6, FWS Division of Migratory Bird Management, and Monte Vista NWR.
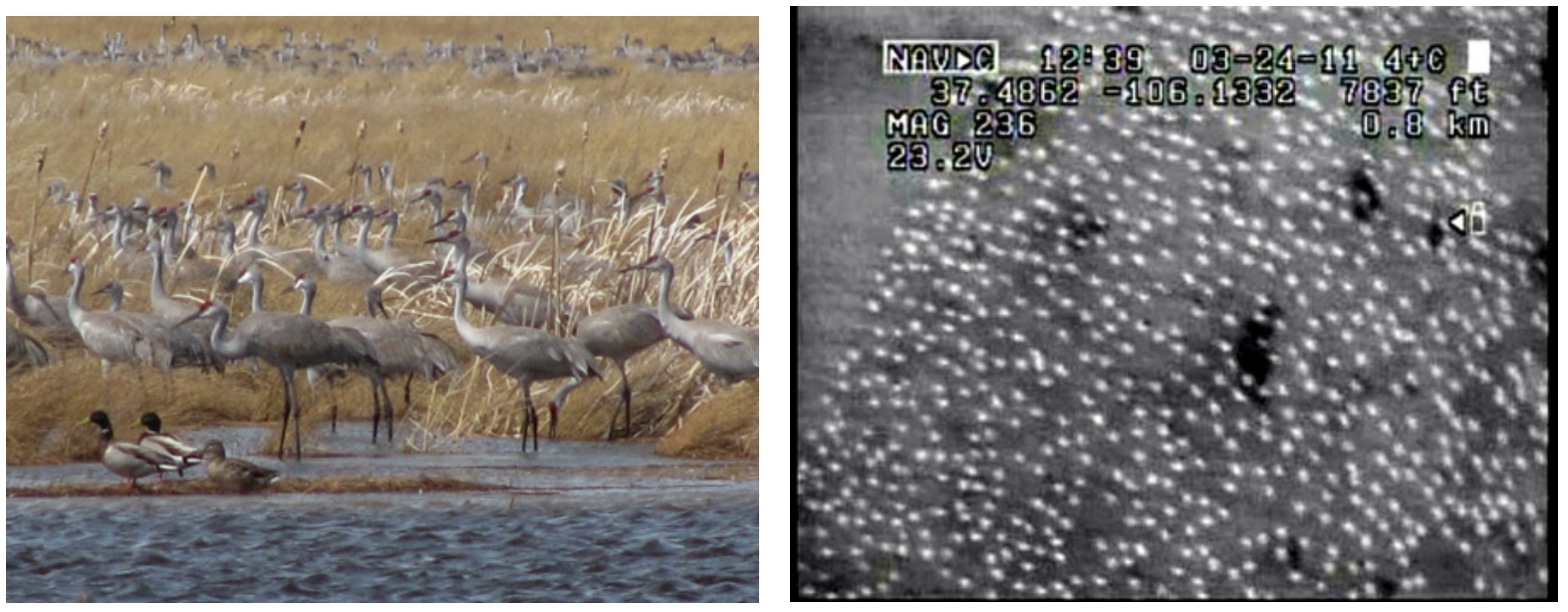

(Left) Sandhill cranes at Monte Vista National Wildlife Refuge, up close and personal. (Right) Sandhill cranes (white dots) as seen from the airborne Raven A using the infrared camera. USGS photos.

Contact: Leanne Hanson 


\section{Woody Riparian Vegetation at Streamgages}

An extensive dataset on the occurrence and dominance of trees and shrubs near streamgages in the western United States was finalized and distributed in 2012 (Auble and others, 2012). Identifying and quantifying relationships between streamflow and vegetation has been an important focus of riparian ecology work at the FORT for more than two decades. Much of that work has been done at a small set of intensively studied sites where specific alterations in streamflow have been made or proposed. Applying the results of these studies of restricted areas to new locations continues to be a challenge.

One approach to identifying general patterns is to examine spatially extensive datasets of riparian vegetation with species-level resolution, consistent methods, and concomitant long-term hydrologic records. In order to develop this kind of dataset, over a number of years we visited and recorded riparian vegetation associated with more than 450 streamgages across 17 states in the western United States.

FORT riparian ecologists have used this dataset to characterize the importance of non-native trees in the current western riparian forests and to analyze the distribution of selected riparian trees with respect to climatic variables (Friedman and others, 2005). Parts of the dataset have also been used in work focused on individual species (Guilbault and others, 2012; Nagler and others, 2011) and to supplement other distributional data compilations (Jarnevich and Reynolds, 2010). We continue to use the dataset to evaluate the consistency of hypotheses generated from intensive studies with broad-scale patterns and have made it available in electronic format to facilitate use by others.

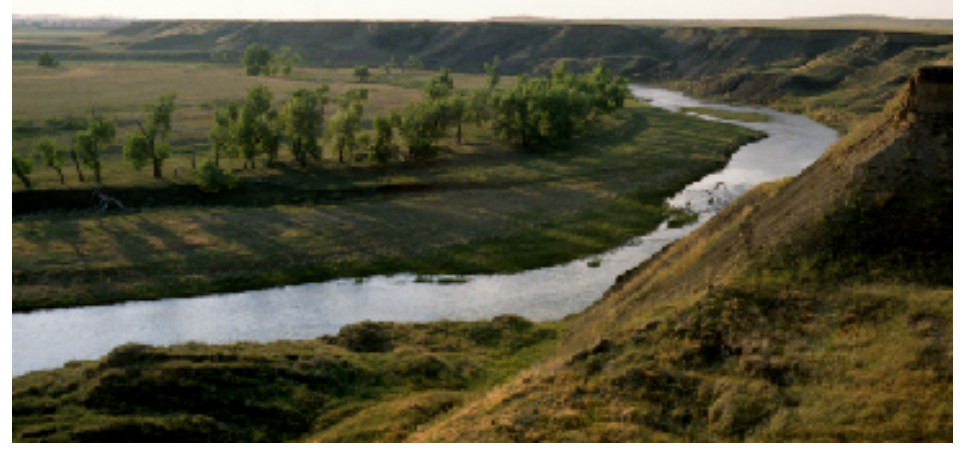

Belle Fourche River, South Dakota. Photo by M.F. Merigliano.

\section{Products and References:}

Auble, G.T., Friedman, J.M., Shafroth, P.B., Merigliano, M.F., and Scott, M.L., 2012, Woody riparian vegetation near selected streamgages in the western United States: U.S. Geological Survey Data Series 708, $8 \mathrm{p}$.

Friedman, J.M., Auble, G.T., Shafroth P.B., Scott, M.L., Merigliano M.F., Freehling M.D., and Griffin E.R., 2005, Dominance of non-native riparian trees in western USA: Biological Invasions, v. 7, p. 747-751.

Guilbault, K.R., Brown C.S., Friedman J.M., and Shafroth, P.B., 2012,. The influence of chilling requirement on the southern distribution limit of exotic Russian olive (Elaeagnus angustifolia) in western North America: Biological Invasions, v. 4, p. 153-163.

Jarnevich, C.S. and Reynolds L.V., 2010, Challenges of predicting the potential distribution of a slowspreading invader-A habitat suitability map for Russian olive (Elaeagnus angustifolia) in the western United States: Biological Invasions, v. 13, p. 153-163.

Nagler, P.L., Glenn E.P., Jarnevich C.S., and Shafroth P.B., 2011, Distribution and abundance of saltcedar and Russian olive in the western United States: Critical Reviews in Plant Sciences, v. 30, p. 508-523.

\section{Contact: Greg Auble}




\section{NEWJ Microbial-Driven Nitrogen Cycling in Aquatic Alpine Ecosystems}

Alpine ecosystems along the Colorado Front Range, and generally across the mountain West, are showing signs of ecosystem-level effects of atmospheric nitrogen deposition. Identifying which part of the ecosystem controls the supply of nitrate to alpine surface waters has important implications for how alpine ecosystems across the mountain West are being altered in the face of global change. This level of understanding is key to essential policy and management decisions in and around our national parks. Loch Vale Watershed (LVWS) within Rocky Mountain National Park is a long-term ecological research site that has been studied for more than 30 years. Nitrate $\left(\mathrm{NO}_{3^{-}}\right)$concentrations have been rising in LVWS and may be the cause of pronounced benthic algal blooms that were observed for the first time during the summers of 2011 and 2012 (see photographs below). Using long-term data on precipitation and surface water chemistry, and sampling of microbial communities conducted over the past two years, FORT scientists are investigating the proximate source of the relatively high $\mathrm{NO}_{3}$ - concentrations and its hypothesized association with the algal productivity in aquatic ecosystems of the LVWS.

In FY2011 and FY2012, FORT scientists collected precipitation from four sites: two National Atmospheric Deposition Sites (NADP CO89 and CO98) within the watershed, a snow pit dug in May below tree line, and an alpine snowfield in September. In FY2011 and FY2012 and FY2013, we also collected surface water and sediment samples four times during the ice-free season from multiple surface water sites within LVWS. We used dual $\left({ }^{15} \mathrm{~N},{ }^{18} \mathrm{O}\right)$ isotope analysis of $\mathrm{NO}_{3}$ - to evaluate whether $\mathrm{NO}_{3}$ - in the watershed was arriving in precipitation and accumulating (inert), or whether ammonium was being converted to $\mathrm{NO}_{3}$ - by bacteria and archaea (reactive). We also used a suite of molecular methods to analyze sediment and microbial community structure in the water column.

The two pools of $\mathrm{NO}_{3}$ - (rain and snow) did not overlap in oxygen isotope concentration. This suggests that the nitrate in the surface water had been nitrified by microorganisms and was distinct in origin from $\mathrm{NO}_{3}$ - in precipitation. In addition, the surface waters became increasingly depleted in ${ }^{18} \mathrm{O}$, suggesting an increasing contribution of nitrification to the dissolved $\mathrm{NO}_{3}$ - pool as the season progressed. Analyses of microbial communities throughout the watershed show evidence for enrichment of nitrogen in the alpine region relative to the systems lower in the watershed. This suggests that microorganisms proximately control the delivery of $\mathrm{NO}_{3}$ - to surface waters, and understanding their controls will ultimately lead to a more robust understanding of ecosystem dynamics.
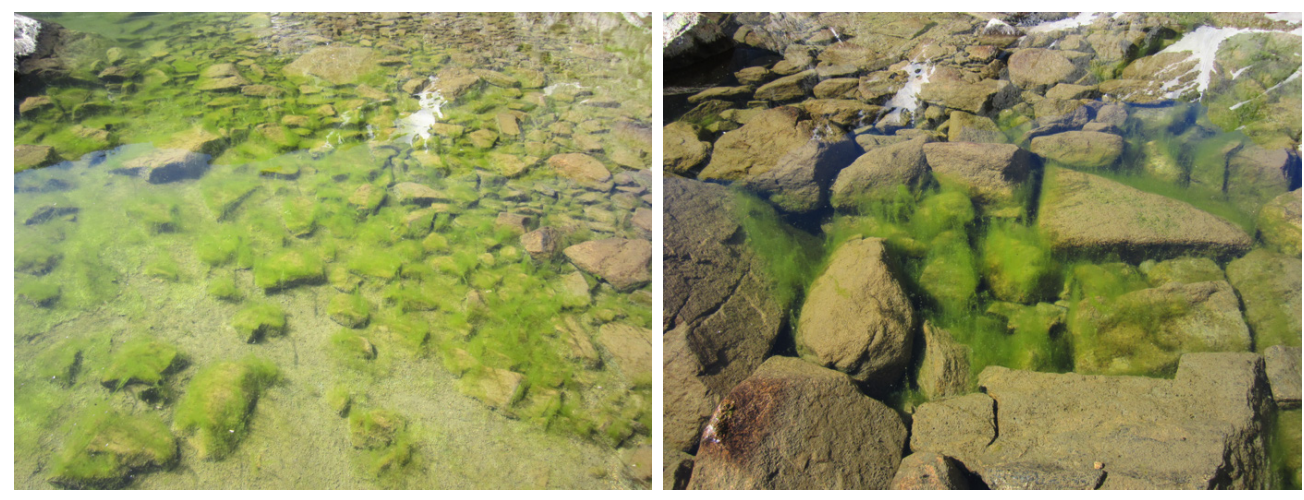

Photographs of algal blooms occurring in surface waters of the Loch Vale Watershed, Rocky Mountain National Park, Colorado. Photos by Jared Heath.

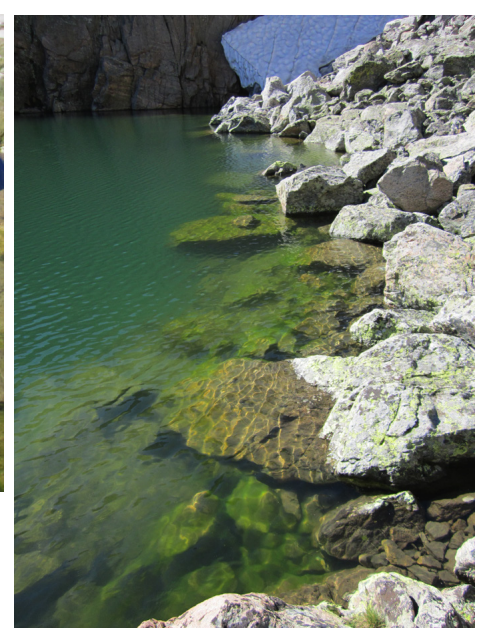

\section{Product:}

Hall, E.K., and Baron, J.S., 2012, The role of nitrifiers in accumulating $\mathrm{NO}_{3}$ - in the surface waters of Rocky Mountain National Park: Oral presentation to the Ecological Society of America Portland, Ore., August 6-10, 2012.

Contact: Ed Hall 


\section{Disturbance and Reclamation Tracking}

As part of their land management efforts, the Bureau of Land Management (BLM) receives thousands of documents, datasets, images and requests for information on natural gas extraction activities. To assist the BLM with this data-management challenge, the USGS Fort Collins Science Center Web Applications Team has developed a Web-based application designed to collect, store and organize the information that BLM offices use to track disturbances and assess reclamation efforts in natural gas fields. The information provided by the system supports decisionmaking regarding reclamation activities associated with oil and gas activities.

Initial work on a common framework that can be used by multiple offices began in FY 2010 with help from the Jonah Interagency Office and the Pinedale Anticline Project Office. The system was designed to help determine whether (1) interim and long-term requirements and criteria were being met, (2) reclamation and monitoring protocols were providing appropriate and sufficient information, and (3) data were being collected as specified. In FY2012 and FY2013, using the same framework, the project expanded to assist the White River Field Office and the Green River District Office of the BLM with their tracking efforts.

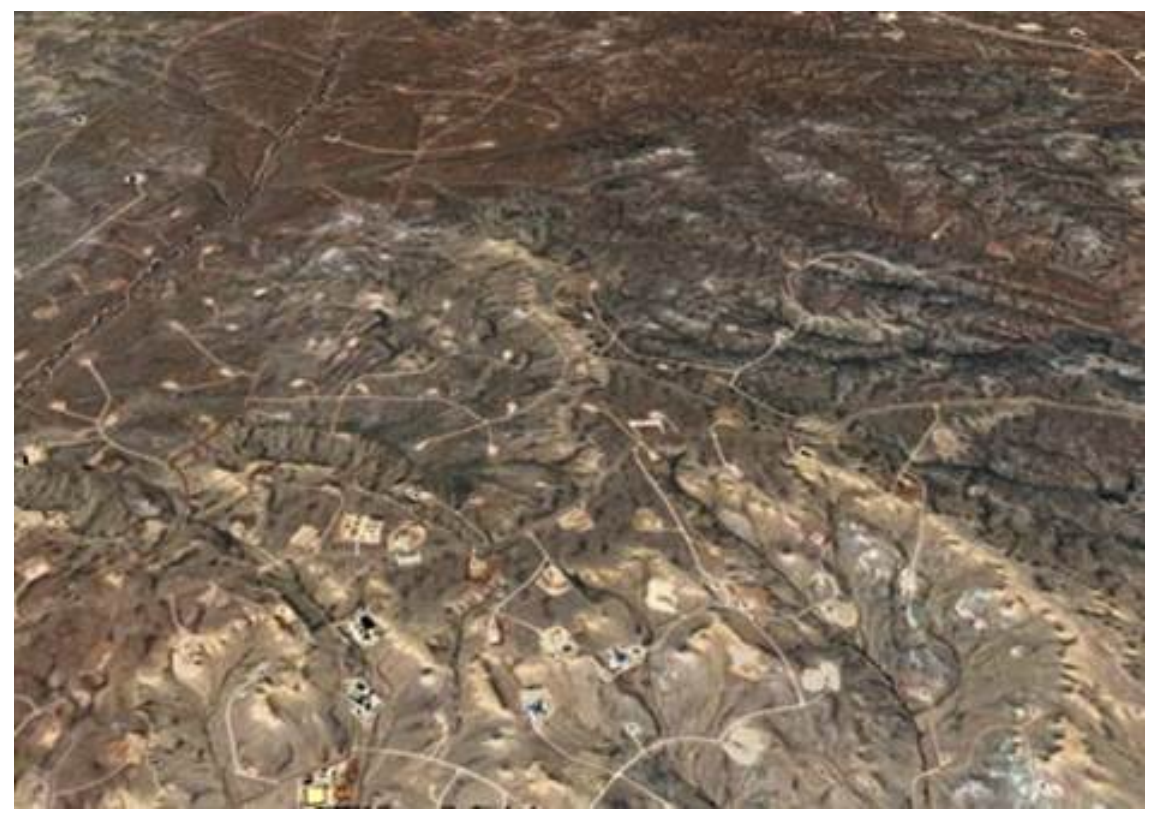

Jonah Infill. Imagery courtesy of the USDA Farm Services Agency, acquired via Google Maps.

\section{Products:}

https://my.usgs.gov/jio/

http://my.usgs.gov/papo/

https://my.usgs.gov/wrdms/

https://my.usgs.gov/green_river/

\section{Contact: Gail Montgomery}


The mission of the Wyoming Landscape Conservation Initiative (WLCI) is to implement a longterm, science-based program of assessing, conserving, and enhancing fish and wildlife habitats while facilitating responsible energy and other development through local collaboration and partnerships. Formal partners in the WLCI include the Bureau of Land Management, USGS, U.S. Fish and Wildlife Service, the Wyoming Game and Fish Commission, the Wyoming Department of Agriculture, the Forest Service, six Wyoming County Commissions, and nine Wyoming Conservation Districts. The role of the USGS as a partner in the WLCI is to provide multidisciplinary scientific and technical assistance to WLCI partners and to advance the overall scientific understanding of ecosystems in southwestern Wyoming.

In 2012, FORT and other USGS scientists, along with WLCI partners, completed and deployed the web application for the initial multi-resource Integrated Assessment (IA) for the WLCI area. The IA is intended to inform planning and decisionmaking in southwestern Wyoming. The IA evaluates the context for energy development and other land uses, with a focus on informing conservation actions and decisions. Specifically, the IA can be used to identify areas with high potential for conservation, restoration, and (or) development, based on current and potential land-use scenarios. This assessment takes into account both conventional and renewable energy resources, with special focus on natural gas and wind energy due to the current growth and future potential for developing them within Wyoming. The IA was presented in several meetings with different audiences in Wyoming and Colorado, including at the 2012 WLCI Science Workshop in Rock Springs, Wyo. Also in 2012, USGS Data Series 700 on the IA was published.

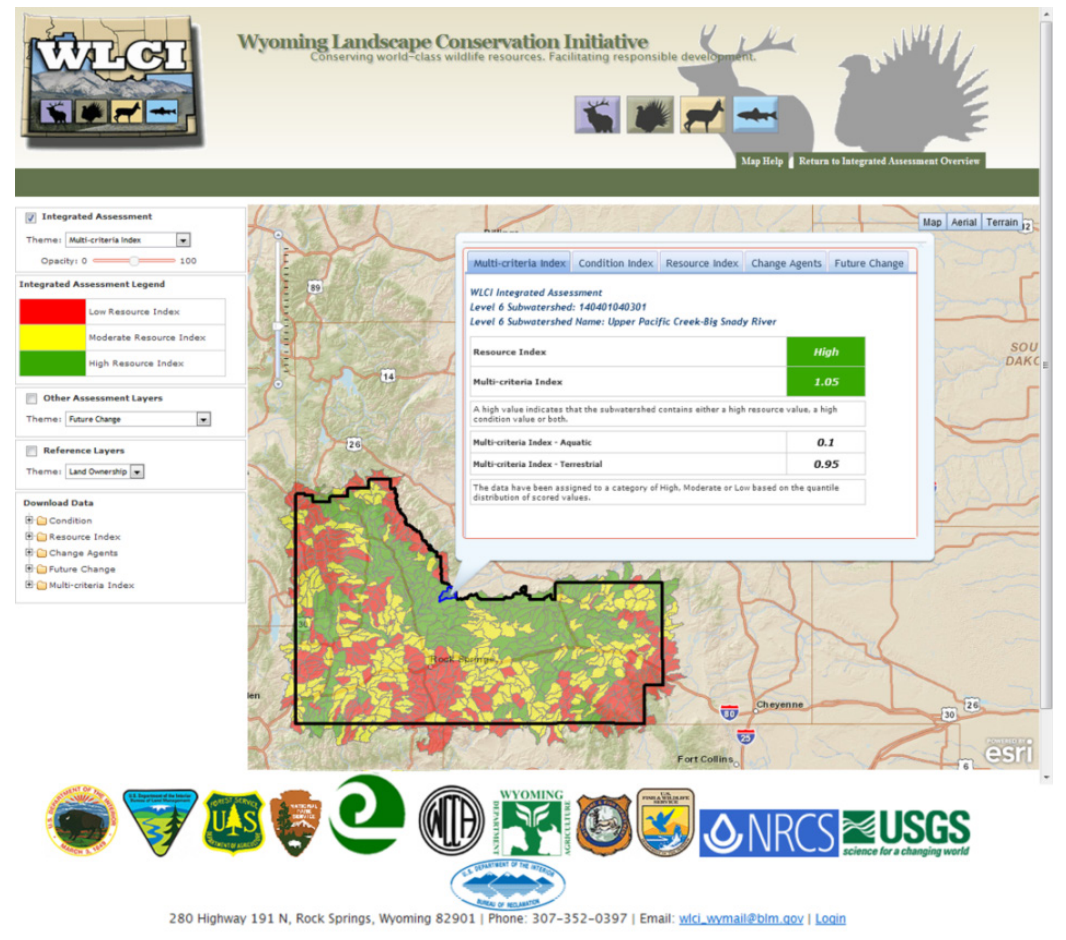

\author{
Screen capture of the Web application \\ for the WLCI Integrated Assessment. The \\ application allows users to view and \\ explore results and download data used \\ in the assessment. USGS image.
}

\title{
Products:
}

Assal, T.J., Garman, S.L., Bowen, Z.H., Anderson, P.J., Manier, D., and McDougal, R.R., 2012, Data

Resources for the Wyoming Landscape Conservation Initiative (WLCI) Integrated Assessment (IA): U.S. Geological Survey Data Series 700, at http://www.fort.usgs.gov/products/publications/pub_abstract.asp?PubID=23486.

Integrated Assessment for WLCI, Web Application, at http://my.usgs.gov/wlciIA/.

Contact: Zack Bowen 


\section{Assessing Effects of Energy Development in Colorado and New Mexico}

An interdisciplinary team of USGS scientists is working to provide land-management agencies and decisionmakers with synthesized information and comprehensive, virtual tools to promote an understanding of the tradeoffs of energy development. Increased demand for energy is driving rapid development of renewable and nonrenewable energy throughout the western United States. Much of the development is occurring on public land, which constitutes about 40 percent of the land area in Colorado and New Mexico. Both of these states benefit from revenues generated by energy development, but resource managers and other decisionmakers must balance the benefits and potential effects of development on historic, scenic, recreational, and ecological resources.

This project entails compiling information on existing energy development and potential energy development across Colorado and New Mexico. In FY2011, FORT scientists digitized the location of wind turbines for these states and published this information in 2011 as separate USGS Data Series reports. In FY2012 and FY2013, we updated the Colorado and New Mexico wind turbine Data Series Reports. In addition, we developed a USGS Data Series on the locations of solar facilities in Colorado and New Mexico. To provide this spatial information to decision-makers and resource managers, in

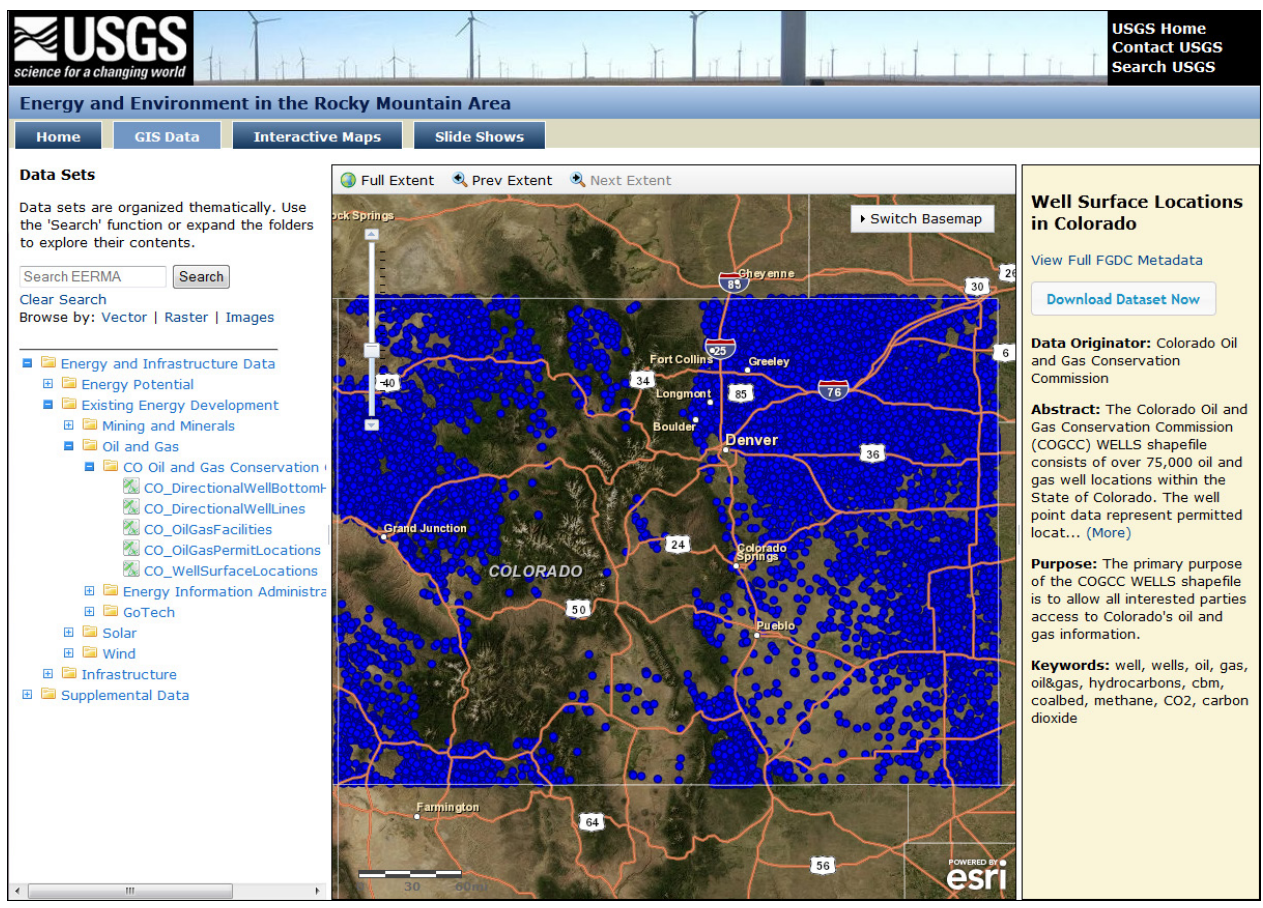

The Data sets page of our interactive, online Energy Atlas for Colorado and New Mexico. The atlas provides GIS data and map packages for online viewing or downloading, and on this baae one can select from a varietv of enerav-related features for manpina. USGS imaae.

FY2011 we had created an online, interactive energy atlas, which was highlighted in a recent USGS science feature. The atlas includes oil and gas, wind, and solar energy development. Improvements to the online atlas continued in FY2012 and FY2013, and we completed an online toolbox that will be used to demonstrate to resource managers how the atlas information can be applied to particular assessment areas. Although the Bureau of Land Management is one of our primary stakeholders, the energy atlas will be useful to other State and Federal agencies, the general public, and policymakers.

\section{Products:}

Ignizio, D.A., and Carr, N.B., 2012, Locations and attributes of utility-scale solar power facilities in Colorado and New Mexico, 2011 [abs.]: U.S. Geological Survey Data Series 693. (Available at http://pubs.usgs.gov/ds/693/.)

Carr, N.B., Babel, N., Diffendorfer, J., Ignizio, D., Hawkins, S., Latysh, N., Leib, K., Linard, J., and Matherne, A., 2012, Interactive energy atlas for Colorado and New Mexico: An online resource for decision-makers and the public: U.S. Geological Survey Web site. (Available at $h t t p: / / w w w . f o r t . u s g s . g o v / E E R M A /$.)

Carr, N.B., Diffendorfer, J.E., Fancher, T.S., Hawkins, S.J., Latysh, N.E., Leib, K.J., and Matherne, A-M., 2013, Locations and attributes of wind turbines in Colorado, 2011: U.S. Geological Survey Data Series 782.

(Available at http://pubs.er.usgs.gov/publication/ds782.)

Carr, N.B., Diffendorfer, J.E., Fancher, T.S., Hawkins, S.J., Latysh, N.E., Leib, K.J., Matherne, A-M., 2013, Locations and attributes of wind turbines in New Mexico, 2011: U.S. Geological Survey Data Series 783. (Available at $h t t p: / / p u b s . e r . u s g s . g o v / p u b l i c a t i o n / d s 783$.

\section{Contact: Natasha Carr}


The overall goal of the Bureau of Land Management's (BLM) Rapid Ecoregional Assessments (REA) is to provide information that facilitates development of ecoregion-based conservation strategies on public lands and facilitates planning and analysis for the management of ecological resources. The REA provides an assessment of ecological condition and can be used to identify priority areas for conservation or restoration of native plant and animal communities. It also provides an improved predictive capacity for Change Agents and for assessing cumulative impact under the National Environmental Policy Act (NEPA). The REA establishes baseline information for long-term monitoring of regional ecological conditions, and it provides enhanced landscape-scale information, understanding, and awareness relevant to planning and decisionmaking for all values and uses of public lands. Finally, the REA provides guidance for adaptation and mitigation planning in response to climate change. Overall, the REA creates stronger, more effective, and more efficient collaboration and cooperation among all parties interested in regional land and resource management.

USGS scientists, including the project lead from FORT, are conducting the Wyoming Basin Ecoregion REA for the BLM. We are currently finalizing the Wyoming Basin work plan, which details the approach we propose to use to address the priority management questions and evaluate the status of Conservation Elements (focal species and ecological communities) and Change Agents identified by the BLM and its partner agencies, including the Wyoming Game and Fish Department and the National Park Service. We are now starting the second phase of the REA and will be implementing the work plan and completing the analyses necessary to address management questions and evaluate the status of Conservation Elements.

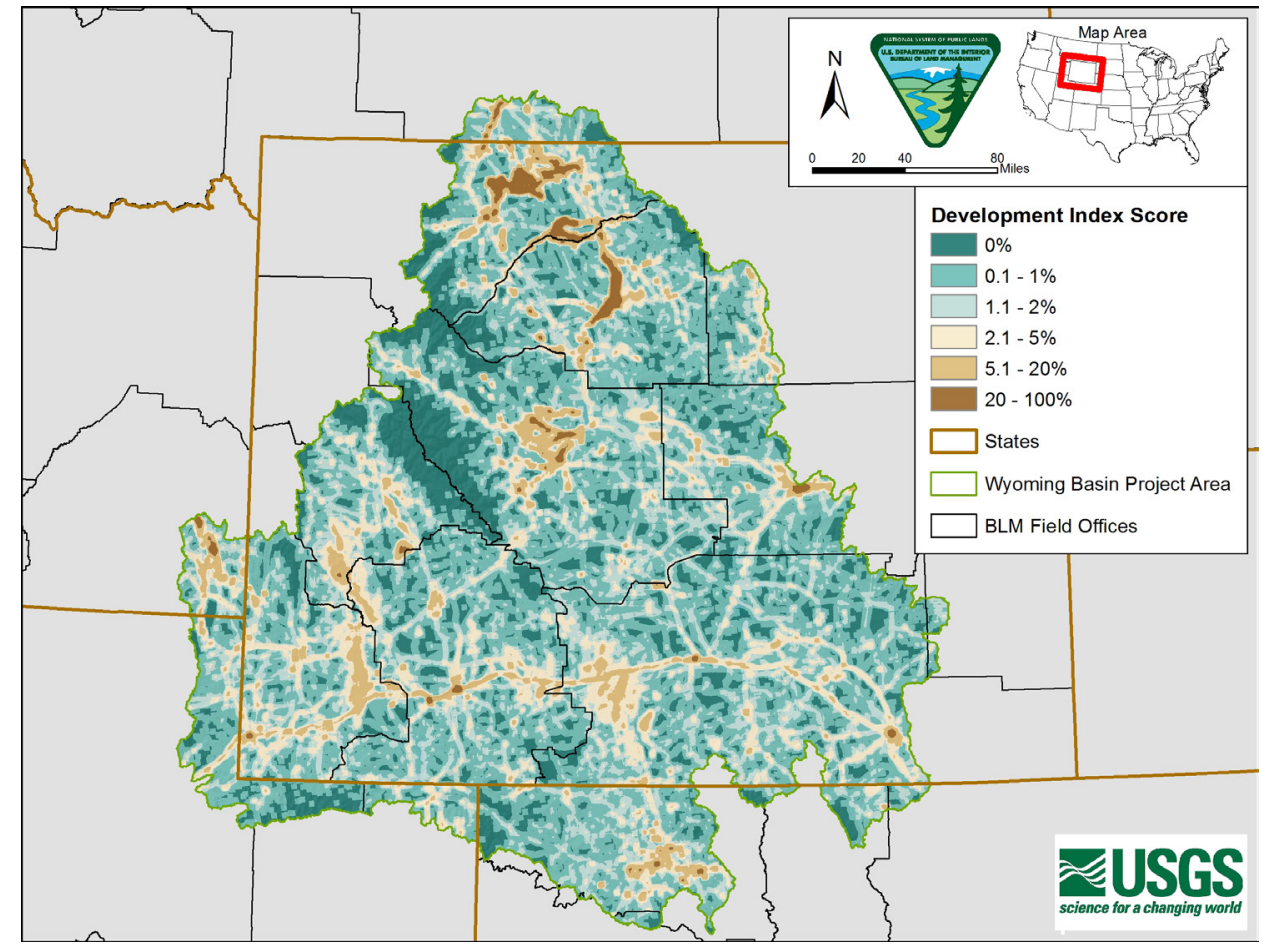

An index of development for the Wyoming Basin Rapid Ecoregional Assessment. This index is used to evaluate the cumulative effects of surface disturbance resulting from energy extraction, transportation, agriculture, and other forms of development. Map by Nils Babel, contracted to the USGS through Cherokee Services Group. USGS image. 


\section{Pygmy Rabbits and Gas Field Development in Wyoming}

Currently, operational gas fields cover more than 2,200 square miles $\left(\mathrm{mi}^{2}\right)$ of land in western Wyoming, and further development is projected for at least the next 25 years. However, there is little or no information on the effects of gas-field development for most of Wyoming's wildlife Species of Greatest Conservation Need (SGCN) that occur in sagebrush ecosystems. The pygmy rabbit (Brachylagus idahoensis) is a SGCN for which there is high conservation interest. The FORT is conducting two studies to examine the relationship between gas fields and pygmy rabbit occurrence patterns in southwestern Wyoming.

Study 1: We have been evaluating the influence of gas well and road density on pygmy rabbit occurrence rates on the Atlantic Rim, Jonah, and Pinedale Anticline Project Area gas fields. In 2012, we expanded this study to include the Moxa Arch gas field. Using GIS maps of gas wells and roads, highresolution imagery, and a current pygmy rabbit habitat map, we established 30 survey plots on each gas field and surveyed each plot for pygmy rabbit sign twice during the summer of 2011 and again in 2012. In early FY2013, we conducted a full analysis of the two years of data and determined that a third year of surveys was necessary to fully identify threshold levels of development above which pygmy rabbit site occupancy becomes impacted. Those surveys were conducted in FY2013. These data will be used to guide development of future gas fields in Wyoming and elsewhere. Cooperators and collaborators include the Bureau of Land Management's Kemmerer, Pinedale, and Rock Springs Field Offices and the Wyoming Game and Fish Department.

Study 2: The Normally Pressured Lance (NPL) gas field in Sublette County, Wyo., is scheduled for development starting in 2014. In FY10 and FY2011, FORT staff conducted predevelopment, site-occupancy surveys for pygmy rabbits at 150 plots distributed evenly across the NPL and three adjacent control areas. After conducting these two years of pre-development data collection, this study was rested in FY2012 and FY2013 so that a third year of predevelopment data collection could occur immediately prior to the onset of development. Once we collect post-development data, we will compare the pre- and post-development occurrence rates on the NPL.

\section{Product:}

Germaine, S., and Kemper, J., 2012,

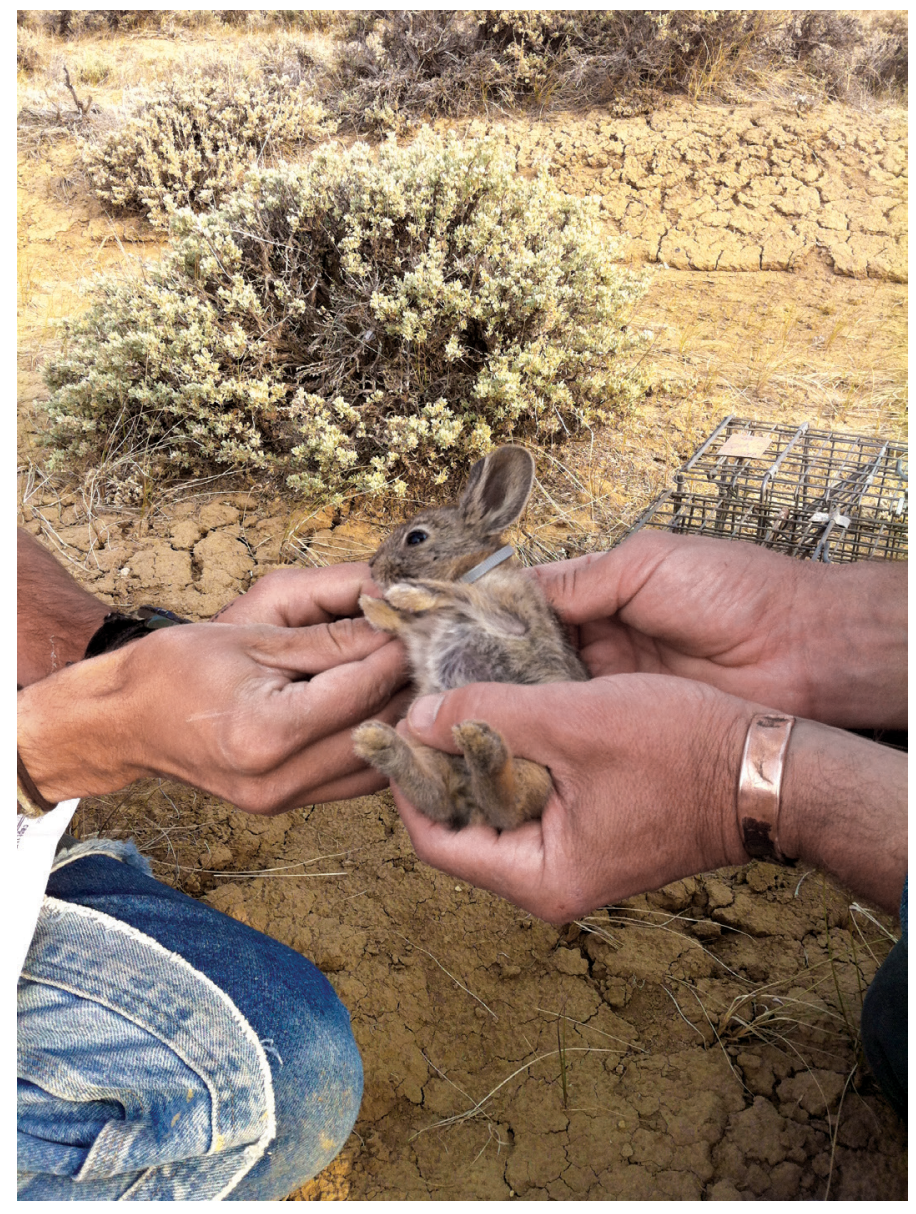

Juvenile pygmy rabbit being fitted with a GPS unit and ID collar as part of a pilot study to evaluate GPS technology for studying pygmy rabbit survival. USGS photo.

Identifying the relationship between natural gas energy development and pygmy rabbit (Brachylagus idahoensis) site occupancy: Abstract presented at the $3^{\text {rd }}$ WLCI Science Meeting, May 14-17, 2012, Rock Springs, Wyo.

Contact: Steve Germaine 


\section{NEII Golden Eagle Population Dynamics across the West}

Region-wide habitat-based conservation tools are lacking and represent a critical need for implementing golden eagle conservation in the United States. Models predicting species occurrence based on landscape attributes are useful for identifying areas likely to be critical habitat and can be used as a decision-support tool by managers. Output from occurrence models displayed as maps with overlays of habitat integrity and potential stressors can be used to inform management decisions. Some landscapes in the western United States are predicted to change drastically in the future, so it is also important to understand the factors that influence where organisms occur and changes in occupancy (that is, extirpation, re-colonization, and range expansion). Dynamic occupancy models will allow users to examine how the probability of eagle occurrence changes through time. By using predictor variables that represent changing conditions over time (e.g., energy development), we can predict how the probability of occupancy will change as a result of future habitat changes.

In FY2012 and FY2013, FORT researchers partnered with the U.S. Fish and Wildlife Service (FWS) and Western Ecosystems Technology, Inc. (WEST, Inc.) to analyze golden eagle survey data. The data have been collected since 2006 during late summer along 168 aerial transects across 13 western states (see map below). The collaborative modeling efforts will fill a critical knowledge gap for the FWS by identifying the geographic areas and habitat attributes most crucial to golden eagles. Once the dynamic models are developed, they will be used to estimate changes in eagle occupancy under future energy development scenarios, such as those developed by the National Renewable Energy Laboratory (NREL) and The Nature Conservancy. Providing natural resource managers with scientifically based forecasting tools will help support proactive conservation for golden eagles across a large portion of their range, while allowing for and mitigating the effects of future energy development.

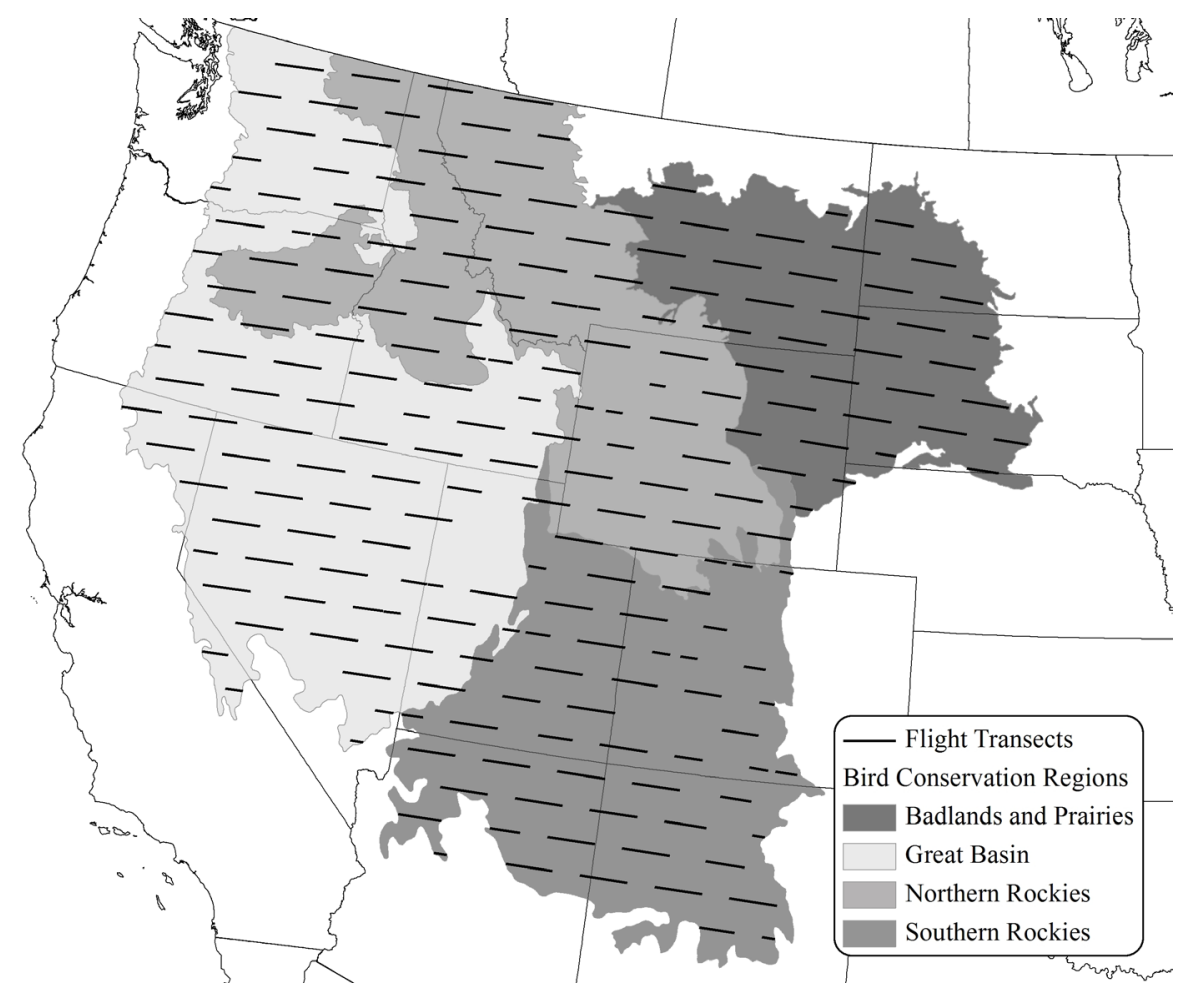

Locations of aerial transects for conducting golden eagle surveys in late summer. The surveys, contracted to Western Ecosystems Technology, Inc. by the U.S. Fish and Wildlife Service, have been conducted annually since 2006. Map by Jason Tack, Cherokee Services Group, contracted to USGS.

Contact: Jason Tack 


\section{Raptors and Wind Development: Developing Science-based Conservation Tools}

Land-use change across the North American West is a primary threat to wildlife populations. Energy development is a major driver of habitat loss and fragmentation in some of the last large and connected landscapes. Development of renewable energy poses a difficult challenge for conservation, because proliferating emission-neutral energy sources expand the human footprint in previously undeveloped areas. Raptors are of particular concern with wind energy development because wind turbines are a known source of raptor mortality, and these otherwise long-lived species have low reproductive capacities. Effects of development can be cumulative to raptors and their prey base as roads, transmission lines, and increased noise and human use rise in concert with development. Balancing the need to achieve energy independence through renewable sources while maintaining robust wildlife populations requires the development of tools that help managers proactively conserve landscapes. Working with State, Federal, and non-governmental entities, FORT investigators have collected extensive records of raptor nest locations across Wyoming. Using FORT's spatial data library, we extracted and created data layers representing features that raptors key in on when choosing nest sites, including topographic indices, land cover, and human use. Combining spatial data with statistical models helps to reveal relationships between landscape features and raptor nest-site selection, allowing for predictions (in a geographic information system, or GIS) of relative habitat quality.

In FY2012 and FY2013, FORT and other scientists from the University of Waterloo and Colorado State University finalized models for nesting golden eagles, prairie falcons, and ferruginous hawks. These models form the basis for multiple-species conservation planning at the largest spatial scales available to date. Then we overlaid spatial data that represent habitat quality with layers representing wind-energy potential that provides agencies with the most rigorous planning tool available to date. Partners, including the U.S. Fish and Wildlife Service, can use the models to guide energy-development companies with project-siting decisions.

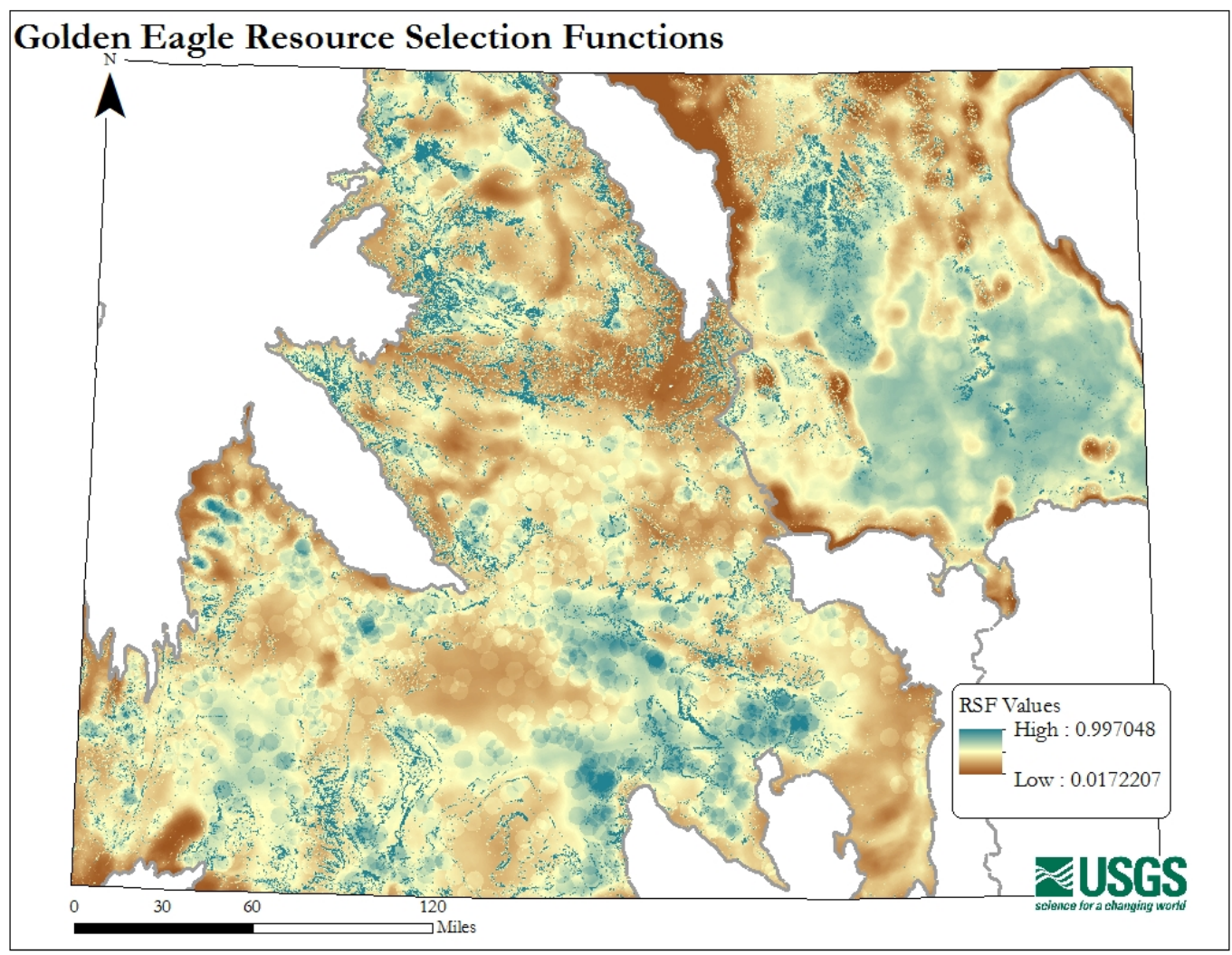

Golden eagle nest-site selection model for Wyoming derived from resource-selection functions (RSF). Values indicate the relative quality of habitat to nesting golden eagles. Models were also developed for ferruginous hawk, and prairie falcons. Map by Jason Tack, Colorado State University, in cooperation with the USGS.

Contact: Jason Tack 
Shifts in river flow resulting from climate change are a major threat to water supplies and riverine ecosystems worldwide. Predicting flow changes and their effects on vegetation is essential to effective river management. The effects of human-induced climate change on river flow cannot be understood, however, unless they can be distinguished from the effects of natural climate variation and water management. Fluctuations in climate over the last century have caused flow shifts similar in magnitude to the effects of construction of major reservoirs. Therefore, studies of flow variation over the last few centuries are needed to assist in detecting and adapting to the effects of climate change. To address this need, FORT scientists are reconstructing flow histories of rivers in the western United States, working in collaboration with the USGS Water Mission Area's National Research Program; the National Park Service; the Universities of Arizona, Arkansas, and Montana; and Colorado State University.

We are using tree rings of plains cottonwood (Populus deltoides var. occidentalis) to relate tree growth and establishment to flow and climate along the Little Missouri River in Theodore Roosevelt National Park (TRNP), North Dakota. In 2012, we developed a chronology based on cores collected from 339 cottonwood trees at the North Unit of the park and related cottonwood growth to climate and flow. We found trees up to 370 years old, the oldest known plains cottonwood trees in the world (Edmondson, J., J. Friedman, D. Meko, R. Touchan, J. Scott, and A. Edmondson. 2014. Dendroclimatic potential of plains cottonwood (Populus deltoides ssp. monilifera) from the northern Great Plains, USA Tree-Ring Research 70:21-30). Annual cottonwood growth along the Little Missouri River is strongly and positively correlated with flow, demonstrating that it will be possible to use the tree-ring record to reconstruct the history of flow. In April 2012, USGS personnel collected additional cottonwood cores from the South Unit of the TRNP to determine whether flow depletions are causing reduced growth. Investigators also began development of a watershed model to allow assessment of how climate change will affect river flows. Over the next two years, we will use the tree-ring record to reconstruct a 267-year record of past climate and flow and to assess the effects of future climate change on cottonwood growth and establishment.

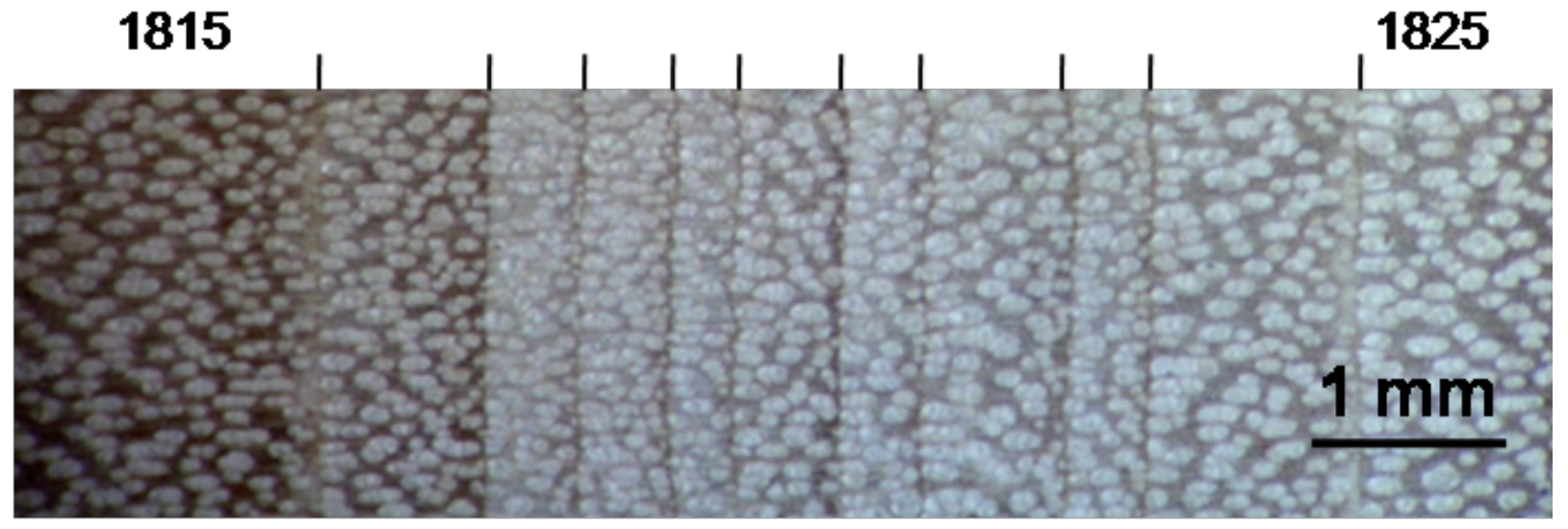

Portion of a cottonwood core from the Little Missouri River in Theodore Roosevelt National Park, North Dakota. Narrow annual rings from 1817 to 1823 were caused by the most intense drought in the 267-year tree-ring record.

\section{Product:}

Friedman, J.M., Edmondson, J.R., Griffin, E.R., Meko, D.M., Merigliano, M.F., Scott, J.A., Scott, M.L., and Touchan, R., 2012, Cottonwood tree rings and climate in western North America: Poster presented at 2012 Fall Meeting, American Geophysical Union, San Francisco, Calif., December 5, 2012. 


\section{Gunnison Sage-Grouse Habitat Use and Movement: The Crawford Population}

In July 2000, the Gunnison sage-grouse (Centrocercus minimus) (GUSG) was officially recognized by the American Ornithologists' Union as a unique, endemic species, and it is listed as a "species of special concern" by Federal and State natural resource management agencies throughout its range. Declines in GUSG populations have been attributed primarily to loss and alteration of sage-steppe habitat. Now these birds exist in seven relatively small, isolated populations, primarily in Colorado and Utah. The largest population (fewer than 3,000 individuals) inhabits the Gunnison Basin in west-central Colorado. The Crawford population, estimated at 128 individuals, inhabits Black Canyon of the Gunnison National Park and the Gunnison Gorge National Conservation Area. Although this population is small, it is still considered a self-sustaining population, and its persistence and growth contribute directly to conservation of the species' genetic diversity. Prior to this project, there was only observational and anecdotal information about the range, movements, and seasonal habitat uses of this population.

To develop much-needed objective information on the Crawford population, the USGS, including FORT, developed a multi-agency (National Park Service [NPS], Bureau of Land Management [BLM], Forest Service [FS], and Colorado Division of Parks and Wildlife [DPW]) project to assess the following: (1) GUSG seasonal habitat use and movement patterns, (2) effects of off-highway vehicle use on the birds' movements and distribution, (3) lek site probability (mapping), (4) effects of vegetation treatment on the species' movements and distribution, (5) historical use by the species in the Crawford area, and (6) nest predation. To address these topics, in FY2011 the USGS began tagging GUSG with GPS backpacks programmed to collect the birds' locations 14 times per day. Locations are emailed to the investigator every five days so that the data are readily available for analysis. In addition to the GPS monitoring, a 15-site OHV-monitoring network was established to monitor the intensity of motorized use in the area.

In FY2012, FORT scientists deployed additional GPS units on GUSG and deployed eight more in FY2013, for a total of 13 GPS-tagged birds. The location data collected by the GPS units were used in FY2012 and FY2013 to develop preliminary GUSG habitat-use models. When sufficient data have been collected, final habitat-use models for GUSG will be developed. The modeling results will be used by BLM, NPS, and FS managers to develop management prescriptions for preserving crucial GUSG habitat.

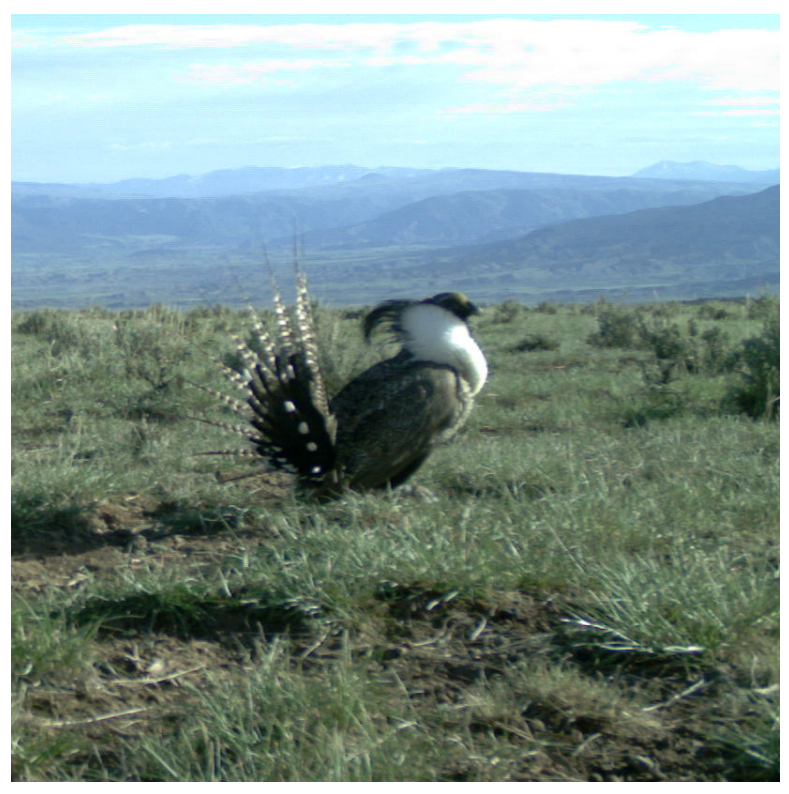

Gunnison sage-grouse strutting on a lek. Photo captured by a remote camera set up by Doug Ouren, USGS.

The multi-year USGS study of the impact of roads and

traffic on Gunnison sage grouse has been the foundation of BLM's efforts to work collaboratively with Federal, State, County and private partners to protect, restore, and enhance Gunnison sage-grouse in the Gunnison Gorge National Conservation Area (GGNCA) and on surrounding private and public lands.

- Karen Tucker, Bureau of Land Management

\section{Product:}

Ouren, D.S., Ignizio, D., Siders, M., Childers, T., Tucker, K., and Seward, N., 2012, Gunnison SageGrouse Lek Site Suitability Mapping: U.S. Geological Survey Open-File Report 2014-1010, 18 p., at http://dx.doi.org/10.3133/ofr20141010.

\section{Contact: Doug Ouren}




\section{Ecosystems-Wildlife and Terrestrial Resources}

\section{Field Testing an Oral Plague Vaccine for Prairie Dogs}

Plague, caused by the bacterium Yersinia pestis, is well known for its capability to cause large-scale epidemics in humans and epizootics (animal epidemics) in rodents. In the 100 years since its introduction in North America, plague has contributed to large-scale population declines of prairie dogs across the western United States, the near extinction of the still endangered black-footed ferret, and has caused human illness and fatalities in areas where prairie dogs reside. Although the black-footed ferret recovery program has made great strides towards the conservation of black-footed ferrets, one of the biggest impediments towards achieving recovery has been plague. Both ferrets and the prairie dogs they prey on are highly susceptible to plague and suffer high mortality in the presence of plague. Efforts to prevent or minimize the effects of plague in ferret reintroduction areas have included the dusting of prairie dog burrows with an insecticide to kill fleas, the carriers of the plague bacterium, as well as an injectable vaccine for ferrets. Both are successful in protecting prairie dogs and ferrets; however, they are labor intensive and time consuming, and the use of an insecticide may have unintended consequences to beneficial insects and arthropods that also reside in prairie dog habitats.

Working under the premise that if plague can be controlled

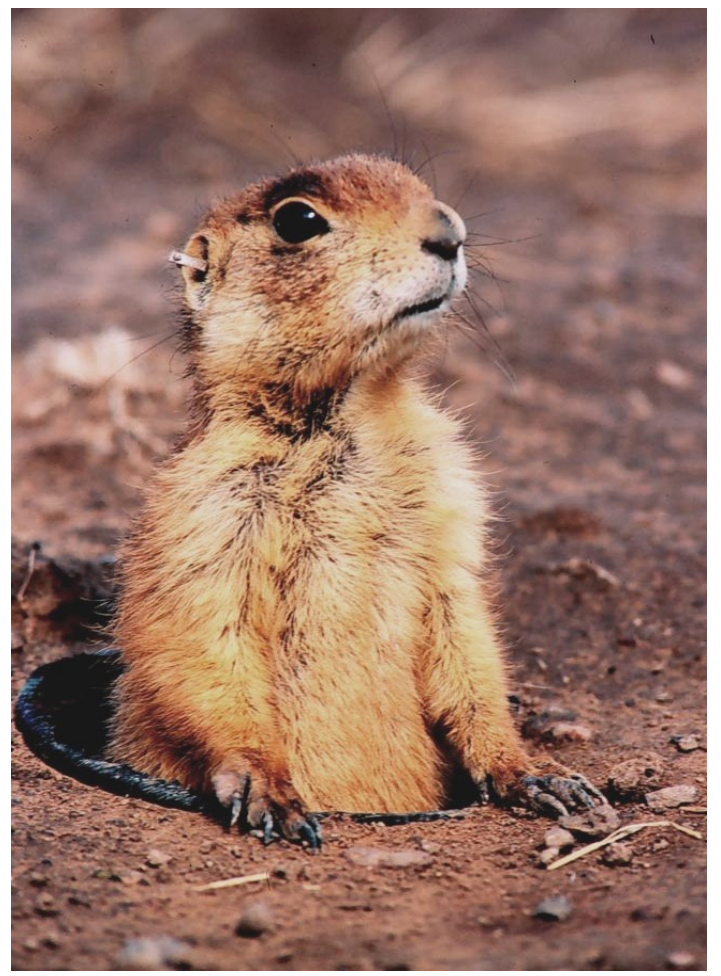

Utah prairie dog. USGS photo by Dean Biggins. in prairie dogs and ferrets will also benefit, a sylvatic plague vaccine (SPV) for prairie dogs has been developed and tested jointly over several years (including FY2012) by FORT, the USGS National Wildlife Health Center (NWHC), and the University of Wisconsin. This vaccine shows great promise as an effective, preemptive method for controlling plague in prairie dogs without the disadvantages and potential collateral environmental effects of dusting with insecticides. This vaccine can be delivered via oral bait. The use of this vaccine to prevent plague outbreaks in targeted prairie dog complexes, particularly where black-footed ferrets have been released or where prairie dog conservation is a goal, could have both economic and environmental benefits. A plague vaccination program could enhance prairie dog and ferret recovery efforts, reduce pesticide use on public lands, allow managers to balance land-use needs (agriculture and development) with conservation efforts on other sites, and reduce the need to close public spaces and military sites due to plague.

The next step in developing a plague vaccination program is to work through the product registration process of the USDA Animal and Plant Health Inspection Service, which ensures that veterinary biologics - such as vaccines for the diagnosis, prevention, and treatment of animal diseases - are pure, safe, potent, and effective. FORT and NWHC scientists have joined biologists from other State, Federal, and Tribal governments to form a science advisory team to help plan and oversee the required safety and efficacy trials of the vaccine in the field. During the summer of 2012, USGS scientists, in collaboration with biologists at the Rocky Mountain Arsenal National Wildlife Refuge, conducted a small field trial to evaluate bait uptake rates by black-tailed prairie dogs. This step was necessary to help determine the density of baits needed to ensure appropriate uptake rates by these animals. Results suggested strong evidence for an interaction between bait density and prairie dog density as predictors of uptake. This interaction is intuitive, but it underscores that to be most efficient, bait delivery must consider both factors. In FY2013, field efficacy trials were initiated across the range of all four species of prairie dogs found in the United States. USGS scientists conducted field efficacy trials for Utah prairie dog on the Aquarius Plateau in Utah and black-tailed prairie dogs at UL Bend National Wildlife Refuge in Montana.

Contact: Dean Biggins 


\section{Science in Support of Wild Horse Management}

With passage of The Wild Free-Roaming Horses and Burros Act of 1971 (Public Law 92-175), the Bureau of Land Management (BLM) was given primary responsibility for managing wild horses on rangelands of the western United States. Since that time, the BLM has faced two primary management challenges. First, given the protection afforded by the Act and a general lack of natural predators in most areas, wild horse populations can double every $3-5$ years and rapidly exceed the carrying capacities of their ranges. Second, depending on terrain, weather, and other factors, it can be very difficult estimate the number of wild horses in a population, which leaves the advisability of any subsequent management action open to question.

For about a decade, FORT ungulate ecologists have been working with the BLM to help address their horse-management challenges. This work has entailed two primary foci: developing fertility control measures to help slow population growth rates, and developing techniques to provide more reliable estimates of population size. The evaluation of fertility control agents in FY2012 and FY2013 primarily focused on SpayVac ${ }^{\circledR}$ (Immunovaccine Inc., Halifax, Nova Scotia). After preliminary data from a pen trial studying the efficacy of SpayVac on captive mares proved promising, we developed a study plan for a field trial to investigate the efficacy and safety of this vaccine on free-roaming mares. This 5-year study started in FY2013 and will compare foaling rates between treated and control groups for 4 years following a single treatment. Since the mechanism of action for how SpayVac renders a mare infertile is still unknown, this question is being investigated through a study which began in early FY2013.

In FY2012, a journal article was published detailing detection probability in aerial surveys of feral horses. The primary objective of the paper was to identify key sources of observation bias and how to mitigate them. Additionally, FORT scientists conducted a course to train BLM personnel on how to collect aerial survey data using either of two established methods for accurately estimating ungulate populations. This training course, along with the published paper on detection probability, will be used by BLM personnel to better conduct their aerial surveys to arrive at more accurate population estimates. Finally, in an attempt to reduce error while counting animals and to streamline the surveying process, we began a distance sampling project

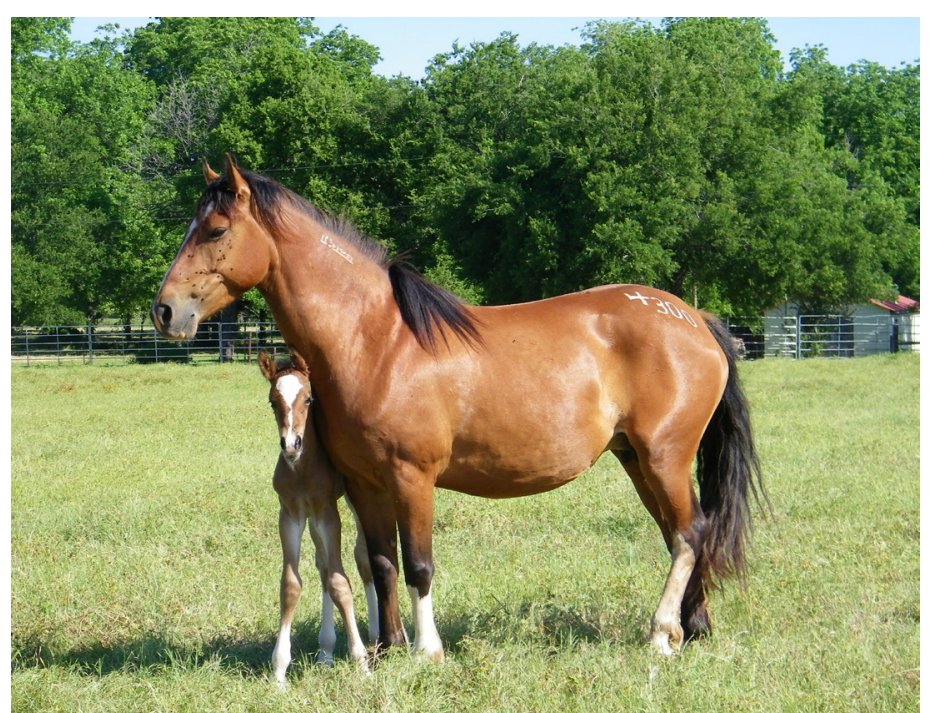

Captive mare and foal in a BLM holding facility at Paul's Valley, Okla. The mare is part of the SpayVac ${ }^{\circledR}$ pen trials. USGS photo bv Butch Roelle. in FY2012. Distance sampling is designed to more accurately capture the distance of a given group of ungulates from a known transect line in order to mitigate the sampling bias of the survey. This method also employs a hand-held tablet to standardize and ease data collection. A paper detailing the results of this experimental approach will be submitted for publication in FY2013. The BLM will use the results of both our contraception and population estimation studies to better manage wild horse populations on western ranges within their jurisdictions.

\section{Product:}

Ransom, J.I., 2012, Detection probability in aerial surveys of feral horses: Journal of Wildlife Management, v. 76, p. 299-307.

Contact: Kate Schoenecker 


\section{Assessing Habitat Use and Seasonal Distributions of Tree-Roosting Bats at Risk from Industrial Wind Energy Development}

The rapid and widespread deployment of industrial wind turbines across North America is having unanticipated adverse effects on certain species of migratory tree-roosting bats. The species of bats most affected by turbines are very hard to see and little is known regarding their population numbers. Some of these species are estimated to be dying at turbines in the hundreds of thousands per year. Because total population sizes of many of these species are not known, it is impossible to rule out the possibility that mortality from turbines could be leading to population declines and potential future extinctions. The reasons why certain species of bats are susceptible to turbines are unknown (although under investigation), and currently there are no validated ways of predicting and minimizing risk to bats before turbines are built. This lack of predictability stems from a limited understanding of the seasonal whereabouts and movements of the mostaffected bat species. Efforts by FORT scientists over the past decade have led to coarse-scale discoveries about the distributions of these bats. However, if we could better understand the fine-scale details of where and when tree-roosting bats move across landscapes, the information could be used to avoid future siting of wind-energy facilities in critical movement areas or to anticipate the seasonal arrival of bats at existing turbine facilities so that operational mitigation strategies could be implemented to minimize fatalities.

In FY2012, USGS scientists (FORT, Pacific Islands Research Science Center) in collaboration with University of Colorado, initiated a new project to determine how landscape features (for example, mountains or forests) and environmental conditions (for example, temperature and humidity) influence the seasonal distribution patterns of migratory tree bats. Using existing bat occurrence records, spatiotemporal models were developed to generate maps of hypothesized seasonal distributions at different spatial scales. These maps include explicit predictions of where hoary bats are most likely to occur during each season if data are insufficient for more fine-grained temporal analysis-including important time periods (like autumn migration) when they are most susceptible to wind turbines.

The hoary bat (Lasiurus cinereus) was used to generate these models and maps, but the approaches developed are applicable to other species as well. Initial efforts were directed toward hoary bats because (1) they are found dead more often than any other species at turbines in the United States and account for more than 40 percent of all documented bat fatalities, (2) a large database of occurrence records for this species already exists as a result of other USGS

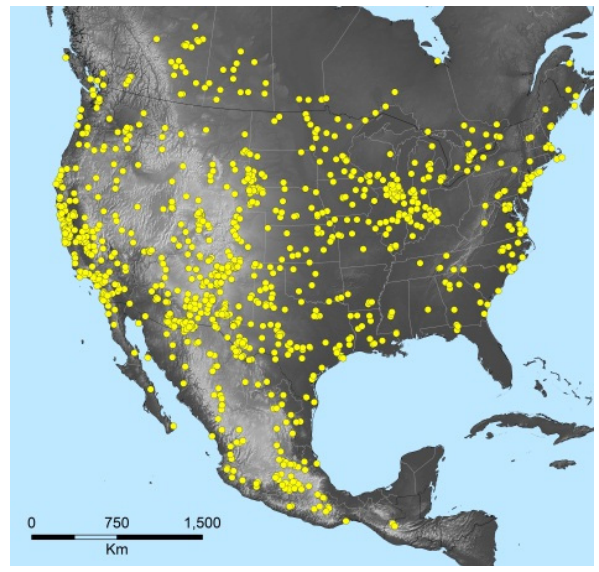

Map showing the distribution of occurrence records of hoary bats (Lasiurus cinereus) that will be used to model their seasonal distributions and habitat associations. Map by Paul Cryan, USGS.

research, and (3) very little is known about their seasonal distributions (for example, wintering grounds), migration behaviors (for example, migration hotspots), or population status. Further, the Hawaiian hoary bat (L. c. semotus), which has been found dead beneath turbines on islands of Hawaii, is the only land mammal endemic to those islands and is listed as endangered by both the U.S. Government and the State of Hawaii. If time permits, similar models will also be developed for the two other species of bats most affected by wind turbines, eastern red bats (Lasiurus borealis) and silver-haired bats (Lasionycteris noctivagans).

Now that the current objectives are completed, the next phase of this project will involve testing the predictions of the bat distribution maps through field studies using acoustic detectors, videography, and satellite tracking, all in an occupancy modeling framework, with a focus on the period of late summer and autumn (roughly mid-July through October) when tree-roosting bats are most susceptible to wind turbines. These efforts will offer new and relevant information on the conditions under which bats migrate and the habitats they are likely to occur in during migration.

Contact: Paul Cryan 


\section{Investigations of White-Nose Syndrome in Bats}

White-nose syndrome (WNS) is an emerging disease of hibernating bats that is causing unprecedented population declines in multiple species in North America. Since 2006, WNS has spread from a small area of New York to a region now covering at least 22 states and 4 Canadian provinces. WNS is caused by a highly invasive fungus (Pseudogymnoascus (formerly Geomyces) destructans) that infects the skin of bats. During FY2012 and FY2013, FORT scientists continued participating in efforts to coordinate the national response to this wildlife emergency, provided support to disease researchers at the USGS National Wildlife Health Center (NWHC), and continued a field study to identify causes and consequences of the disease. This video-monitoring project, in cooperation with the National Park Service (NPS), is investigating the hypothesis that skin infection caused by $P$. destructans triggers unsustainable aberrant behaviors in bats during hibernation, thus causing death. The research is also identifying environmental conditions under which effects of disease occur. Four custom-made, surveillancecamera systems capable of monitoring the behaviors of hibernating bats in deep, dark caves and mines over the entire hibernation period were deployed in four states during FY2012 and FY2013, and monitoring continues in FY2014 at caves in Virginia and Indiana. These new glimpses into the secret lives of hibernating bats will help determine whether behavioral changes associated with skin infection by the cold-growing fungus are contributing to mortality in bats affected by WNS, as well as point to how the disease is spread. Such information will help managers determine when and where to target efforts to minimize disease effects.

Also in FY2012 and FY2013, FORT scientists took the lead for Data and Technical Information Management, an element identified in A National Plan for Assisting States, Federal Agencies, and Tribes in Managing White-Nose Syndrome in Bats. A working group was established whose purpose is to provide a mechanism for making WNS information accessible in a timely fashion to all entities involved with the investigation and management of WNS.

Additional activities during FY2012 and FY2013 included using habitat-association modeling to predict the potential spread of WNS (with Colorado State University), investigating electrolyte imbalance in affected bats (with NPS, NWHC, Bucknell University, and the Pennsylvania Game Commission), and developing an online database for tracking WNS (with the U.S. Fish and Wildlife Service).

Captive mare and foal in a BLM holding facility at Paul's Valley, Okla. The mare is part of the SpayVac ${ }^{\circledR}$ pen trials. USGS photo by Butch Roelle.
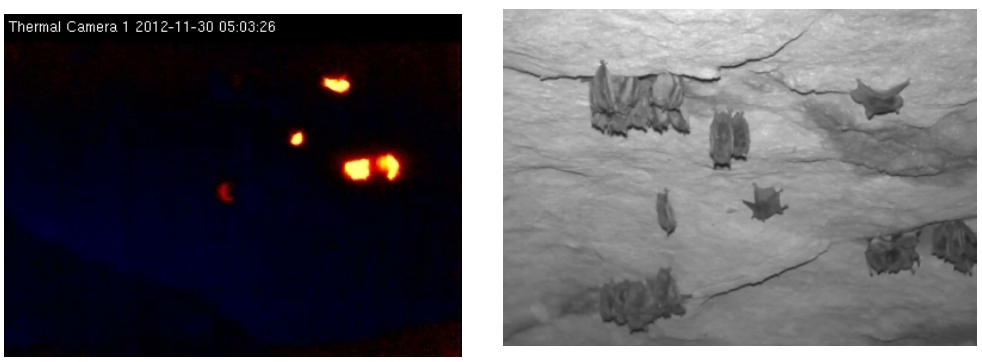

\section{Products:}

Cryan, P.M., Uphoff Meteyer, C., Blehert, D.S., Lorch, J.M., Reeder, D.M., Turner, G.G., Webb, J., Behr, M., Verant, M., and Castle, K.T., 2013, Electrolyte depletion in white-nose syndrome bats: Journal of Wildlife Diseases, v. 49, no. 2, p. 398-402.

Cryan, P.M., Meteyer, C.M., Boyles, J.G., and Blehert, D.S., 2013, White-nose syndrome in bats: illuminating the darkness: BMC Biology, v. 11, p. 47.

Warnecke, L., Turner, J.M., Bollinger, T.K., Misra, V., Cryan, P.M., Blehert, D.S., Wibbelt, G., and Willis, C.K.R., 2013, Pathophysiology of white-nose syndrome in bats: a mechanistic model linking wing damage to mortality: Biology Letters, v. 9, p. 20130177.

Warnecke, L., Turner, J.M., Bollinger, T.K., Lorch, J.M., Misra, V., Cryan, P.M., Wibbelt, G., Blehert, D.S., and Willis, C.K.R., 2012, Inoculation of bats with European Geomyces destructans supports the novel pathogen hypothesis for the origin of white-nose syndrome: Proceedings of the National Academies of Science, USA, www.pnas.org/cgi/doi/10.1073/pnas. 1200374109.

Flory, A.R., Kumar, S., Stohlgren, T.J., and Cryan, P.M., 2012, Environmental conditions associated with bat white-nose syndrome mortality in the northeastern United States: Journal of Applied Ecology, v. 49, p. 680-689.

Meteyer, C.U., Blehert, D.S., and Cryan, P.M., 2012, Confirmation of white-nose syndrome in bats of Europe and implications of this discovery toward understanding the disease in bats of North America: Bat Research News, v. 53, p.1-4.

Contacts: Paul Cryan, Laura Ellison 


\section{Investigating Causes and Consequences of Bat Fatalities at Wind Turbines}

Wind energy is one of the fastest-growing industries in the world and represents an important step toward reducing dependence on non-renewable sources of power. However, turbines are causing unprecedented mortality of migratory tree-roosting bats. Causes of bat collisions with turbines remain unknown. Current USGS research is building upon earlier studies by FORT scientists and their research partners. These studies examined the natural histories of the affected species to help determine such things as the origins of bats killed by turbines, whether bats are attracted to turbines, whether mating and (or) feeding behaviors play a role in fatalities, and how risk to bats might be predicted before turbines are built.

During FY2012, scientists from FORT and four other USGS science centers partnered with industry and a conservation organization to conduct an experiment examining the hypothesis that bats are attracted to wind turbines, particularly during low-wind conditions - most bat fatalities at turbines are found after nights with low winds. Blade speed was manipulated to assess differences in the way bats approach and interact with turbine towers under differing operational conditions. In addition to the blade-speed experiment, the research also combined and compared different methods of monitoring bat activity and fatality at turbines, including carcass searches (Forest and Rangeland Ecosystem Science Center), mobile radar (Northern Rocky Mountain Science Center), acoustic monitoring (Northern Prairie Wildlife Research Center), and video surveillance (Pacific Island Ecosystems Research Center, PIERC). FORT and PIERC scientists further developed a novel video system capable of remotely imaging bats and birds flying in the dark at the heights of wind turbines (greater than $100 \mathrm{~m}$ ) and expanded development of computer programs capable of automatically detecting bat activity of interest in the recorded imagery. This monitoring occurred remotely over entire nights and months at multiple turbines in Indiana, Colorado, and Hawaii. The effort resulted in thousands of hours of recordings that are now being processed and analyzed. For the first time, bats were imaged approaching and interacting with turbine blades and towers across immense areas of the rotor-swept airspace. These new video observations are leading to discoveries about how and why bats interact with wind turbines, as well as factors associated with species susceptibility and different operating conditions. By identifying and substantiating the causes of bat mortality, solutions may be possible in the future to predict and reduce bat mortality at turbines while minimizing costs to the wind-energy industry. In addition to the field experiment carried out at the mainland wind facility in FY2012, FORT is cooperating with PIERC, other USGS science centers, and the FWS to continue this research in Hawaii. The endangered Hawaiian hoary bat is the only land mammal endemic to the Hawaiian Islands, is closely related to the bat species composing about half of all fatalities at turbines on the mainland, and has recently been found dead beneath turbines on several islands of Hawaii. This work aims to assess the risk of energy development to endangered Hawaiian hoary bats while finding new ways of predicting and avoiding risk.

\section{Products:}

Cryan, P.M., Jameson, J.W., Baerwald, E.F., Willis, C.K.R., Barclay, R.M.R., Snider, E.A., and Crichton, E.G., 2012, Evidence of late-
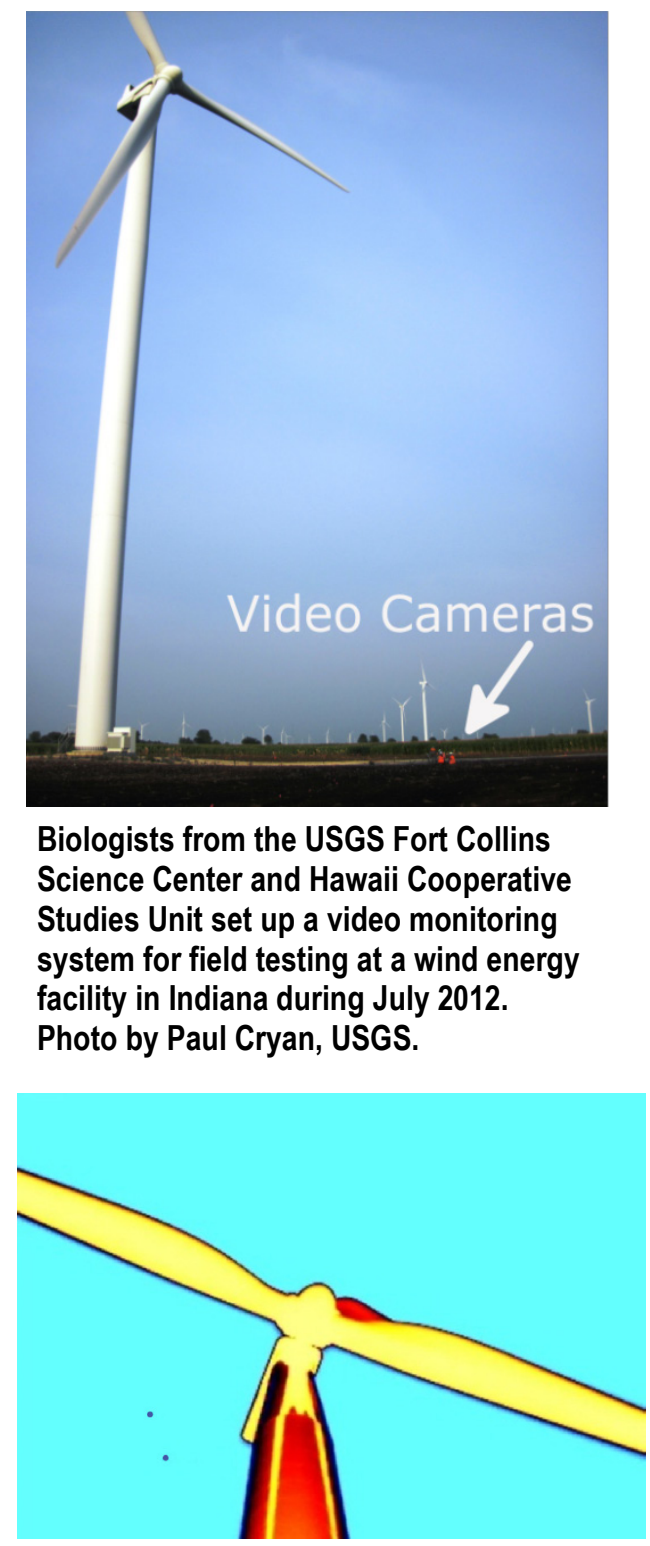

Snapshot from thermal video of two bats (blue dots in lower left quadrant) interacting during the middle of the night near the tower of an industrial wind turbine, about 80 meters above the ground ( $260 \mathrm{ft}$.). Image by Paul Cryan, USGS. summer mating readiness and early sexual maturation in migratory tree-roosting bats found dead at wind turbines: PLoS ONE, v. 7, p. e47586.

\section{Contact: Paul Cryan}


Despite their importance and the many threats facing North American bat populations (for example, white-nose syndrome [WNS], climate change, wind energy development, and habitat loss and fragmentation), there are currently no national programs to monitor and track bat populations in North America. A statistically rigorous and nationally coordinated bat monitoring program is critical for determining the impacts of the many stressors on bat populations and the efficacy of management actions taken to conserve bat populations. Two workshops convened over the past two decades to assess the state of bat monitoring in North America have produced several recommendations on developing standardized methodologies. The first workshop was held in Estes Park, Colo., in 1999 and was organized by FORT scientists [see also The USGS Bat Population Data (BPD) Project description]. The second workshop, held at FORT in April 2012, entailed initiating development of methods for monitoring and mathematically modeling bat populations in the context of the WNS crisis.

A recommendation from the April workshop attendees was that a small group of experts in the field of sampling design should be convened to draft a national sampling framework that can be scaled down for sitebased monitoring. Subsequently, a multi-agency proposal was submitted in response to the national Landscape Conservation Cooperatives call for research proposals under Theme B ("Addressing Existing Needs Identified by National or Large-Scale Conservation Efforts"). Partial funding was received, and with the help of other agency contributions, a total of three workshops were held in 2013. Bat biologists and a small group of statisticians (12-15) with expertise in large-scale monitoring designs participated in these workshops with the goal of developing a national bat monitoring protocol. The workshops were attended by scientists and researchers from multiple agencies, including the U.S. Fish and Wildlife Service, USGS, Forest Service, National Park Service, and the University of Tennessee's National Institute of Mathematical and Biological Synthesis. Representatives from Canada, Mexico, and the United Kingdom were also invited to present their views on national monitoring programs. The North American Bat Monitoring Initiative (or NABat) was conceived during the workshops and the objectives of this initiative are to (1) provide the architecture for coordinated bat monitoring to support local, regional, and range-wide inferences about trends in bat populations and abundances in response to WNS, climate, wind energy, and habitat loss; and (2) provide managers and policymakers with the information they need on bat population trends to effectively manage bat populations, detect early warning signs of population declines, and estimate extinction risk. In order to accomplish these objectives, the program is designing a statistically robust and logically feasible probabilistic sampling frame for bat population monitoring at both local and national scales. In 2014, workshop participants will produce a document describing the sampling frame, its statistical and biological bases, and a detailed protocol to monitor bats that can be followed by biologists with State, Provincial, and Federal agencies, Tribes, and partner organizations. The Bat Population Data (BPD) Project will provide a web-based application to store data collected from local and national monitoring efforts.

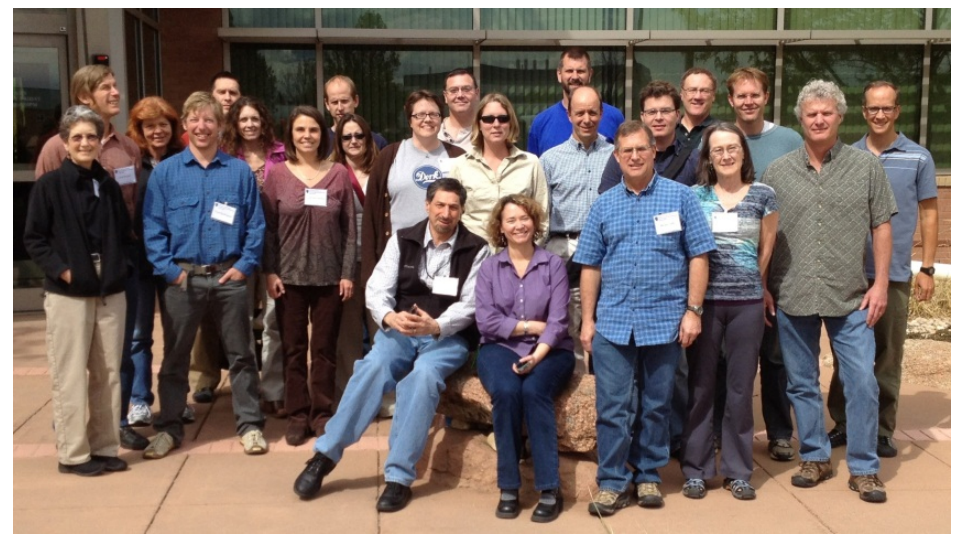

Members of the April 2012 WNS Population Monitoring and Modeling Workshop, including FORT scientists Laura Ellison and Brian Cade (front row, second and third from left, respectively), Sara Oyler-McCance and Tom Stanley (second row, third from left and far right, respectively), and Paul Cryan (back row, far right). Photo by Pat Field.

Contact: Laura Ellison 
In 1994, USGS scientists recognized that, despite increasing concern for many species of bats known or believed to be declining, the data necessary to determine population status and trends were fragmented among agencies and organizations. So began the USGS Bat Population Data (BPD) Project, which has become a comprehensive effort to compile existing population information for bats in the United States and Territories. Initially, this project was developed to (1) synthesize the existing bat population data and publications for the United States and Territories into a relational database, (2) test the utility of these data for estimating trends in bat populations, and (3) evaluate the applicability of these data to design future monitoring programs. The project's initial product, the Bat Population Database (BPD v.1), compiled bat population data from 1855-2001, particularly counts of bats at colony locations, location attributes, and a complete bibliography of bat publications (published literature, theses and agency reports, and state agency files) for the U.S. and Territories.

FORT scientists convened a scientific workshop to evaluate the current status of bat populations and the methods used to estimate their trends and to develop scientific goals for future monitoring programs. Participants included experts in bat biology, wildlife population monitoring, and wildlife population estimation. This workshop resulted in the publication, Monitoring Trends in Bat Populations of the United States and Territories: Problems and Prospects, which includes a summary and analysis of the BPD v.1 data and its utility in guiding the design of future monitoring programs.

In the years since completion of BPD v.1 and the workshop report, North American bat populations have continued to decline. Of particular concern have been the precipitous declines of hibernating bats affected by white-nose syndrome (WNS), a novel fungal pathogen, as well as the significant threat to migrating bats from increasing wind-energy development. These combined threats have generated renewed interest for data suitable for bat population estimation and trend analysis. Currently, USGS scientists are responding to this need by upgrading, updating, and extending the capabilities of BPD v.1 for better data management, accessibility, and utility by USGS and data partners. The ultimate goal for this project is to provide a database framework for a North American Bat Monitoring Program (see also "Developing a North American Bat Monitoring Program" description).

Development of the next version of the database, BPD v. 2, began in April 2012, with a subsequent beta release provided to a set of users to report any bugs or make suggestions for additional features. This beta release provided users with the ability to test the search capability of bibliographic references pertaining to bat populations by various locations, date, and species, and to perform searches for particular species and display range distributions on interactive maps. BPD v.2 became fully operational and replaced the existing BPD v. 1 in January 2013.
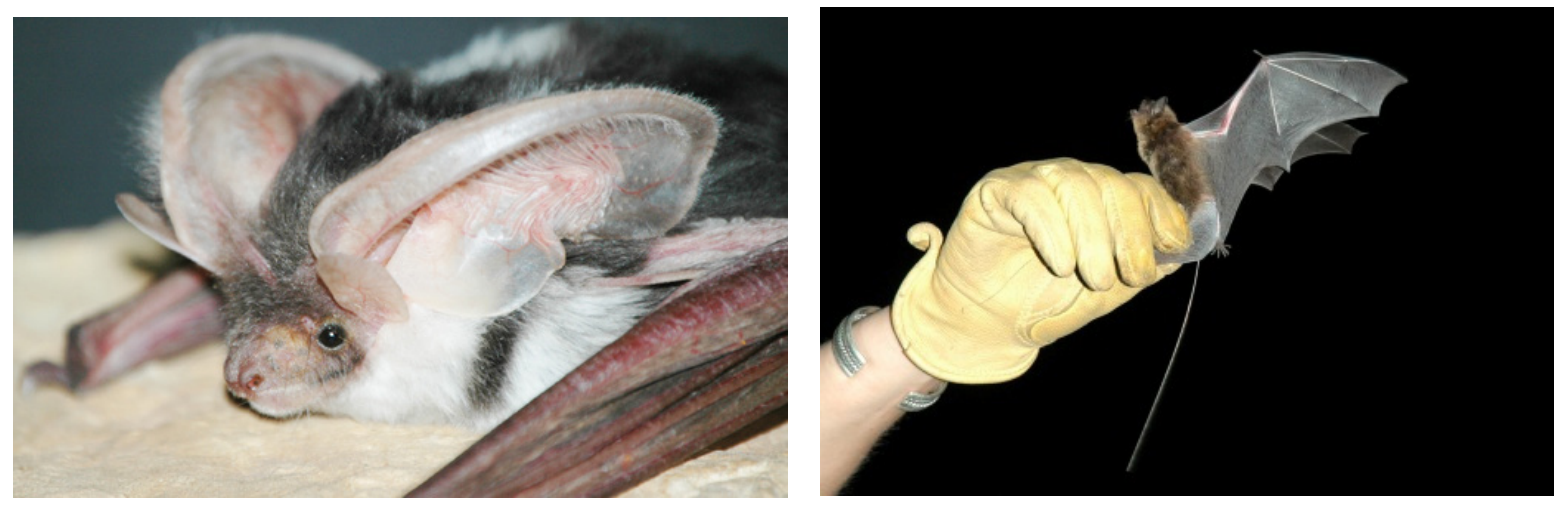

(Left) Spotted bat (Euderma maculatum). (Right) Long-legged myotis (Myotis volans) being released with radio tag. USGS photos by Dan Neubaum.

\section{Contact: Laura Ellison}




\section{NEIIV Greater Sage-Grouse or Not? Using Genomic Methods to Resolve Taxonomic Uncertainty}

Presently, sage-grouse are divided into two species (greater and Gunnison) based on genetic differences as well as morphology (physical characteristics) and behavior. Within the greater sage-grouse range, however, is a population along the border between California and Nevada (the bi-state population) that has been shown to be genetically unique, such that some experts question whether this might or might not be a distinct species. Unlike Gunnison sage-grouse, the bi-state birds are behaviorally and morphologically similar to other greater sage-grouse. The genetic data used to characterize these divisions were generated from a small number of genetic markers. Since then, new advances in conservation genetics offer the ability to expand the amount of genome sampled and locate fast-evolving regions that contribute to observable differences between individuals or populations. In FY2012 and FY2013, when FORT researchers re-examined these divisions using next-generation sequencing-a genomic approach with many thousands more markers spread throughout the genome-they found that the bi-state population, though still genetically different from the rest of the greater sage-grouse population in some ways, is not different in the DNA markers that are under selection-markers that code for things such as behavior and morphology. Such differences in coding genes found in Gunnison sagegrouse that are absent from the bi-state population provide clues as to why Gunnison sage-grouse was designated as a separate species These genomic methods provide much more comprehensive answers to what have been, up until now, problematic questions.
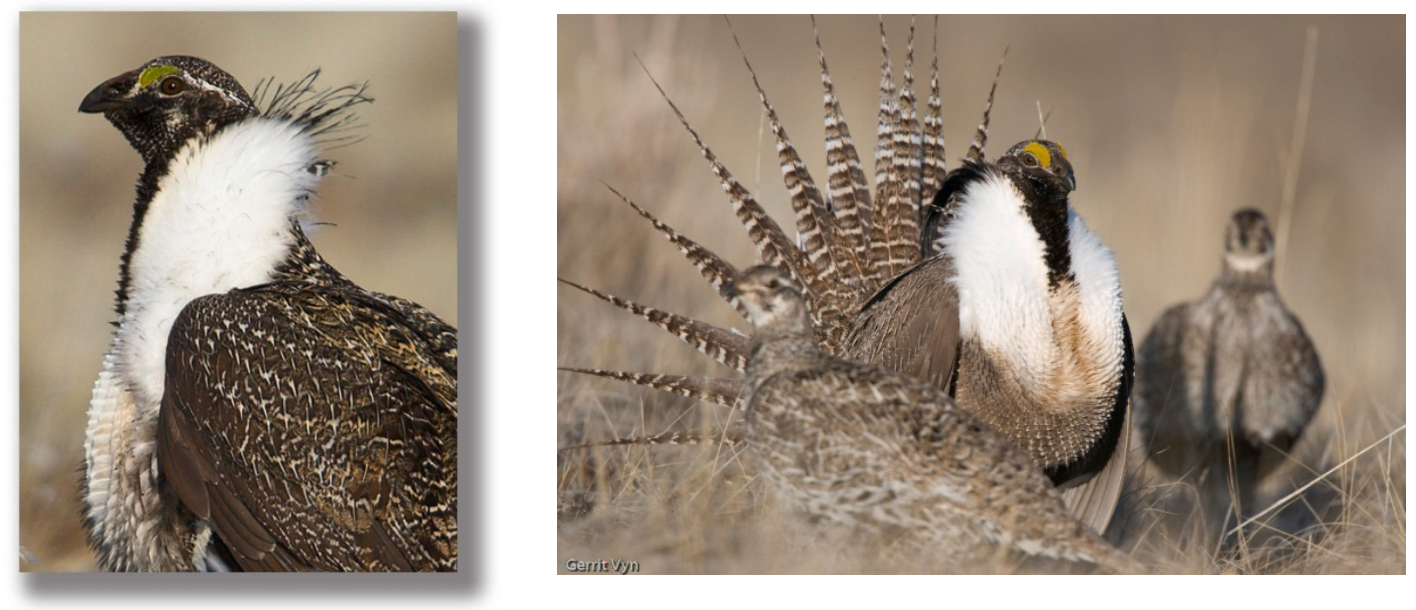

(Left) Greater sage-grouse. Photo by Stephen Ting. (Right) Gunnison sage-grouse. Photo by Gerrit Vyn.

Contact: Sara Oyler-McCance 


\section{Weather Radar Identifies Bird Migration Stopover Habitat in the Arid Southwest}

Twice a year, millions of North American landbirds migrate thousands of miles between their breeding and wintering grounds. Research has shown that this is arguably the most hazardous period of a migratory bird's annual life cycle. An increased understanding of the types of habitats used by migratory birds during stopover can help inform natural resource managers. The United States-Mexico borderlands region typifies the potentially inhospitable arid and mountainous landscapes that western birds traverse during migration; the great majority of western migratory species funnel through this region. Thus, conservation and protection of important migratory habitats in this region are crucial for successful migration. Recognizing the need for research at broader spatial scales than could be conducted using traditional field methodologies, FORT collaborated with the U.S. Fish and Wildlife Service and University of Southern Mississippi to use weather surveillance radar and satellite-based land use and land cover data to study bird stopover habitat associations at broad spatial and temporal scales. A paper describing their findings, Migrating Birds' Use of Stopover Habitat in the Southwestern United States, was published in 2012 in "The Condor," providing information on the habitats with which birds are associated during migration stopover. Although other research has documented the value of riparian habitat for migrants stopping over in the Southwest, these results indicate that the use and importance of stopover habitat is very complex. In parts of Arizona and New Mexico, upland forest supported high densities of migrants, especially in fall. Developed habitats (e.g., suburban areas) in arid areas with little upland forest also supported high migrant densities. Scrub/shrub and grassland habitats supported low to intermediate migrant densities, however, because these habitat types dominate the Southwestern landscape, they may provide stopover habitat for larger numbers of migratory birds than previously recognized. This is particularly the case for short-distance migrant grassland and shrubland birds that require these habitats during migration. This publication is expected to be used by managers and scientists as a basis for future research, monitoring, and management of migratory birds and their habitats in the United States-Mexico Borderlands region.

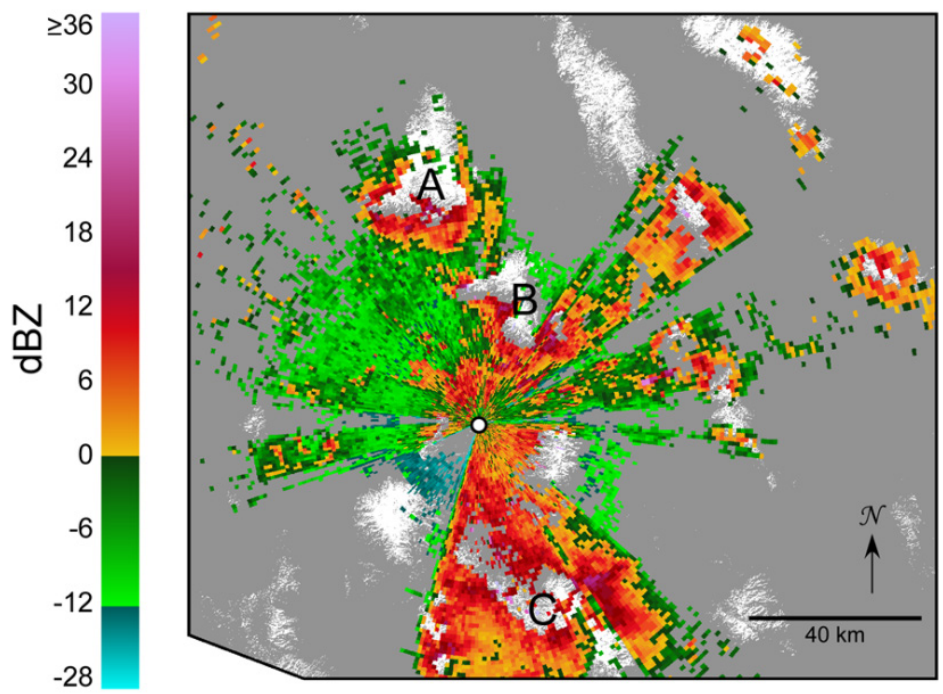

Radar reflectivity over simplified land cover near Tucson, Arizona, 14 May 2005, 19:47 MST. Location of the radar is indicated by a white dot. Upland forest is shown in white with all other land cover types grayed. Letters indicated mountain ranges-Santa Catalina Mountains (A), Rincon Mountains (B), and Huachuca Mountains (C) -that interfere with propagation of the radars beam. Voids in the radar data occur around high altitude evergreen areas where relief in terrain (taller mountain peaks) causes the radar to reject these reflectivities as ground clutter. The red/purple colored radar targets, frequently surrounding the upland forest habitat and/or tall mountain peaks, indicate concentrations of migrants taking off to initiate migration.

\section{Product:}

Ruth, J.M., Diehl, R.H., and Felix, R.K. Jr., 2012, Migrating birds' use of stopover habitat in the southwestern United States: The Condor, v. 114, no. 4, p. 698-710.

\section{Contact: Janet Ruth}




\section{Implications of Climate Change for Avian Conservation in Great Plains Landscapes}

The vulnerability of wetland-dependent avian species in the face of impending climate and land use change is of major concern to land managers within the U.S. Department of the Interior. In FY2012 and FY2013, in cooperation with the USGS South Dakota Water Science Center, the National Center for Atmospheric Research, and the University Corporation for Atmospheric Research, FORT provided downscaled climate models for use in determining where to best apply conservation actions. High-resolution models nest a dynamical Regional Climate Model within the general circulation model (GCM), thereby re-running the GCM based on physics and first principles. Our high-resolution model used the Community Climate System Model (CCSM) at one emissions scenario (A2) to set the boundary condition, and it used a mesoscale model, the Weather Research and Forecasting (WRF) model, to refine the data to a $36-\mathrm{km}$ regional scale. We have completed the dynamical downscaling for the contiguous 48 states and southern Canada.

For clients within the Plains and Prairie Pothole Landscape Conservation Cooperative and the Prairie Pothole Joint Venture of the U.S. Fish and Wildlife Service, we summarized projected climate for the Prairie Pothole region of North Dakota, South Dakota, Minnesota, and Iowa. Temperatures are expected to increase on average by $3.9^{\circ} \mathrm{C}$ and precipitation to increase by $17 \mathrm{~mm} / \mathrm{yr}$. (about a 3 percent increase) from the baseline period of 1981-2000 to the decade 2040-2049. Additional post-processing and analyses of projected temperature, precipitation, and soil moisture are currently underway.

Project staff modeled the probability of occurrence of breeding wetland-dependent birds during contemporary (1981-2000) and future (2040-2049) time periods relative to several predictors of land-use patterns, wetland distribution, and the dynamically downscaled climate data described above. Using a Random Forest approach to species distribution modeling, we based the models on Breeding Bird Survey data from 1971-2010 and made future projections using two climate models. Projected loss of breeding range of 31 wetland-dependent bird species within the Prairie Pothole region of North Dakota, South Dakota, Minnesota, and Iowa averaged 45.6 percent ( \pm 26.9 standard deviation) and ranged from 100 percent loss to 8 percent gain. For example, the black tern (Chlidonias niger) may experience a 66 percent loss in contemporary range within the study area. In general, species distributions were most strongly influenced by wetland distribution and upland land use patterns, yet vulnerable species distributions were most strongly influenced by precipitation and temperature. In ongoing work, we will explore life history and microhabitat correlates of this suite of species to provide management insights into these vulnerability patterns.
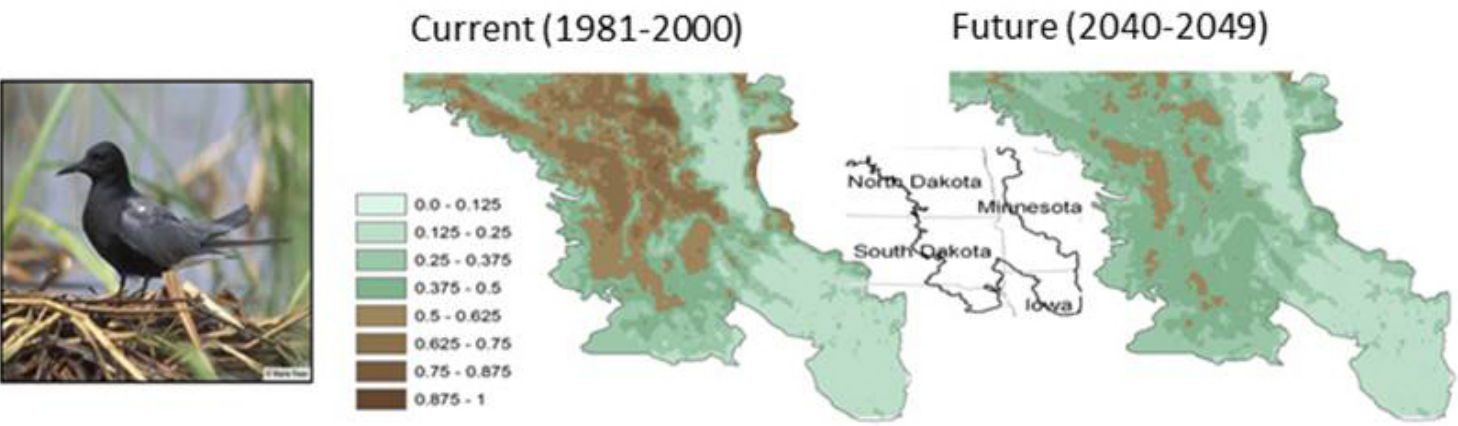

Predicted current and projected future distributions of black tern in the prairie pothole region of North Dakota, South Dakota, Minnesota, and lowa. Areas where the species is expected to occur (probability of occurrence $>0.05$ ) are shown as brown. Photo of black tern by Marie Read. USGS map images from Steen, V., Skagen, S.K., and Noon, B.R., 2014, Towards assessing vulnerability of breeding waterbirds to climate change in the Prairie Pothole Region, USA: PLoS ONE 9(6).

Contact: Susan Skagen 
The Bureau of Land Management (BLM) manages more than 245 million acres of surface land in the United States. These lands are managed for a variety of uses, including recreation, grazing, energy development, and timber harvest. Making decisions about how to manage these lands while protecting natural, cultural, and historic features requires collaboration among a variety of stakeholders.

The BLM provides training and support for collaboration and partnership development to its employees, under the direction of the agency's Washington Office Collaborative Stakeholder Engagement and Appropriate Dispute Resolution program. In order to maximize the efforts of stakeholder engagement activities, the program is developing a Strategic Plan for Collaboration. Researchers in the Policy Analysis and Science Assistance Branch of the FORT are working with the BLM on a needs assessment, which will help direct the efforts of the BLM/DOI strategic planning team.

The first step of the needs assessment was a survey of BLM employees to seek answers to four primary questions:

1. What information sources and assistance resources are BLM employees currently accessing to fill their conflict/dispute resolution and collaboration needs?

2. What are the perceived information and resource needs of BLM employees associated with conflict/dispute resolution and collaboration? What information and resources can the BLM Collaboration/ADR Program provide to fill BLM employee needs?

3. What is the BLM employee level of knowledge associated with conflict/dispute resolution and collaboration?

4. What are the attitudes and perceptions of BLM employees toward conflict/dispute resolution and collaboration?

Approximately 6,700 BLM employees were asked to respond to an online survey that was developed by PASA researchers in collaboration with the BLM project sponsors. The survey response rate was about 50 percent.

The survey results are being used by BLM as part of the strategic planning process because they provide information about existing capacity and attitudes and illuminate gaps that could be filled by specific actions in the strategic plan. The PASA researchers have been interacting with the BLM sponsors and the Strategic Planning team as the plan is being developed. A report of the survey findings is in preparation and will be released as an Open-File Report in FY2014.

\section{Contact: Rudy Schuster}




\section{Energy and Minerals, and Environmental Health}

\section{Core Research Center Well Catalog}

The Core Research Center (CRC) was established by the USGS in 1974 to preserve valuable rock cores for use by scientists and educators from government, industry, and academia. In FY2012 and FY2013, the FORT Web Applications Team worked with CRC staff to implement a geospatial webenabled Well Catalog Cores Database and Cuttings Database (http://my.usgs.gov/crcwc). This effort allows public users to locate cores and cuttings available for study.

Using an Agile project management approach, the Web Applications team refactored and spatially enabled the legacy core database, generated a set of interactive mapping views of the data, developed data search and export options, and built ways for the CRC staff to administer the database and search functions. The team designed the application to be deployed in a cloud-based hosting environment and ensured the system met all Federal and U.S. Department of Interior security requirements.

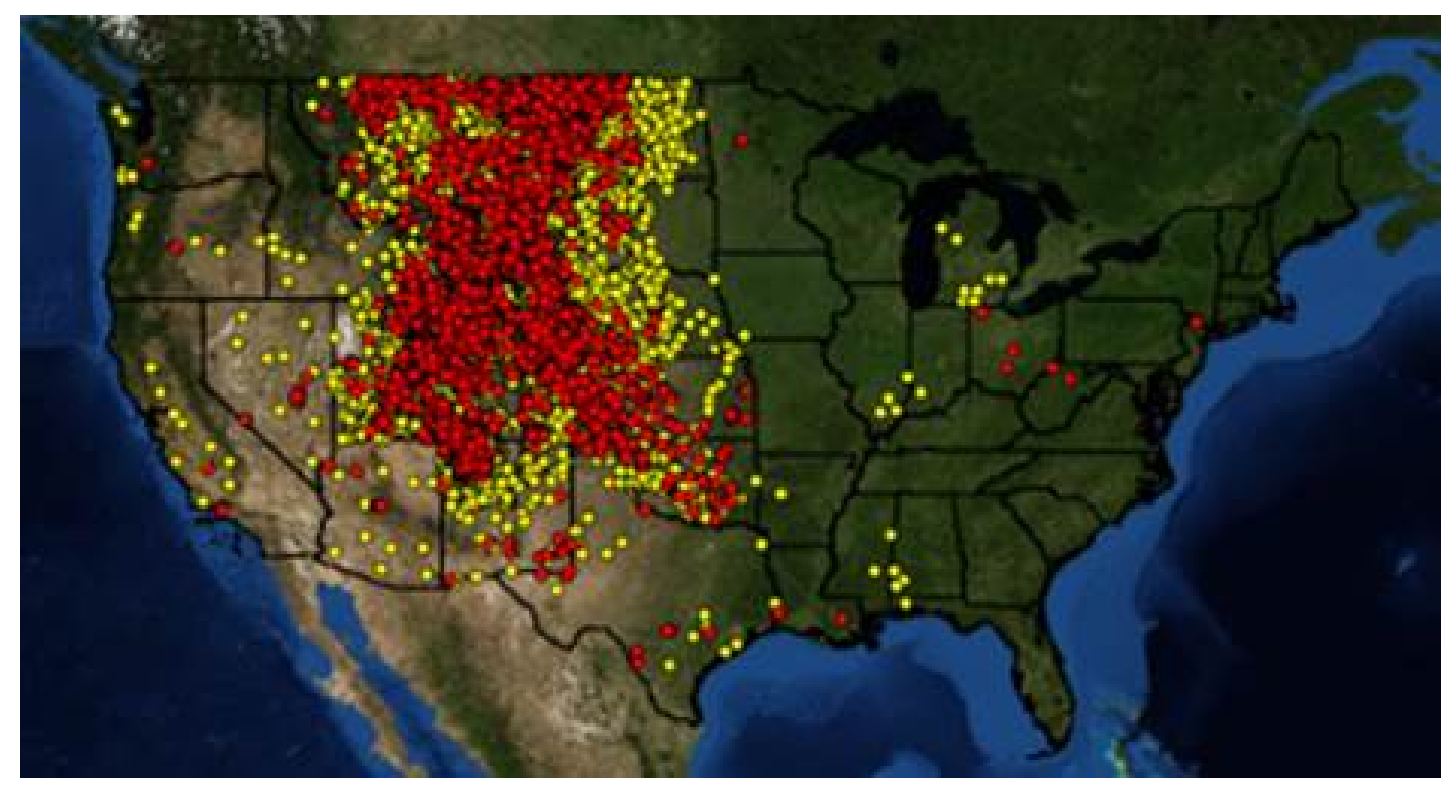

Screen capture of Well Catalog map-based search page. USGS image.

\section{Product:}

http://my.usgs.gov/crcwc

Contact: Gail Montgomery 
In 2011, scientists at FORT developed a laboratory facility where a variety of experiments on lake, stream, and riparian ecosystems will be conducted. The goal of this facility is to enable scientists to address a broad array of resource management issues related to stream ecology, contaminant exposure and food webs, climate change, aquatic-riparian linkages, and invertebrate taxonomy. Our research questions include:

1. What are the effects of trophic transfer (dietary consumption), growth, and metamorphosis on chemical signatures in the environment?

2. What are the effects of climate change on mineral weathering, stream chemistry, and chemical exposure on stream communities?

3. What are the main pathways of organism and contaminant movement between aquatic and riparian ecosystems, and how big are these fluxes?

In 2012, the first manipulative experiment was successfully completed at the facility. In this experiment, larval mayflies were collected from a nearby stream and raised to adulthood in the artificial streams, which contained varying levels of zinc - reflecting the natural gradient in alpine ecosystems in Colorado. This 19-day experiment generated promising preliminary data, showing differential emergence across the zinc gradient. Ongoing analyses from this experiment will address the following questions:

1. How does zinc pollution alter the development and survival of stream insects?

2. Do zinc concentrations differ between adult and larval insects?

3. Do stable isotope ratios vary between larval and adult insects?

Insects from this experiment were analyzed for metal concentrations during winter 2012-2013. The resulting data address each of the above research objectives, and will provide crucial information to the goal of understanding how contaminants move between aquatic and terrestrial ecosystems.

Future planned experiments in the artificial streams will benefit from protocols established in this initial experiment. In addition, FORT recently acquired peristaltic pumps, which will increase the precision of water chemistry manipulations.

USGS collaborators for the laboratory include scientists at FORT, the Colorado Water Science Center, and the Crustal Geophysics and Geochemistry Science Center. External collaborators include the National Park Service, Colorado Division of Parks and Wildlife, and the Metal Environmental Research Association.

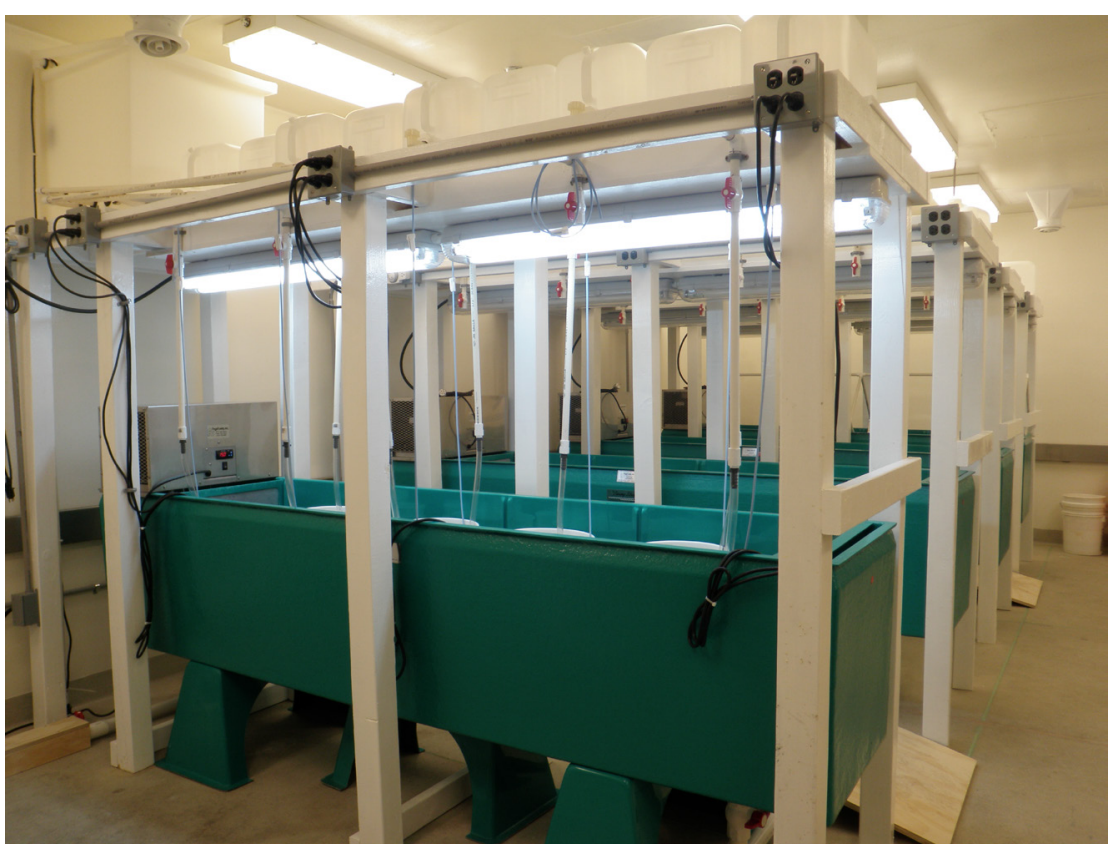

The new Aquatic Experimental Laboratory at FORT includes environmentally controlled aquatic ecosystems and walk-in chambers equipped with independent microcosms capable of simulating stream, lake, and adjacent riparian environments. Photo by Robert E. Zuellig, USGS.

\section{Contact: David Walters}




\section{Natural Hazards}

\section{National Earthquake Information Center Support}

The National Earthquake Information Center (NEIC) compiles and maintains an extensive, global seismic database on earthquake parameters and their effects that serves as a solid foundation for basic and applied earth science research. NEIC also continuously researches new ways to quickly disseminate this information to concerned national and international agencies, scientists, and the general public. The challenge facing NEIC is centered on finding and implementing more efficient ways to distribute the scientific information being generated from multiple NEIC data feeds. To help meet this challenge, in FY2012 and FY2013 the Fort Collins Science Center Web Applications Team supplied both Agile project management and software development support for a number of projects:

- Tweet Earthquake Dispatcher project (@USGSted)_USGS Tweet Earthquake Dispatch distributes alerts for earthquakes worldwide with magnitudes of 5.5 and above. These earthquake tweets contain a magnitude descriptor, location, origin time, and a link to the USGS webpage with the most recent information about the event. In addition to the seismically derived parameters, the alerts also include the frequency of tweets in a region surrounding the event. The Web Applications Team developed the methodology to harvest tweets that contain the word "earthquake" or its equivalent in several languages, techniques to recapture tweets in the event of service interruptions, and moving the application toward an enterprise release.

- NEIC Executive Summary Tool (NEST)_After a significant earthquake, an earthquake coordinator distributes a summary of the event and Earthquake Center actions to a limited high-level USGS audience. This reporting is done within one hour of the event, with updates as more information becomes available. The Web Applications Team worked with NEIC staff to design a tool that earthquake coordinators could use to pull event parameters (e.g., location, magnitude, PAGER loss estimates) from NEIC systems and build customized reports for the target audience. The tool was designed to be extremely easy to use when the coordinators are working long hours under significant stress, providing a quick and easy way to assemble and view event-relevant information and provide a framework to evaluate other additional information.

- ShakeCast-ShakeCast is distributed software that automates ShakeMap delivery to institutions for the notification of shaking levels at user-selected facilities (ShakeMap provides near-real-time maps of ground motion and shaking intensity following significant earthquakes). The Web Applications Team joined the ShakeCast team to help develop new versions of the software, provide deployment and upgrade support, and design novel approaches for additional information delivery.

- Geomagnetism Reporting Tool (GeoMag)_National Geomagnetism Program performs real-time monitoring of the Earth's magnetic field. The Web Applications Team worked with NEIC staff to design a new approach to accessing geomagnetism observatory data and deliver real-time re-scalable charting of these data.

- Database Conversion Support-The Web Applications Team worked with NEIC staff to convert back end database management from a proprietary to open-source solution and refactored the front end source code to conform to the database changes.

\section{Contact: Gail Montgomery}




\section{Water}

NEmy) Assessing Potential Effects of Hydraulic Fracturing for Energy Development on Water Resources

Production of oil and gas from "unconventional" plays (low-permeability reservoirs of shale gas, shale oil, and tight-sands gas) is increasing in the U.S. Extracting hydrocarbons from a low permeability rock formation requires increasing its permeability by hydraulic fracturing. Fractures created during well completion are expanded by injecting fluids under high pressure and then propped open by sands suspended in the fluids. This requires large volumes of water and involves various chemical additives, potential penetration of aquifers, and waste-product disposal. News sources report many claims that hydraulic fracturing has deleterious effects on water resources; however there is little scientific information to support or refute these claims. To help fill this data gap, USGS scientists from the FORT and two other centers received a grant (in FY2011) from the USGS John Wesley Powell Center for Analysis and Synthesis to lead the first broad-scale, data-based assessment of hydraulic fracturing's potential effects on water resources in the U.S. A team of 12 hydrologists, geologists, statisticians, and database management specialists was assembled to conduct the analyses, syntheses, and product development.

In FY2012, the team completed the process of acquiring and assembling national water-quality datasets for both surface water and groundwater, and identified the analytes, or parameters, in the databases that might be suitable for assessing effects of hydraulic fracturing on water resources. The team then developed statistical approaches to analyze the data, and conducted initial analyses. The team also developed two products: a USGS fact sheet about the project and an online application (FRAC-CITE) that provides a regularly updated bibliography of current research articles and reports on potential environmental effects of hydraulic fracturing. For the fact sheet, the team developed maps to show, by hydrologic unit code (HUC), the number of (1) oil and gas wells in the U.S., and the number of (2) groundwater and (3) surface water samples contained in the national water-quality datasets (USGS National Water Information System and the Environmental Protection Agency's STORET database). FRAC-CITE was developed primarily for other scientists conducting investigations on effects of hydraulic fracturing, but it will be useful to policymakers, decisionmakers, and the public as well by providing "one-stop shopping" for the most up-to-date research on the potential effects of hydraulic fracturing on other natural resources.

Upcoming products are expected to report results from the Powell study and identify research and monitoring needed to better address questions regarding the potential effects of hydraulic fracturing on water resources in the United States.

\section{Products:}

Susong, D., Gallegos, T., and Oelsner, G., 2012, Water Quality Studied in Areas of Unconventional Oil: U.S. Geological Survey Fact Sheet 2012-3409, online at http://pubs.usgs.gov/fs/2012/3049/FS123049_508.pdf.

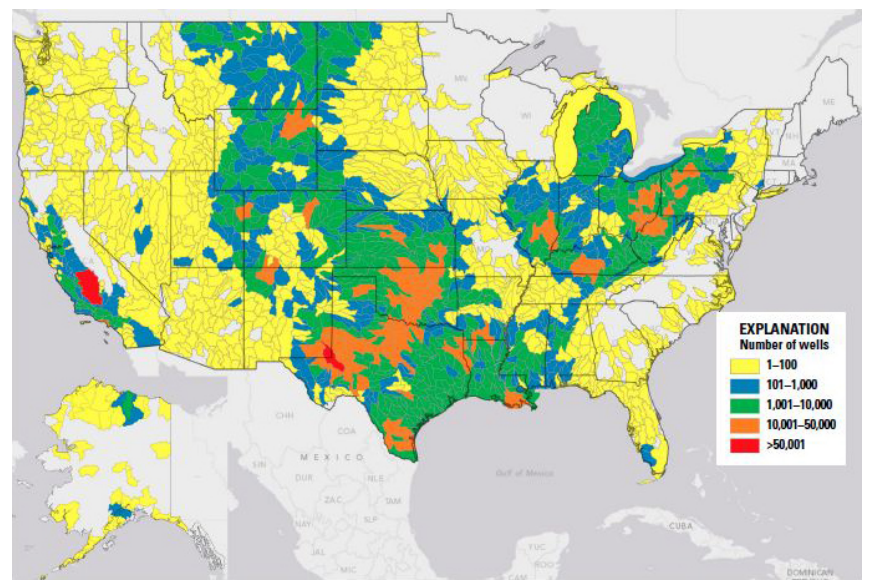

The new Aquatic Experimental Laboratory at FORT includes environmentally controlled aquatic ecosystems and walk-in chambers equipped with independent microcosms capable of simulating stream, lake, and adjacent riparian environments. Photo by Robert E. Zuellig, USGS.

\section{Contact: Zack Bowen}


Table 2. FORT Publications and Other Information Products Released in FY2012 and FY2013.

\begin{tabular}{|c|c|}
\hline Publication Type & Citation \\
\hline \multicolumn{2}{|r|}{ Climate and Land-Use Change } \\
\hline Web App & $\begin{array}{l}\text { O’Malley, R., Fort, E., Hartke-O’Berg, N., and Varela-Acevedo, E., 2012, National } \\
\text { Climate Change and Wildlife Science Center Web site: U.S. Geological Survey, at } \\
\text { https://nccwsc.usgs.gov/. }\end{array}$ \\
\hline Web App & $\begin{array}{l}\text { Thenkabail, P.S., and Mariotto, I., 2012, John Wesley Powell Center Working Group on } \\
\text { global croplands and water use for food security in the } 21 \text { st Century Web site: U.S. } \\
\text { Geological Survey, at https://powellcenter.usgs.gov/globalcroplandwater/home. }\end{array}$ \\
\hline Web App & $\begin{array}{l}\text { Turnquist, M., and Eagles-Smith, C., 2012, John Wesley Powell Center working group on } \\
\text { mercury cycling, bioaccumulation, and risk across North America Web site: U.S. } \\
\text { Geological Survey, https://powellcenter.usgs.gov/mercnet/home. }\end{array}$ \\
\hline Data & $\begin{array}{l}\text { O'Donnell, M.S., and Ignizio, D.A., 2012, Bioclimatic predictors for supporting } \\
\text { ecological applications in the conterminous United States: U.S. Geological Survey Data } \\
\text { Series } 691 .\end{array}$ \\
\hline Journal & $\begin{array}{l}\text { Perry, L.G., Andersen, D.C., Reynolds, L.V., Nelson, S.M., and Shafroth, P.B., 2012, } \\
\text { Vulnerability of riparian ecosystems to elevated } \mathrm{CO}_{2} \text { and climate change in arid and } \\
\text { semiarid western North America: Global Change Biology, v. 18, no. 3, p. 821-842. }\end{array}$ \\
\hline Journal & $\begin{array}{l}\text { Andersen, D.C., and Nelson, S.M., 2013, Floral ecology and insect visitation in riparian } \\
\text { Tamarix sp. (saltcedar): Journal of Arid Environments, v. 94, p. 105-112. }\end{array}$ \\
\hline Journal & $\begin{array}{l}\text { Grant, G.E., Tague, C.L., and Allen, C.D., 2013, Watering the forest for the trees-An } \\
\text { emerging priority for managing water in forest landscapes: Frontiers in Ecology and the } \\
\text { Environment, v. 11, no. 6, p. 314-321. }\end{array}$ \\
\hline Open-File Report & $\begin{array}{l}\text { Homer, C.G., Aldridge, C.L., Meyer, D.K., and Schell, S.J., 2013, Multiscale sagebrush } \\
\text { rangeland habitat modeling in the Gunnison Basin of Colorado: U.S. Geological Survey } \\
\text { Open-File Report 2013-1049, p.1-12. }\end{array}$ \\
\hline Journal & $\begin{array}{l}\text { Morisette, J.T., Jarnevich, C.S., Holcombe, T.R., Talbert, C.B., Ignizio, D., Talbert, M.K., } \\
\text { Silva, C., Koop, D., Swanson, A., and Young, N.E., 2013, VisTrails SAHM- } \\
\text { Visualization and workflow management for species habitat modeling: Ecography, v. 36, } \\
\text { no. 2, p. 129-145. }\end{array}$ \\
\hline Web App & $\begin{array}{l}\text { O’Malley, R., Fort, E., Hartke-O’Berg, N., Varela-Acevedo, E., and Padgett, H., 2013, } \\
\text { National Climate Change and Wildlife Science Center, Version } 2.0 \text { Web site: U.S. } \\
\text { Geological Survey, at https://nccwsc.usgs.gov/. }\end{array}$ \\
\hline Abstract & $\begin{array}{l}\text { Friedman, J.M., Edmondson, J.R., Griffin, E.R., Meko, D.M., Merigliano, M.F., Scott, } \\
\text { J.A., Scott, M.L., and Touchan, R., 2012, Cottonwood tree rings and climate in western } \\
\text { North America [abs.]: 45th Annual Fall Meeting of the American Geophysical Union, } \\
\text { San Francisco, Calif., December 3-7, 2012, p. 1. }\end{array}$ \\
\hline Report, pages in & $\begin{array}{l}\text { Friedman, J.S., Roelle, J.E., and Cade, B.S., 2012, Genetic and environmental influences } \\
\text { on cold hardiness of native and introduced riparian trees, in Haase, D.L., Pinto, J.R., and } \\
\text { Riley, L.E., (tech coords.), National Proceedings-Forest and Conservation Nursery } \\
\text { Associations, 2011, Fort Collins, Colo.: USDA Forest Service, Rocky Mountain Research } \\
\text { Station, p. } 82-86 .\end{array}$ \\
\hline Journal & $\begin{array}{l}\text { Merigliano, M.F., Friedman, J.M., and Scott, M.L., 2013, Tree-ring records of variation } \\
\text { in flow and channel geometry: Treatise on Geomorphology, v. 12, p. 145-164. }\end{array}$ \\
\hline
\end{tabular}


Table 2. FORT Publications and Other Information Products Released in FY2012 and FY2013.-Continued

\begin{tabular}{|c|c|}
\hline Publication Type & Citation \\
\hline \multicolumn{2}{|r|}{ Core Science Systems } \\
\hline Open-File Report & $\begin{array}{l}\text { Bristol, R.S., Euliss Jr., N.H., Booth, N.L., Burkardt, N., Diffendorfer, J.E., Gesch, D.B., } \\
\text { McCallum, B.E., Miller, D.M., Morman, S.A., Poore, B.S., Signell, R.P., and Viger, R.J., } \\
\text { 2012, Science strategy for Core Science Systems in the U.S. Geological Survey, 2013- } \\
\text { 2023, Public Review Release: U.S. Geological Survey Open-File Report 2012-1093, p. } \\
29 .\end{array}$ \\
\hline Fact Sheet & $\begin{array}{l}\text { Kern, T., 2012, U.S. Geological Survey community for data integration-Data upload, } \\
\text { registry, and access tool: U.S. Geological Survey Fact Sheet 2012-3074, p. } 2 .\end{array}$ \\
\hline Web App & $\begin{array}{l}\text { Maluk, T.L., 2012, Web, hosting, and application registry Web site: U.S. Geological } \\
\text { Survey. }\end{array}$ \\
\hline Web App & $\begin{array}{l}\text { Taggart, B.E., and Gilroy, B.K., 2012, U.S. Geological Survey Leetown Science Center } \\
\text { Web site: U.S. Geological Survey, http://www.lsc.usgs.gov/. }\end{array}$ \\
\hline Report, pages in & $\begin{array}{l}\text { Bristol, D.A., Fenn, M.E., and Baron, J.S., 2012, Effects of acid deposition on } \\
\text { ecosystems-Advances in the state-of-the science [Chapter 3], in Burns, D.A., National } \\
\text { Acid Precipitation Assessment Program Report to Congress-An Integrated Assessment: } \\
\text { The White House Office of Science and Technology Policy, p. 45-70. }\end{array}$ \\
\hline Web App & $\begin{array}{l}\text { Govoni, D.L., and Self-Trail, J.M., 2012, 14th International Nannoplankton Association } \\
\text { Meeting Web site, in Reston, Va., September 15-21, } 2013 \text { Web site, } \\
\text { https://my.usgs.gov/ina14/. }\end{array}$ \\
\hline Web App & $\begin{array}{l}\text { Montag, J.M., Willis, C., Glavin, L., Eberhardt Frank, M.K., Everette, A.L. Peterson, K. } \\
\text { Nicoud, S., and Novacek, A., 2013, Western Energy Citation Clearinghouse (v.1) Web } \\
\text { site: U.S. Geological Survey, http://www.wlci.gov/wecc/. }\end{array}$ \\
\hline Web App & $\begin{array}{l}\text { Swanjord, K., Fuller, H.K., and Ahmed, A., 2013, U.S. Geological Survey frequently } \\
\text { asked questions Web site-v. 2.0: U.S. Geological Survey, } \\
\text { http://www.usgs.gov/faq/home. }\end{array}$ \\
\hline \multicolumn{2}{|r|}{ Ecosystems-Terrestrial, Freshwater, and Marine Ecosystems } \\
\hline Open-File Report & $\begin{array}{l}\text { Wilson, J.T., [comp.], 2012, Fort Collins Science Center FY2011 accomplishments } \\
\text { report: U.S. Geological Survey Open-File Report 2012-1169, p. } 107 .\end{array}$ \\
\hline Abstract & $\begin{array}{l}\text { Assal, T.J., Anderson, P.J., and Urza, A.K., 2012, Assessment and monitoring of semi- } \\
\text { arid woodlands in the Little Mountain ecosystem [abs.], in Third Wyoming Landscape } \\
\text { Conservation Initiative (WLCI) Science Meeting, Rock Springs, Wyo., May 14-17, } \\
\text { 2012,: U.S. Geological Survey, p. 1. }\end{array}$ \\
\hline Abstract & $\begin{array}{l}\text { Germaine, S., Kemper, J., Woolwine, D., and Ignizio, D., 2012, Identifying the } \\
\text { relationship between natural gas energy development and Pygmy Rabbit (Brachylagus } \\
\text { Idahoensis) site occupancy [abs.], in Third Wyoming Landscape Conservation Initiative } \\
\text { (WLCI) Science Workshop, Rock Springs, Wyo., May 14-17, 2012: Reston, Va., U.S. } \\
\text { Geological Survey, p. 1. }\end{array}$ \\
\hline Abstract & $\begin{array}{l}\text { Montag, J.M., Willis, C., and Glavin, L., 2012, Western Energy Citation Clearinghouse } \\
\text { (WECC) [abs.] -Wyoming Landscape Conservation Initiative (WLCI) Third Science } \\
\text { Workshop, May 14-17, 2012, Rock Springs, Wyo.: Reston, Va., U.S. Geological Survey, } \\
\text { p. } 1 .\end{array}$ \\
\hline
\end{tabular}


Table 2. FORT Publications and Other Information Products Released in FY2012 and FY2013.-Continued

\begin{tabular}{|c|c|}
\hline Publication Type & Citation \\
\hline Journal & $\begin{array}{l}\text { Aldridge, C.L., Saher, D.J., Childers, T.M., Stahlnecker, K.E., and Bowen, Z.H., 2012, } \\
\text { Crucial nesting habitat for Gunnison sage-grouse-A spatially explicit hierarchical } \\
\text { approach: The Journal of Wildlife Management, v. 76, no. 2, p. 391-406. }\end{array}$ \\
\hline Abstract & $\begin{array}{l}\text { Auble, G., 2012, Riparian forests in dry landscapes [abs.], in Third Wyoming Landscape } \\
\text { Conservation Initiative (WLCI) Science Workshop, Rock Springs, Wyo., May 14-17, } \\
\text { 2012: Reston, Va., U.S. Geological Survey, p. 1. }\end{array}$ \\
\hline Journal & $\begin{array}{l}\text { Blum, M.J., Bagley, M.J., Walters, D.M., Jackson, S.A., Daniel, F.B., Chaloud, D.J., and } \\
\text { Cade, B.S., 2012, Genetic diversity and species diversity of stream fishes covary across a } \\
\text { land-use gradient: Oecologia, v. } 168 \text {, no. 1, p. } 83-95 .\end{array}$ \\
\hline Journal & $\begin{array}{l}\text { Castoe, T.A., Poole, A.W., Koning, A.P., Jones, K.L., Tomback, D.F., Oyler-McCance, } \\
\text { S.J., Fike, J.A., Streicher, J.W., Smith, E.N., and Pollock, D.D., 2012, Rapid } \\
\text { microsatellite identification from Illumina paired-end genomic sequencing in two birds } \\
\text { and a snake: PLoS ONE, v. 7, no. 2, p. 1-10. }\end{array}$ \\
\hline Journal & $\begin{array}{l}\text { Cooper, D.J., and Andersen, D.C., 2012, Novel plant communities limit the effects of a } \\
\text { managed flood to restore riparian forests along a large regulated river: River Research and } \\
\text { Applications, v. } 28 \text {, no. } 2 \text {, p. 204-215. }\end{array}$ \\
\hline Abstract & $\begin{array}{l}\text { Fedy, B., Aldridge, C., Doherty, K., O’Donnell, M., Beck, J., Bedrosian, B., Holloran, } \\
\text { M., Kirol, C., Marshall, D., McKee, G., Mandich, C., Olson, C., Johnson, G., and Walker, } \\
\text { B., 2012, State-wide seasonal habitat selection in Wyoming greater sage-grouse [abs.], in } \\
\text { Third Wyoming Landscape Conservation Initiative (WLCI) Science Meeting, Rock } \\
\text { Springs, Wyo., May 14-17, 2012: Reston, Va., U.S. Geological Survey, p. 1. }\end{array}$ \\
\hline Journal & $\begin{array}{l}\text { Glaser, P.H., Volin, J.C., Givnish, T.J., Hansen, B.C.S., and Stricker, C.A., 2012, Carbon } \\
\text { and sediment accumulation in the Everglades (USA) during the past } 4000 \text { years-Rates, } \\
\text { drivers, and sources of error: Journal of Geophysical Research-Biogeosciences, v. 117, p. } \\
1-18 .\end{array}$ \\
\hline Journal & $\begin{array}{l}\text { Greaver, T.L., Sullivan, T.J.D., Herrick, M., Barber, J., Baron, B., Cosby, M., Deerharke, } \\
\text { R., Dennis, J.J.D., Dubois, C., Goodale, A., Herlihy, G., Lawrence, L., Liu, J., Lynch, and } \\
\text { Novak, K., 2012, A synthesis of the ecological effects of air pollution from nitrogen and } \\
\text { sulfur in the U.S.: Frontiers in Ecology and Environment, v. 10, no. 7, p. 365-372. }\end{array}$ \\
\hline Journal & $\begin{array}{l}\text { Hall, E.K., Besemer, K., Kohl, L., Preiler, C., Riedel, K., Schneider, T., Wanek, W., and } \\
\text { Battin, T.J., 2012, Effects of resource chemistry on the composition and function of } \\
\text { stream hyporheic biofilms: Frontiers in Aquatic Microbiology, v. 3, no. 35, p. 1-14. }\end{array}$ \\
\hline Journal & $\begin{array}{l}\text { Homer, C.G., Aldridge, C.L., Meyer, D.K., and Schell, S.J., 2012, Multi-scale remote } \\
\text { sensing sagebrush characterization with regression trees over Wyoming, USA-Laying a } \\
\text { foundation for monitoring: International Journal of Applied Earth Observation and } \\
\text { Geoinformation, v. } 14 \text {, no. 1, p. 233-244. }\end{array}$ \\
\hline Data & $\begin{array}{l}\text { Ignizio, D.A., and Carr, N.B., 2012, Locations and attributes of utility-scale solar power } \\
\text { facilities in Colorado and New Mexico, 2011: U.S. Geological Survey Data Series } 693 .\end{array}$ \\
\hline
\end{tabular}


Table 2. FORT Publications and Other Information Products Released in FY2012 and FY2013.-Continued

\begin{tabular}{|c|c|}
\hline Publication Type & Citation \\
\hline Journal & $\begin{array}{l}\text { Johnson, W.C., Dixon, M.D., Scott, M.L., Rabbe, L., Larson, G., Volke, M., and Werner, } \\
\text { B., 2012, Forty years of vegetation change on the Missouri River floodplain: BioScience, } \\
\text { v. } 62 \text {, no. 2, p. 123-135. }\end{array}$ \\
\hline Abstract & $\begin{array}{l}\text { Meko, D., Touchan, R., Friedman, J., Edmondson, J., Scott, J., and Griffin, E., 2012, } \\
\text { Deciphering the seasonal climate signal in tree rings [abs.]-Association of American } \\
\text { Geographers Annual Meeting, Feb. 24-28, 2012, New York, N.Y.: Association of } \\
\text { American Geographers, p. 1. }\end{array}$ \\
\hline Software & $\begin{array}{l}\text { Milhous, R.T., and Waddle, T.J., 2012, Physical habitat simulation (PHABSTRACTIM) } \\
\text { software for Windows (v.1.5.1): Fort Collins, Colo., U.S. Geological Survey. }\end{array}$ \\
\hline Report, other agency & $\begin{array}{l}\text { Morris, K., Mast, A., Clow, D., Wetherbee, G., Baron, J., Taipale, C., Blett, T., Gay, D., } \\
\text { and Richer, E., 2012, } 2010 \text { Monitoring and tracking wet nitrogen deposition at Rocky } \\
\text { Mountain National Park: Denver, Colo., U.S. Department of the Interior, National Park } \\
\text { Service NPS/NRSS/ARD/NRR-2012/562, p. 34. }\end{array}$ \\
\hline Journal & $\begin{array}{l}\text { Pardo, L.H., Fenn, M.E., Goodale, C.L., Geiser, L.H., Driscoll, C.T. Allen, E.B., Baron, } \\
\text { J.S., and others, 2011, Effects of nitrogen deposition and empirical nitrogen critical loads } \\
\text { for ecoregions of the United States: Ecological Applications, v. 21, no. 8. p. 3049-3082. }\end{array}$ \\
\hline Journal & $\begin{array}{l}\text { Peters, J.M., Wolf, N., Stricker, C.A., Collier, T.R., and Martinez del Rio, C., 2012, } \\
\text { Effects of trophic level and metamorphosis on discrimination of hydrogen isotopes in a } \\
\text { plant-herbivore system: PLoS ONE, v. 7, no. 3, p. 1-7. }\end{array}$ \\
\hline Book, pages in & $\begin{array}{l}\text { Peterson, D.L., Allen, C.D., Baron, J.S., Fagre, D.B., McKenzie, D., Stephenson, N.L., } \\
\text { Fountain, A.G., Hicke, J.A., Malanson, G.P., Ojima, D.S., Tague, C.L., and van } \\
\text { Mantgem, P.J., 2011, Response of western mountain ecosystems to climatic variability } \\
\text { and change-A collaborative research approach [Chapter 8], in Beever, E.A., and Belant, } \\
\text { J.L. (eds.): Ecological consequences of climate change-Mechanisms, conservation, and } \\
\text { management: Boca Raton, Fla., CRC Press, p. 163-190. }\end{array}$ \\
\hline Journal & $\begin{array}{l}\text { Rinella, D.J., Wipfli, M.S., Stricker, C.A., and Heintz, R., 2012, Spawning salmon and } \\
\text { the fitness of stream-dwelling fishes-Marine-derived nutrients show saturating effects } \\
\text { on growth and energy storage in juvenile salmonids: Canadian Journal of Fisheries and } \\
\text { Aquatic Science, v. } 69 \text {, no. } 1, \text { p. } 73-84 \text {. }\end{array}$ \\
\hline Journal & $\begin{array}{l}\text { Schmitt, C.J., Stricker, C.A., and Brumbaugh, W.G., 2011, Mercury bioaccumulation and } \\
\text { biomagnification in Ozarkstream ecosystems: Ecotoxicology and Environmental Safety, } \\
\text { v. } 74 \text {, no. 8, p. 2215-2224. }\end{array}$ \\
\hline Journal & $\begin{array}{l}\text { Stromberg, J.C., Shafroth, P.B., and Hazelton, A.F., 2012, Legacies of flood reduction on } \\
\text { a dryland river: River Research and Applications, v. 28, no. 2, p. 143-159. }\end{array}$ \\
\hline Open-File Report & $\begin{array}{l}\text { Veblen, K.E., Pyke, D.A., Aldridge, C.L., Casazza, M.L., Assal, T.J., and Farinha, M.A., } \\
\text { 2011, Range-wide assessment of livestock grazing across the sagebrush biome: U.S. } \\
\text { Geological Survey Open-File Report 2011-1263, } 74 \text { p. }\end{array}$ \\
\hline
\end{tabular}


Table 2. FORT Publications and Other Information Products Released in FY2012 and FY2013.-Continued

\begin{tabular}{|c|c|}
\hline Publication Type & Citation \\
\hline Abstract & $\begin{array}{l}\text { Walters, D.M., Blais, J.M., Fritz, K.M., Kraus, J.M., Schmidt, T.S., and Smol, J.P., 2012, } \\
\text { Ecological subsidies-A conceptual framework for integrating ecosystem and exposure } \\
\text { studies in linked aquatic-terrestrial systems [abs.]: Society for Freshwater Science Annual } \\
\text { Meeting: Louisville, Ky., Freshwater Stewardship-Challenges and Solutions, May 20-24, } \\
\text { 2012, p. } 1 \text {. }\end{array}$ \\
\hline Science Feature & $\begin{array}{l}\text { Wilson, J.T., 2012, Investigating global change, environmental response, and } \\
\text { adaptation-Jill Baron's } 30 \text { years as an ecosystem ecologist: U.S. Geological Survey, Fort } \\
\text { Collins Science Center Web Feature, https://www.fort.usgs.gov/science-feature/130. }\end{array}$ \\
\hline Journal & $\begin{array}{l}\text { Xian, G., Homer, C., and Aldridge, C., 2012, Assessing long-term variations in sagebrush } \\
\text { habitat-Characterization of spatial extents and distribution patterns using multi-temporal } \\
\text { satellite remote-sensing data: International Journal of Remote Sensing, v. 33, no. 7, p. } \\
\text { 2034-2058. }\end{array}$ \\
\hline Journal & $\begin{array}{l}\text { Björnsen, G.A., von Dach, S.W., Price, M.F., Aspinall, R., Balsiger, J., Baron, J.S. } \\
\text { Sharma, E., Greenwood, G., and Kohler, T., 2012, Global change and the world's } \\
\text { mountains-Research needs and emerging themes for sustainable development: Mountain } \\
\text { Research and Development, v. 32, no. S1, p. S47-S54. }\end{array}$ \\
\hline Journal & $\begin{array}{l}\text { Friedman, J.S., Roelle, J.E., and Cade, B.S., 2011, Genetic and environmental influences } \\
\text { on leaf phenology and cold hardiness of native and introduced riparian trees: International } \\
\text { Journal of Biometeorology, v. } 55 \text {, no. } 6 \text {, p. } 775-787 \text {. }\end{array}$ \\
\hline Data & $\begin{array}{l}\text { Assal, T.J., Garman, S.L., Bowen, Z.H., Anderson, P.J., Manier, D., and McDougal, R.R., } \\
\text { 2012, Data resources for the Wyoming Landscape Conservation Initiative (WLCI) } \\
\text { Integrated Assessment (IA): U.S. Geological Survey Data Series } 700 .\end{array}$ \\
\hline Data & $\begin{array}{l}\text { Auble, G.T., Friedman, J.M., Shafroth, P.B., Merigliano, M.F., and Scott, M.L., 2012, } \\
\text { Woody riparian vegetation near selected stream gages in the Western United States: U.S. } \\
\text { Geological Survey Data Series } 708 .\end{array}$ \\
\hline Journal & $\begin{array}{l}\text { Cryan, P.M., Jameson, J.W., Baerwald, E.F., Willis, C.K.R., Barclay, R.M.R., Snider, E., } \\
\text { and Crichton, E.G., 2012, Evidence of late-summer mating readiness and early sexual } \\
\text { maturation in migratory tree-roosting bats found dead at wind turbines: PLoS ONE, v. } 7 \text {, } \\
\text { no. } 10 \text {, p. 1-9. }\end{array}$ \\
\hline Abstract & $\begin{array}{l}\text { Germaine, S.S., and Ignizio, D., 2012, Gas energy development and pygmy rabbit } \\
\text { (Brachylagus idahoensis) site occupancy in Wyoming [abs.]: Utah State University's } \\
\text { Restoring the West Conference 2012-Balancing Energy Development and Biodiversity, } \\
\text { October 30-31, 2012, Logan, Utah, p. 1. }\end{array}$ \\
\hline Fact Sheet & $\begin{array}{l}\text { Muths, E., Adams, M.J., Grant, E.H.C., Miller, D., Corn, P.S., and Ball, L.C., 2012, The } \\
\text { state of amphibians in the United States: U.S. Geological Survey Fact Sheet 2012-3092, } 4 \\
\text { p. }\end{array}$ \\
\hline Journal & $\begin{array}{l}\text { Baron, J.S., Seastedt, T., Fagre, D., Hicke, J., Tomback, D., Garcia, E., Bowen, Z., and } \\
\text { Logan, J.A., 2013, Symposium 9: Rocky Mountain futures-Preserving, utilizing, and } \\
\text { sustaining Rocky Mountain ecosystems: Bulletin of the Ecological Society of America, v. } \\
94, \text { no. 2, p. 195-199. }\end{array}$ \\
\hline Data & $\begin{array}{l}\text { Carr, N., Diffendorfer, J., Fancher, T., Latysh, N., Leib, K., Matherne, A., 2013, } \\
\text { Locations and attributes of wind turbines in Colorado, 2011: U.S. Geological Survey Data } \\
\text { Series } 782 .\end{array}$ \\
\hline
\end{tabular}


Table 2. FORT Publications and Other Information Products Released in FY2012 and FY2013.-Continued

\begin{tabular}{|c|c|}
\hline Publication Type & Citation \\
\hline Data & $\begin{array}{l}\text { Carr, N.B., Diffendorfer, J.E., Fancher, T., Hawkins, S.J. Latysh, N., Leib, K.J., and } \\
\text { Matherne, A.M., 2013, Locations and attributes of wind turbines in New Mexico, 2011: } \\
\text { U.S. Geological Survey Data Series } 783 .\end{array}$ \\
\hline Abstract & $\begin{array}{l}\text { Cullinane Thomas, C., and Myrick, E., 2013, The Watts Branch Restoration Project- } \\
\text { Restoring a stream, restoring a community-urban watershed restoration fosters } \\
\text { community improvement [abs.]: NRDA Restoration Program/BLM socioeconomic group } \\
\text { case studies, p. } 4 .\end{array}$ \\
\hline Journal & $\begin{array}{l}\text { Garrity, S.R., Allen, C.D., Brumby, S.P., Gangodagamage, C., McDowell, N.G., and Cai, } \\
\text { D.M., 2013, Quantifying tree mortality in a mixed species woodland using multitemporal } \\
\text { high spatial resolution satellite imagery: Remote Sensing of the Environment, v. 129, p. } \\
54-65 \text {. }\end{array}$ \\
\hline Open-File Report & $\begin{array}{l}\text { Germaine, S., Zeigenfuss, L., and Schoenecker, K.A., 2013, Bison grazing ecology at } \\
\text { Rocky Mountain Arsenal National Wildlife Refuge, Colo.: U.S. Geological Survey Open- } \\
\text { File Report 2013-1112, } 20 \text { p. }\end{array}$ \\
\hline Open-File Report & $\begin{array}{l}\text { Manier, D.J., Wood, D.J.A., Bowen, Z.H., Donovan, R.M., Holloran, M.J., Juliusson, } \\
\text { L.M., Mayne, K.S., Oyler-McCance, S.J., Quamen, F.R., Saher, D.J., and Titolo, A.J., } \\
\text { 2013, Summary of science, activities, programs and policies that influence the rangewide } \\
\text { conservation of Greater Sage-Grouse (Centrocerus urophasianus): U.S. Geological } \\
\text { Survey Open-File Report 2013-1098, } 170 \text { p. }\end{array}$ \\
\hline Journal & $\begin{array}{l}\text { Nekola, J.C., Allen, C.D., Brown, J.H., Burger, J.R., Davidson, A.D., Fristoe, T.S., } \\
\text { Hamilton, M.J., Hammond, S.T., Kodric-Brown, A., Mercado-Silva, N., and Okie, J.G., } \\
\text { 2013, The Malthusian-Darwinian dynamic and trajectory of civilization: Trends in } \\
\text { Ecology and Evolution, v. } 28, \text { no. 3, p. } 127-130 .\end{array}$ \\
\hline Journal & $\begin{array}{l}\text { Webb, R.H., Belnap, J., Scott, M.L., Friedman, J.M., and Esque, T.C., 2013, Long-term } \\
\text { change along the Colorado River in Grand Canyon National Park (1889-2011): } \\
\text { Boatman's Quarterly Review, v. 25, no. 4, p. 24-30. }\end{array}$ \\
\hline \multicolumn{2}{|r|}{ Ecosystems - Fisheries } \\
\hline Journal & $\begin{array}{l}\text { Roberts, J.J., Fausch, K.D., Peterson, D.P., and Hooten, M.B., 2013, Fragmentation and } \\
\text { thermal risks from climate change interact to affect persistence of native trout in the } \\
\text { Colorado River basin: Global Change Biology, v. 19, no. 5, p. 1383-1398. }\end{array}$ \\
\hline Journal & $\begin{array}{l}\text { Baker, B.W., Peinetti, H.R., Coughenour, M.C., and Johnson, T.L., 2012, Competition } \\
\text { favors elk over beaver in a riparian willow ecosystem: Ecosphere, v. 3, no. 11, p. 1-15. }\end{array}$ \\
\hline Science Feature & $\begin{array}{l}\text { Muths, E., and Wilson, J., 2012, Blackrock-Biological hotspot and hotbed of } \\
\text { collaboration: U.S. Geological Survey, Fort Collins Science Center Science Feature, } \\
\text { http://www.fort.usgs.gov/Blackrock. }\end{array}$ \\
\hline Journal & $\begin{array}{l}\text { Scherer, R.D., Muths, E., and Noon, B.R., } 2012 \text {, The importance of local and landscape- } \\
\text { scale processes to the occupancy of wetlands by pond-breeding amphibians: Population } \\
\text { Ecology, v. } 54 \text {, no. } 4 \text {, p. } 487-498 \text {. }\end{array}$ \\
\hline \multicolumn{2}{|r|}{ Ecosystems-Invasive Species } \\
\hline Science Feature & $\begin{array}{l}\text { Wilson, J., 2012, Snakes in the wrong places-Gordon Rodda's career in invasive species } \\
\text { research: U.S. Geological Survey, Fort Collins Science Center Science Feature, } \\
\text { http://www.fort.usgs.gov/rodda/. }\end{array}$ \\
\hline
\end{tabular}


Table 2. FORT Publications and Other Information Products Released in FY2012 and FY2013.-Continued

\begin{tabular}{|c|c|}
\hline Publication Type & Citation \\
\hline Journal & $\begin{array}{l}\text { Campbell III, E.W., Yackel Adams, A.A., Converse, S.J., Fritts, T.H., and Rodda, G.H., } \\
\text { 2012, Do predators control prey species abundance?-An experimental test with Brown } \\
\text { Treesnakes on Guam: Ecology, v. 93, no. 5, p. 1194-1203. }\end{array}$ \\
\hline Journal & $\begin{array}{l}\text { Dorcas, M.E., Willson, J.D., Reed, R.N., Snow, R.W., Rochford, M.R., Miller, M.A., } \\
\text { Meshaka Jr., W.E., Andreadis, P.T., Mazzotti, F.J., Romagosa, C.M., and Hart, K.M., } \\
\text { 2012, Severe mammal declines coincide with proliferation of invasive Burmese pythons } \\
\text { in Everglades National Park: Proceedings of the National Academy of Sciences of the } \\
\text { United States of America, v. 109, no. 7, p. 2418-2422. }\end{array}$ \\
\hline Journal & $\begin{array}{l}\text { Dove, C.J., Snow, R.W., and Reed, R.N., 2012, Consumption of bird eggs by invasive } \\
\text { Burmese pythons in Florida: IRCF Reptiles and Amphibians, v. 19, no. 1, p. 64-66. }\end{array}$ \\
\hline Journal & $\begin{array}{l}\text { Flory, A.R., Kumar, S., Stohlgren, T.J., and Cryan, P.M., 2012, Environmental conditions } \\
\text { associated with bat White-Nose Syndrome mortality in the north-eastern United States: } \\
\text { Journal of Applied Ecology, v. 49, no. 3, p. 680-689. }\end{array}$ \\
\hline Journal & $\begin{array}{l}\text { Guilbault, K.R., Brown, C.S., Friedman, J.M., and Shafroth, P.B., 2012, The influence of } \\
\text { chilling requirement on the southern distribution limit of exotic Russian Olive (Elaeagnus } \\
\text { angustifolia) in western North America: Biological Invasions, v. 14, no, 8, p. 1711-1724. }\end{array}$ \\
\hline Journal & $\begin{array}{l}\text { Logan, M.L., Montgomery, C.E., Boback, S.M., Reed, R.N., and Campbell, J.A., 2012, } \\
\text { Divergence in morphology, but not habitat use, despite low genetic differentiation among } \\
\text { insular populations of the lizard Anolis lemurinus in Honduras: Journal of Tropical } \\
\text { Ecology, v. } 28, \text { no. } 2 \text {, p. } 215-222 \text {. }\end{array}$ \\
\hline Podcast & $\begin{array}{l}\text { Lubeck, M., and Reed, R., 2012, The big squeeze-Pythons and mammals in Everglades } \\
\text { National Park audio podcast, http://gallery.usgs.gov/audios/439. }\end{array}$ \\
\hline Abstract & $\begin{array}{l}\text { Manier, D., Schell, S., and Aldridge, C., 2012, The distribution of invasive plants } \\
\text { measured and modeled across the WLCI Area [abs.]: Third Wyoming Landscape } \\
\text { Conservation Initiative (WLCI) Science Workshop, Rock Springs, Wyo., May 14-17, } \\
\text { 2012, p. } 1 .\end{array}$ \\
\hline Journal & $\begin{array}{l}\text { Mason, L.C., Savidge, J.A., Rodda, G.H., and Yackel Adams, A.A., 2011, Scented guide } \\
\text { ropes as a method to enhance brown treesnake (Boiga irregularis) trap capture success on } \\
\text { Guam: Journal of Herpetology, v. } 45 \text {, no. 3, p. 308-312. }\end{array}$ \\
\hline Fact Sheet & $\begin{array}{l}\text { Morisette, J.T., 2011, Applying remote sensing to invasive species science-A tamarisk } \\
\text { example: U.S. Geological Survey Fact Sheet 2011-3109, } 4 \text { p. }\end{array}$ \\
\hline Journal & $\begin{array}{l}\text { Reed, R.N., Willson, J.D., Rodda, G.H., and Dorcas, M.E., 2012, Ecological correlates of } \\
\text { invasion impact for Burmese pythons in Florida: Integrative Zoology, v. 7, no. 3, p. 254- } \\
270 .\end{array}$ \\
\hline Software & $\begin{array}{l}\text { Talbert, C., 2012, Software details, Software for Assisted Habitat Modeling Package for } \\
\text { VisTrails (SAHM: VisTrails) v.1: U.S. Geological Survey, } \\
\text { https://www.fort.usgs.gov/products/23403. }\end{array}$ \\
\hline
\end{tabular}


Table 2. FORT Publications and Other Information Products Released in FY2012 and FY2013.-Continued

\begin{tabular}{|c|c|}
\hline Publication Type & Citation \\
\hline Software documentation & $\begin{array}{l}\text { Talbert, C., and Talbert, M., 2012, User documentation for the Software for Assisted } \\
\text { Habitat Modeling (SAHM) package in VisTrails: U.S. Geological Survey, } 69 \text { p. }\end{array}$ \\
\hline Software documentation & $\begin{array}{l}\text { Talbert, C.B., and Talbert, M.K., 2012, User Manual for SAHM package for VisTrails: } \\
\text { Fort Collins, Colo., U.S. Geological Survey, } 72 \text { p. }\end{array}$ \\
\hline Software documentation & $\begin{array}{l}\text { Young, N., 2012, Tutorial for the Software for Assisted Habitat Modeling (SAHM) } \\
\text { package in VisTrails: Fort Collins, Colo., U.S. Geological Survey, } 32 \text { p. }\end{array}$ \\
\hline Journal & $\begin{array}{l}\text { Merritt, D.M., and Shafroth, P.B., 2012, Edaphic, salinity, and stand structural trends in } \\
\text { chronosequences of native and non-native dominated riparian forests along the Colorado } \\
\text { River, USA: Biological Invasions, v. 14, no. 12, p. } 2665-2685 \text {. }\end{array}$ \\
\hline Book, pages in & $\begin{array}{l}\text { Auerbach, D.A., Merritt, D.M., and Shafroth, P.B., 2013, Tamarix, hydrology, and fluvial } \\
\text { geomorphology [chapter 7], in Sher, A., and Quigley, M.F., Tamarix-A case study of } \\
\text { ecological change in the American West: New York, Oxford University Press, p. 99-122. }\end{array}$ \\
\hline Journal & $\begin{array}{l}\text { Crall, A.W., Jarnevich, C.S., Panke, B., Young, N., Renz, M., and Morisette, J., 2013, } \\
\text { Using habitat suitability models to prioritize invasive plant species surveys: Ecological } \\
\text { Applications, v. } 23 \text {, no.1, p. } 60-72 \text {. }\end{array}$ \\
\hline Book, pages in & $\begin{array}{l}\text { Jarnevich, C.S., Evangelista, P., and Graham, J., 2013, Predicting tamarisk current and } \\
\text { future distribution [chapter 3], in Sher, A., and Quigley, M.F., Tamarix-A case study of } \\
\text { ecological change in the American West: New York, Oxford University Press, p. 29-43. }\end{array}$ \\
\hline Journal & $\begin{array}{l}\text { Lardner, B., Reed, R.N., Yackel Adams, A.A., Mazurek, M.J., Hinkle, T.J., Levasseur, } \\
\text { P.M., Palmer, M.S., and Savidge, J.A., 2013, Selective predation by feral cats on a native } \\
\text { skink on Guam: IRCF Reptiles and Amphibians, v. 20, no. 1, p. 16-19. }\end{array}$ \\
\hline Journal & $\begin{array}{l}\text { Perry L.G., Shafroth, P.B., Blumenthal, D.M., Morgan, J.A., LeCain, D.R., 2013, } \\
\text { Elevated } \mathrm{CO}_{2} \text { does not offset greater water stress predicted under climate change for } \\
\text { native and exotic riparian plants: New Phytologist, v. 197, no. 2, p. 532-543. }\end{array}$ \\
\hline Book, pages in & $\begin{array}{l}\text { Shafroth, P.B., Merritt, D.M., Briggs, M.K., Beauchamp, V.B., Lair, K.D., Scott, M.L., } \\
\text { and Sher, A.A., 2013, Riparian restoration in the context of Tamarix control [chapter 23], } \\
\text { in Sher, A., and Quigley, M.F., Tamarix-A case study of ecological change in the } \\
\text { American West: Oxford University Press, New York, p. 404-425. }\end{array}$ \\
\hline & Ecosystems-Status and Trends of Biological Resources \\
\hline Journal & $\begin{array}{l}\text { Richardson, L., Champ, P., and Loomis, J., 2012, The hidden cost of wildfires-- } \\
\text { Economic valuation of health effects of wildfire smoke exposure in Southern California: } \\
\text { Journal of Forest Economics, v. 18, no. 1, p. 14-35. }\end{array}$ \\
\hline Open-File Report & $\begin{array}{l}\text { Thomas, C.M., Huber, C., Gascoigne, W., and Koontz, L., 2012, Socioeconomic Issues } \\
\text { for the Bear River Watershed Conservation Area Land Protection Plan: U.S. Geological } \\
\text { Survey, Open-File Report } 2012-1039,15 \text { p. }\end{array}$ \\
\hline
\end{tabular}


Table 2. FORT Publications and Other Information Products Released in FY2012 and FY2013.-Continued

\begin{tabular}{|c|c|}
\hline Publication Type & Citation \\
\hline $\begin{array}{l}\text { Scientific Investigations } \\
\text { Report }\end{array}$ & $\begin{array}{l}\text { Allen, A.W., and Vandever, M.W., 2012, Conservation Reserve Program (CRP) } \\
\text { contributions to wildlife habitat, management issues, challenges and policy choices-An } \\
\text { Annotated Bibliography: U.S. Geological Survey Scientific Investigations Report 2012- } \\
\text { 5066, } 185 \text { p. }\end{array}$ \\
\hline Journal & $\begin{array}{l}\text { Brown, G., Montag, J.M., and Lyon, K., 2012, Public participation GIS-A method for } \\
\text { identifying ecosystem services: Society and Natural Resources, v. 25, no. 7, p. 633-651. }\end{array}$ \\
\hline Journal & $\begin{array}{l}\text { Cade, B.S., and Johnson, P.R., 2011, Quantile equivalence to evaluate compliance with } \\
\text { habitat management objectives: Journal of Fish and Wildlife Management, v. 2, no. 2, p. } \\
\text { 169-182. }\end{array}$ \\
\hline Report, pages in & $\begin{array}{l}\text { Cullinane Thomas, C.M., Skrabis, K.E., and Gascoigne, W., 2012, Ecosystem restoration } \\
\text { [Chapter 4], in The Department of Interior's Economic Contributions, FY2011: Reston, } \\
\text { Va., U.S. Department of the Interior, Office of Policy Analysis, p. 58-92. }\end{array}$ \\
\hline Open-File Report & $\begin{array}{l}\text { Ellison, L.E., 2011, Species accounts for the Alamosa/Monte Vista/Baca National } \\
\text { Wildlife Refuge Complex: U.S. Geological Survey Open-File Report 2011-1285, } 195 \text { p. }\end{array}$ \\
\hline Web App & $\begin{array}{l}\text { Everette, A.L., Cryan, P.M., and Peterson, K., 2012, White-nose Syndrome Disease } \\
\text { Tracking System v. 1: U.S. Geological Survey, } \\
\text { http://my.usgs.gov/wns/samplingPerspective/sampling. }\end{array}$ \\
\hline Abstract & $\begin{array}{l}\text { Manier, D., Garman, S., and Dematatis, M., 2012, The WLCI Interagency Monitoring } \\
\text { Team-Efforts and accomplishments [abs.]: Third Wyoming Landscape Conservation } \\
\text { Initiative (WLCI) Science Workshop, Rock Springs, Wyo., May 14-17, 2012, p. } 1 .\end{array}$ \\
\hline Abstract & $\begin{array}{l}\text { Milley, B.J., Sexton, N.R., Leong, K., and Teel, T., 2012, The state of human dimensions } \\
\text { capacity-Current needs and training opportunities [abs]: } 2012 \text { Pathways to Success } \\
\text { Conference-Integrating Human Dimensions into Fisheries and Wildlife Management, } \\
\text { Breckenridge, Colo., September 24-27, 2012, p. } 1 \text {. }\end{array}$ \\
\hline Abstract & $\begin{array}{l}\text { Perry, L.G., 2012, Projecting climate change effects on cottonwood and willow seed } \\
\text { dispersal phenology, flood timing, and seedling recruitment in western riparian forests } \\
\text { [abs.]: National Climate Change and Wildlife Science Center Web site, p. } 1 .\end{array}$ \\
\hline Report, internal USGS & $\begin{array}{l}\text { Ramotnik, C., and Bogan, M.A., 2012, UNM Museum of Southwestern Biology Annual } \\
\text { Report for 2011: U.S. Geological Survey Annual Report, } 10 \text { p. }\end{array}$ \\
\hline Abstract & $\begin{array}{l}\text { Reed, P., and Montag, J.M., 2012, Collaborative mapping and social learning: Interactive } \\
\text { GIS for natural resource management [abs.]: Wyoming Landscape Conservation Initiative } \\
\text { Third Science Workshop, Rock Springs, Wyo., May 14-17, 2012: Reston, Va., U.S. } \\
\text { Geological Survey, p. 1. }\end{array}$ \\
\hline Report, pages in & $\begin{array}{l}\text { Richardson, L., and Simon, B., 2012, Innovation, information, and technology transfer } \\
\text { [Chapter 6]: The Department of Interior's economic contributions, FY2011: Reston, Va., } \\
\text { U.S. Department of the Interior, Office of Policy Analysis, p. 110-130. }\end{array}$ \\
\hline
\end{tabular}


Table 2. FORT Publications and Other Information Products Released in FY2012 and FY2013.-Continued

\begin{tabular}{|c|c|}
\hline Publication Type & Citation \\
\hline Open-File Report & $\begin{array}{l}\text { Richardson, L., Huber, C., and Koontz, L., 2012, Regional economic impacts of current } \\
\text { and proposed management alternatives for Don Edwards National Wildlife Refuge: U.S. } \\
\text { Geological Survey, Open-File Report 2012-1094, } 19 \text { p. }\end{array}$ \\
\hline Abstract & $\begin{array}{l}\text { Rosenberg, K.V., Ruth, J.M., Beardmore, C.J., Easton, W.E., Will, T.C., and Pashley, } \\
\text { D.N., 2012, Filling knowledge gaps to enhance full life-cycle bird conservation-Partners } \\
\text { in Flight's tri-national vision [abs.]: } 5^{\text {th }} \text { N. American Ornithological Conference, } \\
\text { Vancouver, British Columbia, Canada, August } 14-18,2012 \text {, p. } 1 \text {. }\end{array}$ \\
\hline Abstract & $\begin{array}{l}\text { Schuster, R.M., 2012, Interdisciplinary research-Navigating the pitfalls, processes, and } \\
\text { potential of integrating social and natural science [abs.]: Northeastern Recreation } \\
\text { Research Symposium, Otesaga, N.Y., April 3-5, 2012, } 1 \text { p. }\end{array}$ \\
\hline Abstract & $\begin{array}{l}\text { Schuster, R.M., Holochuck, N., Kuehn, D.M., and Morais, D.B., 2012, Relationships } \\
\text { among resident participation in nature and heritage tourism activities, place attachment, } \\
\text { and sustainability in three Hudson River valley communities [abs.]: Social coast forum } \\
2012 \text {-Social science for coastal decision making, February 15-16, 2012, Charleston, } \\
\text { S.C., } 1 \text { p. }\end{array}$ \\
\hline Data & $\begin{array}{l}\text { Sexton, N.R., Dietsch, A.M., Don Carlos, A.W., Koontz, L., Solomon, A.N., and Miller, } \\
\text { H.M., 2012, National Wildlife Refuge visitor survey-Individual refuge results: U.S. } \\
\text { Geological Survey Data Series } 643 \text {. }\end{array}$ \\
\hline Data & $\begin{array}{l}\text { Sexton, N.R., Dietsch, A.M., Miller, H.M., Koontz, L., and Solomon, A.N., 2012, } \\
\text { National Wildlife Refuge visitor survey results 2010/2011: U.S. Geological Survey Data } \\
\text { Series } 685 \text {. }\end{array}$ \\
\hline Journal & $\begin{array}{l}\text { Skagen, S.K, and Yackel Adams, A.A., 2012, Weather effects on avian breeding } \\
\text { performance and implications of climate change: Ecological Applications, v. 22, no. 4, p. } \\
1131-1145 .\end{array}$ \\
\hline Journal & $\begin{array}{l}\text { Stanley, T.R., Teel, S., Hall, L.S., Dye, L.C., and Laughrin, L.L., 2012, Population size of } \\
\text { island loggerhead shrikes on Santa Rosa and Santa Cruz Islands: Wildlife Society } \\
\text { Bulletin, v. } 36 \text {, no. 1, p. } 61-69 .\end{array}$ \\
\hline Web App & $\begin{array}{l}\text { Montag, J.M., Richardson, L., Koontz, L. Everette, A.L., and Peterson, K., 2012, ASPN- } \\
\text { Assessing Socioeconomic Planning Needs, v.1: U.S. Geological Survey, } \\
\text { http://my.usgs.gov/aspn/. }\end{array}$ \\
\hline Abstract & $\begin{array}{l}\text { Valdez, E., 2011, Assessment of bats for white-nose syndrome at El Malpais National } \\
\text { Monument and adjacent lands, [abs.], in } 1 \text { st One day Chapter conference and corridors } \\
\text { workshop, October 18, 2011: Albuquerque, N. Mex., New Mexico Chapter of the } \\
\text { Wildlife Society, p. 1. }\end{array}$ \\
\hline Report & $\begin{array}{l}\text { Lea, C., Waltermire, B., and Nordman, C., 2013, Vegetation classification and mapping } \\
\text { Vicksburg National Military Park, Mississippi: National Park Service Natural Resource } \\
\text { Technical Report NPS/GULN/NRTR-2013/710,128 p. }\end{array}$ \\
\hline
\end{tabular}


Table 2. FORT Publications and Other Information Products Released in FY2012 and FY2013.-Continued

\begin{tabular}{|c|c|}
\hline Publication Type & Citation \\
\hline Open-File Report & $\begin{array}{l}\text { Burkardt, N., and Ruell, E.W., 2012, Disputes over science and dispute resolution } \\
\text { approaches-A survey of U.S. Bureau of Reclamation employees: U.S. Geological } \\
\text { Survey Open-File Report 2012-1186, } 49 \text { p. }\end{array}$ \\
\hline Abstract & $\begin{array}{l}\text { Gascoigne, W., Perry, J., Hartley, C., Casey, F., and Koontz, L., 2012, Valuing ecosystem } \\
\text { service benefits of sage-grouse habitat conservation [abs.]: ACES and ecosystem markets } \\
2012 \text { conference, Fort Lauderdale, Fla., December 10-14, 2012, p. } 1 \text {. }\end{array}$ \\
\hline Open-File Report & $\begin{array}{l}\text { Bowen, Z.H., Aldridge, C.L., Anderson, P.J., Assal, T.J., Biewick, L.R.H., Blecker, } \\
\text { S.W., Boughton, G.K., Bristol, S., Carr, N.B., Chalfoun, A.D., Chong, G.W., Clark, } \\
\text { M.L., Diffendorfer, J.E., Fedy, B.C., Foster, K., Garman, S.L., Germaine, S., Hethcoat, } \\
\text { M.G., Holloway, J., Homer, C., Kauffman, M.J., Keinath, D., Latysh, N., Manier, D., } \\
\text { McDougal, R.R., Melcher, C.P., Miller, K.A., Montag, J., Olexa, E.M., Potter, C.J., } \\
\text { Schell, S., Shafer, S.L., Smith, D.B., Stillings, L.L., Sweat, M.J., Tuttle, M., and Wilson, } \\
\text { A.B., 2013, U.S. Geological Survey science for the Wyoming Landscape Conservation } \\
\text { Initiative-2011 annual report: U.S. Geological Survey Open-File Report 2013-1033, } \\
145 \text { p. }\end{array}$ \\
\hline Journal & $\begin{array}{l}\text { Burris, L.E., and Skagen, S.K., 2013, Modeling sediment accumulation in North } \\
\text { American playa wetlands in response to climate change, 1940-2100: Climatic Change, v. } \\
117 \text {, no. } 1-2 \text {, p. } 69-83 \text {. }\end{array}$ \\
\hline Data & $\begin{array}{l}\text { Dietsch, A.M., Sexton, N.R., Koontz, L.M., and Conk, S.J., 2013, National wildlife } \\
\text { refuge visitor survey 2012-Individual refuge results: U.S. Geological Survey Data } \\
\text { Series } 754 \text {. }\end{array}$ \\
\hline USGS & $\begin{array}{l}\text { Gascoigne, W.R., Hoag, D.L.K., Johnson, R.R., and Koontz, L.M., 2013, Dynamics of } \\
\text { land-use change and conservation in the prairie pothole region of the United States-- } \\
\text { Environmental and economic implications with linkages to rural community well-being: } \\
\text { U.S. Geological Survey Professional Paper } 1800,65 \text { p. }\end{array}$ \\
\hline Fact Sheet & $\begin{array}{l}\text { Gascoigne, W.R., Hoag, D.L.K., Johnson, R.R., Koontz, L.M., and Thomas, C.C., 2013, } \\
\text { Land-use change, economics, and rural well-being in the Prairie Pothole Region of the } \\
\text { United States: U.S. Geological Survey Fact Sheet } 2013-3046,6 \text { p. }\end{array}$ \\
\hline Journal & $\begin{array}{l}\text { Koontz, L., Hoag, D., and DeLong, D., 2013, Disparate stakeholder management-The } \\
\text { case of elk and bison feeding in Southern Greater Yellowstone: Society and Natural } \\
\text { Resources, v. 26, no. 3, p. } 339-355 .\end{array}$ \\
\hline Open-File Report & $\begin{array}{l}\text { Koontz, L., Sexton, N., Ishizaki, A., and Ritten, J., 2013, Regional economic impacts of } \\
\text { current and proposed management alternatives for Charles M. Russell National Wildlife } \\
\text { Refuge: U.S. Geological Survey Open-File Report 2012-1014, } 43 \text { p. }\end{array}$ \\
\hline Abstract & $\begin{array}{l}\text { Loeb, S., Coleman, J., Ellison, L., Rodhouse, T., and Ingersoll, T., 2013, Tracking white- } \\
\text { nose syndrome and other threats-A population monitoring program for North American } \\
\text { bats [abs.]: International Bat Research Conference, Costa Rica, August 11-15, 2013, p. } 1 .\end{array}$ \\
\hline Journal & $\begin{array}{l}\text { Milchunas, D.G., and Vandever, M.W., 2013, Grazing effects on aboveground primary } \\
\text { production and root biomass of earlyseral, mid-seral, and undisturbed semiarid grassland: } \\
\text { Journal of Arid Environments, v. 92, p. } 81-88 \text {. }\end{array}$ \\
\hline
\end{tabular}


Table 2. FORT Publications and Other Information Products Released in FY2012 and FY2013.-Continued

\begin{tabular}{|l|l|}
\hline \multicolumn{1}{|c|}{ Publication Type } & \multicolumn{1}{c|}{ Citation } \\
\hline Fact Sheet & $\begin{array}{l}\text { Schuster, R.M., and Walters, K.D., 2013, Fort Collins Science Center, Policy Analysis } \\
\text { and Science Assistance Branch: U.S. Geological Survey Fact Sheet 2010-3038, 4 p. }\end{array}$ \\
\hline Journal & $\begin{array}{l}\text { Sexton, N.R., Leong, K.M., Milley, B.J., Clarke, M.M., Teel, T.L., Chase, M.A., and } \\
\text { Dietsch, A.M., 2013, The state of human dimensions capacity for natural resource } \\
\text { management-Needs, knowledge, and resources: The George Wright Forum, v. 30, no. 2, } \\
\text { p. 142-153. }\end{array}$ \\
\hline Open-File Report & $\begin{array}{l}\text { Talbert, M.K., and Cade, B.S., 2013, User manual for Blossom statistical package for R: } \\
\text { U.S. Geological Survey Open-File Report, 81 p. }\end{array}$ \\
\hline
\end{tabular}

\section{Ecosystems-Wildlife and Terrestrial Resources}

\begin{tabular}{|c|c|}
\hline Book, pages in & $\begin{array}{l}\text { Oyler-McCance, S.J., Stricker, C.A., St. John, J. Braun, C.E., Wann, G.T., O’Donnell, } \\
\text { M.S., and Aldridge, C.L., 2011, Effects of climate change on nutrition and genetics of } \\
\text { White-tailed Ptarmigan [chapter 21], in Sandercock, B.K., Martin, K., and Segelbacher, } \\
\text { G., Ecology, conservation, and management of grouse-Studies in Avian Biology: } \\
\text { Berkeley, Calif., University of California Press, p. 283-294. }\end{array}$ \\
\hline Journal & $\begin{array}{l}\text { Schmidt, T.S., Clements, W.H., and Cade, B.S., 2012, Estimating risks to aquatic life } \\
\text { using quantile regression: Freshwater Science: v. 3, no. 3, p. 709-723. }\end{array}$ \\
\hline Fact Sheet & $\begin{array}{l}\text { Adams, M.J., Muths, E. Grant, E.H.C., Miller, D.A., Waddle, J.H., Walls, S.C., and Ball, } \\
\text { L.C., 2012, The U.S. Geological Survey Amphibian Research and Monitoring Initiative- } \\
2011 \text { Annual Update: U.S. Geological Survey Fact Sheet 2012-3090, } 4 \text { p. }\end{array}$ \\
\hline Data & $\begin{array}{l}\text { Assal, T.J., Veblen, K.E., Farinha, M.A., Aldridge, C.L., Cassaza, M.E., and Pyke, D.A., } \\
\text { 2012, Data resources for range-wide assessment of livestock grazing across the Sagebrush } \\
\text { Biome: U.S. Geological Survey Data Series } 690 .\end{array}$ \\
\hline Journal & $\begin{array}{l}\text { Biggins, D.E., 2012, Information on black-footed ferret biology collected within the } \\
\text { framework of ferret conservation: Western North American Naturalist, v. 72, no. 2, p. } \\
\text { 129-133. }\end{array}$ \\
\hline Journal & $\begin{array}{l}\text { Biggins, D.E., 2012, Use of multi-opening burrow systems by black-footed ferrets: } \\
\text { Western North American Naturalist, v. } 72 \text {, no. 2, p. 134-139. }\end{array}$ \\
\hline Journal & $\begin{array}{l}\text { Biggins, D.E., Hanebury, L.R., and Fagerstone, K.A, 2012, Digging behaviors of radio- } \\
\text { tagged black-footed ferrets near Meeteetse, Wyo., 1981-1984: Western North American } \\
\text { Naturalist, v. } 72 \text {, no. 2, p. 148-157. }\end{array}$ \\
\hline Journal & $\begin{array}{l}\text { Biggins, D.E., Ramakrishnan, S., Goldberg, A.R., and Eads, D.A., 2012, Black-footed } \\
\text { ferrets and recreational shooting influence the attributes of black-tailed prairie dog } \\
\text { burrows: Western North American Naturalist, v. } 72 \text {, no. 2, p. 158-171. }\end{array}$ \\
\hline Journal & $\begin{array}{l}\text { Chipault, J.G., Biggins, D.E., Detling, J.K., Long, D.H., and Reich, V., 2012, Fine-scale } \\
\text { habitat use of reintroduced black-footed ferrets on prairie dog colonies in New Mexico: } \\
\text { Western North American Naturalist, v. 72, no. 2, p. 216-227. }\end{array}$ \\
\hline
\end{tabular}


Table 2. FORT Publications and Other Information Products Released in FY2012 and FY2013.-Continued

\begin{tabular}{|c|c|}
\hline Publication Type & Citation \\
\hline Abstract & $\begin{array}{l}\text { Christ, A., Rea, L., Banks, A., Farley, S., and Stricker, C., 2011, Estimating locations for } \\
\text { local extrema of stable isotope signatures in Steller sea lion vibrissae [abs.]: 18th Annual } \\
\text { Conference of The Wildlife Society, Waikoloa, Hawaii, November 5-10, 2011, p. } 1 .\end{array}$ \\
\hline Abstract & $\begin{array}{l}\text { Christ, A.M., Rea, L.D., Waite, J.N., Stricker, C.A., Wunder, M., and Scherer, R., 2012, } \\
\text { Discrimination fact sheetors for } 13 \mathrm{C} \text { and } 15 \mathrm{~N} \text { profiles of vibrissae from adult Steller sea } \\
\text { lion females and their pups in utero and post parturition [abs.]: The } 8 \text { th International } \\
\text { Conference on Applications of Stable Isotope Techniques to Ecological Studies, Brest, } \\
\text { France, August } 20-24,2012 \text {, p. } 1 \text {. }\end{array}$ \\
\hline Journal & $\begin{array}{l}\text { Corn, P.S., Muths, E., Kissel, A., and Scherer, R.D., 2011, Breeding chorus intensity is } \\
\text { weakly related to estimated abundance of Boreal Chorus Frogs: Copeia, v. 2011, no. 3, p. } \\
265-371 .\end{array}$ \\
\hline Abstract & $\begin{array}{l}\text { Cryan, P., Boyles, J., McCracken, G., Castle, K., Dalton, D., Yanez, J., Beeler, J., Wilson, } \\
\text { A., Hicks, A., Herzog, C., vonLinden, R., Johnson, S., Hudson, C., Shier, T., and } \\
\text { Coleman, J., 2012, Lights, camera, action-Behaviors of hibernating bats before and after } \\
\text { WNS revealed by surveillance video [abs.]: Annual White-nose Syndrome Symposium, } \\
\text { Madison, Wis., June 6, 2012, p. 1. }\end{array}$ \\
\hline Journal & $\begin{array}{l}\text { Cryan, P.M., Stricker, C.A., and Wunder, M.B., 2012, Evidence of cryptic individual } \\
\text { specialization in an opportunistic insectivorous bat: Journal of Mammalogy, v. 93, no. 2, } \\
\text { p. 381-389. }\end{array}$ \\
\hline Abstract & $\begin{array}{l}\text { Cryan, P.M., Gorresen, P.M., Bonaccorso, F.J., and Hayes, M.A., 2011, Monitoring } \\
\text { behaviors and activity of bats at wind turbines with near infrared videography [abs.], in } \\
41 \text { st Annual Meeting of the North American Society for Bat Research Toronto, Canada, } \\
\text { October 26-30, 2011: The North American Society for Bat Research, p. 1. }\end{array}$ \\
\hline Journal & $\begin{array}{l}\text { Dusek, R.J., Iko, W.M., and Hofmeister, E.K., 2012, Prevalence and effects of West Nile } \\
\text { virus on wild American kestrel (Falco sparverius) populations in Colorado [Chapter 4]: } \\
\text { Studies in Avian Biology, v. 42, p. 45-54. }\end{array}$ \\
\hline Journal & $\begin{array}{l}\text { Eads, D.A., and Biggins, D.E., 2012, Patterns of surface burrow plugging in a colony of } \\
\text { black-tailed prairie dogs occupied by black-footed ferrets: Western North American } \\
\text { Naturalist, v. } 72 \text {, no. } 2 \text {, p. } 172-178 \text {. }\end{array}$ \\
\hline Journal & $\begin{array}{l}\text { Eads, D.A., Biggins, D.E., Marsh, D., Millspaugh, J.J., and Livieri, T.M., 2012, Black- } \\
\text { footed ferret digging activity in summer: Western North American Naturalist: v. 72, no. 2, } \\
\text { p. } 140-147 .\end{array}$ \\
\hline Journal & $\begin{array}{l}\text { Eads, D.A., Jachowski, D.J., Millspaugh, J.J., and Biggins, D.E., 2012, Importance of } \\
\text { lunar and temporal conditions for spotlight surveys of adult black-footed ferrets: Western } \\
\text { North American Naturalist, v. } 72 \text {, no. 2, p. 179-190. }\end{array}$ \\
\hline
\end{tabular}


Table 2. FORT Publications and Other Information Products Released in FY2012 and FY2013. - Continued

\begin{tabular}{|c|c|}
\hline Publication Type & Citation \\
\hline Journal & $\begin{array}{l}\text { Eads, D.A., Jachowski, D.S., Biggins, D.E., Livieri, T.M., Matchett, M.R., and } \\
\text { Millspaugh, J.J., 2012, Resource selection models are useful in predicting fine-scale } \\
\text { distributions of black-footed ferrets in prairie dog colonies: Western North American } \\
\text { Naturalist, v. } 72 \text {, no. } 2 \text {, p. 206-215. }\end{array}$ \\
\hline Open-File Report & $\begin{array}{l}\text { Ellison, L.E., 2012, Bats and wind energy-A literature synthesis and annotated } \\
\text { bibliography: U.S. Geological Survey Open-File Report 2012-1110, } 57 \text { p. }\end{array}$ \\
\hline Open-File Report & $\begin{array}{l}\text { Ellison, L.E., and Eberhardt Frank, M.K., 2011, A bibliography of literature pertaining to } \\
\text { plague (Yersinia pestis): U.S. Geological Survey Open-File Report 2011-1293, } 43 \text { p. }\end{array}$ \\
\hline Abstract & $\begin{array}{l}\text { Ellison, L.E., Cook, M.T., and Szymanski, J., 2012, Bats and wind energy-State of } \\
\text { knowledge and research priorities for USFWS and USGS [abs.]: Society of Conservation } \\
\text { Biology-The North America Congress for Conservation Biology, p. 15, Oakland, Calif., } \\
\text { July 18, 2012, p. } 1 .\end{array}$ \\
\hline $\begin{array}{l}\text { Scientific Investigations } \\
\text { Report }\end{array}$ & $\begin{array}{l}\text { Germaine, S.S., O’Donnell, M., Aldridge, C.L., Baer, L., Fancher, T., McBeth, J.L., } \\
\text { McDougal, R.R., Waltermire, R., Bowen, Z.H., Diffendorfer, J., Garman, S.L., and } \\
\text { Hanson, L., 2012, Mapping surface disturbance of energy-related infrastructure in } \\
\text { southwest Wyoming-An assessment of methods: U.S. Geological Survey Scientific } \\
\text { Investigations Report 2012-5025, } 42 \text { p. }\end{array}$ \\
\hline Abstract & $\begin{array}{l}\text { Gorresen, P.M., Cryan, P.M., and Bonaccorso, F.J., 2011, Monitoring and researching bat } \\
\text { activity at wind turbines with near infrared videography [abs.], in 18th Annual } \\
\text { Conference of the Wildlife Society Waikoloa, Hawaii, November 5-10, 2011, Bethesda, } \\
\text { Md.: The Wildlife Society, p. } 1 \text {. }\end{array}$ \\
\hline Journal & $\begin{array}{l}\text { Landguth, E.L., Fedy, B.C., Garey, A.L., Oyler-McCance, S.J., Emel, S.J., Mumma, M., } \\
\text { Fortin, M.J., Wagner, H.H., and Cushman, S.A., 2012, Effects of sample size, number of } \\
\text { markers, and allelic richness on landscape genetic inference: Molecular Ecology } \\
\text { Resources, v. 12, no. 2, p. 276-284. }\end{array}$ \\
\hline Journal & $\begin{array}{l}\text { Lorch, J.M., Meteyer, C.U., Behr, M.J., Boyles, J.G., Cryan, P.M., Hicks, A.C., } \\
\text { Ballmann, A.E., Coleman, J.T.H., Redell, D.N., Reeder D.M., and Blehert, D.S., 2011, } \\
\text { Experimental infection of bats with Geomyces destructans causes white-nose syndrome: } \\
\text { Nature, v. 480, no. } 7377, \text { p. } 376-378 .\end{array}$ \\
\hline Abstract & $\begin{array}{l}\text { Miller, H.M., Dietsch, A.M., and Sexton, N.R., 2012, Using the web to gather and } \\
\text { disseminate human dimensions data-Examples from the } 2010 / 2011 \text { national wildlife } \\
\text { refuge visitor survey [abs.]: } 2012 \text { Pathways to Success Conference-Integrating Human } \\
\text { Dimensions into Fisheries and Wildlife Management, Breckenridge, Colo., September } \\
\text { 24-27, 2012, p. } 1 .\end{array}$ \\
\hline Journal & $\begin{array}{l}\text { Muths, E., and Scherer, R.D., 2011, Portrait of a small population of Boreal toads } \\
\text { (Anaxyrus boreas): Herpetologica, v. 67, no. 4, p. 369-377. }\end{array}$ \\
\hline
\end{tabular}


Table 2. FORT Publications and Other Information Products Released in FY2012 and FY2013.-Continued

\begin{tabular}{|c|c|}
\hline Publication Type & Citation \\
\hline Journal & $\begin{array}{l}\text { O’Shea, T.J., Neubaum, D.J., Neubaum, M.A., Cryan, P.M., Ellison, L.E., Stanley, T.R., } \\
\text { Rupprecht, C.E., Pape, W.J., and Bowen, R.A., 2011, Bat ecology and public health } \\
\text { surveillance for rabies in an urbanizing region of Colorado: Urban Ecosystems, v. 14, no. } \\
\text { 4, p. 665-697. }\end{array}$ \\
\hline Abstract & $\begin{array}{l}\text { Oyler-McCance, S.J., 2012, From individuals to families to populations-Using } \\
\text { molecular techniques to help guide wildlife management [abs.], in 28th Western Agencies } \\
\text { Sage and Columbian Sharp-tailed Grouse Workshop, Steamboat Springs, Colo., June 18- } \\
\text { 22, 2012: Western Association of Fish and Wildlife Agencies, p. } 1 \text {. }\end{array}$ \\
\hline Web App & $\begin{array}{l}\text { Oyler-McCance, S.J., Fedy, B.C., Miller, T.W., Eberhardt Frank, M.K., and Montgomery, } \\
\text { G.A., 2012, Feathers Web site: U.S. Geological Survey, https://my.usgs.gov/feathers/. }\end{array}$ \\
\hline Book, pages in & $\begin{array}{l}\text { Oyler-McCance, S.J., Stricker, C.A., St. John, J., Braun, C.E., Wann, G.T., O’Donnell, } \\
\text { M.S., and Aldridge, C.L., 2011, Effects of climate change on nutrition and genetics of } \\
\text { White-tailed Ptarmigan [abs.], in Sandercock, B.K., Martin, K., and Segelbacher G., } \\
\text { (eds.), Ecology, conservation, and management of grouse-Studies in Avian Biology: } \\
\text { Berkeley, Calif., University of California Press, no. 39, p. 283-294. }\end{array}$ \\
\hline Abstract & $\begin{array}{l}\text { Oyler-McCance, S.J., Fike, J.A., Aldridge, C.L., Wann, G., and Braun, C.E., 2012, } \\
\text { Investigating temporal and spatial patterns of genetic diversity in White-tailed Ptarmigan } \\
\text { in and around Rocky Mountain National Park [abs.]: Rocky Mountain National Park } \\
\text { Research Conference, March 28-29, 2012, p. 1. }\end{array}$ \\
\hline Abstract & $\begin{array}{l}\text { Oyler-McCance, S.J., 2012, A brief primer on molecular genetic techniques and their use } \\
\text { in wildlife studies [abs.], in 28th Western Agencies Sage and Columbian Sharp-tailed } \\
\text { Grouse Workshop, Steamboat Springs, Colo., June 18-22, 2012: Denver, Colo., Western } \\
\text { Association of Fish and Wildlife Agencies, p. 1. }\end{array}$ \\
\hline Journal & $\begin{array}{l}\text { Ransom, J.I., 2012, Detection probability in aerial surveys of feral horses: Journal of } \\
\text { Wildlife Management, v. } 76 \text {, no. 2, p. } 299-307 .\end{array}$ \\
\hline Journal & $\begin{array}{l}\text { Ransom, J.I., Roelle, J.E., Cade, B.S., Coates-Markle, L., and Kane, A.J., 2011, Foaling } \\
\text { rates in feral horses treated with the immunocontraceptive porcine zona pellucida: } \\
\text { Wildlife Society Bulletin, v. } 35 \text {, no. 4, p. 343-352. }\end{array}$ \\
\hline Journal & $\begin{array}{l}\text { Ransom, J.I., Kaczensky, P., Lubow, B.C., Ganbaatar, O., and Altansukh, N., 2012, A } \\
\text { collaborative approach for estimating terrestrial wildlife abundance: Biological } \\
\text { Conservation, v, 153, p. 219-226. }\end{array}$ \\
\hline Thesis or Dissertation & $\begin{array}{l}\text { Ransom, J.I., 2012, Population ecology of feral horses in an era of fertility control } \\
\text { management: Fort Collins, Colo., Colorado State University, Ph.D. Dissertation., } 114 \text { p. }\end{array}$ \\
\hline Abstract & $\begin{array}{l}\text { Rea, L.D., Banks, A.R., Farley, S.D., Stricker, C.A., Fadely, B., Mellish, J., Christ, A., } \\
\text { and Pitcher, K., 2011, Delayed age at weaning in southeast Alaska Steller sea lions } \\
\text { determined using stable isotopes of carbon and nitrogen, [abs.], in 19th Biennial } \\
\text { Conference on the Biology of Marine Mammals, Tampa, Fla., November 27-December } \\
\text { 2, 2011: The Society for Marine Mammalogy, p. 1. }\end{array}$ \\
\hline
\end{tabular}


Table 2. FORT Publications and Other Information Products Released in FY2012 and FY2013.-Continued

\begin{tabular}{|c|c|}
\hline Publication Type & Citation \\
\hline Abstract & $\begin{array}{l}\text { Rossman, S.L., Barros, N.B., Stricker, C.A., Ostrom, P.H., and Wells, R.S., 2011, } \\
\text { Foraging ecology of bottlenose dolphins-A stable isotopic reconstruction over six } \\
\text { decades [abs.]: 19th Biennial Conference on the Biology of Marine Mammals, Tampa, } \\
\text { Fla., November 27-December 2, 2011: The Society for Marine Mammalogy, p. } 1 .\end{array}$ \\
\hline Abstract & $\begin{array}{l}\text { Scherer, R.D., Rea, L.D., Christ, A.M., Wunder, M., and Stricker, C.A., 2012, Spatial } \\
\text { variation in the diets of female Steller sea lions inferred from } 13 \mathrm{C} \text { and } 15 \mathrm{~N} \text { values of } \\
\text { vibrissae from pups [abs.]: The 8th International Conference on Applications of Stable } \\
\text { Isotope Techniques to Ecological Studies, Brest, France, August 20-24,2012, p. } 1 .\end{array}$ \\
\hline Journal & $\begin{array}{l}\text { Snow, N.P., Andelt, W.F., Stanley, T.R., and Resnik, J.R., 2012, Effects of roads on } \\
\text { survival of San Clemente Island foxes: The Journal of Wildlife Management, v. 76, no. 2, } \\
\text { p. } 243-252 \text {. }\end{array}$ \\
\hline Abstract & $\begin{array}{l}\text { Stricker, C.A., Rea, L.D., Rosen, D., Tollit, D.J., and Farley, S.D., 2012, Carbon and } \\
\text { nitrogen isotope discrimination Fact Sheetors for Steller sea lion vibrissae on milk and } \\
\text { fish/squid diets [abs.]: The 8th International Conference on Applications of Stable Isotope } \\
\text { Techniques to Ecological Studies, Brest, France, August } 20-24,2012 \text {, p. } 1 \text {. }\end{array}$ \\
\hline Open-File Report & $\begin{array}{l}\text { Valdez, E.W., 2012, Surveillance for White-Nose Syndrome in the bat community at El } \\
\text { Malpais National Monument, N. Mex., 2011: U.S. Geological Survey Open-File Report } \\
\text { 2012-1097, } 37 \text { p. }\end{array}$ \\
\hline Journal & $\begin{array}{l}\text { Perry, G., Bertoluci, J., Bury, B., Hansen, R.W., Jehle, R., Measey, J., Moon, B., Muths, } \\
\text { E., and Zuffi, M.A., 2011, The "Peer" in "Peer Review": Herpetological Conservation } \\
\text { and Biology, v. 6, no. 3, p. i-ii. }\end{array}$ \\
\hline Journal & $\begin{array}{l}\text { Wiley, A.E., Welch, A.J., Ostrom, P.H., James, H.F., Stricker, C.A., Fleischer, R.C., } \\
\text { Gandhi, H., Adams, J., Ainley, D.G., Duvall, F., Holmes, N., Hu, D., Judge, S., } \\
\text { Penniman, J., and Swindle, K.A., 2012, Foraging segregation and genetic divergence } \\
\text { between geographically proximate colonies of a highly mobile seabird: Oecologia, v. 168, } \\
\text { no. 2, p. 119-130. }\end{array}$ \\
\hline Journal & $\begin{array}{l}\text { Assal, T.J., and Montag, J.M., 2012, A tale of two land uses in the American West- } \\
\text { Rural residential growth and energy development: Journal of Maps, v. 8, no. 4., p. } 327- \\
333 \text {. }\end{array}$ \\
\hline Abstract & $\begin{array}{l}\text { Biggins, D.E., Matchett, M.R., Wimsatt, J. Rocke, T.E., Godbey, J.L., Eads, D.A., } \\
\text { Ramakrishnan, S., and A.R., Goldberg, 2012, Plague disrupts ecosystems and creates } \\
\text { challenges for wildlife conservation [abs.]: The Wildlife Society 19th Annual Conference, } \\
\text { Portland, Oreg., October } 13-18,2012, \text { p. } 1 \text {. }\end{array}$ \\
\hline Abstract & $\begin{array}{l}\text { Cade, B.S., Noon, B.R., and Scherer, R.L., 2012, Alternative statistical models for small } \\
\text { counts of California spotted owl fledglings [abs.]: The Wildlife Society 19th Annual } \\
\text { Conference, Portland, Oreg., October 13-18, 2012, p. } 1 .\end{array}$ \\
\hline Abstract & $\begin{array}{l}\text { Cryan, P., Valdez, E., Stricker, C., Wunder, M., Barclay, R., Baerwald, E., Willis, C., } \\
\text { Jameson, J., Snider, E. A., and Crichton, E., 2012, Carcass ecology-Forensic techniques } \\
\text { shed light on the possible causes of bat susceptibility to turbines [abs]: The Wildlife } \\
\text { Society } 19 \text { th annual conference, Portland, Oreg., October 14, 2012, p. } 1 \text {. }\end{array}$ \\
\hline
\end{tabular}


Table 2. FORT Publications and Other Information Products Released in FY2012 and FY2013.-Continued

\begin{tabular}{|c|c|}
\hline Publication Type & Citation \\
\hline Abstract & $\begin{array}{l}\text { Eads, D.A., Biggins, D.E., Antolin, M.F., Long, D., and Gage, K.L., 2012, Flea and } \\
\text { plague ecology in prairie dog colonies-Ages of colonies, means of colony establishment, } \\
\text { and soil characteristics [abs.]: The Wildlife Society 19th Annual Conference, Portland, } \\
\text { Oreg., October } 12-18,2012 \text {, p. } 1 \text {. }\end{array}$ \\
\hline Abstract & $\begin{array}{l}\text { Loeb, S., Coleman, J., Ellison, L., Cryan, P., Rodhouse, T., Ingersoll, T., and Ewing, R., } \\
\text { 2012, Development of a North American Bat Population Monitoring and Modeling } \\
\text { Program [abs.]: North American Society for Bat Research (NASBR), 42nd Annual } \\
\text { Symposium on Bat Research, San Juan, P.R., October 24-27, 2012, p. } 1 .\end{array}$ \\
\hline Abstract & $\begin{array}{l}\text { Oyler-McCance, S.J., 2012, Isolation and fragmentation in sage-grouse-Genetic } \\
\text { fingerprints at the crime scene, [abs.]: The Wildlife Society's 19th Annual Meeting, } \\
\text { Symposium-Prairie Grouse Management-Doomed to Repeat the Past?, Portland, Oreg, } \\
\text { October } 13-18,2012 \text {, p. } 1 \text {. }\end{array}$ \\
\hline Abstract & $\begin{array}{l}\text { Ruth, J., 2012, Breeding ecology of the Arizona Grasshopper Sparrow [abs.]: Western } \\
\text { Field Ornithologists' Annual Meeting, Petaluma, Calif., Septempler 26-30, 2012, p. } 1 .\end{array}$ \\
\hline Journal & $\begin{array}{l}\text { Ruth, J.M., Diehl, R.H., and Felix Jr., R.K., 2012, Migrating birds' use of stopover habitat } \\
\text { in the southwestern United States: The Condor, v. 114, no. 4, p. 698-710. }\end{array}$ \\
\hline Journal & $\begin{array}{l}\text { Scherer, R.D., Muths, E., Noon, B.R., and Oyler-McCance, S.J., 2012, The genetic } \\
\text { structure of a relict population of Wood Frogs: Conservation Genetics, v. 13, no. 6, p. } \\
\text { 1521-1530. }\end{array}$ \\
\hline Abstract & $\begin{array}{l}\text { Wimsatt, J., Biggins, D.E., Rocke, T.E., and Ramakrishnan, S., 2012, Woodrat survival is } \\
\text { influenced by plague in the absence of an epizootic-A preliminary [abs.]: American } \\
\text { Association of Zoo Veterinarians 44th Annual Conference, Oakland, Calif., October } 20- \\
\text { 26, 2012, p. } 1 \text {. }\end{array}$ \\
\hline Journal & $\begin{array}{l}\text { Wunder, M.B., Jehl Jr, J.R., and Stricker, C.A., 2012, The early bird gets the shrimp-- } \\
\text { Stable isotopes prompt revisit of ideas on resource use in molt migration strategy: Journal } \\
\text { of Animal Ecology, v. 81, no. 6, p. 1223-1232. }\end{array}$ \\
\hline Journal & $\begin{array}{l}\text { Adams, M.J., Miller, D.A.W., Muths, E., Corn, P.S., Campbell Grant, E.H., Bailey, L.L., } \\
\text { Fellers, G.M., Fisher, R.N., Sadinski, W.J., Waddle, H., and Walls, S.C., 2013, Trends in } \\
\text { amphibian occupancy in the United States: PLoS ONE, v. 8, no. 5, p. 1-5. }\end{array}$ \\
\hline Journal & $\begin{array}{l}\text { Bowen, R.A., O'Shea, T.J., Shankar, V., Neubaum, M.A., Neubaum, D.J., and Rupprecht, } \\
\text { C.E., 2013, Prevalence of neutralizing antibodies to rabies virus in serum of seven species } \\
\text { of insectivorous bats from Colorado and New Mexico, United States: Journal of Wildlife } \\
\text { Diseases, v. } 49 \text {, no. } 2 \text {, p. } 367-374 \text {. }\end{array}$ \\
\hline Fact Sheet & $\begin{array}{l}\text { Bowen, Z.H., Melcher, C.P., and Wilson, J.T., 2013, Ecosystems Dynamics Branch- } \\
\text { Interdisciplinary research for addressing complex natural resource issues across } \\
\text { landscapes and time: U.S. Geological Survey Fact Sheet } 2013-3009,4 \text { p. }\end{array}$ \\
\hline
\end{tabular}


Table 2. FORT Publications and Other Information Products Released in FY2012 and FY2013.-Continued

\begin{tabular}{|c|c|}
\hline Publication Type & Citation \\
\hline Fact Sheet & $\begin{array}{l}\text { Carr, N.B., Garman, S.L., Walters, A., Ray, A., Melcher, C.P., Wesner, J.S., O’Donnell, } \\
\text { M.S. Sherrill, K.R., and Bowen, Z.H., 2013, Wyoming Basin rapid ecoregional } \\
\text { assessment: U.S. Geological Survey Fact Sheet 2013-3062, } 2 \text { p. }\end{array}$ \\
\hline Journal & $\begin{array}{l}\text { Cryan, P.M., Meteyer, C.U., Blehert, D.S., Lorch, J.M., Reeder, D.M. Turner, G.G., } \\
\text { Webb, J., Behr, M., Verant, M., Russell, R.E., and Castle, K.T., 2013, Electrolyte } \\
\text { depletion in white-nose syndrome bats: Journal of Wildlife Diseases, v. 94, no. 2, p. 398- } \\
402 .\end{array}$ \\
\hline Journal & $\begin{array}{l}\text { Cryan, P.M., Meteyer, C.U., Boyles, J.G., and Blehert, D.S., 2013, White-nose syndrome } \\
\text { in bats-Illuminating the darkness: BMC Biology, v. 11, no. 47, p. 1-4. }\end{array}$ \\
\hline Journal & $\begin{array}{l}\text { Hayman, D.T.S., Bowen, R.A., Cryan, P.M., McCracken, G.F., O'Shea, T.J., Peel, A. } \\
\text { Gilbert, A., Webb, C.T., and Wood, J.L.N., 2013, Ecology of zoonotic infectious diseases } \\
\text { in bats-Current knowledge and future directions: Zoonoses and Public Health, v. 60, no. } \\
\text { 1, p. } 2-21 \text {. }\end{array}$ \\
\hline Journal & $\begin{array}{l}\text { Luis, A.D., Hayman, D.T.S., O'Shea, T.J., Cryan, P.M., Gilbert, A.T., Pulliam, J.R.C., } \\
\text { Mills, J.N., Timonin, M.E., Willis, C.K.R., Cunningham, A.A., Fooks, A.R., Rupprecht, } \\
\text { C.E., Wood, J.L.N., and Webb, C.T., 2013, A comparison of bats and rodents as } \\
\text { reservoirs of zoonotic viruses-Are bats special?: Proceedings of the Royal Society B, v. } \\
\text { 280, no. 1756, p. 1-9. }\end{array}$ \\
\hline Journal & $\begin{array}{l}\text { Mkongewa, V.J., Newmark, W.D., and Stanley, T.R., 2013, Breeding biology of an } \\
\text { afrotropical forest understory bird community in northeastern Tanzania: Wilson Journal } \\
\text { of Ornithology, v. } 125 \text {, no. 2, p. } 260-267 .\end{array}$ \\
\hline Journal & $\begin{array}{l}\text { Oyler-McCance, S.J., Fedy, B.C., and Landguth, E.L., 2013, Sample design effects in } \\
\text { landscape genetics: Conservation Genetics, v. 14, no. 2, p. 275-285. }\end{array}$ \\
\hline Journal & $\begin{array}{l}\text { Oyler-McCance, S.J., Fike, J.A., Castoe, T.A., Tomback, D.F., Wunder, M.B., and } \\
\text { Schaming, T.D., 2013, Development and characterization of thirteen microsatellite loci in } \\
\text { Clark's nutcracker (Nucifraga columbiana): Conservation Genetics Resources, v. 5, p. } \\
\text { 303-305. }\end{array}$ \\
\hline Abstract & $\begin{array}{l}\text { Peters, J., del Rio Martinez, C., and Stricker, C., 2013, Effects of land use on seasonal } \\
\text { foraging behavior in white-winged doves of Arizona-Insights from stable isotope } \\
\text { analysis [abs.]: The Society for Integrative and Comparative Biology Annual Meeting, } \\
\text { San Francisco, Calif., January 3-7, 2013, p. } 1 \text {. }\end{array}$ \\
\hline Journal & $\begin{array}{l}\text { Ransom, J.I., Hobbs, N.T., and Bruemmer, J., 2013, Contraception can lead to trophic } \\
\text { asynchrony between birth pulse and resources: PLoS One, v. 8, no. 1, p. 1-9. }\end{array}$ \\
\hline Abstract & $\begin{array}{l}\text { Shively, R., Barboza, P.S., Jung, T., and Stricker, C.A., 2013, Activity and diet of little } \\
\text { brown bats in interior Alaska, [abs.]: The Wildlife Society Alaska Chapter Annual } \\
\text { Meeting, Fairbanks, Alaska, April 3-5, 2013, p. 1. }\end{array}$ \\
\hline
\end{tabular}


Table 2. FORT Publications and Other Information Products Released in FY2012 and FY2013.-Continued

\begin{tabular}{|c|c|}
\hline Publication Type & Citation \\
\hline Journal & $\begin{array}{l}\text { Snider, E.A., Cryan, P.M., and Wilson, K.R., 2013, Roost selection by western long-eared } \\
\text { myotis (Myotis evotis) in burned and unburned pinon-juniper woodlands of southwestern } \\
\text { Colorado: Journal of Mammalogy, v. } 94 \text {, no. 3, p. 640-649. }\end{array}$ \\
\hline Journal & $\begin{array}{l}\text { Warnecke, L., Turner, J.M., Bollinger, T.K., Misra, V., Cryan, P.M., Blehert, D.S., } \\
\text { Wibbelt, G., and Willis, C.K.R., 2013, Pathophysiology of white-nose syndrome in bats- } \\
\text { A mechanistic model linking wing damage to mortality: Biology Letters, v. 9, no. 4, p. 1- } \\
5 \text {. }\end{array}$ \\
\hline Science Feature & $\begin{array}{l}\text { Wilson, J.T., and Schoenecker, K.A., 2013, Where the Bison roam-Public-private } \\
\text { partnership supports potential restoration: U.S. Geological Survey Science Feature, } \\
\text { http://www.fort.usgs.gov/Bison/. }\end{array}$ \\
\hline \multicolumn{2}{|r|}{ Energy and Minerals, and Environmental Health } \\
\hline Journal & $\begin{array}{l}\text { Dang, V.D., Walters, D.M., and Lee, C.M., 2013, Assessing ongoing sources of dissolved } \\
\text { phase Polychlorinated Biphenyls (PCBs) in a contaminated stream: Environmental } \\
\text { Toxicology and Chemistry, v. 32, no. 3, p. 535-540. }\end{array}$ \\
\hline Open-File Report & $\begin{array}{l}\text { Smith, S.B., Anderson, P.J., Baumann, P.C., Deweese, L.R., Goodbred, S.L., Smith, } \\
\text { D.S., and Coyle, J.J., 2012, A multi-metric assessment of environmental contaminant } \\
\text { exposure and effects in an urbanized reach of the Charles River near Watertown, } \\
\text { Massachusetts: U.S. Geological Survey Open-File Report 2012-1195, 116 p. }\end{array}$ \\
\hline Web App & $\begin{array}{l}\text { Carr, N.B., Babel, N., Diffendorfer, J., Hawkins, S., Ignizio, D., Latysh, N., Leib, K., } \\
\text { Linard, J., and Matherne, A.M., 2012, Interactive Energy Atlas for Colorado and New } \\
\text { Mexico Web site: U.S. Geological Survey, http://my.usgs.gov/eerma/. }\end{array}$ \\
\hline \multicolumn{2}{|r|}{ Enterprise Information } \\
\hline Science Feature & $\begin{array}{l}\text { Carr, N.B., Babel, N., Diffendorfer, J., Ignizio, D., Hawkins, S., Latysh, N., Leib, K., } \\
\text { Linard, J., and Matherne, A., 2012, Interactive Energy Atlas for Colorado and New } \\
\text { Mexico-An online resource for decision-makers and the public: U.S. Geological Survey } \\
\text { Science Feature, http://www.fort.usgs.gov/EERMA/. }\end{array}$ \\
\hline Web App & $\begin{array}{l}\text { Swanjord, K., Fuller, H.K., and Ahmed, A., 2012, GSAnswers Administrative Interface } \\
\text { Web site: U.S. Geological Survey. }\end{array}$ \\
\hline Science Feature & $\begin{array}{l}\text { Tack, J., and Wilson, J., 2012, Where eagles nest, the wind also blows-Consolidating } \\
\text { habitat and energy needs: U.S. Geological Survey Science Feature, } \\
\text { http://www.fort.usgs.gov/Eagles/. }\end{array}$ \\
\hline Brochure & $\begin{array}{l}\text { Wilson, J.T., and Banowetz, M.M., 2012, The Fort Collins Science Center [Brochure]: } \\
\text { Reston, Va., U.S. Geological Survey. }\end{array}$ \\
\hline \multicolumn{2}{|r|}{ Natural Hazards } \\
\hline Journal & $\begin{array}{l}\text { Cade, B.S., Terrell, J.W., and Neely, B.C., 2011, Estimating geographic variation on } \\
\text { allometric growth and body condition of Blue Suckers with quantile regression: } \\
\text { Transactions of the American Fisheries Society, v. 140, p.1657-1669. }\end{array}$ \\
\hline Web App & $\begin{array}{l}\text { Smyrl, L., Kern, T., and Allen, J., 2011, Twitter Earthquake Dispatch (@USGSted): U.S. } \\
\text { Geological Survey. }\end{array}$ \\
\hline
\end{tabular}


Table 2. FORT Publications and Other Information Products Released in FY2012 and FY2013.-Continued

\begin{tabular}{|c|c|}
\hline Publication Type & Citation \\
\hline \multicolumn{2}{|r|}{ Water } \\
\hline Abstract & $\begin{array}{l}\text { Holloway, J.M., Bern, C., Schmidt, T.S., McDougal, R.R., Clark, M.L., Stricker, C.A., } \\
\text { and Wolf, R.E., 2011, Predicting long-range impact of gas extraction in an Upper } \\
\text { Colorado headwater catchment [abs.], in AGU Fall Meeting 2011, San Francisco, Calif., } \\
\text { December 5-9, 2011: American Geophysical Union, } 1 \text { p. }\end{array}$ \\
\hline Journal & $\begin{array}{l}\text { Kondratieff, B.C., Zuellig, R.E., and Lenat, D.R., 2011, A new species of Perlesta } \\
\text { (Plecoptera: Perlidae) from North Carolina with additional records for North Carolina } \\
\text { and Virginia: Illiesia, v. 7, no. 27, p. 297-301. }\end{array}$ \\
\hline Journal & $\begin{array}{l}\text { Zuellig, R.E., and Schmidt, T.S., 2012, Characterizing invertebrate traits in wadeable } \\
\text { streams of the contiguous U.S.-Differences among ecoregions and land uses: Freshwater } \\
\text { Science, v. } 31 \text {, no. 4, p. } 1042-1056 \text {. }\end{array}$ \\
\hline
\end{tabular}

Publishing support provided by: Denver Publishing Service Center

For more information concerning this publication, contact:

Center Director, USGS Fort Collins Science Center

2150 Centre Ave., Bldg. C

Fort Collins, CO 80526-8118

(970) 226-9398

Or visit the Fort Collins Science Center Web site at: http://www.fort.usgs.gov/ 